\title{
4 "Wie lebt es sich in Deiner Haut?«: Von der Herkunfts- zur Konfliktgesellschaft in Literatur, Film und Debatten der 1990er Jahre
}

\subsection{In der Gesellschaft überleben}

»Erst habe ich die Soldaten gesehen, ich stand da im Bauch meiner Mutter zwischen den Eisenstangen, ich wollte mich festhalten und faßte an das Eis und rutschte und landete auf dem demselben Platz, klopfte an die Wand, keiner hörte. « ${ }^{1}$ Mit diesem Satz beginnt der erste Roman der Autorin Emine Sevgi Özdamar Das Leben ist eine Karawanserei. Hat zwei Türen. Aus einer kam ich rein. Aus der anderen ging ich raus von 1992. Ungeboren befindet sich die Ich-Erzählerin im Mutterbauch, den sie wie eine ungemütliche dunkle Gefängniszelle beschreibt. Während dieser Beschreibung sind Ich-Erzählerin und ihre Mutter mit Soldaten in einem Zugabteil unterwegs zu Vater und Großvater in die türkische Provinz. ${ }^{2}$ Dort soll die Ich-Erzählerin auf die Welt kommen. Beim Abfahren des Zuges ruft eine Frau, die die hier noch ungeborene Protagonistin »später im Leben >Baumwolltante« «nennen wird, der schwangeren Frau zur Beruhigung hinterher, dass alle herauskommen und niemand im Mutterbauch bleiben würde. Sie solle nur warten, bis sie im Haus ihres Vaters angekommen sei. ${ }^{3}$ Dort auf die Welt gekommen, schreit das Neugeborene ohne Unterlass über mehrere Tage. Die fünf Frauen des Großvaters empfehlen der Mutter aus Sorge, das Kind könne unheilbar krank sein, auf den Friedhof zu gehen und den Säugling in ein frischausgehobenes Grab zu legen. Wenn es darin immer noch schreien sollte, würde es überleben. Die Mutter legt den Säugling auf dem Friedhof in ein nasses dunkles Loch und zieht sich zurück. Das Kind überlebt, aber nicht weil es weiterschreit. Es hat im Gegenteil aufgehört zu schreien und in das Erdreich uriniert. Das Kind überlebt, weil seine Großmutter, eine der fünf Frauen des Großvaters, diesem Aberglauben ein Ende setzt. Mit Hilfe des verrückten Kutschers Hüseyin, der Mutter, Großmutter und Kind zum Friedhof gebracht hat, holt sie es wieder aus dem Erdloch heraus. Diese eindringliche Friedhofsse-

1 Özdamar, Emine Sevgi (1992): Das Leben ist eine Karawanserei. Hat zwei Türen. Aus einer kam ich rein. Aus der anderen ging ich raus, Köln: Kiepenheuer \& Witsch, S. 9.

2 Auch der Protagonist in Zafer Şenocaks Roman Gefährliche Verwandtschaft von 1998 ist im Bauch seiner Mutter unterwegs im Zug von Istanbul nach München. Er ist das Kind einer deutschen Frau und eines türkischen Mannes. Gezeugt wurde er in Istanbul, auf die Welt kommt er in München. Siehe hierzu: ŞENOCAK, Zafer (1998): Gefährliche Verwandtschaft, Fuchstal: Babel, S. 11.

3 Ebd. 
quenz wird mit einer Grabsteininschrift, einem in den Fließtext eingefügten Zitat kommentiert, das zugleich das Leitmotiv des Romans einführt.

\author{
Als ich ging aus dieser Welt \\ reden wir nicht von Karawanserei und Bäder besitzen \\ uns genügte das Teilen des Tageslichts \\ reden wir nicht von Glücklichsein \\ das Hoffen reichte uns \\ nichts haben wir gefunden \\ die Melancholie haben wir uns geschaffen \\ sie tröstete uns nicht \\ oder vielleicht \\ waren wir nicht von dieser Welt. ${ }^{4}$
}

Wenn alle aus dem Mutterbauch herauskommen und dieser, die im Romantitel genannte eine Tür ist, so ist das Verlassen der Welt die zweite Tür, durch die ebenfalls jeder gehen muss. Diese Vorrangigkeit der Endlichkeit des Lebens, die den Titel des Romans im Text selbst wiedergibt und einem alten türkischen Volkslied entnommen ist ${ }^{5}$, der Aberglaube der Familie, Begriffe wie Karawanserei und die Sensitivität der Eröffnungssequenz bemühen zwar orientalistische Assoziationen, wie sie beispielsweise Edward Said in seinem bekannten Buch Orientalismus festhält. ${ }^{6}$ Doch ist dies nur die eine Seite des Romans. Ihre andere Seite ist die surreale Diktion der Erzählung, die die Geschichte mit der Perspektive aus dem Mutterbauch beginnen lässt. Hinzu kommt - und das werden noch viel Auszüge aus dem Roman zeigen -, dass nicht eine orientalische Sinnlichkeit im Roman zur Disposition steht, sondern eine allgemeine Körperlichkeit der Akteure. Und schließlich endet der Roman nicht mit dem Tod der Protagonistin. Im Gegenteil steht die zweite Tür am Ende von Das Leben ist eine Karawanserei für die Migration der Erzählerin nach Deutschland. Die zweite Tür ist die der grenzüberschreitenden Migration.

4 ÖZDAMAR (1992): S. 13.

5 Der Titel von Emine Sevgi Özdamars Roman geht auf das türkische Volkslied Uzun ince bir yoldayım (Ich bin auf einem langen schmalen Weg) des Volksdichters Aşık Veysel zurück. In diesem Lied taucht in jeder zweiten Strophe die Formulierung auf, dass das Leben ein Haus zwischen zwei Türen darstellt und das der Sänger morgens wie abends zwischen diesen beiden Türen unterwegs ist. Siehe hierzu: SIEDEL, Elisabeth (1989): »Aşık Veysel und sein Publikum«. In: Die Welt des Islams, New Series, Bd. 29, Nr. 1 / 4 (1989), S. 83-100.

6 Die Zuschreibung von Aberglauben, Endlich-, Vergeblichkeit des Lebens und ganz besonders die Sinnlichkeit sind in Edward Saids großem Buch zum Orientalismus ausschlaggebende Kategorien der westlichen Wahrnehmung des Orients im 19. und 20. Jahrhundert. Siehe hierzu: SAID, Edward W. (2014): Orientalismus, Frankfurt a. M.: Fischer, S. 223f. 
Aber nicht nur das Ende steht quer zur orientalistischen Rahmung des Romans. Allein die Prominenz von Geburt und Tod zeigt die Erzählerin und ihre Verwandten zunächst als Menschen und nicht in erster Linie als Menschen, die einem bestimmten Kulturkreis angehören. Auch die körperliche Aktivität der Protagonistin, ihr Verlangen, aus dem Mutterbauch herauskommen zu wollen, die erzählerisch ungemeine Geschwindigkeit der Ortswechsel vom Zugabteil über die türkische Provinz bis zum Friedhof auf den ersten Seiten des Romans und der im Alter von achtzehn Jahren einsetzende große Wunsch der Erzählerin, nach Deutschland zu migrieren, widersetzen sich zudem der Passivität und Schicksalsergebenheit des Orientalen. ${ }^{7}$ Ganze viermal teilt sie am Ende des Romans ihrer Mutter ihren Wunsch mit, nach Deutschland zu wollen. Auf diese Idee kommt sie plötzlich als sie an einem Istanbuler Strand aufs Meer schaut und beeindruckt der Bewegung der großen Schiffe in die Welt hinaus nachsieht. ${ }^{8}$ Dieser Lebensdrang spiegelt sich auch im Leben ihres Großvaters, der über das islamische Gesetz hinaus, nicht vier, sondern mit fünf Frauen verheiratet war. ${ }^{9}$ Doch so insistierend und überschüssig ${ }^{10}$ dieser Drang nach draußen zu kommen dargestellt wird,

7 Nach Said sind Passivität und Ergebenheit in das eigene Schicksal zentrale Codes in der Konstruktion des Orients, wie ihn Wissenschaft und Politik des Westens im 19. Jahrhundert und 20. Jahrhundert vorangetrieben haben. Diese Zuschreibungen waren mitunter die Grundlage für die Legitmität des westlichen Kolonialismus in arabischen und osmanischen Gebieten im 19. und 20. Jahrhundert. Die Grundlogik lautete: Da die Orientalen sich nicht aus sich selbst heraus entwickeln können, müssen die Europäer ihnen bei der Modernisierung helfen. Siehe hierzu. SAID (2014): S. 62-64.

8 Siehe hierzu: ÖZDAMAR (1992): S. 368.

9 Etwas mehr als zehn Jahre später setzt das islamkritische Buch Große Reise ins Feuer. Die Geschichte einer deutschen Türkin der deutsch-türkischen Rechtanwältin Seyran Ateş, das mit der Ankunft ihrer Familie in Deutschland beginnt, mit der Erwähnung ein, dass ihr Großvater dem islamischen Gesetz entsprechend mit vier Frauen verheiratet war. Siehe hierzu: ATEş, Seyran (2003): Große Reise ins Feuer. Die Geschichte einer deutschen Türkin, Reinbek: Rowohlt, S. 8. So banal dieser Unterschied auf den ersten Blick wirken mag, ist das Brechen und das Befolgen von Regeln ein konstitutiver Unterschied zwischen den 1990er und den 2000er Jahren. Denn die Anzahl von fünf Frauen korreliert mit orientalistischer Fabulierlust im Positiven und orientalistischem Sexhunger im Negativen. In beiden Fällen ist die sensitive Dimension bestimmend. Die Zahl vier hingegen verweist direkt auf ein allen Lesern bekannte islamische ehegesetzliche Ordnung. Wenn in Özdamars Roman ein bestimmter Orientalismus zugleich bedient und in Frage gestellt wird, ist es im Fall von Ateş umgekehrt. Die Regeln des Islam werden hier befolgt, ohne Kritik und ohne sie in Frage zu stellen.

10 Voll körperlicher Energie stecken viele Akteurinnen und Akteure in den 1990er Jahren. Selbst bei einem Autor wie Selim Özdoğan, der in seinen Romanen der 1990er Jahre als einer der ganz wenigen das Thema der Migration konsequent vermeidet, sind die Akteure in einem Gemütszustand zwischen »Lebensdurst \& Todessehnsucht«. Wie Özdoğan selbst schreibt, wollen sie mehr als »Bücher, Sex, Drogen, Musik, Kino, Tanzen, Schreiben, Schwitzen«. Und wenn es die- 
steuert Das Leben ist eine Karawanserei erzählerisch und dramaturgisch keineswegs teleologisch, durch eine Struktur der Entwicklung einfach auf die Arbeitsmigration der Ich-Erzählerin am Ende zu. Stattdessen bestimmt die Migration das Leben sogar noch vor der Geburt. Im Unterschied zu Aras Örens Was will Niyazi in der Naunynstraße? oder zu Helma Sanders-Brahms SHIRINs HochzeIT, in denen die Arbeitsmigration aufgrund ungerechter sozialer Mechanismen erfolgt und ähnliche deutsche und türkische Lebens- und Arbeitswelten (Frau Kutzer und Niyazi) von daher gezeigt werden, steht die Frage der Herkunft allgemein zur Disposition.

Zeitnah zur Entstehungszeit von Özdamars Roman konstatiert Salman Rushdie in seiner Essaysammlung zum Zusammenhang von Migration und Literatur, dass die Autoren seiner Generation mit Migrationsgeschichte ihre Herkunft nicht mehr präzise beschreiben könnten und dass daraus eine "paradoxical opposition « zwischen Inhalt und Form resultiere. ${ }^{11}$ Hinzu kommt, dass in einer Zeit, in der der Staat die Wirklichkeit selbst in die Hand nimmt, verzerrt und verändert sie nach Rushdie die Vergangenheit und damit auch die Bedürfnisse der Gegenwart. Auf dieser Grundlage wird dann die Herstellung von Literatur und Film zu einer politischen Aktivität. Das Darstellen alternativer Wirklichkeiten ist hier ein politisches Projekt der Freiheit und Weltverbundenheit. Denn Adressat dieser explizit ästhetisch-politischen Konstellation ist weder eine bestimmte Gruppe noch eine Mehrheit oder Minderheit, sondern "people who feel part of the things I write ,about', but also for everyone else whom I can reach «. ${ }^{12}$ Und was könnte noch zu Beginn der 1990er Jahre allgemeiner sein und alle Menschen miteinbeziehen, sie inkludieren, als die Herkunft aus dem Mutterbauch ${ }^{13}$

Dieses körperliche Sein und Werden bricht mit der national bzw. territorial verstandenen Herkunft und der vorher bestimmten kulturellen Zugehörigkeit. Erkennbar wird es durch ein verfremdendes nicht realistisches Erzählen und

ses Mehr nicht gebe, könne man gleich das »Handtuch schmeißen«. Siehe hierzu: ÖzDoĞAN, Selim (1995): Es ist so einsam im Sattel, seit das Pferd tot ist, Berlin: Rütten \& Loening GmbH, S. 7. 11 RusHDIE, Salman (1991): Imaginary Homelands, London: Granta Books, S. 16.

12 Ebd., S. 20.

13 In der Zeit zwischen Ende der 1980er und Anfang der 1990er Jahre glaubt auch Zafer Şenocak daran, dass nationale Zugehörigkeiten und Pässe der Vergangenheit angehören. 1989 zieht er von München nach Berlin. »In Berlin angekommen, habe ich meinen türkischen Pass in der Tasche. Die Mauer ist gefallen, und einige Augenblicke lang kann man fest daran glauben, dass es nie wieder Pässe geben wird, nie wieder Passkontrollen, nur Passagen, frei, für jedermann zugängliche Passagen.« Dass die Geschichte sich entgegen dieser Globalisierungseuphorie von den 1990er Jahren bis heute anders entwickeln wird, bestimmen besonders seine aktuellen essayistischen Reflexionen. Siehe hierzu: ŞENOCAK, Zafer (2016): In deinen Worten. Mutmaßungen über den Glauben meines Vaters, München: Babel. ŞENocaK, Zafer (2018): Das Fremde, das in jedem wohnt. Wie Unterschiede unsere Gesellschaft zusammenhalten, Hamburg: Körber Stiftung, S. 139. 
durch viele Ortswechsel und einer besonderen Ereignisdichte $\mathrm{zu}$ Beginn des Romans. Auch der Orient erfährt dabei als Ort fatalistischer Lebensweisheit eine Abwertung. Denn die schönen Verse aus dem zitierten Volkslied und dem Titel des Romans kontrastieren die ordinären Aussagen des türkischen Kutschers. Dieses Ordinäre führt uns in den Friedhof hinein und auch wieder hinaus. »Ich ficke die Welt, gehen wir, ich ficke den Friedhof, ich ficke den Tod«, heißt es da etwa. Oder später, als der Kutscher die Großmutter samt Säugling aus dem Grab herauszieht: »Hier nimm meine Hand, ich ficke meine Hand, ich ficke deine Enkelin, ich ficke das Grab ${ }^{14}{ }^{14}$ Nicht die zitierte orientalische Lebensweisheit ist hier ausschlaggebend, sondern die Wut auf die Welt einer sozial prekären Existenz wie der des Kutschers, der trotzdem hilft. An seine Stelle tritt im weiteren Verlauf des Romans eine andere sozialstrukturell prekäre und zugleich transkulturell und transnational greifende Figur, die ebenfalls helfen wird und auf Roman und Protagonistin entscheidenden Einfluss nimmt: die »Hure«. Die »Huren« oder Frauen, die als solche bezeichnet werden, tauchen in vielen Texten und Filmen deutsch-türkischer Provenienz in den 1990er Jahren als positiv konnotierte Figuren auf. ${ }^{15}$

So steht am Anfang von Özdamars Roman eine sozialstrukturell gefärbte Umwertung der Werte. Soziologisch gesprochen geht es hier um soziale Anomie, die die körperliche Existenz von der kulturellen Identifikation und einer funktional ausdifferenzierten Gesellschaft im Sinne Durkheims unterscheidet. ${ }^{16}$ Doch bleiben diese Seiten der Thematisierung der Migration und ihrer Folgen aufeinander angewiesen. Das Leben ist eine Karawanserei wird 1992 veröffentlicht und gehört seit seinem Erscheinen zu den meistrezipierten Romanen in Forschung und Feuilleton. Für einen Auszug aus diesem Roman erhält die Autorin 1991

14 Ebd., S. 15. Diese Aufeinanderfolge von Thanatos, Eros und Wut finden wir auch in Tevfik Başers drittem Film LeBewohl, Fremde von 1991. Darin steht der Aufenthalt des politischen Flüchtlings Deniz Varlık auf der Nordsee-Hallig Langeneß im Vordergrund. Siehe hierzu: BAŞER, Tevfik (1991): Lebewohl, Fremde, Spielfilm, eye see movies, Schweiz.

15 Siehe hierzu: DöRRIE, Doris (1992): Happy Birthday, Türke!, Spielfilm, Cobra Film GmbH, Deutschland; Kutlucan, Hussi (1998): Ich Chef, Du Turnschuh, Spielfilm, Zero Fiction Film GmbH, Deutschland; Polat, Ayşe (1999): Auslandstournee, Spielfilm, ZDF - das kleine Fernsehspiel, Deutchland; Ataman, Kutluğ (1999): Lola und Bilidikid, Spielfilm, Zero Fiction Film GmbH, Deutschland.

16 Der Aspekt der sozialen Anomie wie der Prostitution, der Kriminalität und des Selbstmords, die Durkheim als gesellschaftlich verstandene strukturelle Widersprüche, als abweichende Verhaltensformen beschrieben hat, wird uns in Film und Literatur der 1990er Jahre häufig begegnen. Siehe zur sozialen Anomie: DuRKHeIM, Emile (1992): Über soziale Arbeitsteilung. Studie über die Organisation höherer Gesellschaften, Frankfurt a. M.: Suhrkamp. 
den Ingeborg-Bachmann-Preis als erste »nichtdeutschstämmige Autorin « ${ }^{17}$ Ihr Roman wird wider seiner ästhetischen Logik als ein autobiografisches Zeugnis der türkischen Kultur gelesen. Wir werden allerdings sehen, dass nicht nur Erzählung und deutsche Rezeption in einem widersprüchlichen Verhältnis stehen, sondern auch die türkische und die deutsche Rezeption des Romans.

Eine Dekade später begegnen wir in einer ebenfalls sehr bekannten und vielprämierten deutsch-türkischen Produktion, deren Drehbuchkonzeption noch in den 1990er Jahren liegt, im Kinofilm GEGEN DIE WAND von Fatih Akın einer ähnlich brüchigen Konstellation von Kultur, Sprache, Sozialstruktur und Rezeption. ${ }^{18}$ Akıns bekannter Film schließt die Phase des Leitzsatzes $» W i e$ lebt es sich in Deiner Haut« der vorliegenden Kulturgeschichte ab, treibt sie zugleich aber auch auf ihren Höhepunkt. GEGEN DIE WAND beginnt ähnlich wie Özdamars Roman mit einem klassisch-türkischen Musikstück, das von einer Musikkapelle am Bosporus gespielt wird. Die ganze Szenerie wirkt wie eine orientalische Postkarte. Hinter Kapelle und Bosporus sehen wir die Celebi Moschee. Es ist die hellste Sequenz im Film. Auf sie folgt ein totaler Cut. Kurze Dunkelheit, Neonröhren in einem dunklen Keller werden eingeschaltet. Wir wissen in den ersten Einstellungen nicht, wo wir sind, denn Akın hat zwischen diesen ersten Sequenzen keinen establishing shot eingesetzt. Establishing shots definieren in filmischen Erzählungen den Raum, in dem das darauffolgende filmische Geschehen stattfindet. Sie beschreiben einen »overall space « und dienen dem Zuschauer als Orientierung. ${ }^{19}$ In dieser Sequenz des Films begreifen wir erst nach und nach, dass wahrscheinlich ein Konzert in einem Club zu Ende gegangen ist. Doch geht es wie bei Özdamar nicht um den Ort, sondern um die Einführung des ersten Protagonisten und mit der erzählerischen Verbindung von Orientalismus und einem Hamburger Kellerkonzertraum zugleich darum, so viele Menschen wie möglich zu erreichen. Cahit, ${ }^{20}$ ein Mit-

17 KAISER, Birgit Mara (2014): »A new German, singularly Turkish. Reading Emine Sevgi Özdamar with Derrida's Monolingualism of the Other«, In: Textual Practice, Vol. 28, No. 6, S. 969-987, S. 974. 18 Neben vielen anderen auch internationalen Preisen erhielt er 2004 den renommiertesten und äußerst repräsentativen deutschen Filmpreis, den Goldenen Bären der Berlinale. Der letzte deutsche Film vor GEGEN DIE WAND, der den Goldenen Bären gewann, war 1986 der Film STAMMHEIM von Reinhard Hauff, in dem der Gerichtsprozess im Jahre 1975 gegen die RAF-Terroristen Andreas Baader, Ulrike Meinhof, Gudrun Ensslin und Jan-Carl Raspe im Hochsicherheitsgefängnis Stammheim nacherzählt wird. Siehe hierzu: HAufF, Robert (1986): Stammheim, Spielfilm, Bioskop-Film GmbH, Deutschland.

19 Siehe hierzu: Bordwell, David/Thompson, Kristin (2012): Film Art. An Introduction, 10. Aufl., New York: McGraw-Hill, S. 235.

20 Cahit kommt zwar als türkischer Name vor, seine Semantik geht aber auf das arabische Verb ğahada (sich bemühen, anstrengen) zurück. Daraus leitet sich auch das Nomen Ğihad ab, das besonders in religionspolitischen Zusammenhängen bekannt ist und mitunter in Integrations- 
dreißiger mit schwarzer Lederjacke, sammelt als Gelegenheitsarbeiter Biergläser und Flaschen nach Konzerten ein. Wir sehen ihn bei dieser Arbeit frustiert und am Ende seiner Arbeit mit großem Durst gierig die stehengelassenen Bierflaschen austrinken. Cahit ist gereizt. Als sein türkischer Arbeitskollege ihm besorgt rät, dass er doch Wasser trinken solle, wenn er so durstig sei, antwortet ihm Cahit in gebrochenem Türkisch mehrmals, dass er kein Tier, sondern ein Mensch sei. Dies ist die erste Aussage des Protagonisten im Film. Später werden wir nebenbei erfahren, dass es sich bei dieser Lokalität um Die Fabrik, ein Kultur- und Veranstaltungszentrum in Hamburg-Altona handelt. Wir werden sehen, dass in kaum einem Film oder einem Text der 1990er Jahre, die Migration thematisieren, die Bestimmung der Orte mit einem establishing shot eingeführt wird. Diese Art der Erzählung und Unmittelbarkeit steht in einem spannungsreichen Verhältnis zum Begriff der Integration. Denn »Integration« zieht immer die Frage nach sich, wohinein man integriert ist und worin etwas stattfindet.

Im Vordergrund stehen hingegen hier die sich bewegenden Akteurinnen und Akteure, deren Gereiztheiten mit Bewegung korrelieren. ${ }^{21}$ Intensiviert wird dieser Fokus durch eine besondere Lichtdramaturgie. In GEGEN DIE WAND folgt auf den künstlichen orientalischen Einstieg mit künstlichem Licht eine Sequenz in der Fabrik ohne externe Lichtquellen bzw. filmsprachlich gewendet: mit Einsatz von natürlichem Licht. ${ }^{22}$ Da die Aufnahmen im Kellergewölbe der Fabrik gemacht

debatten zum Einsatz kommt, wenn es um die Frage der Gewalt im Islam geht. Doch ist auch bei diesem arabischen Begriff das semantische Feld breit. Beispielsweise werden Freiheitskämpfer mūğahid genannt - etwa die afghanischen Kämpfer in den 1980er Jahren, die sich gegen die sowjetische Intervention von 1979 bis 1989 wehrten. Mitte der 1990er Jahre werden aus den Mūğahidin die Taliban-Kämpfer, die sich als Koranschüler begreifen. Siehe WEHR, Hans (1977): Arabisches Wörterbuch für arabische Schriftsprache und Supplement, Beirut: Otto Harrassowitz, S. $128 \mathrm{f}$.

21 In sehr vielen Filmen der 1990er Jahre deutsch-türkischer Provenienz sind die Protagonisten von Beginn an gereizt oder begonnene Dialoge werden durch das Gereiztsein gestört und abgebrochen. Dieses Phänomen gilt nicht allein für deutsch-türkische Filme, sondern ab Mitte der 1990er Jahre besonders auch für deutsche Filme. Siehe hierzu folgende deutsch-türkischen Filme: YAvUZ, Yüksel (1998): Aprilkinder, Spielfilm, Zero Fiction Film GmbH, Deutschland. ARSLAn, Thomas (1997): Geschwister, Spielfilm, ZDF, Deutschland; ders. (1998): Dealer, Spielfilm, Trans-Film GmbH, Deutschland. AKIN, Fatih (1998): Kurz und schmerzlos, Spielfilm, Wüste Film Produktion, Deutschland. Siehe zu den deutschen Produktionen: ScHMID, Hans-Christian (1995): Nach fünf im Urwald, Spielfilm, Claussen + Wöbke Filmproduktion, Deutschland. BECKER, Wolfgang (1995-1997): Das Leben ist eine Baustelle, Spielfilm, X-Filme Creative Pool, Deutschland. TYKWER, Tom (1998): Lola rennt, Spielfilm, X-Filme Creative Pool, Deutschland. DRESEN, Andreas (1998): Nachtgestalten, Spielfilm, Rommel Film e. K., Deutschland.

22 In Başers Film LEBEWOHL, FREMDE spielt das natürliche Licht im Unterschied zu seinen ersten beiden Filmen aus den 1980er Jahren ebenfalls eine herausragende Rolle, seien es Innen- oder 
wurden, ist die Sequenz in ihrem Grundton dunkel. Cahits Trinken erinnert an die Beschreibungen des Mutterbauchs und an das feuchte Loch auf dem Friedhof in Özdamars Erzählung. ${ }^{23}$ Wie in Das Leben ist eine Karawanserei steht auch hier gleich zu Anfang das Leben auf dem Spiel. ${ }^{24}$

Denn nach dieser Sequenz im Kulturzentrum wird Cahit, wie die zweite Protagonistin Sibel zu Beginn des Films, einen Selbstmordversuch begehen. Er fährt mit dem Auto gegen eine Wand, sie schneidet sich die Pulsadern auf. Sibel und Cahit lernen sich im Krankenhaus kennen. Auf Sibels Wunsch und auf ihr Drängen hin gehen sie gemeinsam eine Scheinehe ein. Sie will der Enge des traditionellen türkischen Lebens ihrer Eltern in Deutschland entkommen, um mit so vielen Männern wie möglich »ficken« zu können. ${ }^{25}$ Dass die Scheinehe sich $\mathrm{zu}$ einem Liebesverhältnis entwickelt, ist der genreübliche Strang der Geschichte, die GEGEN DIE WAND erzählt. Dass es aber um mehr geht, nämlich um kulturelle Desintegration, genauer um Exklusion statt Integration und Inklusion in den 1990er Jahren, hat mit einem anderen Strang im Film zu tun, den ich am Ende dieses Kapitels aufzeigen werde. ${ }^{26}$ Nicht das Zusammenfinden der Liebenden steht im Mittelpunkt, sondern der körperliche Ausdruck als Form einer besonderen Gefühlskonstellation. Diese basiert wie in Özdamars Roman auf dem komplizierten Verhältnis zwischen orientalischem Postkartenmotiv und der Wut seiner Akteurinnen und Akteure aus einer emotional geprägten Existenz heraus. ${ }^{27}$ Kompliziert ist dieses Verhältnis, weil der

Außenaufnahmen. Letztere bestimmen in bemerkenswerter Differenz zu 40QM DeUTSCHLAND und ABSCHIED vom FALSCHEN PARAdiES die ästhetische Struktur des Films. Das Hinausgehen in LEBEWOHL, FREMDE ist ein anderes als in den Filmen davor. Siehe hierzu: BAŞER (1991).

23 Am Tag der Beerdigung des Vaters des Protagonisten Jan Nebel (Jochen Vogel) in Wolfgang Beckers Film DAS LEBEN IST EINE BAUSTELLE regnet es während der Beerdigung sehr stark in das Grab - so sehr, dass der Sarg im Wasser nicht mehr zu sehen ist. Siehe hierzu: BECKER (1995-1997). 24 Tod, Geburt und Leben stehen auch im Zentrum der kafkaesken Erzählung »Die Treppe« in Kemal Kurts Erzählband Der Chinese von Schöneberg. Siehe hierzu: KuRT, Kemal (2000a): „Die Treppe«. In: ders.: Der Chinese von Schöneberg, Berlin: Hitit, S. 10-15.

25 Akin, Fatih (2004): Gegen die Wand. Das Buch zum Film mit Dokumenten, Materialien, Interviews, Köln: Kiepenheuer \& Witsch, S. 39.

26 Meine Analyse von GEGEN DIE WAND steht hier in einem engeren Zusammenhang mit Literatur und Film der 1990er Jahre und wird differenzierter ausfallen als in den Aufsatzpublikationen zuvor. Siehe hierzu: EzLI, Özkan (2009): »Von der Identität zur Individuation - Gegen die Wand. Eine Problematisierung kultureller Identitätszuschreibungen«. In: Soziale Welt. Sonderband 17: Konfliktfeld Islam in Europa, S. 283-304.

27 In einer vergleichbaren gegenorientalisierenden Rahmung konstatiert Kemal Kurt in seiner Erzählung Die Lösung, dass mit dem Wechsel vom Warten zum Suchen die Ungeduld an die Stelle der Geduld getreten sei. Diesen Satz wiederholt er sogar zweimal nacheinander. Wie Özdamar und Akın beginnt und schließt er seinen Erzählband Der Chinese von Schöneberg mit den volksliterarisch bekannten türkischen Schattenspielfiguren Hacıvat und Karagöz ebenfalls mit 
Orient nicht einfach das Fremde oder das Eigene wiederspiegelt, mit der die zweite Generation sich einfach identifizieren oder ihn einfach hinter sich lassen könnte. Vielmehr speisen die Akteurinnen und Akteure ihre Kraft und ihren Ausdruck aus der Verbindung von hier und dort, wobei diese Verbindung keinen anderen Austragungs- und Kommunikationsort hat als ihre Erzählung und die Akteure selbst. In jedem Fall pendelt die Bindung von Deutschem und Türkischem zwischen dem Orient als Aphorismus und Postkartenmotiv und einer erzählerischen Kraft. Letztere hält mit einem Zusammenstoß von Bild-, Lichtverhältnissen und surrealen Beschreibungen eine überzogene, laute körperlich-existenzielle Realität gegen die Mehrheitsgesellschaft und orientalistische Zuschreibungen, in deren Zentrum Konflikte und das Überleben stehen. ${ }^{28}$ Diese Körperlichkeit bestimmt auch die Bewegungen der Akteure durch den Raum, die zwar für Kritik, aber nicht für Ankunft stehen. Artikulierbar werden diese Spannungen trotz Fehlens eines konkreten Ortes durch Mobilität, Körperlichkeit und Komik. Auch hier steht im Zentrum der Erzählung die Anrufung der »personhood «. ${ }^{29}$

Diese Aspekte zeichnen ebenfalls den Zugang aus, den Feridun Zaimoğlu für seinen Protagonisten in Abschaum. Die wahre Geschichte von Ertan Ongun

orientalisch-türkischen Markern, die zu den acht Erzählungen selbst quer und fremd stehen. KURT, Kemal (2000b): »Die Lösung«. In: ders.: Der Chinese von Schöneberg, Berlin: Hitit, S. 23.

28 Diese Konstellation gilt keineswegs allein für die deutsch-türkischen Filme, sondern ist auch in den genannten deutschen Komödien bzw. Tragikomödien der 1990er Jahre anzutreffen. Im Überraschungserfolg ABGESCHMINKT von 1992 schreibt die Comiczeichnerin Frenzy (Katja Riemann) zu Beginn des Films an die Wand ihres Ateliers, dass das Leben eine große Scheiße sei und man dann sterbe. In Wolfgang Beckers Film DAs LEBEN IST EINE BAUSTELLE erfährt Jan Nebel zu Beginn des Films, dass er sich sehr wahrscheinlich mit dem HIV-Virus infiziert hat, kurz darauf stirbt sein Vater in ihrer alten Berliner Wohnung beim Abendessen vor dem Fernseher. In Doris Dörries Spielfilm KeINER LIEBT MICH von 1994 übt sich die Protagonistin Fanny (Maria Schrader) in der wilden Tragikomödie in einem Kurs und zu Hause im Sterben, weil das Leben ohne eine Liebesbeziehung für sie keinen Sinn macht. In ihrer Wohnung steht ebenfalls ein Sarg, den sie am Ende des Films vom Balkon wirft, als sie dann doch den für sie vorherbestimmten Mann kennenlernt. Mathieu Kassovitz' bekannter Spielfilm über die Banlieues in Paris aus dem Jahre 1995 LA HAINE (HASs) beginnt mit der Beschreibung aus dem Off, dass ein Mann aus dem 50. Stock stürzt und sich nach jeder Etage sagt, dass bisher alles gut gegangen sei. Der Kommentar aus dem Off schließt aber mit der Bemerkung, dass das Wichtige nicht der Fall, sondern die Landung sei. Im Film kommt es dann zwar zur Katastrophe: Ein maghrebinischer Jugendlicher erschießt aus Rache einen französischen Polizisten. Doch steht dies nicht für den Aufprall des Mannes. Denn der Film schließt mit derselben Aussage, dass ja alles noch gut gehen würde, obwohl man sich im freien Fall befinde. Siehe hierzu: GARNIER, Katja von (1992): Abgeschminkt, Spielfilm, Hochschule für Film und Fernsehen, Deutschland. DöRRIE (1994); BECKER (1995-1997); KASSOviTz, Mathieu (1995): La Haine, Spielfilm, Studiocanal, Frankreich.

29 Vgl. SOYSAL (1994): S. 142. 
wählt. $^{30}$ Darin erzählt er die Geschichte eines 25-jährigen deutsch-türkischen Kriminellen und Drogenabhängigen in der norddeutschen Stadt Kiel. Obwohl sich alles in diesem Roman in dieser Stadt abspielt, fallen kaum Stadt- oder Straßennamen. ${ }^{31}$ Am Anfang von Abschaum steht der Tod eines Freundes aus Ertan Onguns krimineller Milieuclique. In der »Beerdigungs-Story«, mit der die als eine reale inszenierte, auf Interviews basierende Erzählung beginnt, wäscht Ertan mit einem türkischen muslimischen Geistlichen und einem Gehilfen die Leiche seines Freundes. Dieser ist zwar in Deutschland geboren, wird aber in Syrien beerdigt. Nach der rituellen Waschung sagt er seinem toten syrischen Freund auf Türkisch, dass er ihm bald folgen werde; so viel sei schon geschehen. ${ }^{32}$ Aber auch dieser über den Tod hinausgehende kollegial-solidarische Spruch wird nur wenige Zeilen später - wie bei Özdamar - am Ende der ersten »Story« wieder konterkariert. »Jetzt liegt Farouk da, jetzt soll mir irgendeiner sagen, er kommt ins Paradies oder in die Hölle oder irgend so ne Scheiße, er liegt da, und das wars, Ende, er hat ein Scheiß-Leben geführt, is beschissen krepiert, is ein Monat im Leichenschauhaus vergammelt, und jetzt liegt er im Loch, das wars, Ende, aus. Ich frag mich, obs das gewesen sein kann. « $^{33}$

Drei Jahre vor Zaimoğlus Roman steht bereits in Ayhan Salars prämiertem Kurzfilm Totentraum von 1994 die muslimische Leichenwaschung im Zentrum. Wie bei Zaimoǧlu wird damit aber nicht die Darstellung einer fremden kulturellen Praxis bezweckt, sondern das Zeigen existenzieller Zustände. Denn Salars Kurzfilm beginnt mit der Ankunft eines gut gekleideten, aber barfüßigen Gastarbeiters an irgendeinem deutschen Bahnhof. Nach der Nahaufnahme seiner nackten Füße folgt ein Cut, und wir sehen, wie seine Leiche, sein ganzer Körper, nach muslimischem Ritus gewaschen wird. Aus dem Off wird dazu ein Brief seiner Frau aus der Türkei über ihre fragilen familiären und prekären finanziellen Bedingun-

30 Der Filmregisseur Lars Becker hat diese Geschichte mit KANAK ATTAK unter Mitwirkung von Feridun Zaimoğlu 1999 verfilmt. Siehe: BECKER, Lars (2000): Kanak Attack, Spielfilm, UIG Entertainment $\mathrm{GmbH}$, Deutschland.

31 In LEBEWOHL, FREMDE wissen wir auch den ganzen Film über nicht, auf welcher Insel wir uns befinden.

32 Original aus dem Text: »Bizden bu kadar moruk, yakında bende yanına uğrarım, hadi eyvallah.« Siehe hierzu: ZAIMoĞLU, Feridun (1997): Abschaum. Die wahre Geschichte von Ertan Ongun, Hamburg: Rotbuch, S. 11. Dieser türkische Passus wird in Abschaum weder direkt noch mit einer Fußnote ins Deutsche übersetzt. Dies gilt im Übrigen für viele Textpassagen und Filmsequenzen deutsch-türkischer Provenienz der 1990er Jahre. In LEBEwoHL, Fremde spricht der türkische Flüchtling nur türkisch. Başer setzt dabei weder deutsche Untertitel ein, noch dolmetscht eine andere Person, was Deniz Varlık im Film sagt. Dennoch entsteht eine Beziehung zwischen Karin und Deniz. Siehe hierzu: BAŞER (1991).

33 Ebd. 
gen vorgelesen. Die Frau weiß noch nicht, dass ihr Mann verstorben ist. In der letzten Sequenz des Filmes wird ein Sarg in einen Zug getragen. ${ }^{34}$ Wie der Titel des Kurzfilms es schon andeutet, wirken die gedrehten Sequenzen traumartig. ${ }^{35}$ Auch Başers dritter Film LeBewoHL, Fremde, in dem es um den Aufenthalt politischer Flüchtlinge auf einer deutschen Insel geht, erzählt vom Überleben. Im ersten Drittel des Films kommt ein pakistanischer Flüchtling im Meer um, weil er die Gezeiten Ebbe und Flut nicht kennt. Im zweiten Drittel wird der Bauwagen, in dem neben dem türkischen politischen Flüchtling noch zwei weitere Geflüchtete leben, von den deutschen Inselbewohnern in Brand gesteckt. Schließlich sind am Ende des Films alle Bewohner der Insel von einem massiven Unwetter bedroht. Sie werden evakuiert, und wir finden die beiden Protagonisten Karin und Deniz in einem Zelt auf dem Festland wieder. ${ }^{36}$ Evident sind auch hier die Themen des allgemeinen Menschseins und die Frage des dauerhauften Wohnens. Aras Ören lässt in seinem ersten Roman aus den 1990er Jahren, Berlin Savignyplatz, seine Gastarbeiterfigur Ali Itir aus Bitte nix Polizei von 1981, die dort im Berliner Landwehrkanal umgekommen war, in einer surreal gestalteten und komplex erzählten Narration auferstehen, über- und weiterleben. ${ }^{37}$ Ali Itir ist darin auf der Suche nach seinem Erzähler. Im Audiokommentar zu GEGEN DIE WAND hält Fatih Akın schließlich fest, dass seine Protagonisten Cahit und Sibel am Anfang wie »Zombies « seien, die sich gegenseitig zum Leben erwecken. ${ }^{38}$

Wenn in den 1960er und 1970er Jahren die Gastarbeiter sich auf der Zugfahrt fragten, wo denn die europäische Zivilisation beginne und in den 1980er Jahren die Frage nach dem türkischen Aussehen mit klaren Stereotypen verbunden war, scheinen nun nicht mehr die Verhaltensweisen oder falsche Vorstellungen vom Anderen im Zentrum zu stehen, sondern über den Körper die Frage nach den Vorstellungen von und über Kultur bzw. Existenz und das Wohnen in der Welt

34 Siehe hierzu: http://www.salarfilm.de/salarfilm/films.html (23.05.2018). Siehe auch: KuLAoğLu, Tuncay/PrIESSNER, Martina (2016): »Stationen der Migration. Aufbruch, Unterwegssein, Ankunft und Rückkehr im türkischen Yeşilçamkino bis zum subversiven Migrationskino der Jahrtausendwende«. In: Deutsch-Türkische Filmkultur im Migrationskontext, hg. v. Ömer Alkın, Wiesbaden: Springer, S. 25-44, S. 31f.

35 Auch Kemal Kurts »Die Treppe« beginnt damit, dass der Erzähler seinen letzten Traum in seine Jacke steckt und damit auf die Straße geht. Surreal bleibt die Erzählung bis zum Schluss, als der Erzähler stirbt und zugleich seine eigene Geburt sieht. Siehe hierzu: KuRT (2000a): S. 10-15. 36 Siehe hierzu: BAŞER, Tevfik (1991).

37 Siehe hierzu: ÖREN, Aras (1981): Bitte nix Polizei, Berlin: claasen, S. 116. Siehe hierzu auch: ÖREN, Aras (1995): Berlin Savignyplatz, Berlin: Elefanten Press.

38 AKIN, Fatih (2004): »Audiokommentar zu Gegen die Wand«. In: ders.: Gegen die Wand, Spielfilm, Wüste Film Produktion, Deutschland. 
an sich. So war Feridun Zaimoğlus Leitfrage in Kanak Sprak. 24 Misstöne vom Rande der Gesellschaft tatsächlich eine ganz andere als in der deutsch-türkischen Migrationsgeschichte zuvor. Für dieses Buch von 1995, das die programmatische Grundlage für die darauffolgenden Werke Abschaum und Koppstoff darstellt, hat der Autor über zwei Dutzend ansässige türkeistämmige Kieler Jugendliche und Heranwachsende über ihre »Lebenssituation« interviewt. Anstelle von Fragen wie: Was willst du werden? Warum sind Deine Eltern migriert? Oder wie lebt es sich als Türke in Deutschland? brauchte er nur eine einzige Frage zu stellen, um seine Interviewpartner zum Sprechen zu bringen: »Wie lebt es sich in Deiner Haut «? ${ }^{39}$ Aus dem Interviewmaterial und Zaimoğlus ästhetischer Überformung ist eine »Kanak Sprak« entstanden, die eine Bewegung initiierte und fast ein Jahrzehnt anhielt. ${ }^{40}$

Nach eigener Ansicht und aus den Schlussfolgerungen seiner Interviews sucht diese Generation »keine kulturelle Verankerung«. Ihre prägenden Erfahrungen macht sie »außerhalb des Elternhauses« im öffentlichen Raum. Die Jugendlichen »haben eine eigene innere Prägung und ganz klare Vorstellungen von Selbstbestimmung«. Es ist ihre Sprache, die Kanak-Sprak - »eine Art Creol oder Rotwelsch mit geheimen Codes und Zeichen« - und ihr Aufritt, der über ihre »Existenz entscheidet ${ }^{41}$

Ich hab meinen eigenen grundstrang, der geht da mitten durch'n leib vom hirn zum herzende, in dem beben und schütteln sich meine extrasache, mein instinkt und mein koscherer wille, und diesem dreiergespann teilt sich alles zucken und recken mit, was so außen abgeht, aber die zonengrenze zwischen mir und dem da draußen meißel ich streng jeden verdammten tag, ich achte, daß mir die haut sauber bleibt, daß mir keiner an stil und meinung und mode und trend was anhängt, denn, bruder, mein einziges hab und gut is meine saubere moral, die hier in diesem kadaver durch und durch steckt. ${ }^{42}$

39 ZAIMoĞLU, Feridun (1995): Kanak Sprak. 24 Misstöne vom Rande der Gesellschaft, Hamburg: Rotbuch, S. 15.

401998 wird die transethnische Netzwerk-Plattform Kanak Attak gegründet. Zu ihren Mitbegründern gehören unter anderen Feridun Zaimoğlu, Mark Terkessidis und Imran Ayata. Im Kern geht es darum, den Begriff des `Kanaken umzuwerten. Er soll nicht mehr für die Opfer der Folgen der Migration stehen, sondern umgekehrt für ein neues Bewusstsein, das sich nicht aus der Herkunft, einer »in die Wiege gelegten Identität« speist, sondern gegen die Frage »nach dem Paß und der Herkunft« Stellung und »Haltung« bezieht. Die erste Generation der `Kanaken « ist die zweite Generation der Immigranten, zu der dann im Zuge ihrer Entwicklung auch Nicht-Migranten »Deutsche der n2-Generation« gehören können. Siehe hierzu das Manifest der Plattform Kanak Attak von 1998: http://www.kanak-attak.de/ka/about/manif_deu.html (26.10.2016). Siehe hierzu auch: ZAimoĞLU (1995): S. 9. Siehe auch: LotTmanN, Joachim (Hg.): Kanaksta, Berlin: Quadriga; Tuschick, Jamal (Hg.): Morgen Land. Neueste deutsche Literatur, Frankfurt a. M.: Fischer.

41 Ebd., S. 10 und 13.

42 ZAIMOĞLU (1995): S. 22. 
Straßen und Viertel, Sprache und Körper sind die Elemente der Selbstbestimmung der Akteure; eine ästhetische Sprache, die auf Krawall setzt, um in erster Linie gehört und nicht unbedingt, um verstanden $\mathrm{zu}$ werden. Politisch positionieren sich die > Kanaken ` gegen die bürgerlich-liberalen Deutschen.

\begin{abstract}
Was ich rede, Meister, das ist nicht reden gegen irgendwas, gegen ne ganz bestimmte Adresse isses, die vornehm tut und glaubt, sich mit allen Wassern zu waschen und alle Schikanen zu kennen, und mein Reden, Meister, ist strikt gegen das Liberalultramild, gegen sein Schickimicki, sein Jet-set, gegen sosyete bebe, gegen sein Kopfzerbrechen, wie er den Mohr vom letzten Dreck waschen kann, gegen s Pintwedelige, was er Kulturforschen nennt, gegen den gottverkackten Sprech mit wie interessant!, und was es nicht alles gibt! [...] Gegen sein Merci und sein Weißweinvernissagenquark und sein Krawattennadelgetue schmeiß ich ein Fick-dich in die Runde und oute so nen Liberal als Kannibal, als erster Yamyam und Fresser von Kanak. ${ }^{43}$
\end{abstract}

Der schriftliche und mündliche Gebrauch der Sprache stellt hier eine soziale Praxis und einen Zugang dar, der sich auch in der sprachwissenschaftlichen und pädagogischen Forschung zu Akteuren mit Migrationshintergrund oder Bindestrichidentität wiederfindet. Vom Einsatz der Sprache hängen soziale, politische, rechtliche und kulturelle Bedingungen ab. Denn bei »Äußerungen stellt sich nicht allein die Frage, ob sie wahr oder falsch sind; sondern vielmehr, ob sie glücken oder nicht glücken «. Entscheidend ist dabei nicht nur Kompetenz, sondern auch die "mikropolitischen Bedingungen, an die das `Glückenkönnen` der Äußerungen von Sprecher/innen gebunden ist ${ }^{44}{ }^{44}$ Indem die Kanak Sprak den in den 1980er Jahren diskriminierenden Begriff "Kanake« umkehrt, findet eine sprachliche und identitätspolitische Umwertung statt. Eine Umkehrung der

43 ZAIMoĞLU, Feridun (1997): »Ich bin n taffer Liberalkiller. Nesrin, Rapperin und Street-Fighterin «. In: ders., Koppstoff, Hamburg: Rotbuch, S. 11-15, hier S. 11f.

44 Mecheril, Paul (2010): Migrationspädagogik, Weinheim und Basel: Beltz, S. 102. Arbeiten und Forschungen von Ben Rampton für den englischsprachigen Raum (1995), von Ulla-Brit Kotsinas für den Gebrauch des Rinkeby-Schwedisch (1998), einer ethnolektal basierten subkulturellen Varietät des Schwedischen, in multiethnischen Vierteln in Stockholm und von Inci Dirim und Peter Auer zum deutschsprachigen Raum (2004) haben gezeigt, dass der spezifische Sprachgebrauch durch die Erfindung nicht-normativer Sprachformen den Jugendlichen als Identifikationsressource dient. Zugleich zeigen besonders Kotsinas, Dirim und Auer auf, dass diese neuen Sprachformen auch von Kindern der Alteingesessenen gesprochen werden. Siehe hierzu: RAMPTON, Ben (1995): Crossing language and Ethnicity among adolescents, London: Longman. KotsinAs, Ulla-Britt (1998): »Language Contact in Rinkeby. An Immigrant Suburb«. In: Jugendsprache, hg. v. Jannis Androutsopoulos, Anno Schulz, Frankfurt a. M.: Lang, S. 125-148; AuER, Peter/DIRIM, Inci (2004): Türkisch sprechen nicht nur die Türken. Über die Unschärfebeziehung zwischen Sprache und Ethnie in Deutschland, Berlin: De Gruyter. 
Diskriminierung, die dem "place« der informellen Zugehörigkeit des Denizens eine Form gibt, ohne dabei Teil der Gesellschaft als Staatsbürger sein zu müssen. Tatsächlich unterscheidet Tomas Hammar den »full citizen« als »formal citizen« vom »informal member«, dem Denizen. Narrativ-ästhetitisch gewendet hat der Staatsbürger bereits eine Form, mit der er auftreten kann, die der Denizen erst generieren muss.

Deshalb reicht die Frage des »Kanaken« in den 1990er Jahren weit über die der zweiten Generation hinaus. Sie steht als Artikulationsgrundlage auch im Zentrum der Romane Özdamars und der Filme Akıns. Die kulturelle Frage ist zu einer zugleich natürlich-existenziellen geworden, einer Frage danach, wie es sich in der eigenen Haut im öffentlichen deutschen Raum lebt. Durch ihre erzählerisch-existenzielle Rahmung mit Geburt und Tod ist sie eine Frage der Selbstbestimmung und des Schutzes zugleich. Die Frage der Präsenz im öffentlichen Raum steht auch im Zentrum der Überlegungen von Hammar und Soysal. ${ }^{45}$ Gestellt wird sie ebenfalls in den Dokumentarfilmen MÄDCHEN AM BALL (1995) und NACH DEM SPIEL (1997) von Aysun Bademsoy, die den Alltag fünf türkeistämmiger Mädchen und deren sich darin vollziehende »dynamische Selbstbehauptung« ihrer Akteurinnen thematisieren. ${ }^{46}$ Der dritte Teil dieser Dokumentationstrilogie ICH GEHE JETZT REIN von 2008, der erneut das Alltagsleben derselben Personen thematisiert, unterscheidet sich von den ersten beiden. Hier steht mehr das »Erwachsenwerden [...], die Melancholie über die vergangene Zeit« und die Diskriminierung auf dem Arbeitsmarkt im Vordergrund. ${ }^{47}$ Als Aysun Bademsoy in FREMDE DEUTSCHE NACHBARSCHAFT von 1987 das erste Mal die türkische Migration nach Deutschland dokumentierte, zeigte sie die alltäglichen Wege türkischer Jugendlicher von ihren Wohnungen zu Straßenbahnhaltestellen, von U-Bahn zur Schule. ${ }^{48}$ Wollte man Stuart Halls These zum Aufkommen der Kategorie »Kultur» an dieser Stelle umkehren, könnte man sagen, dass die Dinge in erster Instanz nicht dazu benutzt werden, um zu zeigen, wer man ist, sondern vielmehr, wer man nicht ist. In Örens Berlin Savignyplatz von 1995 ist der Gastarbeiter Ali nicht mehr auf der Suche nach Persönlichkeit wie Anfang der 1980er Jahre, sondern damit beschäftigt, allen Deutschen zu erklären, dass er »nicht er ist«, der Türke, von dem alle denken, dass er es sei. ${ }^{49}$ Er wollte »in der Andersartigkeit seiner

45 Siehe hierzu: Hammar (1990): S. 13f. Soysal (1994): S. 144 u. S. 166.

46 Siehe hierzu: BADEMsoy, Aysun/Mennel, Barbara (2017): ")Als würde man einem Gefühl, einer Spur folgen .... Die Filmregisseurin Aysun Bademsoy im Gespräch«. In: Deutsch-Türkische Filmkultur im Migrationskontext, Wiesbaden: Springer, S. 151-168.

47 Ebd., S. 156

48 Ebd., S. 152.

49 ÖREN (1995): S. 16. 
Andersartigkeit seine Originalität beweisen«, seine »zweite Haut«, die Identität abziehen..$^{50}$

Der entscheidende Punkt ist nur, dass bei aller Umkehrung der kulturellen Selbstbestimmung dennoch mit spezifisch kulturellen Markern gearbeitet wird. Der große Unterschied zu den 1980ern liegt darin, dass an die Stelle der Immobilität der Akteurinnen und Akteure auf unterschiedlichsten Ebenen Bewegung getreten ist. In Film und Literatur sind die Figuren zu Fuß oder in Autos oft in peripheren Stadtbezirken unterwegs. ${ }^{51}$ Dies gilt mitunter auch für die erwähnten deutschen Produktionen, in denen in der Regel klar ist, wohin die Akteure sich bewegen. In den deutsch-türkischen Produktionen wissen wir das in der Regel nicht. Selim Özdoğans Protagonist in Es ist so einsam im Sattel seit das Pferd tot ist von 1995 räsoniert, was er am liebsten machen würde: »Einfach so fahren, mit dem Auto verschmelzen, an nichts mehr denken, nur geradeaus, immer weiter, während die Straße von alleine vorüberzieht, dafür kann ich mich begeistern, so könnte ich ziellos weiterfahren oder, wie einmal jemand gesagt hat: Leben ist wie fahren. ${ }^{52}$ Dass dieses zu einem Körper in Bewegung werden tatsächlich konstitutiv ist, zeigt sich, als der Protagonist mit seinem Auto in einem Stau steckenbleibt und keine Musik mehr hilft. »Alle Schwierigkeiten der Welt kommen dir lächerlich vor, und du träumst von einer Kalaschnikow, um dir den Weg freizuschießen irgendwo müssen die aufgestauten Aggressionen ja hin. « ${ }^{53}$

Die skizzierten Beispiele zeigen, dass sich die ästhetischen Bearbeitungen der Folgen der türkischen Migration nach Deutschland im Übergang von den 1980ern zu den 1990er Jahren grundlegend verändern. Wenn es in Tevfik Başers Filmen, in Alev Tekinays Literatur in den 1980er Jahren nur eine Tür gibt und diese verschlossen ist und auch die Assimilationstheorien als die gängigen Integrationstheorien bis in die 1980er Jahre hinein nur eine Richtung - von der Herkunft zur Ankunft - also ebenfalls nur eine Tür kennen ${ }^{54}$, begegnen uns in Literatur,

50 Ebd., S. 121.

51 In Kemal Kurts Erzählband beginnt jede der acht Erzählungen damit, dass entweder der Erzähler oder Protagonist zu Fuß, mit dem Auto oder einem Kleinbus unterwegs ist. Siehe hierzu: KuRT (2000).

52 ÖZDOĞAN (1995): S. 11.

53 Ebd., S. 23.

54 Die Insel Ellis Island in New York war für alle Einwanderer zwischen den Jahren 1892 und 1956 das »Tor« zu den Vereinigten Staaten von Amerika. Es gab strenge Aufnahmekriterien, mit denen Gesundheit, Besitz und Sprachkenntnisse der Einwanderer geprüft wurden. Die Aufnahme und der Eintritt in die Vereinigten Staaten waren dabei immer mit dem Versprechen auf Freiheit und auf sozialstrukturellen Aufstieg verbunden. Siehe hierzu: MELzER, Chris (2012): »Ellis Island war Tausenden ein Tor in die Freiheit«. In: Die Welt, 12.11.2014, https://www.welt.de/reise/ staedtereisen/article134268707/Ellis-Island-war-Tausenden-ein-Tor-in-die-Freiheit.html (zuletzt 
Film, Theorie und Debatte der 1990er Jahre immer zwei Türen. Nach klassischer Lesart der Integration folgt auf die kognitive, strukturelle und soziale Assimilation die identifikative, wobei sich der ursprüngliche Migrant oder spätestens die dritte Generation mit der Kultur der Mehrheitsgesellschaft identifiziert und die alten Bindungen aufgibt. Die Argumentation in den öffentlichen Debatten und teils in den Sozialwissenschaften versteht in den 1990er Jahren Integration hingegen als einen wechselseitigen Prozess, im Zuge dessen sich auch die aufnehmende Gesellschaft anzupassen und zu verändern habe. ${ }^{55}$ Nicht mehr die Fortschrittlichkeit der Ankunftsgesellschaft als Zukunft und die Rückschrittlichkeit der Herkunft als Vergangenheit geben die Richtung des Prozesses vor. Stattdessen gilt es, unter der Prämisse einer gemeinsamen Gegenwart die Andersartigkeit des jeweils Anderen anzuerkennen. Das Verhältnis zwischen Existenz und Kultur, zwischen Körper und Repräsentation wird aber unter den bereits kurz skizzierten politischen Bedingungen der »Invisibilisierung « der Folgen der Migration artikulatorisch zu einem äußerst schwierigen Unterfangen. Denn Türkisches und Deutsches gehören spätestens seit den 1990er Jahren in einer identitätspolitischen Bindestrichkonstellation zusammen. Beispielsweise konstatiert Pazarkaya Ende der 1980er Jahre, dass zumindest in einigen »Lebensbereichen« zwischen Deutschen und Türken eine sogenannte Integration, »was auch immer darunter $\mathrm{zu}$ verstehen ist«, sich verwirklicht habe. Denn man habe sich mehr und mehr aneinander gewöhnt. Diese Gewohnheit sei nach Pazarkaya und vielen weiteren deutsch-türkischen Autoren mit der deutschen Einheit aufgebrochen und wieder in Frage gestellt worden. ${ }^{56}$

Diese Konstellation ist weder in Literatur und Film, noch in der Dokumentation einfach darzustellen. Was sie kommunizierbar macht, sind die Bewegungen der Akteurinnen und Akteure als Metapher und Praxis sowie der Einsatz erzählerischer Mittel, die die Realität und politisch geführten Diskurse verfremden. Denn manchmal ist nur eine Tür auf, manchmal sind beide zu und in ganz seltenen Fällen sind beide Türen auf. In jedem Fall geht es nicht mehr allein um die Frage, ob eine bestimmte Tür als Ankunft oder Herkunft nun offensteht oder nicht. Interessanterweise verwendet der schwedische Migrationsforscher Hammar zur genauen Bestimmung der Position des Denizens ebenfalls die Metapher des

10.04.2019). Siehe auch: von HELlFELD, Matthias (2017): „US-Immigration. Über diese Insel lief alles«. In: Deutschlandfunk Nova. Eine Stunde History, 06.01.2017, https://www.deutschlandfunknova.de/beitrag/eine-stunde-history-ellis-island (zuletzt 10.04.2019).

55 Siehe hierzu FaIsT, Thomas (2000): "Jenseits von Nation und Postnation. Eine neue Perspektive für die Integrationsforschung «. In: ders.: Transstaatliche Räume. Politik, Wirtschaft und Kultur in und zwischen Deutschland und der Türkei, Bielefeld: transcript, S. 339-394.

56 PAZARKaYa (2000): S. 78. 
»second gate«, die weder für die Herkunft noch für die Ankunft des Migranten steht. Das erste Tor ist für Hammar die »immigration regulation«, wenn der Einwanderer als Fremder (»alien«) im Land der Aufnahmengesellschaft ankommt. Nach klassischen Vorstellungen der Integration als Assimilation würde nach einem Prozess der Anpassung als zweites Tor die »legal naturalisation into full citizenship « stehen. ${ }^{57}$ Doch haben die Folgen der Gastarbeitermigration in Europa zur Öffnung einer Tür zwischen Herkunft und Ankunft geführt. Dadurch haben sich auch die Bedingungen und Verbindungen des Privaten und Öffentlichen verändert. Durch die zweite Tür rückt der Weg zwischen den beiden anderen in den Vordergrund, der wiederum das hohe Maß an Beweglichkeit bestimmt, und, wie wir noch sehen werden, die Gereiztheit der Akteurinnen und Akteure. Diese Konstellation zeigt bereits, dass es das Verstehen des Anderen wie in den 1980er Jahren nicht mehr gibt, weil es diesen Anderen in dieser Form einfach nicht mehr gibt. Als der Arzt Dr. Anders in Aras Örens Berlin Savignyplatz von 1995 zu verstehen glaubt, was Ali Itir damit meint, dass Ali nicht Ali sei, fällt ihm als Antwort eine Metapher ein. »Ich gehe in der Dämmerung über eine Brücke, die Brücke endet, ich stehe an ihrem Ende, aber ich bin noch nicht am gegenüberliegenden Ufer angelangt, denn die Brücke endet im Leeren. Ich schaue zum anderen Ufer hinüber und erreiche es nicht.« Der Erzähler fragt, was Dr. Anders mit dieser Metapher erklären wollte. »Sich selbst oder seinen Patienten Ali Itir, der ihm seine Beklemmungen verständlich zu machen suchte? Dr. Anders ließ diese Frage unbeantwortet. « ${ }^{58}$

Wir werden im Laufe dieses Kapitels sehen, dass diese ziellose Bewegung auch daraus resultiert, dass sich die Deutsch-Türken der zweiten Generation zwar auf den deutschen Straßen aufhalten. Doch begegnen sie dort nicht Deutschen, mit denen sie verhandeln könnten. ${ }^{59}$ Auf der besonderen Begegnungssituation von Deutschen und Deutsch-Türken im öffentlichen Raum der Bundesrepublik basiert, so eine These in diesem Kapitel, der in diesen Produktionen auffallende Globalisierungsdrang und ein Verbundenheitsgefühl. Es gibt Orte und Räume, in denen man sich bewegt und lebt. Doch wird in den Erzählungen tunlichst vermieden, zu bestimmen worin man lebt. Diese Gesamtkonstellation generiert einen Bewegungsschub, ein immerwährendes Unterwegssein, das über den gegebenen öffentlichen Raum in ein Jenseits, auf einen dritten Raum verweist: die Welt, die

57 HAMMAR (1990): S. 16f.

58 ÖREN (1995): S. 118.

59 Tatsächlich ist das Casting und die Besetzung der deutschen Rollen in den deutsch-türkischen Filmen oft ein Problem, wie beispielsweise in Fatih Akıns erstem abendfüllendem Spielfilm KuRz Und SCHMERzLos von 1998. Die Haupt- und Nebenrollen mit einem nicht-deutschen Hintergrund waren in der Regel schnell besetzt. Siehe hierzu: AkIN, Fatih (2011): Im Clinch. Die Geschichte meiner Filme, Reinbek: Rowohlt, S. 55-59. 
transkulturell zusammengehört. Und weil sie nicht einfach gegeben ist, muss das Hier immer erst mit einem Dort verbunden werden, so wie Soysal konstatiert, dass erst mit der Anrufung der universellen Menschenrechte nationale Grenzen verschoben werden können. Und um den gesellschaftlichen Wandel, wir er sich in den 1990er Jahren zeigt, erfassen zu können, ist es erforderlich »to go beyond the nation state ${ }^{60}$. Doch kann es unmöglich bei diesem »beyond «bleiben. Denn letztlich wird die Gewährung von »individual rights and privileges [...] primarily organized by the nation-state«, auch wenn die Legitimität genannter Rechte seit dem Ende des Zweiten Weltkriegs auf einer transnational errichteten neuen Ordnung basiert. ${ }^{61}$ Die Projektion und der Wunschgedanke hier ist, dass mit der Universalisierung von nationalen Rechtskodices und der Rechtssprechung der postnationale Bürger oder Weltbürger zum full Membership und citizenship erklärt wird. Identitätspolitisch korreliert diese paradoxe Bindung mit der kulturwissenschaftlichen Erkenntnis der 1990er Jahre, dass im Eigenen immer auch das Fremde stecke und umgekehrt im Fremden auch immer das Eigene. Yüksel Pazarkaya beschreibt das »lyrische« und »epische Ich« der 1990er Jahre etwa als einen Nomaden, dessen Zuhause der Weg sei. Er kehrt weder zurück noch kommt er an. Denn wohin soll insbesondere der migrierende Mensch »Kurs nehmen«?

Auf das vergessene und aus dem Gedächtnis gelöschte Land oder auf das in vierzig Jahren im Gedächtnis entstandene?

Da entsinnt es sich - eben in dieser Zwickmühle - auf einmal seiner alten Jurte, die nichts anderes als Odyssee bedeutet. Der Weg als Zuhause? Das Zuhause des Nomaden ist der Weg. ${ }^{62}$

Körper, Bewegung, sprachliche und erzählerische Verfremdungen führen aus der »diskursiven Zwickmühle« der 1980er Jahre, aus dem Nicht-Sprechen-Können heraus. Erzählerisch gelangen beispielsweise auf nur drei, vier Seiten die Akteure in Özdamars Roman Das Leben ist eine Karawanserei vom Istanbuler Bahnhof über eine Zugfahrt in die türkische Provinz und von dort auf einen Friedhof. In GEGEN DIE WAND sind wir in Istanbul am Bosporus, bei der nächsten Einstellung in einem Hamburger Kellerraum. Claus Leggewie durchschreitet in seiner programmatischen, bekannten und als Intervention verstandenen Publikation Multikulti. Spielregeln für die Vielvölkerrepublik bei der Bestimmung der multikulturellen Gesellschaft auf nur wenigen Seiten reale und fiktive Orte von Babylon,

60 Soysal (1994): S. 139.

61 Ebd., S. 143.

62 Pazarkaya (2000): S. 122. 
Chicago, Musils Kakanien bis Südafrika. ${ }^{63}$ In Zaimoğlus Abschaum kundschaften die Akteure in einem Kurzkapitel zunächst die peripheren Stadtteile Kiels aus. Im nächsten fliegen sie in die Türkei und sind schon auf den folgenden zwei, drei Seiten wieder zurück. Der Aufenthalt im Flugzeug wird dabei fast immer beschrieben. Diese Mobilität bestimmt auch die Akteurinnen und Akteure in Selim Özdoğans Romanen der 1990er Jahre Es ist so einsam auf dem Sattel seit das Pferd tot ist (1995) und Mehr (1999) sowie diejenigen in Zafer Şenocaks Romantetralogie (1995-1999), der wir uns analytisch noch ausführlich widmen werden. ${ }^{64}$ Für alle genannten Protagonisten gilt, was die Mutter des gefährdeten Säuglings in Das Leben ist eine Karawanserei später über die Lebensweise ihrer Tochter sagt. Sie hätte nur eines im Kopf: die Straße. ${ }^{65}$ In jedem Fall ist das hohe Maß an Bewegung der Akteurinnen und Akteure in kleiner wie auch großer Reichweite ein besonderes Kennzeichen von Literatur und Film der 1990er Jahre.

Die oben eingeführten Filme und Romane der 1990er Jahre sind natürlich Werke, die mit einer besonderen Intensität, Lautstärke und Verfremdungen des Deutschen wie Türkischen in den deutschen Kulturbetrieb eingedrungen sind und so auch rezipiert wurden. ${ }^{66}$ Kanak Sprak und Abschaum haben Zaimoğlu beispielsweise als "Krawalltürken« in den Medien bekannt gemacht. ${ }^{67}$ Aber auch die vermeintlich leiseren und für sich mehr Differenziertheit reklamierenden Autoren und Filmemacher wie Aras Ören, Zafer Şenocak, Ayşe Polat, Aysun Bademsoy, Tevfik Başer, Kemal Kurt, Yüksel Yavuz, Yilmaz und Thomas Arslan machen auf das Problem des Gehörtwerdens aufmerksam. Trotz der leiseren Töne spielt die Irritation des Verhältnisses zwischen Deutschen und Deutsch-Türken auch in ihren Werken der 1990er Jahre eine herausragende Rolle. Beispielsweise ist Şenocaks Romantetralogie, bestehend aus Der Mann im Unterhemd (1995), Die Prärie (1997), Gefährliche Verwandtschaft (1998) und Der Erottomane (1999), eine »unerhörte« Kritik an deutscher gesellschaftspolitischer Zuschreibungspolitik. Ein Beispiel: Der alle Bände verbindende Protagonist Sascha Muhtesem ${ }^{68}$

63 Siehe hierzu: Leggewie, Claus (1990): »Der Turmbau. Ein soziologisches Gleichnis«. In: ders., Multikulti. Spielregeln für die Vielvölkerrepublik, Berlin: Rotbuch, S. 9-25, hier S. 9-16.

64 ÖZdogan, Selim (1995): Es ist so einsam auf dem Sattel seit das Pferd tot ist, Köln: Kiepenheuer \& Witsch. Siehe auch: Özdogan, Selim (1999): Mehr, Berlin: Aufbau.

65 Özdamar (1992): S. 218.

66 Siehe hierzu: Tratz, Susanne/ZaimoĞLu, Feridun (2010): Feridun Zaimoğlu - Mein Leben, Filmportrait, ARTE/ Radio Bremen.

67 ZIERAU, Cornelia/ZAImoĞLU, Feridun (2007): »Ein Gespräch mit Feridun Zaimoğlu «. In: Entgrenzungen. Vierzehn Autorengespräche über Liebe, Leben und Literatur, hg. v. Olga Olivia Kasaty, München: edition text+kritik, S. 431-464, hier S. 437. Siehe auch: TrATz/ZAimoĞLU (2010).

68 Muhtesem bedeutet im Türkischen »fabelhaft«, "wundervoll« oder »hervorragend«, ist ein Adjektiv und wird in der Regel im Türkischen auch so verwendet. Als Nachname ist der Begriff 
- er hat einen deutsch-türkisch-jüdischen Hintergrund - lebt als writer-in-residence im Roman Die Prärie in der amerikanischen Provinz. Er ist »stolz auf seine Unabhängigkeit « und erhält aus Deutschland per Telefon die Anfrage, ob er nicht einen Artikel darüber schreiben möchte, was die Türken in Amerika über die Vorfälle in Mölln ${ }^{69}$ denken. Es gebe keine Türken in Amerika, erwidert Muhtesem. Der deutsche Redakteur entgegnet, dass es überall Türken gebe. »Türken, Mölln in Amerika? Ich gehe hier auf die Jagd, vögele in Tankstellen und gebe Deutschunterricht. " Auf diese Antwort von Sascha legt der Redakteur auf. ${ }^{70}$ Şenocak schließt diese Sequenz, indem er Muhtesem sagen lässt, dass er sich »von denen [...] hier nicht mehr einfangen« lässt. »Er sei jetzt ein ১Jäger in der Prärieく und ১jage nur noch Tiere $«$ « ${ }^{71}$ Dennoch wird der Protagonist in die Bundesrepublik zurückkehren.

Auch wenn Zafer Şenocak sich distanziert über Özdamars ersten Roman geäußert hat - etwa in der Form, dass er orientalistische Klischees ${ }^{72}$ bediene -, irritieren seine Romane und Prosatexte der 1990er auf vergleichbare Weise. Nicht nur die in Kritik stehende Körperlichkeit ist ähnlich. Das »Ficken« spielt auch hier, wie in unzähligen anderen Werken deutsch-türkischer Provenienz dieser Dekade, eine äußerst wichtige Rolle. Ferner sind Şenocaks Protagonisten wie die von Özdamar und Kurt immer unterwegs. Ihr Unterwegssein ist dabei keine Frage der jeweiligen »Lebenssituation«, sondern sie gehört - wie bei Özdamars Protagonistin - zur »wesentlichen Existenzform « der Person. ${ }^{73}$ In der ersten Erzählung »Fliegen « aus Şenocaks postmodernem Erzählband Der Mann im Unterhemd von 1995, träumt Muhtesem, der hier ein Detektiv für multikulturelle Kriminalfälle

weniger geläufig. Zudem vermeidet Şenocak die richtige Schreibweise: Korrekterweise heißt es muhteşem, nicht muhtesem. Diese Vernachlässigung türkischer Rechtschreibung und Aussprache findet sich aber auch im Gebrauch der Namen deutsch-türkischer Autoren und Filmemacher wie Feridun Zaimoglu (richtig: Zaimoğlu), Zafer Senocak (richtig: Şenocak) oder Fatih Akin (richtig: Akın). Im Folgenden folge ich der von Zafer Şenocak verwendeten Schreibweise Muhtesem. 69 In der Nacht auf den 23. November 1992 werden in Mölln zwei Brandanschläge an türkischen Familien verübt. Drei Menschen sterben dabei, und neun Personen verletzen sich schwer. Nach den Ausschreitungen in Rostock-Lichtenhagen, in Hoyerswerda ist mit dem Anschlag in Mölln der Grundtenor in den Medienberichten, dass der neu entstandene Rechtsradikalismus in der Bundesrepublik eine substantielle Gefahr für die neue deutsche Einheit darstellt. Siehe hierzu: IKEN, Katja (2012): »Brandanschläge in Mölln. Wenn ich Böller höre, kommt alles wieder hoch«. In: DER SPIEGEL, 20.11.2012, http://www.spiegel.de/einestages/brandanschlag-von-moelln-1992ibrahim-arslan-erinnert-sich-a-947806.html (14.11.2016).

70 ŞENOCAK, Zafer (1997): Die Prärie, Hamburg: Rotbuch, S. 88.

71 Ebd.

72 Siehe hierzu: ŞENOCAK, Zafer (1992): Atlas des tropischen Deutschland, Berlin: Babel, S. 69. 73 Siehe: KonZETT, Matthias (2003): »Zafer Şenocak im Gespräch«. In: The German Quarterly 76.2, S. 131-139, hier S. 132. 
ist, davon, an mehreren Orten gleichzeitig $\mathrm{zu}$ sein und unsichtbar werden $\mathrm{zu}$ können. ${ }^{74}$ Im erwähnten Roman Die Prärie flieht der Erzähler Ende der 1980er wegen existenzieller Unbehaglichkeit aus der Bundesrepublik Deutschland in die nordamerikanische Provinz, wo er für unbestimmte Zeit bleiben will. In Die Gefährliche Verwandtschaft kehrt der Erzähler in der Erzählzeit des Romans 1992 in die Bundesrepublik zurück und fühlt sich in dem Land, in dem er geboren wurde, als Fremder ${ }^{75}$, weil er das »Ereignis schlechthin «, den Mauerfall, verpasst hat. ${ }^{76}$ Den Einfluss und die Folgen der Deutschen Einheit auf die Deutsch-Türken und ihre Literatur verhandelt auch Yüksel Pazarkaya in seinen poetischen Überlegungen von 2000. Die Wiedervereinigung habe den Integrationsprozess der Türken in Deutschland um mindestens ein Jahrzehnt zurückgeworfen. ${ }^{77}$ In Örens Berlin Savignyplatz hat der Lokaljournalist Jürgen B., ein Freund des Erzählers, gegen Ende des Romans einen Text zu den Nachtgestalten des Berliner Savignyplatz verfasst - dazu zählt er sich selbst, den "großen Türken« und Erzähler des Romans, Ali Itir, Franco und einen weiteren Freund namens Manfred Kohlhaas. Doch weil sich in der DDR gerade Weltgeschichte ereigne und eine neue Zeit beginne, hat der Chefredakteur »keinen Platz mehr für eine Handvoll Bohèmiens aus der Vergangenheit «. ${ }^{78}$ Am Rande, aber regelmäßig fügt auch Kemal Kurt den Mauerfall in seine Erzählungen ein. Im Unterschied zu Ören und vielen anderen Autoren setzt er die deutsche Wiedervereinigung in Relation zu den rechtsradikalen Brandanschlägen in Mölln und Solingen von 1992 und 1993. ${ }^{79}$

Von abrupten Brüchen sind auch Şenocaks vier Romane von 1995 bis 1999 bestimmt. Wenn der Erzähler in Der Mann im Unterhemd von 1995 fast unsichtbar wirkt und selten ins Geschehen eingreift, tritt er im Roman Die Prärie von 1997 und in Die gefährliche Verwandtschaft von 1998 deutlich auf, um jedoch im vierten Roman Der Erottomane. Ein Findelbuch der 1990er Jahre wieder zu verschwinden. ${ }^{80}$ Er stirbt einen vermeintlich selbstgewollten rituellen Tod. Doch sprechen am Ende von Der Erottomane ein Professor der Literaturwissenschaft und seine Assistentin, die den Nachlass des Verstorbenen erhalten, über ihn als Opfer. Sie sind froh, wieder ein Thema zu haben, über das sie sprechen

74 Siehe: ŞENOCAK, Zafer (1995): Der Mann im Unterhemd, Berlin: Babel, S. 7.

75 ŞENOCAK (1998): S. 34.

76 Chemsman, Tom/ŞenocaK, Zafer (2003): »'Einfach eine neue Form`: Gespräch mit Zafer Şenocak«. In: Contemporary German Writers. Zafer Şenocak, hg. v. Tom Cheesman, Karin Yeşilada, Cardiff: University of Wales Press, S. 19-30, hier S. 26.

77 Siehe hierzu: PAZARKAYA (2000): S. 78.

78 ÖREN (1995): S. 154.

79 KuRT (2000a): S. 31. Siehe auch: KuRT, Kemal (2000c): »Der Chinese von Schöneberg«. In: ders., Der Chinese von Schöneberg, Berlin: Hitit, S. 31, S. 94.

80 Ebd., S. 21. 
können. ${ }^{81}$ Wenn dieses aus der Wissenschaft stammende Opfernarrativ am Ende im Widerspruch zur Tetralogie steht, ist sie aus meiner kulturgeschichtlichen Perspektive nicht widersprüchlich, sondern inhärenter Bestandteil des Weitersprechens. Im Unterschied zu den 1980ern ist die Suche nach den Wurzeln in Şenocaks Schreiben nicht einfach eine geistige Angelegenheit, sondern vor allem eine »körperlich-organische«, die deshalb auch immer wieder neu entsteht und vergeht. ${ }^{82}$

Meine Dichtung ist das Ergebnis einer ständigen Bewegung. Dort im Unbewußten, im Land der Eingebung, wo sich Eindrücke und Erlebnisse niederlassen, aus dem das Poetische hinauswächst, findet durch eine emotionale Zündung eine Art Übertragung zwischen Außenund Innenwelt statt, eine ständige Chiffrierung des Sichtbaren und Dechiffrierung des Verborgenen. Diese Übertragung entspricht genau meinem Lebensgefühl zwischen zwei Welten und Sprachen, zwischen Herz und Haut. ${ }^{83}$

Theoretisch habe Şenocak nach eigener Beschreibung neben der Dichtung mit seinen vier Prosabänden in den 1990er Jahren den Versuch unternommen, zu zeigen, dass das, was vermeintlich » dazwischen ist, immer im Innern passiert, im Innern von einem selbst «. ${ }^{84}$ Auch Kemal Kurts Erzählung »Der Chinese vom Schöneberg" ist am Ende eine, in der sich der Autor in einem vermeintlichen Chinesen (in Wirklichkeit ein Koreaner), als jemand spiegelt, der am liebsten »das Fenster aufmachen und hinausschreien « würde.$^{85}$ In Kurts und Şenocaks Literatur gibt es einen zweiten Ausgang, der auf eine andere Wirklichkeit aufmerksam macht als die in den 1990er Jahren über den Begriff des ausländischen Mitbürgers postulierte. Von dieser »Differenz im Herzen ${ }^{86}{ }^{6}$ geht auch Zaimoğlus Leitfrage aus.

Im selben Jahr, in dem Zaimoğlus Abschaum als literarische Darstellung des `Kanaken` Ertan Ongun aus Kiel erscheint, entsteht auch der Kino-Spielfilm GESCHWISTER des deutsch-türkischen Regisseurs Thomas Arslan, in dessen Fokus wie bei Zaimoğlu und Bademsoy die zweite Generation türkischer Immigranten steht. Er basiert zum einen auf einer umfangreichen Recherchearbeit, bei der sehr viele Interviews mit Berliner Deutsch-Türken der zweiten Generation geführt wurden; zum anderen aus den Erfahrungen seines ersten langen TV-Spielfilms MACH DIE MuSIK LeISER (1993/1994), in dem Arslan das Alltagsleben einer

81 ŞENoCAK, Zafer (1999): Der Erottomane. Ein Findelbuch, München: Babel, S. 124.

82 KonZeTt (2003): S. 132.

83 ŞENOCAK, Zafer (1992): Atlas des tropischen Deutschland, Berlin: Babel, S. 100.

84 Cheesman/ŞEnocaK (2003): S. 22.

85 KURT (2000c): S. 96.

86 BhabHa, Homi (2000): Die Verortung der Kultur, Tübingen: Stauffenburg S. 13. 
jugendlichen Gruppe in Essen porträtiert. ${ }^{87}$ Aufgrund des großen Interviewmaterials zu Geschwister beschließt Arslan, eine ganze Trilogie zu diesem Thema zu drehen, die er mit den auf Geschwister folgenden Filmen DEALER und DeR sCHÖNE TAG 1998 und 2001 abschließt. ${ }^{88}$ Auch Bademsoys zuvor erwähnte Trilogie entwickelte sich erst aus dem Material zur ersten Dokumentation MÄDCHEN AM BALL von 1995. ${ }^{89}$

Wie in Özdamars Roman ist das Hinauskommen der Protagonisten in Arslans gesamter Trilogie zentral. Alle drei Filme beginnen damit, dass ein deutsch-türkischer Protagonist oder eine deutsch-türkische Protagonistin in Nahaufnahme gezeigt werden, wie er oder sie aus einem Zimmer nach draußen auf ein Stadtviertel blickt. In der nächsten Sequenz verlässt er oder sie die Wohnung und bewegt sich in langen Einstellungen durch das ihm oder ihr vertraute Berliner Stadtviertel. Sie gehen dabei entweder zur Schule (GESCHWISTER), zum Drogendealen (DEALER) oder zur Arbeit (DER SchöNE TAG), wobei wir als Zuschauer nie wissen, wo genau sie hingehen. Drei Viertel aller Geschehnisse in Arslans Filmen ereignen sich entweder auf Straßen - die Laufwege der Akteure von a nach b werden minutiös gezeigt - an abgeschiedenen Straßenecken oder in Übergangsbereichen. Seine Protagonisten definieren sich durch Bewegung und ihre körperliche Präsenz in Berlin. ${ }^{90}$ Wie bei Hammar und Soysal markieren sie dadurch einen Platz in der Öffentlichkeit, der ihre inhärente Hybridität sichtbar machen soll. Diese Bereiche sind die Grundlagen ihres Auftretens, sie bleiben aber unmarkiert und unbenannt. Auch wenn Metropolen wie Berlin oder Istanbul für eine hohe Dichte an Fremdheitserfahrungen stehen, hat Arslan aus der Vorarbeit zu seinen Filmen gelernt, dass die Jugendlichen und Heranwachsenden zu dieser Stadt Berlin »organisch gehören ${ }^{91}{ }^{91}$ Berlin ist dabei nicht eine Stadt, die sich in der Darstellung aus einer Aneinanderreihung von Orten und bestimmten Stadtteilen ergibt. Sie wird erlaufen und ist damit Raum anstelle einer Ansammlung

87 Siehe hierzu: http://www.filmportal.de/film/mach-die-musik-leiser_13895d6387344cf99aaf 45d6c2bc4618 (24.05.2018).

88 Ebd.

89 Siehe hierzu: BADEMSOy/MENNEL (2016): S. 156f.

90 Diese Form der Bewegung in der Stadt korrespondiert mit der Bewegung, die Homi Bhaba mit dem »Hin und Her im Treppenhaus « für hybride Identitäten vergleicht. Nach ihm verhindert sie, »daß sich Identitäten an seinem oberen oder unteren Ende zu ursprünglichen « identitären Polaritäten festsetzen. Siehe hierzu: BHABHA (2000): S. 5. Siehe auch: KNöRER, Ekkehard (2011): »Bewegungen durch Berlin. Thomas Arslan: `Geschwister«, ১Der schöne Tag` und `Im Schatten`, Filmgalerie 451«. In: taz. Die tageszeitung, 05.05.2011, http:// http://www.taz.de/!295711/ (24.01.2017).

91 ARSLAN, Thomas (1997): »Thomas Arslan über Geschwister«. In: ders.: Geschwister, Spielfilm, Filmgalerie 451, Deutschland. 
und eines Zusammenhanges von Orten. Die Stadt ist mit den Akteuren zusammen auch eine Protagonistin. ${ }^{92}$ Örens Erzähler in Berlin Savignyplatz schreibt, die »riesige Stadt Berlin bewegt sich in meinem Kopf. Berlin bewegt sich. Nein, die Zeit bewegt sich «. ${ }^{93}$

Nach Certeau unterscheidet sich der Ort vom Raum dadurch, weil beim Letzteren im Gegensatz zum Ersten an und derselben Stelle, zwei unterschiedliche Entitäten zugleich sein können. ${ }^{94}$ Der Zusammenschluss von Heterogenem geschieht vor allem dann, wenn beispielsweise in GESCHWISTER ein Protagonist seine türkische Herkunft - wie auch die Protagonisten bei Özdamar, Zaimoğlu und Şenocak - ausschließlich auf Deutsch thematisiert. Er gehört trotzdem zum Raum, zur Stadt Berlin, in der er sich wie die anderen bewegt. ${ }^{95}$ Fremdheit und Zugehörigkeit stehen hier in keinem gegensätzlichen Verhältnis, weil die Gleichzeitigkeit und Gegenwärtigkeit von innen und außen sie umschließt. Allein auf die Sprache bezogen, bezeichnet Jacques Derrida Mitte der 1990er Jahre diese Bindung von eigen und fremd als eine »alienation without alienation «. ${ }^{96}$ Filmtechnisch fängt Arslan diese hybride und widersprüchliche Kopplung besonders in DER SCHÖNE TAG mit den ästhetischen Mitteln der Berliner Schule und der Nouvelle Vague ein, in denen es um das Erschließen einer neuen, noch nicht vorgestellten, Realität geht. ${ }^{97}$ Auch Bhabha sieht die Großstadt im Westen als den Raum an, der »den liminalen Charakter kultureller Identität [...] hervorbringt«. Äußerst bemerkenswert ist jedoch, dass die Stadt - auch bei Bhabha - ausschließlich als Raum im

92 Die Stadt ist in den Reflexionen zur Denizenship und postnational Membership äußerst konstitutiv. In ihrer Conclusio zur postnational Membership verweist Soysal beispielsweise auf das Motto »Wir sind Berlin« der Berliner Ausländerbehörde zu Anfang der 1990er Jahre. »Perhabs the motto, `Wir sind Berlin`, promoted by Berlin's Foreigner's Office and invoked by migrants themselves, best captures the way the migrants live their lives and interact with the host polity, within which their membership is realized. The trajectory (Bahnen) of `being part of Berlin national fixities and allows for shifting categories and fluid confines, and thus can traverse multiple borders. «Siehe hierzu: SoySAL (1994): S. 166.

93 ÖREN (1995): S. 82.

94 De CeRTEAU, Michel (2006): »Praktiken im Raum«. In: Raumtheorie. Grundlagentexte aus Philosophie und Kulturwissenschaften, hg. v. Jörg Dünne, Stephan Günzel, Frankfurt a. M.: Suhrkamp, S. 343-353, hier S. 345.

95 ARSLAN (1997).

96 Ebd.

97 Siehe hierzu: ScHIck, Thomas (2010): »A `Nouvelle Vague Allemande`? Thomas Arslan’s films in the context of the Berlin School«. In: Acta Universitatis Sapientiae, Film and Media Studies 03, S. 143-155. Siehe allgemein hierzu: Grob, Norbert/KiEfER, Bernd (2006): »Mit dem Kino das Leben entdecken «. In: Nouvelle Vague, hg. v. Norbert Grob, Bernd Kiefer, Thomas Klein, Marcus Stiglegger, Mainz: Ventil, S. 8-27. 
Spiel ist, aber nicht als eine Vernetzung bestimmter einzelner Orte. ${ }^{98}$ Obwohl wir viel mit den Protagonisten in der Stadt unterwegs sind, wissen wir daher sehr selten, wo genau wir uns befinden. Der topografische Unterschied zwischen Ort und Raum wird uns in diesem und im letzten Kapitel dieser Kulturgeschichte noch ausführlich beschäftigen; besonders auch in dem Zusammenhang, welchen Einfluss er auf die Fragen der Integration haben wird.

Auch wenn die Ästhetik der Filme Fatih Akıns umgekehrt nicht vom französischen, sondern vom amerikanischen Kino geprägt ist, ${ }^{99}$ wie in KURZ UND SCHMERZLOS (1998), IM JULI (1999), Solino (2002) oder in seinem ersten weltbekannten Film GEGEN DIE WAND (2003/2004), stehen sie ebenfalls wie Arslans Trilogie aus den 1990ern für ein physisches und urbanes Kino. Die Akteure in Akıns Filmen bewegen sich wie diejenigen in der Literatur Özdamars, Zaimoğlus und in den Filmen Arslans mit einer körperlichen »Selbstverständlichkeit « durch ihre Umgebung. ${ }^{100}$ Sie sind alle laut und treiben »Unerhörtes « wie Sibel in GEGEN DIE WAND. ${ }^{101}$ Doch so konfliktfrei und emanzipiert sich dies auch anhören mag, sind die Auseinandersetzungen, die in Film, Literatur und Theorie dieser Dekade ausgetragen werden, keineswegs. Denn draußen richtiggehend zu wohnen, führt

98 Внавна (1994): S. 169.

99 Siehe hierzu: LösER, Claus (2004): „Berlin am Bosporus. Zum Erfolg Fatih Akıns und anderer türkischstämmiger Regisseure in der deutschen Filmlandschaft«. In: Apropos: Film. Das Jahrbuch der DEFA-Stiftung, Berlin, S. 129-147, hier S. 130.

100 Diese "Selbstverständlichkeit« des Auftritts stellt die soziologische Forschung in unterschiedlichen Beschreibungsformen fest. Jörg Hüttermann macht etwa auf einen besonderen »lokalen« Figurationswandel im öffentlichen Raum aufmerksam: Das Auftreten der Gastarbeiter sei noch von einem »defensiven Ausweichverhalten « im öffentlichen Raum geprägt gewesen, während sich der Auftritt der zweiten Generation durch ein »ostentatives Durchhalten von gleicher Augenhöhe (Blickkontakt) und eigenem Kurs auszeichne - sei es um den Preis von Konfrontation und Konflikt«. HütTERmanN, Jörg (2015): »Mit der Straßenbahn durch Duisburg. Der Beitrag indifferenzbasierter Interaktion zur Figuration urbaner Gruppen«. In: Zeitschrift für Soziologie, Jg. 44, Heft 1, S. 63-80, hier S. 67. Siehe hierzu auch die Studie von Hermann Tertilt: TERTILT, Hermann (1996): Turkish Power Boys. Ethnographie einer Jugendbande, Frankfurt a. M.: Suhrkamp. Hinsichtlich der Entwicklung des türkischen Islams in Deutschland macht Werner Schiffauer ebenfalls auf einen Wandel von einem defensivem »Exil-Islam « zu einem aktiven Verhalten und Auftreten im öffentlichen Raum eines »Diaspora-Islam « aufmerksam. Siehe: SCHIFFAUER (2004). 101 Vgl. EzLI (2006): S. 287. Interessant ist in diesem Zusammenhang, dass deutsche Medien die Verleihung des Silbernen Bären an die Darstellerin Sibel Kekilli für ihre Rolle in GEGEN DIE WAND als skandalös ansahen. So beschwerte sich etwa die Bild Zeitung darüber, wie eine ehemalige Pornodarstellerin einen so ehrenwerten Preis erhalten konnte. Im Gegensatz hierzu wurde der Film in der türkischen Presse gelobt, selbst von den nationalistischen und konservativ-islamischen Zeitungen TÜRKIYE und ZAMAN, die damals der AKP von Recep Tayyib Erdoğan nahestanden. Siehe hierzu: AKIN, Fatih (2004): Gegen die Wand. Das Buch zum Film, Köln: Kiepenheuer \& Witsch, S. 219. 
dazu, dass alles, was innen ist (Wohnung, intime Beziehungen, Familie und kulturelle Hintergründe) fremd wird. Dafür liefern die Texte und Filme Materialien, die den theoretischen Bestimmungen von Jacques Derrida und Homi Bhabha nicht entsprechen. Für Gereiztheiten zu Hause und im öffentlichen Raum sorgt mitunter die dargestellte soziale Anomie. Dass sich der Ort, den man in der Gesellschaft einnimmt, tatsächlich auf den körperlichen Zustand auswirkt, zeigen dann Film und Literatur der 2000er Jahre.

Es sind aber nicht nur die hier genannten bekannten deutsch-türkischen Erzählungen und Filme der 1990er Jahre, die im Unterschied zu den Produktionen der 1970er und 1980er einen Paradigmenwechsel in der ästhetischen und politischen Gestaltung der Migration nach Deutschland und ihrer Folgen einläuten. Die Kombination aus sprachlicher Verfremdung, Mobilität, Körperlichkeit, Lautstärke und Stille ist für die Erzählweisen der weniger bekannten Romane und Filme der 1990er ebenfalls bestimmend: LANGER GANG (1992) von Yilmaz Arslan, BERLIN IN BERLIN (1993) von Sinan Çetin, Ayhan Salars Kurzfilme, APRILKINDER (1998) von Yüksel Yavuz, Auslandstournee (1998) von Ayşe Polat, LolA UND BILIDIKId (1998) von Kutlu Ataman und die anarchische Komödie ${ }^{102}$ ICH Chef, Du TuRnschuH (1998) von Hussi Kutlucan; Berlin-Savignyplatz (1995), Sehnsucht nach Hollywood (1999) von Aras Ören, Kemal Kurts autobiografischer Essay Was ist die Mehrzahl von Heimat? Bilder eines türkisch-deutschen Doppellebens (1995), Ja, sagt Molly (1998) und Der Chinese von Schöneberg, Teestunden am Ring (1999) von Güney Dal, die Romane der 1990er des bereits genannten Selim Özdoğan und nicht zuletzt der Roman Ich und die Rose (2002) von Yüksel Pazarkaya. Wie bereits erwähnt, beginnen die Erzähler bei Özdamar und Pazarkaya schon im Mutterbauch zu erzählen. ${ }^{103}$ Auf seinen Körper in unterschiedlichster Form zurückgeworfen fühlt sich in den 1990er Jahren auch Kemal Kurt in seinem langen autobiografischen Essay Was ist die Mehrzahl von Heimat? Zu Beginn konstatiert er noch, dass er in den 1970ern wie viele andere Migranten davon überzeugt gewesen sei, dass ein »neuer, universeller Typus Mensch im Entstehen war, der sich in der ganzen Welt zu Hause fühlen würde «. ${ }^{104}$ Doch hat sich die Geschichte der Migration in der Bundesrepublik anders entwickelt. Eine Heimat und eine weitere Heimat haben nicht einfach zwei

102 GöKTÜRK, Deniz (2008): „Strangers in Disguise. Role-Play beyond Identity Politics in Anarchic Film Comedy«. In: New German Critique, No. 92, Special Issue on: Multicultural Germany. Art, Performance and Media, (Spring - Summer, 2004), S. 100-122, hier S. 112-119.

103 Siehe hierzu: PAZARKaYA, Yüksel (2002): Ich und die Rose, Hamburg: Rotbuch, S. 5. In Odyssee ohne Ankunft hält Pazarkaya fest, dass er das erste Manuskript für diesen Roman bereits 1985 verfasst hätte. Erst 1989 verlegte ihn ein türkischer Verlag, 2002 ein deutscher. Siehe hierzu: PAZARKAYA (2000): S. 108.

104 KuRT, Kemal (1995): Was ist die Mehrzahl von Heimat?, Reinbek bei Hamburg: Rowohlt, S. 4. 
Heimaten oder eine neue Heimat ergeben. Kurts Essay ist von Hier- und Dort-Beschreibungen (Deutschland/Türkei) geprägt. Die zuverlässigste Antwort, die er uns auf die titelgebende Frage geben kann, ist hinsichtlich der Türkei, dass ihm dieses Land gehöre, »aber ich gehöre ihm nicht «. ${ }^{105}$ Für Deutschland gilt umgekehrt, wie für die »Kanaken « in Zaimoğlus Abschaum, dass er zu einem Land gehört, das ihm aber nicht gehört. Und wenn er mit seiner Familie zum Sommerurlaub in die Türkei fährt, gibt er die beschriebene Spannung auch als ein körperliches Stocken wieder. Mit einem Bein bewegt sich die Familie in Richtung Türkei, wobei das andere in Deutschland bleibt. ${ }^{106}$ Die Spannung, die dabei entsteht, muss der Körper aushalten. Dass nicht der Raum ein Problem darstellt, sondern der Ort, das Territorium, hat bereits Zaimoğlus Protagonist Ertan Ongun für das Revier der »Kanaken« in Kiel festgehalten, das er »Pseudoterritorium « genannt hat. ${ }^{107}$ Diese Form der kulturellen Entortung und gespaltenen Verortung macht die Heimat zu einer körperlichen und vergänglichen Angelegenheit.

Etwas vereinfacht und zahm bringt dies die deutsch-türkische Bestsellerautorin und Schauspielerin Renan Demirkan mit dem eigentlichen Bestseller der deutsch-türkischen Literatur der 1990er Jahre Schwarzer Tee mit drei Stück Zucker auf den Punkt: »Heimat ist wie Fruchteis, solange du es leckst, erfrischt es dich, vielleicht errätst du noch die Geschmackssorte, aber hinterher hast du Durst wegen der süßen Pampe. «108 Wie die genannten Werke Özdamars, Pazarkayas und Kurts beginnt auch dieser Roman mit einer Schwangerschaft. Am Ende von Schwarzer Tee mit drei Stück Zucker hören wir im Unterschied zum Karawanserei-Roman das Neugeborene mit einem »winzigen Krächzen « rufen. ${ }^{109}$ Trotz dieser körperlich-existenziellen Dimension der Verhandlung von Migration und ihrer Folgen erzählen alle genannten Werke keine einfachen Opfergeschichten von Ausbeutern und Ausgebeuteten oder kulturell Verlorenen mehr. Vielmehr heben spezifische Poetologien, sprachliche Kompetenzen und ein besonderer Sinn für das Komische und Absurde in den 1990er Jahren die Reflexion von und über Migration und Integration in Deutschland auf eine neue Ebene. Die künstlerische Bearbeitung macht die

105 Ebd., S. 10.

106 Kurt (1995): S. 9. Siehe hierzu auch: PAZARKaya (2000): S. 57.

107 ZAimoĞLU (1997): S. 65.

108 Demirkan, Renan (1991): Schwarzer Tee mit drei Stück Zucker, Köln: Kiepenheuer \& Witsch, S. 36.

109 Ebd., S. 139. Auch der tschechische Philosoph Vilém Flusser vergleicht in seiner essayistischen Sammlung zur Freiheit der Migration die Folgen der Migration mit der Geburt. Jahrzehnte vorher hatte er sie noch als einen chirurgischen Einschnitt beschrieben.

Siehe hierzu: Flusser, Vilém (2007): Von der Freiheit des Migranten. Einsprüche gegen den Nationalismus, Berlin: Europäische Verlagsanstalt, S. 10. 
Opfer zugleich zu Tätern. Zafer Şenocaks Roman Gefährliche Verwandtschaft leitet diese komplexe figurale Konstellation familienbiografisch ab. ${ }^{110}$

Jenseits von biografischen, gesellschaftlichen und kulturellen Referenzen bietet sich der Zusammenschluss von Opfer und Täter am eindrücklichsten in Yilmaz Arslans Spielfilm LANGER GANG dar. Er erzählt vom Leben schwerbehinderter Menschen mit unterschiedlichen kulturellen Hintergründen in einem Rehabilitationszentrum irgendwo in Süddeutschland; darauf weist zumindest der Dialekt eines »Liliputaner« genannten armlosen Kleinwüchsigen hin, der mit der Deutsch-Türkin Nesrin zusammen ist, die im Rollstuhl sitzt. Allerdings stehen weder Ort noch Transkulturalität im Vordergrund dieses außergewöhnlichen Films, obwohl selbst im Reha-Zentrum amerikanischer Blues gesungen und französische Lyrik vorgelesen werden. ${ }^{111}$ In Başers Film LEBEwOHL, FREMdE hören

110 Siehe hierzu: ŞENOCAK (1998): S. 40.

111 Äußerst markant und konstitutiv ist der Einsatz von amerikanischer Musik von Jazz bis Rock ' $n$ ' Roll auch in den deutschen Filmen NACH FÜNF IM URWALD und DAS LEBEN IST EINE BAUSTELLE. In Hans-Christian Schmids erstgenanntem Film schenkt die jugendliche Protagonistin Anna (Franka Potente), die aufgrund eines Familienkonflikts eine ganze Nacht unerlaubt in München unterwegs ist, am Ende des Films ihrem Vater eine seltene Schallplatte des afroamerikanischen Jazzers Thelonious Monk. Auf der Party zu ihrem 17. Geburtstag zu Hause, mit der der Film einsetzt und die völlig außer Kontrolle gerät, zerstört einer der jugendlichen Gäste diese Platte von Monk, was den Vater sehr wütend macht. In Wolfgang Beckers Film DAS LEBEN IST EINE BAUSTELLE ist Jans bester Freund, den er bei seiner Arbeit im Schlachthof kennenlernt, ein Musiker, der ausschließlich amerikanische Musik spielt und singt. Er ist zwar Deutscher, trägt jedoch eine amerikanische Haartolle und sein Rufname lautet Buddy. Dieser starke Amerikabezug in den deutschen Filmen der 1990er Jahre wird in keiner Besprechung oder Kritik erwähnt. Vielmehr steht beispielsweise Beckers DAS LEBEN IST EINE BAUSTELLE für einen »Hunger auf Gegenwart « und als ein Beweis dafür, dass das Leben wirklich eine Baustelle sei. Siehe hierzu: WeINGARTEN, Susanne (1997): »Was nun, Jan? ১Das Leben ist eine Baustelle«, behauptet Wolfgang Beckers Berliner Beziehungspuzzle - und beweist es auch«. In: DER SPIEGEL, 12/1997, S. 216-217. Siehe hierzu auch: Nicodemus, Katja (2004): »Film der Neunziger Jahre. Neues Sein und altes Bewußtsein«. In: Geschichte des deutschen Films, hg. v. Wolfgang Jacobsen, Stuttgart, Weimar: Metzler, S. 319-357, hier S. 335. Der Ausgangspunkt in diesem Film ist eine soziale Anomie, denn "Normalos« kommen darin nicht vor. Siehe hierzu: GESPRÄCH MIT WOLFGANG BECKER (1997): »Normalos kommen nicht vor«. In: DER SPIEGEL, 12/1997, S. 217. Allgemein ist die Bedeutung von Musik als Zeichen von Globalität und Verknüpfung in sehr vielen Filmen der 1990er Jahre konstitutiver Bestandteil der ästhetischen Erzählungen. Besonders in deutschen Filmen verbindet sie mitunter unterschiedliche politische Generationen. In den deutsch-türkischen Filmen sind hingegen Artikulationsformen die Verbindungsglieder, die aber zugleich immer einen Bruch artikulieren, entweder gegenüber der Elterngeneration oder gegenüber Deutschen. In Arslans Film GESCHWISTER übernimmt diese Funktion beispielsweise der HipHop. Tatsächlich spielt der heute sehr bekannte deutsche Rapper Cool Savaş (Savaş Yurderi) damals als 20-jähriger eine der Hauptrollen in Arslans Film. Siehe hierzu: ARSLAN (1997). Siehe zum Konnex von Musik, Ethnizität und Hybridität bei Fatih Akın seine Filme SENSIN - DU BIST Es! (1995), KURZ UND SCHMERZLOS 
Karin und Deniz in ihren zweisamen Stunden bei ihr zu Hause weder deutsche, noch türkische, sondern spanischsprachige Revolutionsmusik. Dieser musikalisch politisch erschlossene Raum verdeutlicht dabei nicht die Nähe zwischen der Deutschen und dem türkischen politischen Flüchtling, sondern die Entwicklung ihrer körperlichen Annäherung; eindrücklich ist besonders die Filmsequenz, in der Karin Deniz' von Narben gezeichneten Körper berührt. ${ }^{112}$

In Arslans LANGER GANG bewegen sich die körperlich behinderten Menschen in den langen Gängen des labyrinthartigen Gebäudekomplexes mit Krücken, in Rollstühlen oder auf speziell angefertigten Rädern. Daneben wird der Alltag der Akteurinnen und Akteure gezeigt, besonders ihre körperlichen Bedürfnisse etwa nach Zigaretten, Alkohol oder Sex. So versuchen etwa zwei Spastiker Sex zu haben, wobei die Lust in Gewalt umkippt, die der Mann der Frau antut. Später wird dieser Täter von einem anderen Patienten im Fahrstuhl vergewaltigt. Wir sehen aber auch einige zärtliche Momente, wie zwischen Didi, dem »Liliputaner«, und seiner deutsch-türkischen Freundin Nesrin - eine Beziehung, die einer türkischen Rollstuhlgang im Reha-Zentrum gar nicht gefällt. Deren Mitglieder drohen Nesrin am Anfang des Films, zerren sie aus dem Rollstuhl, den sie die Treppe hinunterstoßen, doch tauchen sie im weiteren Verlauf nicht mehr auf. Wie in einigen vielen anderen bekannten deutsch-türkischen Produktionen dieser Dekade besteht die gewalttätige Gruppe aus drei Männern. ${ }^{113}$ Und diese werden nicht als Deutsch-Türken, sondern eindeutig türkisch markiert.

(1998) und IM Juli (1999/2000). Zu den beiden letztgenannten Filmen sind jeweils die Soundtracks als Audio-CDs erschienen; ebenso zu DAS LEBEN IST EINE BAUSTELLE. Soundtracks zu Kinofilmen erfreuen sich in den 1990er Jahren einer besonderen Beliebtheit.

112 Im Casting für GEGEN DIE WAND stand für Fatih Akın der Hauptdarsteller Birol Ünel als Cahit sehr früh fest. Für ihn verkörperte er einen »echten Rebellen«, der auf alle »Normen und Traditionen scheißt«. Das, was er nicht machen durfte, machte er einfach. Obendrein war er auch noch ein »Deutsch-Türke«, also ein »echter Typ«. Siehe hierzu: AKIN, Fatih/ZIEgLER, Helmut (2004): »Ich will kein Sonntagskind sein! Ein Gespräch«. In: ders.: Gegen die Wand. Das Buch zum Film, Köln: Kiepenheuer \& Witsch, S. 238-243, hier S. 240. Siehe auch: AkIN, Fatih/ZaimoĞLU, Feridun (2004): »Der Regisseur Fatih Akın. Ein Gespräch mit Feridun Zaimoğlu«. In: ders.: Gegen die Wand. Das Buch zum Film, Köln: Kiepenheuer \& Witsch, S. 233-237, hier S. 233. Im Drehbuch zu GEGEN DIE WAND wird Cahit als ein »abgefuckter Typ mit graubraunen Haaren, unrasiert und in dunklen Klamotten« eingeführt. »Er hat viele Narben im Gesicht (und auch welche in der Seele) und traurige, kaputte Augen.« Akın beschreibt Cahit aber auch als jemanden, der einen "ganz eigenen Stil« hat. AKIN, Fatih (2004): Gegen die Wand. Das Buch zum Film, Köln: Kiepenheuer \& Witsch, S. 18. Selim Özdoğan wählt für seinen ersten Roman von 1995 das Zitat von Rolf Dieter Brinkmann: »Wisst ihr, daß Wörter nur Brandblasen der Seele sind?«. Siehe hierzu: ÖzDoğAN (1995): S. 5.

113 Siehe hierzu auch Die Brücke vom Goldenen Horn von Emine Sevgi Özdamar (1998), AusLANDSTOURneE von Ayşe Polat (1999) und Gegen Die WAND von Fatih Akın (2003). In Lola UND 
Wie Ayhan Salars Kurzfilm Der Totentraum beginnt auch LANGER GANG mit nackten Füßen, mit denen von Didi, dem armlosen »Liliputaner«. Er zerreißt mit seinen Füßen zuerst eine Schwarzweiß-Aufnahme des Rehabilitationszentrum und dreht sich daraufhin mit den Zehen eine Zigarette. Seinen Kopf sehen wir erst, nachdem die Zigarette fertig gedreht ist und er sie sich in den Mund steckt. ${ }^{114}$ Die Einrichtung, also das Reha-Zentrum, in dem der gesamte Film von Yilmaz Arslan stattfindet, wird als geschlossenes Bild zerissen, für nichtig erklärt und damit zu einem unwirklichen Ort. Filmtechnisch gesprochen wird erneut ein establishing shot vermieden.

Der kurze Einblick in die zentralen Charakteristika der genannten Produktionen lässt uns zu Beginn dieses Kapitels über die 1990er Jahre aus integrationstheoretischer Perspektive bereits folgende Beobachtung festhalten: Während in den 1970er und 1980er Jahren bei Ören, Sanders-Brahms, Başer, Bohm und Tekinay Phänomene der Migration im Wirkungsfeld von wechselseitigen Assimilationsvorstellungen standen, wird das Verhältnis von Migration, Binnenmigration bei Özdamar, transnationale Migration bei Şenocak, Kurt, Demirkan und Pazarkaya und die Bewegung im Raum bei Thomas und Yilmaz Arslan, Akın, Alakuş und Yavuz von assimilatorischen Integrationsvorstellungen losgelöst. Diesen Wandel von Assimilation zu Migration als Mobilität beschreiben wissenschaftliche Publikationen seit dem Ende der 1990er Jahre als einen Übergang von subnationalen zu transnationalen Konstellationen. Als Nachweis für diese Transformation dienen neben der Mobilität etwa Beobachtungen, dass Filme wie LoLA UND BILIDIKID global vertrieben und nicht nur auf migrationsspezifischen Festivals gezeigt wurden; ${ }^{115}$ oder musikalische Verweise auf Rap oder Hiphop oder Verweise auf berühmte Persönlichkeiten wie Muhammad Ali, Malcolm X, Al Pacino oder Bruce Lee. ${ }^{116}$ Für Leslie Adelson hat sich Zafer Şenocak mit Gefährliche Verwandtschaft irritierend produktiv über die Transnationalisierung des Tabuthemas Genozid in die deutsche Kulturgeschichte eingeschrieben. ${ }^{117}$

Diese Befunde sind zwar richtig, behandeln aber nur die eine Seite dieser Texte und Filme. Denn entgegen dieser positiven Positionsbestimmungen finden

BILIDKID von Kutlu Ataman (1998) haben wir es mit einer deutschen rechtsradikalen Dreiergruppe zu tun.

114 ARSLAN, Yilmaz (1992): Langer Gang, Spielfilm, Deutsche Kinemathek für Film und Fernsehen, Deutschland.

115 Siehe hierzu: GöKTÜRK (2000): S. 341.

116 Siehe hierzu: MenNel, Barbara (2002): »Bruce Lee in Kreuzberg and Scarface in Altona: Transnational Auteurism and Ghettocentrism in Thomas Arslan's BROTHERS AND SISTERS and Fatih Akıns SHORT SHARp SHOCK«. In: New German Critique, 87, S. 133-156, S. 144.

117 Adelson, Leslie (2005): The Turkish Turn in Contemporary German Literature. Toward a New Critical Grammar of Migration, New York: Palgrave Macmillan, S. 79-122. 
wir in den genannten und hier zu analysierenden Werken keine Formen dauernder Befreiungen, keine Bilder des Ankommens oder der Öffnung, weder in einem individuellen noch in einem sozialen Sinne. Ihre Grundstruktur ist von individuell artikulierten und versprachlichten, aber ungelösten Konflikten bestimmt. Die Akteurinnen und Akteure bleiben in Bewegung. Dort, wo globale Verbindungen gezeigt werden, regen sie zwar die Vorstellung von neuen sozialen Gemeinschaften an. Im Nahbereich scheitern die sozialen Bindungen allerdings. Im Vordergrund stehen eine performative Intervention, der Bruch mit bisherigen Regeln sowie die Produktion irritierender Zeichen, die vom Fokus auf neue mögliche soziale Verhandlungen zeugt. Deshalb möchte ich für die Produktionen der 1990er Jahre in Abgrenzung von der bisherigen Forschung nicht von »transnationalen Gemeinschaften« sprechen, sondern von »vorgestellten transnationalen Verbindungen«. Denn die Forschung hat bislang mit ihrem Fokus auf das hybride Subjekt, mit ihm auf eine spezifische Globalisierungseuphorie und den damit einhergehenden Transnationalismus übersehen, dass sich mit dem Wechsel von Integration/Assimilation auf Migration auch der Wechsel von Heimat zum Wohnen in jeglicher Form vollzogen hat, das nun besonders auf der Straße und im Körper der Akteurinnen und Akteure stattfindet. ${ }^{118}$ Dieses Wohnen ist im Kern von unterschiedlichen Graden der Lautstärke, der Stille und der intensiven Körperlichkeit von Kämpfen in Sprache und Bildern bestimmt, weniger von einer globalen Kommunikation und viel weniger noch von einem stabilen sozialen Austausch. Die globale Verknüpfung ist in den Filmen gegeben und wird gesetzt, aber nicht ausbuchstabiert.

Die Akteurinnen und Akteure halten sich im Unterschied zu den 1980er Jahren überwiegend draußen im öffentlichen Raum auf, wo sie dynamisch selbstbestimmend auftreten. Dabei entstehen häufig Konflikte. Die Interaktionen finden nicht an bestimmten Orten wie in Schulen, in Schwimmbädern oder anderen öffentlichen Einrichtungen statt, an denen bestimmte Verhaltensregeln und mitunter Hausordnungen gelten; sondern auf Straßen, an Straßenecken, in Einkaufspassagen, Parks oder ganz ,unbenutzten' Orten, wo die Regeln informeller Natur sind. In keiner Aufnahme lässt sich ein Straßenname erkennen. Mit dem Ethnologen Marc Augé gesprochen dominieren hier anthropologische Nicht-Orte. ${ }^{119}$ Diese Diskrepanz zwischen selbstbewusstem Auftreten und öffentlicher Unbestimmtheit ist deshalb von besonderem Interesse, weil die zwei äußerst erfolgreichen

118 Die weibliche Hauptdarstellerin für GEGEN DIE WAND zu finden, war für Fatih Akın äußerst schwierig. "Als wir gemerkt haben, es gibt keine Schauspielerin dafür, haben wir angefangen, auf der Straße nach ihr zu suchen «, erzählt Akın. Sibel Kekilli setzte sich gegen insgesamt 350 Laiendarstellerinnen durch. Siehe hierzu: AKIN/ZAimoĞLU (2004): S. 234.

119 Siehe hierzu: Auge, Marc (1994): Nicht-Orte, Frankfurt a. M.: Fischer. 
theoretischen Konzepte der 1990er Jahre, nämlich Hybridität und Dissemination nach Bhabha und Transnationalität im weitesten Sinne von Arjun Appadurai bis Nina Glick-Schiller, diese umgehen. Ihre Theorien verweisen wie Literatur und Film deutlich auf ein Jenseits der Gegenwart, der Darstellung und ihrer Bedingungen. ${ }^{120}$ Auch ihre Anrufung ist eine Anrufung nach dem Menschsein.

Im Bereich des darüber Hinausgehenden zu sein heißt [...], einen Zwischenraum zu bewohnen. Aber im >Darüber Hinaus` zu wohnen heißt auch, wie ich gezeigt habe, an einer re-visionären Zeit teilzuhaben, an einer Rückkehr zur Gegenwart, um unsere kulturelle Gleichzeitigkeit neu zu beschreiben; um unsere menschliche, geschichtliche Gemeinsamkeit neu einzuschreiben; die Zukunft auf der uns zugewandten Seite zu berühren. In diesem Sinne wird also der Zwischenraum des >Darüber Hinaus zu einem Raum der Intervention im Hier und Jetzt. ${ }^{121}$

Die Gleichzeitigkeit, die menschliche und geschichtliche Gemeinsamkeit, letztlich die Rede von einer einzigen Kultur, lässt sich immer nur als eine medial geschaffene denken. »[W]e are living in an increasingly global media environment «, konstatiert Hamid Naficy Mitte der 1990er über den Film hinaus und bestimmt die »transnational media« als die Grundlagen der Kritik nationalkutlureller Zuschreibungen. Von nun an ist im Sinne Arjun Appadurais »Imagination [...] social practice «. ${ }^{122}$

120 Vgl. BнAвHA, Homi (2000): Verortung der Kultur, Tübingen: Stauffenburg, S. 10. Der Verweis auf ein Jenseits ist auch deshalb interessant, weil Film und Literatur der 1990er Jahre neben der bereits erwähnten Volksreligiosität häufig auf Gott oder auf Engel Bezug nehmen. In seinem Roman Mehr, in dessen Zentrum das kompromisslose Leben eines Deutsch-Türken der zweiten Generation zwischen Deutschland und Türkei steht und in dem Religion explizit überhaupt keine Rolle spielt, dankt Selim Özdoğan am Ende dieses Textes erst Gott, dann seinem Vater und zuletzt seiner Mutter. Am Ende von KuRz und SchmerzLos beten Vater und Sohn zusammen; Fatih Akın dankt im Abspann Gott und Martin Scorsese. In Aras Örens Roman Berlin, Savignyplatz von 1995 tauchen im Restaurant »Zwiebelfisch« »zwei dicke Engel auf, die aus den Biergläsern trinken«. Sie schweben über allen Anwesenden, die dadurch zu einer zusammengehörenden Gemeinschaft werden. Als sie jedoch in die Berliner Nacht hinausgehen, ist die deutsche Wiedervereinigung in vollem Gange, und der Artikel über diese transnationalen Bohemians aus dem »Zwiebelfisch «, den Jürgen B. verfasst hatte, wird nicht gedruckt. In Ayşe Polats Film AusLANDSTOURNEE erscheint Zeki, als er von drei türkischen Nationalisten auf der Straße zusammengeschlagen wird, seine kleine Begleiterin Şenay »wie ein Engel«. Denn die Schläger fliehen, als das kleine Mädchen vor ihnen steht. Selbst in Zaimoğlus Kanak Sprak beziehen sich die `Kanaken`, die Drogen konsumieren, Sex haben und Gesetze brechen, häufig auf Gott. Siehe hierzu: ÖzDoĞAN, Selim (1999): Mehr, Berlin: Rütten \& Loening, S. 244; AKIN (1998); ÖREN (1995): S. 172; ZAIMOĞLU (1995); PoLAT (1998).

121 ВНАвна (2000): S. 12.

122 NAficy, Hamid (1996): »Phobic Spaces and Liminal Panics. Independent Transnational Film Genre«. In: Global/Local. Cultural Production and the Transnational Imaginary, Durham: Duke University Press, S. 119-144, hier S. 119. 
Dass die Umgebung nun mehr global als lokal sei und deshalb jede Form von Nationalität oder kultureller Prägung keine Bedeutung mehr habe, ist ein fataler intellektueller Fehlschluss der 1990er Jahre. Denn in den bekannten und weniger bekannten Produktionen deutsch-türkischer Provenienz spielen dafür Konflikte und der Gebrauch spezifisch kultureller Marker eine viel größere Rolle als die Vorstellung neuer transnationaler Gemeinschaften. Das »transnationale Wir«, das Bhaba und viele andere beschwören, ist prekär. Die Deutsch-Türken können sprachlich und modisch so deutsch und global in den Filmen auftreten wie sie wollen, die kulturellen Marker bleiben mitbestimmend. Woran das liegt, werde ich besonders anhand der Analysen der Texte von Zafer Şenocak und den Filmen von Fatih Akın und Thomas Arslan aufzeigen.

Im Folgenden werden wir sehen, wie immanent und nicht imaginär-transzendent das vielfältige Verhältnis zwischen den Ebenen des öffentlichen Raums, der Körperlichkeit, der Selbstbeschreibungen und Individualisierungen in Literatur und Film ist. Es gibt kein stabiles Jenseits in diesen Texten und Filmen der 1990er Jahre, das auf eine reale (ob nun individuelle oder kollektive) Zukunft verweisen könnte. Vielmehr haben neben den spezifischen kulturellen die gesetzten globalen Marker die Funktion eines Stauraums, der zur Entdramatisierung der Konflikte beiträgt. »Welt« ist im Unterschied $\mathrm{zu}$ »Nation« oder »Monokultur« in den 1990er Jahren positiv besetzt und kann daher diese Stauraum-Funktion einnehmen. Die Konflikte finden hingegen in Auseinandersetzung mit den Kategorien »Nation« und »Kultur « statt. Nicht das Globale im Lokalen ist dabei Ort der Austragung. Weil konkrete Orte fehlen, organisieren die Körper der Akteurinnen und Akteure, der Gruppen und Vereine ihre kulturellen Entortungen, die sie ebenfalls körperlich kommunizieren. Dabei korrespondieren sie auffallend mit Debatten zur Integration, mit Theorien zu Migration, Integration und zur Multikulturalität. ${ }^{123}$ Denn produktive kulturelle Entortungen, die viele Forschungsbeiträge zu Film und Literatur der 1990er Jahre aufgezeigt haben - Bhabhas Hybriditätstheorie baut auch auf Analysen der Literaturen von Salman Rushdie, Nadine Gordimer und Toni Morrison -, finden keineswegs nur in den kulturellen Produkten der Zeit statt. Sie sind ebenfalls tief in andere kulturwissenschaftliche Theorien und der Publizistik zur Migration in einer Dekade eingelagert, die von einer neuen »Unübersichtlichkeit« heimgesucht wird. ${ }^{124}$

123 Vgl. Vogl, Joseph (Hg.) (1994): Gemeinschaften. Positionen einer Philosophie des Politischen, Frankfurt a. M.: Suhrkamp. Siehe auch: RöDEL, Ulrich (Hg.) (1990): Autonome Gesellschaft und libertäre Demokratie, Frankfurt a. M.: Suhrkamp.

124 Siehe hierzu: HERBERT, Ulrich (2014): Geschichte Deutschlands im 20. Jahrhundert, München: Beck, S. 1137-1207. 
Im Zentrum vieler solcher Schriften steht die Frage des kulturellen »Überlebens « durch Anerkennung. Während von den 1970ern zu den 1980ern der Übergang von einer Arbeitergesellschaft zu einer Kommunikationsgesellschaft stattgefunden hat, zeigt sich im Übergang zu den 1990er Jahren erneut eine Abwendung von den organisierenden Kategorien »Klasse« und »Geschlecht» der 1960er und 1970er. Diesmal geht es jedoch nicht um die Frage der interaktiven oder intersubjektiven Kommunikation, wie auf der Zugfahrt Aysel Özakıns Anfang der 1980er Jahre. An die Stelle dieser Begegnungsstruktur, die auf das Verstehen des Anderen zielte, tritt nun eine »bewusste Wahrnehmung der Positionen des Subjekts « ${ }^{125}$. Es geht nun um die Umformung des artikulatorischen Prozesses, die die Spannung von symbolischer Aufladung und Formlosigkeit der 1980er Jahre, das Nicht-Sprechen-können, entlädt. Zafer Şenocak beschwört in dieser Hinsicht für seine Literatur der 1990er Jahre eine »negative Hermeneutik«, um wieder ins Gespräch zu kommen: »Nicht mehr das vermeintlich Verstandene, sondern das, was nicht verstanden wird, sollte in den Blick gerückt werden, das Unverdauliche, das, was aufstößt, Tabus und Grenzen verletzt «. ${ }^{126}$ So habe auch Emine Sevgi Özdamar Das Leben ist eine Karawanserei »absichtlich in einem Sprachdadaismus geschrieben, wo die Sprache nicht sofort zu verstehen ist «. Dies sei ihre "große Absicht [gewesen], weil die Begegnung ja erst stattfindet, wenn die Fremdheit wahrgenommen wird «. ${ }^{127}$ Auch in Başers LEBEWOHL, FREMDE versteht Karin kein einziges Wort von Deniz. ${ }^{128}$ Allein diese Grundlagen, dieses Nicht-Verstehen in deutsch-türkischer Literatur und Film zeigen, dass es sich hier keineswegs um lediglich selbstreferenzielle Poetologien handelt und schon gar nicht um bereits verwirklichte transnationale Gemeinschaften. Im Kern dieser Überlegungen steht vielmehr, dass jegliche Form von Realität künstlich ist und dass sie nur wirklich ist, wenn sie die Teilhabenden, das Gegenüber irritiert. Auch Homi Bhabha hält in seinem vielzitierten und programmatischen Text Dissemination fest, dass es ihm gar nicht darum gegangen sei, eine allgemeine Theorie zu entwerfen. Er habe - fast wie im Sinne der Kanak Sprak - eine "productive tension of the perplexity of language in various locations of living « erzeugen wollen. ${ }^{129}$ Und der Ethnologe Werner Schiffauer konstatiert im Unterschied zu seinen Arbeiten Ende der 1970er und Anfang der 1980er Jahre, die noch auf ein Verstehen ausgerichtet waren, in seiner Essaysammlung Fremde

125 BHABHA (2000): S. 2.

126 ŞENOCAK, Zafer (1994): War Hitler Araber?, München: Babel, S. 28.

127 Zitiert nach: Konuk, Kader (1997): "Das Leben ist eine Karawanserei. Heimat bei Emine Sevgi Özdamar «. In: Kein Land in Sicht. Heimat - weiblich?, hg. v. Gisela Ecker, München: Fink, S. 143-158, hier S. 151.

128 Siehe: BAŞER (1991).

129 BнABHa (1994): S. 170. 
in der Stadt von 1997, dass selbst das Ziel der Kulturanalyse darin bestehe, beide involvierten Seiten zu verunsichern und zu irritieren. ${ }^{130}$

Diese Praxis der Irritation soll das soziale Feld für eine Begegnungsstruktur erschließen helfen, die der eigentlichen kulturellen Realität, nämlich ihrer Hybridität, gerecht wird. Dieser ästhetisch-politische Prozess positioniert sich dabei vermeintlich im Gegensatz zur Kultur, wie sie in den Leitmedien in der Bundesrepublik in den 1990er Jahren besprochen und verhandelt wird. Das behauptet die Theorie. Wir werden aber sehen, dass es sich nicht um ein kontradiktorisches Verhältnis handelt, sondern dass es darum geht, miteinander zu kommunizieren - ein Verhältnis also, das vom Weitersprechen bestimmt ist. Denn die Fragen des Hinauskommens, Überlebens und der Mobilität sind nicht nur im Karawanserei-Roman zentral, sondern auch in den heute viel kritisierten Texten und Debatten zur Integration, zum Multikulturalismus und Transnationalismus der 1990er Jahre.

\subsection{Kultur als eine Frage des "Wohnens»}

Viele der genannten Autoren und Filmemacher sprechen in ihren unterschiedlichsten ästhetischen Sprachen und Bildern von der surrealen Poesie (Özdamar, Kurt) über die Sachlichkeit der Berliner Schule (Arslan), spezifische sprachliche Verfremdungen wie die Kanak Sprak (Zaimoğlu) bis hin zum physischen Kino (Akın, Yavuz, Polat), immer wieder selbst von einem »neuen Realismus« oder wurden oft dahingehend interpretiert. Dieser Realismus findet sich auch im Kern der Debatten und Theorien in den 1990er Jahren. ${ }^{131}$ Alle genannten Autoren und Filmemacher beschreiben eine untrennbare Verschränkung des Türkischen und Deutschen auf unterschiedlichsten Ebenen wie Sprache, Körper und Raum; ein Großteil der genannten Produktionen trägt dabei autobiografische Züge. ${ }^{132}$ Die 1990er Jahre sind besonders aus der Perspektive der zweiten, mitunter aber auch der ersten Migranten-Generation die Geburtsstunde der Bindestrich-Identität: Ob sie sie nun kritisieren oder bestätigen, auf jeden Fall setzt man sich mit dieser Realität des Deutschen und Türkischen auseinander. In den 1990er Jahren machen sich sehr viele »Schriftsteller, Wissenschaftler und Publizisten stark

130 Siehe hierzu: SchIFfAUER, Werner (1997a): Fremde in der Stadt, Frankfurt a. M.: Suhrkamp, S. 10.

131 Für viele siehe hierzu: AdELSon (2005): S. 99. Siehe auch Hofmann (2005): S. 206.

132 Siehe hierzu: Alkin, Ömer/TronnIER, Claudia (2017): »Ein Interview, ein Rückblick und eine Filmographie. Die Redaktionsleiterin des >Kleinen Fernsehspiels`Claudia Tonnier zum deutsch-türkischen Kino«. In: Deutsch-Türkische Filmkultur im Migrationskontext, hg. v. Ömer Alkın, Wiesbaden: Springer VS, S. 383-406. 
dafür, daß man Deutscher oder Deutsche werden und Türke oder Türkin bleiben kann «. ${ }^{133}$ Diese identitätspolitische sowohl-als-auch-Struktur spiegelt auch den Kern transnationaler und transkultureller Theorien, wenn es dort beispielsweise heißt, Identität ist »diverse, more fluid, more ad hoc, more provisional, less coherent, less organized, and simply less implicated in the comparative advantages of the nation state ${ }^{134}$

Im Zentrum vieler Sachbücher und Debattenbeiträge in den 1990er Jahren steht jenseits der biografischen die Anerkennung der gewordenen multikulturellen Realität der bundesrepublikanischen Gesellschaft. ${ }^{135}$ Dieser sich als politische Intervention begreifende Publizistik und der zuvor eingeführten literarischen und filmischen Produktionen scheint auf den ersten Blick der Gesetzesänderung des deutschen Ausländerrechts $\mathrm{zu}$ widersprechen. Das deutsche Ausländerrecht wird nach 1965 erst wieder 1990 geändert. Nach der wenig erfolgreichen Geschichte des Rückkehrförderungsgesetzes von 1983 leuchtete auch der Bundesregierung ein, dass man den Status von Ausländern, die schon lange in Deutschland lebten und bleiben würden, rechtlich durch eine Gesetzesänderung verstetigen müsse. ${ }^{136}$ Insgesamt sollte die Gesetzesnovellierung nichts an den Grundprinzipien der deutschen Ausländerpolitik ändern, »wonach Deutschland kein Einwanderungsland und der Aufenthalt der Ausländer im wesentlichen vorübergehender Natur sei «. ${ }^{137}$

Das Gesetz, das am 1. Juli 1990 erlassen und am 1. Januar 1991 nach der Wiedervereinigung für West- und Ostdeutschland, rechtskräftig wurde, ermöglichte ein erleichtertes Verfahren der Annahme der deutschen Staatsbürgerschaft für

133 Leggewie, Claus/ŞenocaK, Zafer (Hg.) (1993): Deutsche Türken - Türk Almanlar. Das Ende der Geduld. Sabrn Sonu, Reinbek bei Hamburg: Rowohlt, S. 8.

134 AppaduraI, Arjun (1996): Modernity al Large. Cultural Dimensions of Globalization, Minneapolis, London: University of Minnesota Press, S. 168.

135 Siehe hierzu: LEGGEwIE, Claus (1990): Multikulti. Spielregeln für den Vielvölkerstaat, Berlin: Rotbuch; CoHn-Bendit, Daniel/Schmid, Thomas (1992): Heimat Babylon. Das Wagnis der multikulturellen Demokratie, Hamburg: Hoffmann und Campe. Auch Homi Bhabha konstatiert in seiner Location of Culture, dass der aus der »kulturellen Entortung « entstehende »third space» nur dann politisch auch wirkmächtig sein könne, wenn auf seinen produktiven »Akt des Darüberhinausgehens«, über monokulturelle Zuschreibungen, eine Rückkehr zur »Gegenwart« folgt. Siehe hierzu: ВНАвHA (2000): S. 5.

136 HERBERT, Ulrich (2001): Geschichte der Ausländerpolitik in Deutschland. Saisonarbeiter, Zwangsarbeiter, Gastarbeiter, Flüchtlinge, München: Beck, S. 281. Siehe hierzu auch: HunN, Karin (2005): »Nächstes Jahr kehren wir zurück«. Die Geschichte der türkischen Gastarbeiter in der Bundesrepublik, Göttingen: Wallstein, S. 549. Tнум, Daniel (2017): »Migrationsfolgenrecht«. In: Veröffentlichungen der Vereinigung Deutscher Staatsrechtslehrer 76, Berlin: De Gruyter, S. 169216, hier S. 186f.

137 HERBERT (2001): S. 284. 
Ausländer der ersten und zweiten Generation. Die Novellierung räumte Ausländern der ersten Generation, die länger als 15 Jahre in Deutschland lebten, die Möglichkeit ein, die deutsche Staatsbürgerschaft anzunehmen. Für in Deutschland geborene Kinder gilt diese Novellierung schon nach acht Jahren Aufenthalt in der Bundesrepublik. ${ }^{138}$ Trotz der Novellierung hält das Staatsbürgerschaftsrecht weiter am Abstammungsprinzip (ius sanguinis) fest, ${ }^{139}$ das eine mehrstaatliche Zugehörigkeit ausschließt. Jeder Türke, der Deutscher werden will, muss weiterhin seine türkische Staatsbürgerschaft aufgeben. Die Novellierung erlaubt ausländischen Bürgern aus Nicht-EWG-Staaten außerdem nicht, kommunal zu wählen. Dieses Recht ist EWG-Bürgern in Deutschland vorbehalten. Damit stellt das neue Ausländergesetz aber auch fest, dass der- oder diejenige, der oder die die deutsche Staatsbürgerschaft nicht annimmt, sich identitätspolitisch auf einer »Zwischenstufe« befindet. »Ausländer werden - anders als im klassischen Fremdenrecht - nicht länger dem Heimatstaat zugeordnet, sondern gleichsam als halbe Inländer behandelt. « ${ }^{140}$ Auch wenn jemand in der Bundesrepublik lebt, gehört er oder sie nicht ganz dazu. Neben der bereits erwähnten und erläuterten migrationssoziologischen und politischen Bestimmung der Denizenship hat auch die juristische Fachliteratur Anfang der 1990er Jahre diese juristische Figur eingeführt, ${ }^{141}$ der konkret eine Wirtschafts- und Sozialbürgerschaft ohne Wahlrecht meint. Die Rechtsgleichheit auf sozialstruktureller und wirtschaftlicher Ebene folgt, »wenn sich der Aufenthalt verfestigt «. ${ }^{142}$ Sozioökonomische Gleichstellung ist gegeben, aber keine politische Teilhabe, wenn der ausländische Mitbürger seine Staatsangehörigkeit nicht wechselt. Zafer Şenocak interpretiert diese Gesetzesnovellierung als einen politischen Akt, der seine und die Realität anderer Deutsch-Türken, besonders der zweiten Generation »missachtet«. Für Şenocak gilt in Deutschland

138 Siehe: Deutsches Ausländerrecht. 19. Auflage 2005, München: dtv, S. 272-276.

139 Siehe hierzu: https://www.bundesregierung.de/Content/DE/Lexikon/IB/I/ius-sanguinis.html. Diesem Abstammungsprinzip steht das ius soli (wörtlich: »Recht des Bodens «) entgegen - wie es beispielsweise in Frankreich praktiziert wird, dem gemäß der Erwerb einer Staatsangehörigkeit an den Geburtsort des Kindes gebunden ist. Seit dem 1. Januar 2000 gilt das ius soli neben dem Abstammungsprinzip auch in Deutschland. Allerdings muss sich nach der Gesetzesänderung von 2000 das Kind mit dem Eintritt in die Volljährigkeit für eine Staatsbürgerschaft, beispielsweise die deutsche oder türkische, entscheiden. Siehe hierzu: https://www.bundesregierung.de/ Content/DE/Lexikon/IB/I/ius-soli.html.

140 Thym (2017): »Migrationsfolgenrecht«, S. 19.

141 Siehe hierzu: Hammar, Tomas (1990): Democracy and the Nation State. Aliens, Denizens and Citizens in a World of international Migration, Aldershot: Avebury. Der Begriff »Denizenship« ist dem britischen Common Law entlehnt, wo er sich auf nichtbritische Bürger des Commonwealth bezieht.

142 Тнум (2017): S. 187. 
daher immer noch das Prinzip der Assimilation, das die Aufgabe der Herkunftskultur zur Grundlage gelingender Integration erklärt. ${ }^{143}$ Und integrationstheoretisch könnte man meinen, dass hier weiterhin das Prinzip der Assimilation greift, da es immer noch darum geht, die Herkunftskultur aufzugeben. In praktischer und symbolischer Hinsicht ist dies aber keineswegs der Fall. Erstens setzte der Einbürgerungsanspruch nicht einmal deutsche Sprachkenntnisse voraus, und zweitens wurde einfach das bestehende »sozialstaatliche Gleichheitsversprechen auf die Ausländer « ausgeweitet, die länger im Land lebten. Damit war die Denizenship »eine Nebenfolge des sozialen Wohlfahrtsstaats und des liberalen Rechtsstaats, die man auf Ausländer erweiterte, ohne zu thematisieren, wie die Gesellschaft sich grundsätzlich zur Migration verhalten solle «. ${ }^{144}$ Im Kern ging es wohl darum, Geschichte und Folgen der Migration durch das Konzept der Denizenship zu verdecken. Diese Verschleierungspraxis lässt sich, ein wenig anders gelagert, auch in der deutsch-türkischen Literatur und im Film feststellen.

Erst vor diesem Hintergrund wird verständlich, warum die Novellierung des Ausländergesetzes aus der Perspektive des »Chefdenkers « des damaligen Innenministers Wolfgang Schäuble, Eckart Schiffer, als ein Zeichen der Integration zu verstehen ist. In einem ausführlichen Beitrag zum Spiegel mit dem Titelthema Hass. Gewalt gegen Fremde von Ende September 1991 spricht Schiffer sich für diese Konstruktion des modifizierten Staatsbürgerschaftsrechts aus, die Integration statt öffentlicher multikultureller Gesellschaft ermöglicht. Denn das überarbeitete Gesetz respektiere und schütze die Herkunftskultur der Ausländer »im personalen Bereich [...], ohne deshalb von der Kultur des Aufnahmestaates rezipiert zu werden (Integration) «. ${ }^{145}$ Der Garant für diese Trennung von privat und öffentlich ist für Schiffer die Staatsbürgerschaft, die den Begriff der Nation nicht in Widerspruch zu menschenrechtlichen Vorstellungen bringe. Denn »im privaten Bereich « könne man sich nach seinem Geschmack benehmen. ${ }^{146}$ Eine multikulturelle Gesellschaft würde im Gegensatz »Gleichberechtigung aller Herkunftskulturen von Eingewanderten mit der überkommenen deutschen Kultur auf dem deutschen Territorium bedeuten «. ${ }^{147}$ Warum diese Politik einen Schritt

143 Ebd.

144 Tнум, Daniel (2018): »Vom >Fremdenrechtく über die >Denizenship ২ zur >Bürgerschaft`. Gewandeltes Selbstverständnis im deutschen Migrationsrecht«. In: Der Staat, Zeitschrift für Staatslehre und Verfassungsgeschichte, Deutsches und Europäisches Öffentliches Recht, Berlin: Duncker \& Humblot, S. 77-117, S. 97.

145 Schiffer, Eckart (1991): »Der Koran ist nicht Gesetz«. In: DER SPIEGEL 40/1991, S. 53-59, hier S. 55.

146 Ebd., S. 57.

147 Ebd. 
nach vorne und zwei Schritte zurück machte, lässt sich eindrücklich an der politischen und gesellschaftlichen Konstellation Ende der 1980er und Anfang der 1990er ablesen, die von einer semantischen Konfusion des Ausländerbegriffs und des »Deutschseins « in der Bundesrepublik geprägt ist.

Hintergrund der Novellierung des Ausländergesetzes und auch der späteren Änderung des Asylrechts 1993 (»Asylkompromiss «) ist ein erneuter bevölkerungspolitischer Wandel in der Bundesrepublik, der sich vor allem zwischen 1988 und 1992 ereignet. In diesem Zeitraum wandern in der Folge der Ausbrüche der jugoslawischen Bürgerkriege (1991-1995) und des Zusammenbruchs der Sowjetunion 3,5 Millionen Menschen, Asylbewerber, Bürger anderer Staaten und Spätaussiedler in die Bundesrepublik ein. ${ }^{148}$ Zwei Drittel dieser Einwanderer sind Spätaussiedler, die als »Herkunftsdeutsche« gelten. Auf einen politischen Grundsatzbeschluss von 1957 zurückgehend, ist der »Herkunftsdeutsche« als ein »Volkszugehöriger» anzusehen, wenn er "sich in seiner Heimat zum Deutschsein bekannt hat «. ${ }^{149}$ Damit wurden die Spätaussiedler Ende der 1980er Jahre rechtlich mit den deutschen Vertriebenen des Zweiten Weltkriegs gleichgestellt.

Trotz dieser identitätspolitischen Rahmung in Debatten zur Einwanderung aus der ehemaligen Sowjetunion nach Deutschland in den 1990er Jahren werden die Spätaussiedler in der Bevölkerung aber kaum als »Volkszugehörige« begriffen oder wahrgenommen, ${ }^{150}$ sondern als Fremde, als Ausländer. Zu dieser Spannungslage zwischen politischem Willen und sozialer Wirklichkeit gesellt sich die Debatte um bosnische und albanische Asylbewerber. Insgesamt führt diese Zunahme von Fremdheitserfahrungen zu einem beachtlichen Stimmenzuwachs rechter Parteien. ${ }^{151}$ Wahlanalysen Ende der 1980er und Anfang der 1990er Jahre zeigen auf, dass der Zuwachs an Mitgliedern und Stimmen für die rechtsextremen Republikaner beispielsweise nicht an erster Stelle auf die Abwehr von Ausländern und Asylbewerbern zurückzuführen war, sondern auf eine »Konfusion des Ausländerbegriffs «. ${ }^{152}$ Deutsch war nun auch, wer überhaupt kein Deutsch sprach, während Menschen, die schon lange in der Bundesrepublik lebten und Deutsch mit oder ohne Akzent sprachen, keine Deutschen waren.

Hinzu kam, dass man die deutsch-deutsche Einheit auch als eine ethnisch-integrative Herausforderung ansah. Der Historiker Rudolf von Thadden hält Anfang

148 Siehe hierzu: CoHn-BEndit/SCHMid (1992): S. 340.

149 Deutsches AusländerRecht (2005): S. 284. Siehe auch: MünZ, Rainer/SEIfERT, Wolfgang/UlRICH, Ralf (1999): Zuwanderung nach Deutschland. Strukturen, Wirkungen, Perspektiven, Frankfurt a. M.: Campus, S. 23.

150 Siehe hierzu: HERBERT (2001): S. 276f.

151 Ebd., S. 277.

152 Ebd., S. 280. 
der 1990er fest, dass nach der Vereinigung »die beiden Teile Deutschlands [...] zusammenwachsen [müssten] «. Im Unterschied zu den Einwanderern »geschieht diese Eingliederung im Namen der ethnischen Zusammengehörigkeit. Auf der anderen Seite kann die Integration der Einwanderer jedoch nicht im Namen einer ethnischen Nation vollzogen werden «. ${ }^{153}$ Womit sie gelingen kann, bleibt unerwähnt. Der Historiker Ulrich Herbert verwendet zeitdiagnostisch für die Anfänge der 1990er Jahre den schon oben zitierten Begriff der Unübersichtlichkeit, den er nicht allein auf den Wandel der Arbeiter- zur Kommunikationsgesellschaft wie Habermas Anfang der 1980er beschränkt. ${ }^{154}$ Durch eine spezifische identitätspolitische Konstellation rücken Ende der 1980er und Anfang der 1990er Jahre Konflikt- und Verhandlungsformen des Kulturellen im öffentlichen Raum weitaus stärker in den Fokus. ${ }^{155}$ Erschreckenderweise geschieht dies mitunter auch ganz ohne Verhandlung, wie die Angriffe auf Flüchtlingsheime in Hoyerswerda im September 1991, das mehrere Tage andauernde Pogrom in Rostock-Lichtenhagen im August 1992 und die Brandanschläge Ende 1992 in Mölln und in Solingen im Mai 1993 mit neun Toten zeigen. Besonders mit dem Anschlag in Mölln sei eine neue Stufe des Ausländerhasses erreicht, titelt die Frankfurter Allgemeine Zeitung. ${ }^{156}$ Dies habe nicht nur damit zu tun, dass 19- und 25-jährige deutsche Täter die Tat kühl kalkuliert hätten. Eckhard Fuhr sieht diese Stufe vor allem darin, dass das Ziel nicht Asylbewerberheime waren, die »Konflikte der Zuwanderung verdichten«, sondern Wohnhäuser, »in denen seit langem in Deutschland türkische Familien leben. Der Angriff richtete sich also gegen die Integration, gegen das friedliche Miteinanderauskommen von Ausländern und Deutschen «. Stefan Kornelius konstatiert, dass die Zeitrechnung der Türken in Deutschland nun in Vor-Mölln und Nach-Mölln eingeteilt sei. Deutschland sei den Türken eigentlich »ein Stück Heimat geworden«; Kornelius zitiert einen Türken, der meint, sie, die Türken, hätten sich in Deutschland »eingewurzelt«. »Gerade haben wir gedacht, wir sind in unserem Land, alles lief so gut. [...] Aber patsch, jetzt ist alles im Wasser, jetzt ist alles kaputt. « ${ }^{157}$ In diesem Zusammenhang schreibt Yüksel Pazarkaya, dass er nach Hoyerswerda, Rostock, Mölln, Solingen und Magdeburg überlegt habe, seine »spitze Feder [...] aus der Hand « zu legen. Denn wieder einmal sei er vertrieben worden, von einer Kälte zur nächsten. Die Wiedervereinigung habe

153 Zitiert nach: DiRKe, Sabine (1994): »Multikulti. The German Debate on Multiculturalism«. In: German Studies Review 17, S. 513-536, hier S. 532.

154 Siehe hierzu: HERBERT (2017): S. 1171-1180.

155 Vgl. Bомmes, Michael (1991): »Der Gebrauchswert von Selbst- und Fremdethnisierung in Strukturen sozialer Ungleichheit«. In: Prokla 21, Heft 83, S. 291-316.

156 Aus: Hunn, Karin.

157 Zitiert nach: Ebd., S. 556. 
neue politische Prioritäten gesetzt. Doch er legte seine »Feder gegen Gewalt» dann doch nicht aus der Hand. ${ }^{158}$

Im Zusammenhang des Brandanschlags in Solingen sind drei Punkte äußerst bemerkenswert. Erstens folgte daraus keine Rückkehr der Türken in die Türkei ${ }^{159}$; zweitens reagierten die Türken mit Protesten und mitunter auch Ausschreitungen in Solingen. ${ }^{160}$ Obwohl Wut und die große Angst vor neuen Anschlägen überwogen, artikulierte sich drittens seitens der Türken keine allgemeine Zuschreibung, dass alle Deutschen Rassisten seien. Die deutsch-türkische Journalistin Dilek Zaptcıoğlu hat in dieser Zeit viele Interviews mit Türken und anderen, die zu »Ausländern gemacht werden«, geführt. »Sie sind in ihrer Wut vereint. Aber sie verteufeln nicht `die Deutschen`, von denen sie wissen, daß es sie nicht gibt. « ${ }^{161}$ So empfand etwa der Bruder des Überlebenden des Anschlags, Kamil Genç, als er dem Gerichtsprozess zum Solinger Brandanschlag beiwohnte und 125 Tage den Tätern gegenübersaß deren »Haß wie heißes Wasser « auf seinem Körper. ${ }^{162}$ Die Überlebenden der Familie Genç in Solingen nahmen nach diesem furchtbaren Brandanschlag, bei dem drei Mädchen und zwei Frauen ihrer Familie starben, die deutsche Staatsbürgerschaft an und legten die türkische ab. ${ }^{163}$ Allein diese dramatische Konstellation zeigt bereits Anfang der 1990er Jahre, dass das Deutsche vom Türkischen und das Türkische vom Deutschen nicht mehr zu trennen sind, selbst wenn keine staatliche Entsprechung dieser lebenswirklichen Bindung in Form einer doppelten Staatsbürgerschaft existiert. Die Überlebenden der Familie Genç nahmen die deutsche Staatsbürgerschaft als ein Zeichen "gegen Fremdenhaß und für ein friedvolles Miteinander« an. ${ }^{164}$ Austragungsort der Darstellung und Medium dieser Bindung ist nicht mehr die Wohnung des Ausländers, sondern der eigene Körper und der öffentliche Raum.

158 PazARKaYa (2000): S. 112 u. 116f. Siehe hierzu auch: KuRT (1998).

159 Fatih Akın macht diesen Punkt in seinen filmbiografischen Reflexionen auch stark, wenn er in Im Clinch konstatiert, dass seine Eltern trotz Mölln und Solingen in Deutschland geblieben sind. Siehe hierzu: AKIN (2011): S. 11.

160 GÜr, Metin/Turhan, Alaverdi (1996): Die Solingen-Akte, Düsseldorf: Patmos, S. 14.

161 ZAPTCIoğLU, Dilek (1993): »Leben in zwei Welten«. In: Der Weltspiegel, 20.04.1993:

162 Siehe hierzu: Loose, Hans-Werner (1998): „Vom endlosen Leiden des Bekir Genç«. In: Die Welt, 27.05.1998, https://www.welt.de/print-welt/article619562/Vom-endlosen-Leiden-des-BekirGenc.html (08.06.2017).

163 Siehe hierzu: GÜR/TURHAN (1996): S. 8.

164 Ebd. Zwanzig Jahre später sieht es jedoch bei der Gedenkveranstaltung zum Brandanschlag in Mölln ganz anders aus. Ort und Veranstaltung sind 2012 zum »Kampfplatz gegen rechts" geworden. Siehe hierzu: Pergande, Frank (2012): »Mölln. Die Hoheit über das Gedenken«. In: FRANKFURTER ALLGEMEINE ZEITUNG, 23.11.2012, https://www.faz.net/aktuell/politik/inland/ moelln-die-hoheit-ueber-das-gedenken-11967418.html (zuletzt 22.01.2019). 
In diesem Zusammenhang steht auch die wissenschaftliche, politischinterventionistische Veröffentlichung von Das Manifest der 60, die ebenfalls auf die »Unübersichtlichkeit der neuen Einwanderungssituation « reagiert. ${ }^{165} \mathrm{Nach}$ Ansicht der 60 Unterzeichner des Manifests würde nach dem »verlorenen Jahrzehnt der 1980er Jahre « ${ }^{166}$ eine weitere Vernachlässigung der politischen Herausforderung »im Problemfeld Migration« den »inneren Frieden und die kulturelle ToleranzinDeutschland « gefährden. ${ }^{167}$ Aufgrund »widerspenstiger « und »unübersichtlicher Entwicklungen« konstatiert auch der Konfliktforscher Wilhelm Heitmeyer in einer vergleichbar dramatischen Diktion, dass »vieles darauf hindeutet, dass Desintegration zu einem Schlüsselbegriff zukünftiger gesellschaftlicher Entwicklungen avancieren wird «. ${ }^{168}$ Am Ende des 20. Jahrhunderts stecke die Bundesrepublik in einer elementaren Identitätskrise. Und im Unterschied etwa zu den USA reagieren Schiffauer gemäß europäische Staaten »nach dem Zusammenbruch der Weltordnung« weitaus »empfindlicher« und »gewalttätiger « auf den Migrationsstrom der 1990er Jahre. ${ }^{169}$ Die Reaktionen in Deutschland hängen für ihn mit »einer schwach ausgeprägten civilité zusammen «. ${ }^{170}$

Der Intellektuelle Lothar Baier führte diese Gewalttätigkeit hingegen auf die Angst vor Armut zurück und darauf, dass der bedürftige Fremde »den Stolz auf die zivilsatorische Allmacht« kränke. Der Fremde mache folglich die Grenzen des Westens erkennbar, letztlich seine »Begrenztheit der eigenen Macht $« .{ }^{171} \mathrm{Ihr}$

165 BADE, Klaus (1994): Das Manifest der 60. Deutschland und die Einwanderung, München: Beck; TAYLOR, Charles (1993): Multikulturalismus und die Politik der Anerkennung, Frankfurt a. M.: Suhrkamp. S. 18.

166 BADE (1994): S. 19.

167 Ebd., S. 14.

168 HeITMEYER, Wilhelm (1997): Was treibt die Gesellschaft auseinander? Bundesrepublik Deutschland: Auf dem Weg von der Konsens- zur Konfliktgesellschaft, Frankfurt a. M.: Suhrkamp, S. 9.

169 SCHIFFAUER, Werner (1997): »Die >civil society< und der Fremde. Grenzmarkierungen in vier politischen Kulturen«. In: Fremde in der Stadt, von Werner Schiffauer, Frankfurt a. M.: Suhrkamp, S. 35-49, hier S. 35.

170 Ebd., S. 48, Hervorhebung im Original. Mit der bürgerlichen Kraft und Kompetenz der civilité, die von freiheitlichem Austausch und von der Fähigkeit bestimmt ist, Verantwortung zu tragen, wird Kultur nicht als »ein geschlossenes Konzept, sondern als ein offenes Diskursfeld « begriffen. Ausgangspunkt der civilité ist dabei nicht, was man miteinander teilt, sondern worüber man sich auseinandersetzen und streiten kann. Siehe hierzu: SchIFfaUER (1997). Diese Definition korreliert aufs Engste mit den Beschreibungen zur Denizenship nach Soysal und Hammar, nach der nicht die gemeinsame Vergangheit oder gemeinsame Ortsbindung im Zentrum steht, sondern einfach die Präsenz.

171 BAIER, Lothar (1993): »Die Gnade der richtigen Geburt«. In: Transit Deutschland. Debatten zu Nation und Migration, hg. v. Deniz Göktürk, David Gramling u. a., Konstanz: Konstanz University Press, S. 169-172, hier S. 171. 
»Anblick« bringe schon »in kleinen Dosen unsere Zivilisation aus dem Gleichgewicht «. ${ }^{172}$ Dieser Zugang, der die zuvor klar getrennte Verteilung von Macht und Ohnmacht auf Alteingesessene, Einwanderer und Flüchtlinge mitunter ins Wanken bringt, zeigt sich besonders am Bild des Türken, der nicht nur als Opfer von Mölln und Solingen, sondern als Unterdrücker der kurdischen Minderheit in der Türkei medial präsent war. ${ }^{173}$ Hinzu kommt, dass man in diesem Zusammenhang offen den Medienkonsum der Türken kritisierte. Der Einfluss der türkischen Medien in Deutschland sei so groß, dass ihn auch die Doppelstaatsbürgerschaft nicht brechen könnte. Türken seien »konservativ und manipuliert«. Beispielsweise könnten sie überhaupt nicht verstehen, warum »[deutsche] Kinder und Jugendliche [...] aus den Wohnungen der Eltern ausziehen«, hält die Bundesvorsitzende der Gesellschaft für bedrohte Völker (GfbV), Irina Wiessner, im Jahr 1994 fest. ${ }^{174}$ Auch in diesem Fall bedeutet das Auf-der-Straße-sein statt in der türkischen Wohnung in der Bundesrepublik eine politische Aussage.

Unter diesen neuen, sehr aufgeheizten gesellschaftspolitischen Umständen hat besonders der Begriff des Multikulturalismus Hochkonjunktur. Zu seinen bekanntesten Verfechtern gehören Claus Leggewie, Daniel Cohn-Bendit, Thomas Schmid, Klaus Bade, Heiner Geißler und nicht zuletzt Jürgen Habermas mit seinem Kommentar zu Charles Taylors bekanntem Essay Multiculturalism and the Politics of Recognition von 1992. ${ }^{175}$ Alle genannten Autoren fordern, dass es die neue multikulturelle Wirklichkeit der Gesellschaft anzuerkennen und ausländer- und integrationspolitisch zu gestalten sei. ${ }^{176}$ Fremdheit sei dabei nicht nur eine Kategorie für den Anderen, sondern ebenso wichtiger Bestandteil der Geschichte der Mehrheitsgesellschaften selbst. ${ }^{177}$ So argumentieren etwa Cohn-Bendit und Schmid in ihrer gesellschaftspolitisch wirkmächtigen Publikation Heimat Babylon. Darin analysieren sie zwar vorwiegend die aktuelle migrationsbedingte gesellschaftspolitische Disposition in Deutschland - besonders der Türken. Doch ist ihr Ausgangspunkt mit der

172 Ebd., S. 172.

173 Zitiert nach: HunN (2005): S. 559. Heute erinnert man vor allem an die Ausschreitungen in Rostock-Lichtenhagen 1992 und die Brandanschlage gegen turkische Familien in Molln (1992) und Solingen (1993). Der erste Film, der den Angriff auf das Asylbewerberheim in Rostock-Lichtenhagen am 24. August 1992 minutios aufbereitet, ist Burhan Qurbanis Wir sind jung. Wir sind stark von 2015. Siehe: Qurbani, Burhan (2015): Wir sind jung. Wir sind stark, Spielfilm, Good Movies/Zorro, Deutschland.

174 WIESSNER, Irina (1994): »Konservativ und manipuliert«. In: tageszeitung, 15.10.1994, S. 1819, hier S. 18.

175 Siehe hierzu: Leggewie (1990); CoHn-Bendit/Schmid (1992); BADE (1994); TAYloR (1993). 176 Siehe hierzu für viele: BADE (1994): S. 14.

177 Vgl. ebd., S. 18f. 
neuen globalpolitischen Situation nach dem Zusammenbruch der Sowjetunion (1991) und den Jugoslawienkriegen, kein europäischer oder nationaler mehr, sondern nun ein weltpolitischer. Das Buch selbst beginnt mit einer weltpolitischen Rahmung seines Themas, der multikulturellen Gesellschaft in Deutschland. Die Kategorie des Fremden und der Fremdheit sei weitreichend, heißt es etwa. An vielen Stellen weisen Cohn-Bendit und Schmid auch auf die Auswanderungsgeschichten heutiger Mehrheitsgesellschaften hin, beispielsweise die deutsche Auswanderung in die USA, die ebenfalls von Verfremdungen und Konflikten geprägt sei. ${ }^{178}$ Die Geschichte von Einwanderungsgesellschaften ist dabei auch immer eine Geschichte innerer Fremdheiten.

Beide Autoren betonen aber nicht nur Überseemigrationen, sondern auch die regen Binnenmigrationen im Deutschland des 19. Jahrhunderts. ${ }^{179}$ Das Verhältnis von Territorium und Bevölkerung ist ein kurzzeitiges und fragiles. Garanten der Interaktion sind also nicht prozessentbundene kulturelle Einheiten, sondern die Resistenz einzelner Personen und Gruppen. Insgesamt zeichnen Cohn-Bendit und Schmid ein Bild des deutschen Migranten, der durch seine Zähheit die Chancen der Integration genutzt hat, selbst dort, wo sie sich kaum boten. Der Deutsche hat sozusagen immer eine zweite Tür gefunden, wo es eigentlich keine gab. Ähnlich begreifen die Autoren die Türken als äußerst anpassungsfähige Einwanderer in der Bundesrepublik, die sich trotz denkbar schlechter Bedingungen integriert hätten wie früher die Deutschen im Ausland. ${ }^{180}$ Dies beweise eindeutig die Zahl der exorbitanten Zunahme der türkischen Einwanderer in Deutschland im Dienstleistungsbereich. Türken seien beruflich weit risikofreudiger als die Alteingesessenen. Die Zahl der Selbstständigen war bei ihnen Anfang der 1990er Jahre doppelt so hoch als bei den Deutschen. ${ }^{181}$ Die Risikofreude der »deutschen Ausländer« ist ein wichtiger Integrationsmarker für Cohn-Bendit und Schmid. Auch ihre Berufs- und Familienkonstellationen hätten sich grundlegend gewandelt und den modernen deutschen Lebensformen angepasst, beispielsweise was die Anzahl der Kinder und die Arbeit von Frauen betreffe. ${ }^{182}$ Die Zahl »aufnahmelandorientierter Organisationsgründungen « türkischer Vereinigungen ist in dieser Zeit ebenfalls angestiegen. ${ }^{183}$ Der bekannteste Verein, der Mitte der 1990er

178 Cohn-Bendit/Schmid (1992): S. 190. Siehe hierzu auch: GeIsSLER, Heiner (1993): »Auf Zuwanderung angewiesen «. In: DER SPIEGEL, 3/1993, S. 40-47, hier S. 40.

179 Ebd., S. $221 \mathrm{f}$.

180 Cohn-BEndit/SCHMid (1992): S. 170.

181 Ebd., S. $129 f$.

182 Ebd., S. 163-169.

183 Cetinkaya, Handan (2000): »Türkische Selbstorganisationen in Deutschland. Neuer Pragmatismus nach der ideologischen Selbstzerfleischung«. In: Einwanderer-Netzwerke und ihre 
Jahre als »aufnahmelandorientierte Organisation« gegründet wird, ist die Türkische Gemeinde Deutschlands (TGD), die bis heute eine äußerst öffentlichkeitswirksame Funktion ausübt. ${ }^{184}$

Allerdings kommen die Autoren am Ende zu dem Ergebnis, dass im öffentlichen Diskurs eine Anerkennung dieser Anpassungsleistungen der Türken und ihres Risikobewusstseins gänzlich fehle. Während die Minderheiten sich anpassten, würde die Mehrheit ihnen kaum Schutz und Rechte als gleichberechtigte Bürger zugestehen. ${ }^{185}$ Sie seien Fremde in einer Welt, die der Mehrheit eigentlich »weit weniger fremd ist «. Deshalb seien sie auch benachteiligt. ${ }^{186}$ Auf der anderen Seite ist der Migrant - trotz seiner Leistungen - »auf Durchzug eingestellt«. Obwohl er sich anpasst, will er in der Fremde nicht ankommen und sie auch nicht anerkennen. ${ }^{187}$ Dafür würden zwei Zahlen sprechen: zum einen die weiterhin äußerst geringe Einbürgerungsquote türkischer Mitbürger. ${ }^{188}$ Erst gegen Ende der 1990er Jahre steigt die Zahl der Einbürgerungen erheblich, weil rechtliche Reformen in der Türkei es in dieser Zeit den Auslandstürken ermöglichen, bei Aufgabe der türkischen Staatsbürgerschaft »in erb-, eigentums-, und aufenthaltsrechtlicher Hinsicht wie türkische Staatsbürger behandelt « zu werden. ${ }^{189} \mathrm{Zum}$ anderen sprechen vergleichende Zahlen zum Kauf von Wohnungen und Häusern in der BRD eine eindeutige Sprache. Nach einer Statistik von 1998 haben im Unterschied zu Deutschen über $90 \%$ der Türken keine Wohnungen oder Häuser als Eigentum in Deutschland erworben und wohnen zur Miete. Lediglich 6,5 \% leben in eigenen Häusern oder Wohnungen in Deutschland. Unter Deutschen besitzen 199855 \% ein Eigenheim und 43 \% wohnen zur Miete. ${ }^{190}$ Nach Cohn-Bendit und Schmid stimmt deshalb »für den Einheimischen die Welt nicht mehr: Die dableiben und doch gehen wollten, müssen Eindringlinge sein «. ${ }^{191}$ In diesem durch und durch widersprüchlichen Szenario wird Integration letztlich zum Glücksfall. ${ }^{192}$

Integrationsqualität in Deutschland und Israel, hrg. von Dietrich Thränhardt und Uwe Hunger, Münster: LIT, S. 83-109, hier S. 95f.

184 Siehe hierzu allgemein: RAUER, Valentin (2008): Die öffentliche Dimension von Integration. Migrationspolitische Dachverbände in Deutschland, Bielefeld: transcript.

185 Cohn-BEndit (1992): S. 169-173.

186 Ebd., S. 170.

187 Ebd., S. 74.

188 GEISSLER (1993): S. 44.

189 HunN (2005): S. 551.

190 HERBERT (2001): S. 294.

191 Ebd.

192 Siehe hierzu: Cohn-Bendit/Schmid (1992): S. 74. Interessanterweise ist der Befund, dass Integration in den 1990er Jahren auf Umwegen und über Zufälle stattfinde, keine Seltenheit. Aufstiegsgeschichten verdanken sich oft Begegnungen einzelner Einheimischer mit Ausländern, 
Trotz dieses allgemeinen Tenors unterschlagen die Autoren von Heimat Babylon nicht, dass wiederum viele der türkischen Arbeiter und ihre Kinder entgegen ihrer Anpassungsleistungen sich nicht zur deutschen Gesellschaft bekennen wollen. Die andere Seite der Rechteverweigerung ist also eine Gesellschaftsverweigerung. Cohn-Bendit und Schmid hoffen, dass eine Angleichung der Rechte auch eine Identifikation mit der multikulturellen Gesellschaft nach sich zieht. Bemerkenswert ist im Vergleich zum früheren in jedem Fall zum alten Narrativ, dass eine Viktimisierung der Migranten vermieden wird - schon allein deshalb, um sie in die Pflicht nehmen zu können. ${ }^{193}$

Aber auch in den soziologischen und explizit integrationstheoretischen Überlegungen in den 1990er Jahren sind die Kategorien »Fremdheit«, »Kontingenz« und ein hohes Maß an Komplexität als Grundlagen theoretischer Reflexionen wie in der Publizistik weit verbreitet. ${ }^{194}$ Sie spiegeln sich auch in der zuneh-

vor allem der zweiten Generation, die ein Potential in Kindern und Heranwachsenden sehen. Siehe hierzu: AKIN, Fatih (2011): Im Clinch. Die Geschichte meiner Filme, Reinbek bei Hamburg: Rowohlt, S. 38. Siehe auch: BотA, Alice/Рнам, Khuê/Topçu, Özlem (2012): Wir neuen Deutschen. Wer wir sind, was wir wollen, Reinbek bei Hamburg: Rowohlt. Zu diesem Befund gehört auch, dass Diskriminierungen auf dem Gebiet der Berufswahl und -suche zu einem immer wichtigeren Forschungsthema in den 1990er Jahren avancieren. Äußerst aufschlussreich ist in diesem Zusammenhang die Arbeit Ethnizität und Raum im Aufstiegsprozess. Eine Untersuchung zum Bildungsaufstieg in der zweiten türkischen Migrantengeneration von Andreas Pott. In den Beschreibungen der Jugendlichen und Heranwachsenden, die Pott analysiert, spielt der Bezug darauf, dass man Glück gehabt habe, eine ausnehmend wichtige Rolle, so dass dieser Verweis fast schon als eine Kategorie betrachtet werden muss. Siehe hierzu: PotT, Andreas (2002): Ethnizität und Raum im Aufstiegsprozess. Eine Untersuchung zum Bildungsaufstieg in der zweiten türkischen Migrantengeneration, Wiesbaden: Verlag für Sozialwissenschaften.

193 Diese Konstellation macht sich in Literatur und Film besonders dadurch bemerkbar, dass die Akteurinnen und Akteure entweder sich selbst diskriminieren oder aber auf Diskriminierungen souverän reagieren. In Dörries HAPPY BIRTHDAY TÜRKE findet die Form der Diskriminierung als Autokommunikation statt, die zugleich aus einer souveränen Position heraus geschieht. Als der türkeistämmige Privatdetektiv Kemal Kayankaya zu Beginn des Films in sein Büro kommt, fällt sein Blick auf das verunstaltete Namensschild: Kemal ist mit Kamel überschrieben. Ohne davon irritiert zu sein, wischt Kayankaya das Gekritzel einfach weg. Er betritt sein Büro, legt seine Jacke nicht ab und zelebriert mit einem Yes-Kuchen und einer Kerze darauf seinen Geburtstag. Und bevor er sie auspustet, sagt er zu sich selbst allein im Raum mit einem ironischen Unterton: »Herzlichen Glückwunsch, Du kleines Arschloch«. Siehe hierzu: DöRRIE (1992). Äußerst souverän gehen auch der deutsch-türkische homosexuelle Nachtclubsänger Zeki (Hilmi Sözer) in Ayşe Polats Film AuslandstourneE und homo- und transsexuelle Türken in Hussi Kutlucans Film Lola Und BiLdikid mit Diskriminierungen um. Siehe hierzu: Polat (1999). KuTLUCAN (1998).

194 Für Schiffauer ist neben der Frage nach Fremden auch die nach der Großstadt in seinen Arbeiten der 1990er zentral. Siehe: SCHIFFAUER, Werner (1997): S. 8. 
menden Popularität postmoderner Theorien oder der Luhmann'schen Systemtheorie wieder. Der Soziologe Rudolf Stichweh hebt beispielsweise den Aspekt der Fremdheit bei der Unterscheidung von Mehrheit und Minderheit besonders hervor. In seinem großen Projekt der 1990er Jahre versucht er, anhand der Figur des Fremden die Evolution der Weltgesellschaft als eine Inklusionsgeschichte nachzuzeichnen. ${ }^{195}$ In modernen Gesellschaften, die zugleich von funktionaler Ausdifferenzierung und zunehmender Individualisierung geprägt seien, stelle der Fremde eine besondere Signatur neben den Status Freund und Feind dar. Da für Stichweh die Dauer von Interaktionen zwischen unterschiedlichen Personen durch technische Errungenschaften und berufliche Diversifikation im Laufe der Geschichte abgenommen hat und weiter abnimmt, "tritt die Kompaktheit einer Person in all ihren beunruhigenden Aspekten hinter das Interaktionsgeschehen zurück«. ${ }^{196}$ Kommunikation wird hier vor allem in ihrer Funktionalität begriffen: Sie sichert Abläufe. Der Schlüssel zur Integration ist dabei nicht mehr die Assimilation, der Wandel der ganzen Person, sondern die Inklusion, die für das Gelingen von Interaktionen und spezifischen Funktionsabläufen die ganze Person nicht braucht; funktionierende Kommunikation reicht dafür schon aus. ${ }^{197}$ Die Welt und die Kulturen sind viel zu komplex und ihre Geschichte viel zu sehr von Auseinandersetzungen geprägt als dass sie in kurzen Interaktionen, von einzelnen Akteuren oder Gruppen verhandelt und verstanden werden könnten. Stattdessen soll die Inklusion Komplexität reduzieren und muss dafür mit einem bestimmten Wert an Fremdheit, an Nicht-Verstehen arbeiten - das hatte Şenocak bereits als Bedarf an einer negativen Hermeneutik erläutert. Das Nicht-Verstehen ist hier die Grundlage der Kommunikation, und die andere Seite der Inklusion ist die Exklusion. Im Zentrum steht bei diesen Überlegungen, dass die Gesellschaft als funktional differenzierte Einheit eine paradoxe Form hat. Gesellschaften und Gemeinschaften lassen sich nicht mehr darstellen. ${ }^{198}$ Integration ist nicht mehr eine Frage der Entwicklung, des modern-werdens, sondern eine Frage der Zeit als Dauer.

195 Siehe hierzu: http://www.uni-bielefeld.de/soz/personen/stichweh_5.htm (14.06.2018). STichweH, Rudolf (1997): »Der Fremde. Zur Soziologie der Indifferenz«. In: Furcht und Faszination. Facetten der Fremdheit, hg. v. Herfried Münkler, Berlin: Akademie, S. 45-64, hier S. 47.

196 Ebd., S. 56.

197 Tatsächlich finden in den deutsch-türkischen Filmen der 1990er Jahre viele Szenen in Telefonzellen statt, die das Hier mit dem Dort verbinden, wobei die Gespräche regelmäßig im Streit enden. Siehe hierzu: Dörrie (1991); AKIN (1998); Polat (1999).

198 Siehe hierzu: NANCY, Jean-Luc (1988): Die undarstellbare Gemeinschaft, Stuttgart: Edition Schwarz. 
Dieser Ausgangspunkt bildet auch die Grundlage der integrationstheoretischen Überlegungen von Armin Nassehi. Die moderne Gesellschaft zeichnet sich darin nicht mehr durch solidarisches Verhalten oder rechtlichen Vertrag aus, sondern sie besteht aus disparat differenzierten Teilen, »die zugleich hochgradig unabhängig und hochgradig abhängig voneinander sind «. ${ }^{199}$ Nicht mehr Integration ist jetzt der Normalzustand, sondern - wie bei Heitmeyer - die Desintegration, letztlich die Fremdheit. Für systemtheoretisch beeinflusste Theoretiker der Folgen der Migration hat die Modernisierung $\mathrm{zu}$ einem »Exklusionsbereich« in modernen Gesellschaften geführt, den der Nationalismus nur »temporär kompensieren konnte ${ }^{200}$ Partizipation am gesellschaftlichen Geschehen könne kaum mehr noch durch »fremdreferentielle Beobachtung " gesichert werden. An ihre Stelle treten Selbstbeschreibungen und Selbstbeobachtungen, die den Exklusionsbereich in modernen Gesellschaften füllen. ${ }^{201}$ Dort, wo einst das soziale Kollektiv, das ausbeuterische System oder der Nationalismus ihren Ort hatten, steht nun das Selbst, das sich positiv aus sich heraus entwerfen, gestalten oder negativ sich selbst verschwenden und an der Wucht der Realität und Gegenwärtigkeit scheitern und zerbrechen kann. Gesellschaftliche Dynamiken, die in einzelnen Funktionssystemen nicht ausagiert werden, gelangen auf diese Weise in die »Exklusionsindividualität «. ${ }^{202}$ Nach Bhabha erfordert die Beschreibung der multikulturellen Gesellschaft auch »eine Person, die aus sich selbst heraustreten kann, um wirklich zu sehen, was sie gerade tut «. ${ }^{203}$ Und tatsächlich nimmt das Individuum in den Integrationstheorien der 1990er Jahre eine besondere Position ein. ${ }^{204}$ Sie gilt nach Heitmeyer sogar als »kulturelle Norm « für alle. ${ }^{205}$

199 NASSEHI, Armin (1997): »Inklusion, Exklusion - Integration, Desintegration. Die Theorie funktionaler Differenzierung und die Desintegrationsthese«. in: Bundesrepublik Deutschland. Auf dem Weg von der Konsens- zur Konfliktgesellschaft - Band 2, hg. v. Wilhelm Heitmeyer, Frankfurt a. M.: Suhrkamp 1997, S. 113-148, hier S. 118.

200 Ebd., S. 139.

201 Nach Niklas Luhmanns Systemtheorie, auf die sich Nassehi bezieht, musste in vormodernen (stratifizierten) Gesellschaften Individualität nicht thematisiert werden, da man Menschen immer als zugehöriger Teil von Familien, Haushalten, Klöstern oder Zünften verstand. Siehe: LuHmanN, Niklas (1999): »Inklusion und Exklusion«. In: ders.: Die Gesellschaft der Gesellschaft Bd. 2, Frankfurt a. M.: Suhrkamp, S. 618-633.

202 NASSEHI (1997): S. 130.

203 BHABHA (2000): S. 4.

204 Vgl. FAIST (2000).

205 Heitmeyer (1997): S. 11. Auch Verteidiger des Asylkompromisses vom Dezember 1992, der durch Drittstaatenregelung und Bestimmung von sicheren Herkunftsländern eine restriktive Änderung des Artikels 16 des Grundgesetzes mit sich brachte, argumentieren, dass der individuelle Antrag eines politisch Verfolgten weiterhin möglich sei. Für den Autor Günter Grass war der Asylkompromiss, der im Bundestag am 6. Dezember 1992 verabschiedet wurde, umgekehrt Grund 
Der kanadische Philosoph Charles Taylor versucht diese Verschiebung der Verbindung von Integration und Desintegration in seiner bekannten Schrift zum Ist-Zustand moderner multikultureller Gesellschaften mit dem »Bedürfnis, zuweilen auch mit der Forderung nach Anerkennung « einzelner Akteure und kultureller Minderheiten einzufangen. ${ }^{206} \mathrm{Neu}$ ist das Bedürfnis nach Anerkennung natürlich nicht. Im Unterschied zu früheren Vorstellungen beruht sie nun nicht mehr allein auf gesellschaftlichen Kategorien wie Beruf und Stand, sondern begründet sich aus dem Inneren einer unverwechselbaren persönlichen Identität, die nicht ohne Weiteres Anerkennung genießt. Sie entsteht aus Interaktionen heraus und ist fragil, muss verhandelt werden und kann scheitern. ${ }^{207}$ So ist ein anderer Begriff, der in Taylors Reflexionen zu multikulturellen Gesellschaften eine herausragende Rolle spielt, nicht der des Respekts, sondern der des »Überlebens« (survivance) kultureller Selbstbeschreibung von Individuen und Gruppen. Ort der Austragung ist politisch mehr denn je die öffentliche Sphäre. ${ }^{208}$ Auch Bhabha spricht zu jener Zeit vom »Überleben«, wenn es um das Leben und Bewohnen des »Zwischenraums« geht. 209

Dieser Fokus auf das Selbst und das »Überleben« zeigt sich im Zusammenhang integrationstheoretischer Überlegungen besonders im deutschsprachigen Kontext. Denn zur Anerkennung der individuellen kulturellen Identität als

dafür, seine SPD-Mitgliedschaft zu kündigen. Denn die Grundlage des Artikel 16 von 1949 waren die Erfahrungen deutscher politischer Flüchtlinge während der NS-Zeit. LuFT, Stefan/SchIMANY, Peter (2014): »Asylpolitik im Wandel«. In: 20 Jahre Asylkompromiss. Bilanz und Perspektiven, hg. v. dens., Bielefeld: transcript, S. 11-32. Letztlich artikuliert sich im Asylkompromiss ebenfalls das Individuum als kulturelle Norm, nur dass wir im politischen Zusammenhang der Änderung des Artikel 16 von einer »individualistischen Zersplitterung « sprechen müssten, denn nur derjenige, der resilient und schlau genug ist, kommt durch; nur der, dem es gelingt, eine überzeugende Erzählung zu entwickeln. In Ayşe Polats Film EN GARDE rät eine Pädagogin einem jungen Flüchtlingsmädchen, dass sie erzählen solle, sie hätte den Bus von der Türkei nach Deutschland kein einziges Mal verlassen. Selbst wenn sie auf der Toilette einer Raststätte in Österreich gewesen sei, sollte sie das den Behörden gegenüber nicht erwähnen. Siehe hierzu: Polat, Ayşe (2003/2004): En Garde, Berlin: X Filme Creative Pool GmbH. Eine »individualistische Zersplitterung « attestiert die Filmkritikerin Katja Nicodemus auch dem deutschen Film der 1990er Jahre. Im Unterschied zum Neuen Deutschen Film der 1960er und 1970er Jahre, der die Verdrängungsstrategien des deutschen Nachkriegskinos der 1950er Jahre »entlarvte und gleichzeitig Spuren der Geschichte in der deutschen Gegenwart suchte und entdeckte«, bot nach Nicodemus die gesellschaftliche Wirklichkeit in den 1990er Jahren dem deutschen Kino keine »vergleichbare Angriffsfläche«. Siehe hierzu: Nicodemus (2003): S. 319.

206 TAYLOR (1993): S. 13.

207 Ebd., S. 24.

208 Ebd., S. 27.

209 Vgl. BHABHA (2000): S. 1 u. 10. 
wichtiger Integrationsmotor gehört für Taylor auch die Anerkennung kultureller Minderheiten mittels Erlassung von Sonderrechten - weil »heute immer mehr Gesellschaften multikulturell werden, insofern sie mehr als eine kulturelle Gemeinschaft umfassen, die überleben will «. ${ }^{210}$ Taylor empfiehlt diesbezüglich eine gesetzliche Erweiterung liberaler Demokratien, um über Gesetze auf die entstandene kulturelle Komplexitätssteigerung reagieren und sie gestalten zu können. Für Habermas würde dies eine Erweiterung der Anerkennungspolitik bedeuten, ein Gegenmodell, das er nicht für tragfähig hält, da es sich dabei nicht um eine Form des »administrativen Artenschutzes« handeln könne. ${ }^{211}$ Zudem könnten Minderheitenrechte als Sonderrechte die Individualrechte beschneiden, die in liberalen Demokratien Grundrechte seien. An diesem Punkt verkenne, so Habermas weiter, Taylor, dessen Ansatz der Anerkennung differenter kultureller Identität über das Individuum er absolut teilt, die »Gleichursprünglichkeit von privater und öffentlicher Autonomie«. Nach Habermas »bedarf es keines Gegenmodells, das den individualistischen Zuschnitt des Systems der Rechte durch andere normative Gesichtspunkte korrigierte«. Vielmehr müssten diese Rechte verwirklicht werden, was jedoch »ohne soziale Bewegungen und politische Kämpfe« schwer zu realisieren sei. ${ }^{212}$

Dieser kurz skizzierten Differenz zwischen Taylor und Habermas liegt eine grundsätzlich unterschiedliche Auffassung von Kultur zugrunde, die für unsere Analysen der Literatur, der Filme und der Publizistik besonders auch im Zusammenhang mit den soziologischen, postkolonialen und philosophischen Theorien der 1990er Jahre interessant ist. Bei Habermas ist Kultur vor allem politische Kultur, die durch die Kommunikation und Verhandlung subjektiver Interessen im öffentlichen Raum entsteht. Sie ist das Ergebnis demokratischer Auseinandersetzung, Produkt von Konflikten und zwingt zu öffentlicher Partizipation, wenn es um die Frage der Rechte geht. Taylor geht hingegen weniger von einem Kampf als vielmehr von einer dialogisch-sozialen Grundstruktur aus, in dessen Zentrum das Erkennen des Potentials der anderen Kultur steht. »Als Annahme formuliert«, lautet Taylors Zugang, »dass alle menschlichen Kulturen, die ganze Gesellschaften über längere Zeiträume mit Leben erfüllt haben, allen Menschen etwas Wichtiges zu sagen haben «. ${ }^{213}$ Die vorhandene Gestaltungs- und Überlebenskraft von gegenwärtigen oder vergangenen Kulturen verweist auf ein inhärentes Potential, das zugleich universell ver-

210 TAYLOR (1993): S. 56.

211 HABERMAS, Jürgen (1993): »Kommentar«. In: TAYLOR (1993): S. 173.

212 Ebd. S. 154. Im Manifest der 60 verweisen die Autoren darauf, dass nach dem Zweiten Weltkrieg »Gruppenrechte« zugunsten von »Individualrechten« zurückgegangen seien. Siehe hierzu: BADE (1994): S. 50.

213 TAYLOR (1993): S. 63. 
bindlich ist: Kultur hat demnach allen Menschen etwas zu sagen. ${ }^{214}$ Dies ist Taylors Ausgangspunkt, Anrufung und seine Vorstellung von Verbundenheit, wenn es in liberalen multikulturellen Gesellschaften darum geht, den Anderen oder die andere Kultur zu studieren. Für Taylor existiert also trotz aller Differenzen ein gemeinsamer Boden. Bei Habermas und Cohn-Bendit stehen der Kampf, die Auseinandersetzung um Anerkennung im öffentlichen Raum und die Resilienz einzelner Individuen am Anfang. Erst der Türke oder die Türkin, die nach draußen gelangt sind bzw. sich dorthin gekämpft haben, haben das Potential zur Integration und sind dadurch bereits integriert. In diesem Prozess darf am Ende die Kultur kein Differenzmarker mehr sein. Das Potential für die gemeinsame Zivilgesellschaft liegt an erster Stelle nicht an oder in ihrer Kultur oder auf einem gemeinsamen Boden, sondern sie hat sich an den Akteuren und durch sie zu behaupten, indem sie Heterogenes wie Nationalität und Unversalität über das Menschsein zusammenführen. Intergation ist so eine Form der öffentlichen Inkorporation. Ebenso steht für Habermas der Verfassungspatriotismus, den Dolf Sternberger Anfang der 1980er Jahre als eine innerdeutsche Angelegenheit adressierte, für eine Form politischer Integration, die die deutsche Gesellschaft mit den universellen Menschenrechten untrennbar zusammenführt. Der liberale Rechtsstaat ist dabei für Habermas eine politische Regierungsform, die die politische von der ethnisch-kulturellen Integration eindeutig trennt. ${ }^{215}$

Die Grundlage dieser politischen multikulturellen und transnationalen Prozesse, die im Kern eher ökonomisch und politisch als kulturell sind und an deren Ende die Anerkennung steht, ist jedoch ohne die Verwirklichung gleicher Rechte, ohne ihre Verwirklichungskanäle nicht möglich. Diese Rechte bestehen

214 Interessant ist in diesem Zusammenhang, dass wissenschaftliche, populärwissenschaftliche und belletristische neue und wieder veröffentlichte Arbeiten, die die Aufgeklärtheit und Toleranzkraft der islamischen Religion in ihrer Geschichte oder in ihrem Mystizismus in den Vordergrund ihrer Untersuchungen stellen, in den 1990er prominent sind. Siehe hierzu: Schulze, Reinhard (1996): „Was ist islamische Aufklärung?«. In: Die Welt des Islam 36 (1996), S. 276-325. HunKe, Sigrid (1997): Allahs Sonne über dem Abendland, Frankfurt a. M.: Fischer. ScHIMMEL, Annemarie (1993): Wanderungen mit Yunus Emre, Köln: Önel; dies. (1992): Mystische Dimensionen des Islam, München: Diederichs. Molina, Muňoz (1994): Stadt der Kalifen. Historische Streifzüge durch Cordoba, Reinbek bei Hamburg: Rowohlt. GoRDon, Noah (1990): Der Medicus, München: Droemer.

21515 Jahre später wird Habermas im historischen und gesellschaftspolitischen Zusammenhang von deutschen Integrationsgipfeln und Islamkonferenzen (2005; 2006-2009) feststellen, dass die muslimischen Einwanderer nicht gegen, sondern nur mit ihrer Religion »in eine westliche Gesellschaft integriert werden « können. Doch dann wird es primär nicht mehr darum gehen, wie es sich im öffentlichen Raum in der eigenen Haut lebt, sondern darum, was man lebt. Siehe zu Habermas: HABERMAS, Jürgen (2008): »Die Dialektik der Säkularisierung«. In: Blätter für deutsche und internationale Politik, April 2008, S. 33-46, hier S. 41. Siehe hierzu auch: Vgl. LöFFLER, Bertold (2010): Integration in Deutschland, Berlin: Oldenbourg, S. 201. 
für Deutsche und seit 1993 für EU-Bürger, aber nicht für Menschen außerhalb dieser Zugehörigkeitsräume, selbst wenn sie in Deutschland geboren wurden. Und genau an diesem Punkt ist die hier kurz skizzierte philosophisch-multikulturelle Debatte der 1990er Jahre Taylor'scher aber auch Habermas'scher Prägung auf den bundesrepublikanischen Alltag nicht so recht zu übertragen. Der Vorrang und die Anrufung - »invocation $\aleph^{216}$ - einer »universal personhood « gegenüber einer nationalen Staatsbürgerschaft, wie sie auch in Literatur und Film anvisiert und erprobt wird, erweist sich dort, wo vermeintlich alle Freiheiten herrschen, als instabil. Die mit ihr einhergehende Globalisierungseuphorie ist präsent, doch erzählerisch brüchig. Mediale Verknüpfungen können keine sozialen Bindungen und notwendige territoriale Verhältnisse ersetzen. Dennoch waren diese theoretischen Zugänge und Beschreibungen diskursiv äußerst wirkmächtig, weil sie von der Fiktion einer gemeinsam geteilten Welt und der Idee einer allgemeinen Gleichheit aller Menschen ausgingen. Auch die postnationale Bestimmung der Denizenship bei Yasemin Soysal fußt auf diesen Überlegungen, die im Zusammenhang der Entwicklungen in Europa nach dem Fall der Berliner Mauer entstanden. $^{217}$ Allerdings ist dieser Widerspruch zwischen dem Sprechen über Migration und Integration und ihrer Praxis in den 1990er Jahren nie zu Ende gedacht worden. Zum einen deshalb, weil das Sprechen oft über eine Kritik systemischer Politik, im Besonderen die Kritik der Novellierung des Ausländergesetzes und der Kritik am Asylkompromiss, nicht hinausging. Zum anderen, weil das hybride Subjekt an anderen theoretischen Stellen zwischen den Kulturen als ein grundlegend internationales adressiert wurde, für eine zukünftige postnationale Zeit. Darüber hinaus begriff man die 1990er Jahre auf dem Weg der voranschreitenden Europäisierung, mit der Konjunktur des Begriffs »Weltgesellschaft« und der deutschen Einheit besonders aus migrationssoziologischer Perspektive als ein Übergangsjahrzehnt. ${ }^{218}$ Dabei ist der Aspekt des Überlebens, was die Frage der Praxis betrifft und wie unsere anfänglichen kurzen Einblendungen in Literatur und Film gezeigt haben, sehr wohl in Debatte, Theorie, Literatur und Film übersetzbar. Auch wenn es in den 1990er Jahren eine Aufspaltung zwischen Sprechen und Praxis gibt, ist das Motiv des existenziellen »Überlebens« in Literatur und Film auch immer ein kulturelles Überleben. Denn kulturelle Identität »steht hier für das Bedürfnis nach Anerkennungsverhältnissen, die nicht nur materielle Absicherung ermöglichen, sondern die Versprechung beinhalten, individuelle

216 Siehe hierzu: Soysal (1994): S. 7f.

217 Siehe hierzu: Soysal, Yasemin (1994): »Toward a Postnational Model of Membership«. In: dies.: Limits of Citizenship. Migrants and Postnational Membership in Europe, Chicago: University of Chicago Press, S. 136-162.

218 Siehe hierzu: BADE (1994): S. 50. 
Lebenspraxis in verbindliche Zusammenhänge einzubetten und so die prekäre Zumutung individueller Lebenskonstruktion zu minimieren ${ }^{219}$ Das Modell der Denizenship der 1990er Jahre kollidierte damals mit einer identitätspolitischen Bedürfnisstruktur, die beispielsweise in den 1970er Jahren nicht bestand. ${ }^{220}$ Tatsächlich entsprang die Denizenship in der Bundesrepublik keineswegs einem postnationalen Konzept, das sie auch nicht anvisierte. Vielmehr ging es darum, mit der nicht mehr zu ignorierenden Dauerpräsenz besonders der türkischen Mitbürger sinnvoll und praktisch umzugehen. Man war auf eine Gleichstellung aus, die die symbolische und politische Zugehörigkeit der Ausländer weiterhin in ihren vier Wänden verortet wissen wollte.

Selbst Eckart Schiffer, der die stark kritisierte Novellierung des Ausländergesetzes mit auf den Weg gebracht hat, konstatiert, dass Heimat »vertraute Umwelt« ist, besonders »im Hinblick auf die Kürze des Lebens«. Daher sollte sie »so etwas wie ein kollektives Menschenrecht« sein. ${ }^{221}$ Davon ist im Ausländergesetz zwar nicht die Rede, doch ist die »vertraute Umwelt« der Ausländer ja nach Schiffer nicht der öffentliche, sondern ihr privater Raum, in dem sie sich »nach ihrem Geschmack benehmen können «. ${ }^{222}$ Wir wissen allerdings spätestens nach dem Befund der vorliegenden Kulturgeschichte, dass schon in den 1980er Jahren der private Raum für die zweite, aber auch für die erste Generation der Türken zu eng, zu klein, mit Identitätsstress ${ }^{223}$ verbunden und letztlich keine Grundlage für stabile Identifikationen sein kann. So leidet die migrationsbedingte Vergesellschaftungsgeschichte seit den 1960er Jahren in der Bundesrepublik als ein Teil ihrer eigenen Geschichte auch in den 1990er Jahren weiterhin an ihrer nicht repräsentativen und anzuerkennenden Sichtbarkeit, wobei Debatte,

219 BOMMES/SCHERR (1991): S. 305.

220 Das Phänomen der Denizenship war in der BRD auch 1973 juristisch schon eine Beschreibungskategorie, die damals jedoch in einem ganz anderen Zusammenhang stand. Denn politische Teilhabe in Form einer Identitätspolitik war zu jener Zeit kein Anliegen der Gastarbeiter und das Narrativ der Rückkehr noch nicht rein imaginär. Siehe zur Verwendung des Begriffs »Denizenship« in den 1970 Jahren: Tнyм (2018): S. $17 \mathrm{f}$.

221 SCHIFFER (1991): S. 57.

222 Ebd.

223 Dies hält auch Metin Gür in seiner Dokumentation Meine fremde Heimat aus der Mitte der 1980er Jahre fest, in der es um die Frage geht, wie es sich als Türke in Bergkamen lebt. Er gibt repräsentativ für viele eine Antwort aus einem Interview wieder, in der ein Gastarbeiter beschreibt, wie er sich in den eigenen vier Wänden an einem normalen Wochenende fühlt: »Besonders samstags und sonntags, wenn mich ein Gedanke nicht losläßt, kann ich es im Zimmer nicht mehr aushalten. In der frischen Luft spazierengehen, beruhigt mich etwas. Außerdem bin ich sehr vergeßlich. Wenn ich an meine Kinder und an die Freizeit denke, vergesse ich alles, was ich weiß. Die Freizeit nimmt mich sehr mit.«Siehe hierzu: Gür, Metin (1987): Meine fremde Heimat. Türkische Arbeiterfamilien in der BRD, Köln: Weltkreis, S. 96. 
Reflexion und Realität, besonders nach 1992, von Differenz durchzogen sind. ${ }^{224}$ Nach Habermas wird der Kampf um Anerkennung, nach Cohn-Bendit die anerkannte Resilienz der »ausländischen Deutschen«, ihr berufliche Selbstständigkeit zu dieser Sichtbarkeit führen.

Dass aber dieser Prozess, deutsch zu werden, der sich am Behaupten misst, mit Berufen wie Kutscher, Prostituierte, Dealer usw., also aus einer sozialen Anomie heraus, äußerst schwierig ist, liegt auf der Hand. Zumal die Berufe der Protagonistinnen und Protagonisten in Literatur und Film der 1990er Jahre auch keinen sozialstrukturellen Aufstieg versprechen. Die Austragungen subjektiver oder kollektiver Interessen finden zwar im Unterschied zu den 1980ern im öffentlichen Raum statt. Doch sind es periphere und unbestimmte, nicht zentrale und konkrete Orte, die mit bestimmten Verhaltensweisen codiert sind. Wie bereits angedeutet, gehören dazu Straßen, Straßenecken, Übergänge zwischen Haus, Wohnung und Straße. Hier sind die Akteure der zweiten Generation beheimatet. Sie gehören dazu, aber ihnen gehören die Orte nicht, die kaum benannt sind und keine Adressen haben. ${ }^{225}$ Ob sie in diesen "Zwischenräumen« wirklich wohnen können, wie Bhabha behauptet, oder ob sie das Denken über die Heimat, wie in den 1980er Jahren, in ein Denken des Wohnens in den 1990ern werden übersetzen können, möchte ich an dieser Stelle noch offen lassen. ${ }^{226}$ Letztlich stellt sich auch hier die Frage, ob man ohne Eigentum und Zugehörigkeit angemessen leben kann.

Zu Beginn der 1990er Jahre erlebte die zweite Generation der Einwanderer in Deutschland nach einer kulturellen Entortung eine neue politische Phase der Globalisierung, die den Prozess funktionaler Differenzierung überall verortete, und am Horizont vermeintlich eine in Kommunikation stehende Weltgesell-

224 In den 1990er Jahren kommt es zu äußerst vielsagenden neuen Begriffsbildungen wie »Bildungsinländer« und »Fußballdeutscher«. So ist es für Heranwachsende, die Kinder von Arbeitsmigranten sind, in Deutschland geboren wurden, Kindergarten und Schule besucht haben, ihre Eltern über fünf Jahre Steuern bezahlt haben, durch die identifizierende Kategorie des »Bildungsinländers« möglich, für ihre Weiterbildung BAföG zu beantragen. Nach der Logik dieses Terminus teilt sich der Alltag des Bildungsinländers wie folgt: in den Tageszeiten, in denen sich die Person weiterbildet, gehört sie zum Inland. Wenn sie aber in der gleichen Räumlichkeit frühstückt oder zu Abend isst, gehört sie zum Ausland. Das Gleiche gilt für den wunderbaren Begriff des »Fußballdeutschen «, den die DFB Anfang der 1990er Jahre kreierte, weil nicht mehr als vier ausländische Spieler in einem Stammaufgebot spielen durften. Siehe hierzu: CoHN-BENDIT (1992): S. 77. Allein diese Begriffsbildungen dokumentieren eindrücklich die Verschleierung der Folgen der Migration in diskursiven Zusammenhängen.

225 Diese schwierige topografische Konstellation findet sich auch in vielen deutschen Spielfilmen der 1990er Jahre. Sie erstreckt sich von DER BEWEGTE MANN (1994), LOLA RENNT (1998), über Der Campus (1998) bis hin zu NaChtgestalten (1999).

226 Siehe zur Unterscheidung von Heimat und Wohnung: FluSSER (2007): S. 27. 
schaft aufscheinen ließ, die alle zu Fremden und Gleichen machte. Unter diesen Umständen ist es zunächst der individuelle Körper, der als einziger Ort der Auseinandersetzungen und Verhandlungen zurückbleibt. Danach, ob der Körper eines Individuums dazu in der Lage ist, fragt das folgende Kapitel. Denn diese Frage wird im Zusammenhang mit soziologischen, postkolonialen und philosophischen Theorien kaum gestellt. In diesen Theorien ist das hybride Subjekt eines, das diese Spannung schafft und aushält, weil es sich bei ihm in Wirklichkeit um ein universelles Subjekt handelt. Denn im Lokalen steckt vermeintlich immer das Globale. Allerdings steht das Subjekt im Raum einer nicht funktionierenden öffentlichen Kommunikation, die sich aus dem Widerspruch zwischen Sprechen und Praxis in unserer Geschichte für die 1990er Jahre ergibt. Dass man an diesem Widerspruch auch scheitern kann, werden uns die Analysen der Filme und Texte dieser Dekade zeigen. Obwohl deutsch-türkische Literatur und Film der 1990er Jahre hinsichtlich ihrer Rezeption eine Erfolgsgeschichte erzählen, muss man von einem Scheitern sprechen. Das liegt daran, dass Opfer und Täter nicht mehr voneinander getrennt werden, sondern in einzelnen Figuren kulminieren. Dieser These steht ein Forschungsaufkommen entgegen, das in den Produktionen der 1990er Jahre mehr Selbstermächtigung oder »celebrity of hybridity« sieht.

Meinem Zugang und meinen analytischen Ergebnissen zu den 1990er Jahren entsprechen mehr die theoretischen Überlegungen Niklas Luhmanns aus der Mitte und dem Ende der 1990er Jahre zur Gleichzeitigkeit und zum asymmetrischen Verhältnis zwischen Inklusion und Exklusion. Auch wenn seine Systemtheorie auf Talcott Parsons strukturalistischer Systemtheorie der Gesellschaft aus den 1960er Jahren aufbaut, sieht er die Inklusion weitaus kritischer als Parsons. Zwar meint auch Luhmann, dass Inklusionsprozesse Personen Plätze im Gesellschaftssystem zuweisen, »in deren Rahmen sie erwartungskomplementär handeln können«. Und er fügt hinzu, dass man diesen Prozess romantisch auch als ein »heimisch fühlen können« der Individuen beschreiben könne. Milton Gordons »feel comfortable« im öffentlichen Raum, das ebenso wie Parsons Theorie auf der Möglichkeit der gesellschaftlichen Solidarität aufbaut, ist bei Luhmann aber nur noch ein romantisches Zitat. Sein Fokus liegt nicht auf dem sozialen Handeln, nicht auf veränderbaren sich ähnlicher werdenden Handlungsmustern, wie in Parsons Theorie der 1960er Jahre, sondern auf Kommunikation und Differenz. Mitunter deshalb können Inklusionen nicht einfach vorhergehende Exklusionen ablösen oder sie in spezifischen Handlungssituationen aufheben, wie es sich Talcott Parsons im Rahmen einer »wider solidary social system « vorgestellt hatte. Für Luhmann gibt es Inklusion nur, wenn auch Exklusion möglich ist. Beide sind zwei Seiten einer Kommunikationsform. Denn erst die Existenz nichtintegrierbarer Personen oder Gruppen lässt soziale Kohäsion sichtbar werden und macht 
es möglich, Bedingungen der Inklusion dafür zu spezifizieren. ${ }^{227}$ Da es für ihn kein Teilsystem wie Recht, Wirtschaft, Erziehung oder sogar Politik gibt, das anderen Systemen werteorientiert vorschreiben könnte, wie man zu beobachten und zu handeln habe, versteht Luhmann »Gesellschaft « nicht als »wider solidary system«, sondern als eine paradoxe Einheit.

Luhmann entwirft die Systemtheorie Ende der 1970er Jahre. Tatsächlich setzen, wie in der vorliegenden Kulturgeschichte bereits gezeigt, mit den 1980er Jahren erstmals in Deutschland, Frankreich aber auch in den Vereinigten Staaten Debatten und Politiken ein, die an die zentrale Stelle der verbindlichen Zivilgesellschaft, der Gesellschaft als einer sich endogen entwickelnden Einheit, die Kulturen von Mehrheiten und Minderheiten als nationale Zugehörigkeiten rücken. Diesen Wandel hat wahrscheinlich keine Aussage so sehr auf den Punkt gebracht, wie die der ehemaligen britischen Premierministerin Margaret Thatcher, dass es nämlich so etwas wie Gesellschaft überhaupt nicht gebe. ${ }^{228}$ Wie bereits gezeigt, werden die Türken in den 1980er Jahren, die zu diesem Zeitpunkt bereits zwischen 10 und 20 Jahren in Deutschland mit ihren dort geborenen Kindern leben, also »praktisch« Einwanderer sind, diese gesellschaftliche Realität ignorierend als eine ausländische Minderheit bestimmt, und zwar als eine Minderheit, die nicht integrationswillig ist, weil sie einer anderen Kultur angehört. Diese politik- und debattenbezogene Rhetorik und Überzeugung ist wichtig, wenn auf der deutschen Seite soziale Kohäsion entstehen soll. Tatsächlich werden in der Bundesrepublik in den 1980er Jahren die Begriffe »Nation« und »Kultur« für die eigene Selbstbeschreibung äußerst beliebt, wie die Politik der regierenden CDU eindrücklich dokumentiert. Es gibt also keine Inklusion ohne die Möglichkeit der Exklusion. Doch das Verhältnis zwischen Inklusion und Exklusion ist asymmetrisch. Denn mit Luhmanns Worten ist das zentrale Problem bei diesen zeitgleichen In- und Exklusionen, dass Exklusionen in Inklusionsprozessen lediglich als warnende Beispiele fungieren und «nicht als Teil der gesellschaftlichen Wirklichkeit mit entsprechender Sorgfalt beschrieben werden «. ${ }^{229}$ Wenn also ein türkischer Vater, der seit zwei Jahrzehnten in Deutschland lebt, seine Tochter in Deutschland tötet, kann es sich dabei nur um das Inkrafttreten eines rückständigen und barbarischen Ehrenkodex handeln, aber nicht um eine individuelle psychosoziale Disposition. Letzterer Zugang wäre problematisch, weil sie an der Asymmetrie zwischen In- und Exklusion rühren würde und den türkischen Gastarbeiter in ein vergleichbares Verhältnis mit dem Deutschen brächte.

227 Luhmann (1999): S. 621.

228 Diese Aussage stammt aus einem Interview mit dem Magazin Women's Own. Siehe hierzu: http://www.margaretthatcher.org/document/106689 (30.11.2017).

229 LUHMANN (1999): S. 627. 
In den 1980ern hat man dieses Problem umgangen, indem man auf die Türkei als Territorium und als Herkunft verwies und sich auf diese Weise das Narrativ des »Wie lebt es sich als Türke in Deutschland? « in der gezeigten Breite zwischen Bestätigung und Kritik von Skandalisierungen, diskursiven Aussagen, über Werner Schiffauers Analysen bis zur Literatur Aysel Özakıns entfalten konnte. Doch Ende der 1980er und zu Beginn der 1990er war dieses Narrativ der Türkei als Herkunft, als Rückkehr und letztlich als ein Territorium, auf das man sich bezog, nicht mehr aufrechtzuerhalten. Das lag mitunter daran, dass sich durch den anhaltenden Daueraufenthalt der Türken in der Bundesrepublik die entstandene »sedentäre Konstellation sich zunehmend ins Inland« verlagerte und sich dort auch nicht mehr verbergen ließ.230 Sprich, der eigentliche Anstoß für die Änderung des Ausländergesetzes von 1990 war, dass nun selbst die Türken der ersten Generation, nun schon länger in der Bundesrepublik lebten als sie in der Türkei gelebt hatten, nicht mehr länger zu ignorieren war. Dass man sich nicht mehr auf die Türkei als Territorium bezog, wie noch in Hark Bohms Film YASEMIN, führte zu einer anders gearteten Gleichzeitigkeit von Inklusion und Exklusion. Nach dem Anschlag von Mölln (1992) begründete ein Betroffener seine tiefe Verunsicherung sowie seinen Wunsch, dennoch in Deutschland bleiben zu wollen damit, dass sie, die Türken, sich in Deutschland nun »eingewurzelt« hätten. ${ }^{231}$ Die sich daraus ergebenden neuen Beschreibungsformate von Inklusion und Exklusion müssen und können nur andere sein als in den 1980er Jahren.

\begin{abstract}
Während im Inklusionsbereich Menschen als Personen zählen, scheint es im Exklusionsbereich fast nur auf ihre Körper anzukommen. Die symbolischen Mechanismen der Kommunikationsmedien verlieren ihre spezifische Zuordnung. Physische Gewalt, Sexualität und elementare, triebhafte Bedürfnisbefriedigung werden freigesetzt und unmittelbar relevant, ohne durch symbolische Rekursionen zivilisiert zu sein. Voraussetzungsvollere soziale Erwartungen lassen sich dann nicht mehr anschließen. Man orientiert sich an kurzfristigen Zeithorizonten, an der Unmittelbarkeit der Situationen, an der Beobachtung von Körpern. ${ }^{232}$
\end{abstract}

Die Deutsch-Türken sind in den 1990er Jahren inkludiert und exkludiert zugleich. Sie sind Person und Nicht-Person, Täter und Opfer, hier und dort; eine paradoxe Einheit, die ein selbstverständliches Deutsch- und Türkischsein erschwert. Wie ich anhand der deutsch-türkischen Literatur und des Films zeigen möchte, ist die kulturelle Frage in den 1990er Jahren auf den ersten Blick vielleicht eine der kulturellen Hybridität, eine des »Darüber-hinaus«-Verweisens. Dies suggerieren

230 Siehe hierzu: Tнум, Daniel (2017): »Migrationsfolgenrecht«. In: Veröffentlichungen der Vereinigung der Deutschen Staatslehrer, 76, 2017, Berlin: De Gruyter, S. 169-216.

231 Zitiert nach: HunN (2005): S. 556.

232 LuhmanN (1998): S. 633. 
postkoloniale und transnationale Theorien, die auch in der ästhetischen Bearbeitung ein gelingendes Sich-Hinauskämpfen sehen. Aufgrund der beschriebenen Trennung funktioniert diese Bewegung aber nicht. Wir werden sehen, dass die Protagonistinnen und Protagonisten der Filme und der Literatur in den 1990er Jahren scheitern. Denn ihr Blick über die Gegenwart hinaus hat im Übergang von 1980ern zu den 1990ern nicht mit der Leitfrage zu tun, wie es sich zwischen den Kulturen oder in den »Zwischenräumen « lebt, sie wird vielmehr aus einer existenziellen Situation heraus gestellt. Ihre Frage, die eine Kultur der Auseinandersetzungen schaffen wird, lautet: „Wie lebt es sich in Deiner Haut?« Bereits im Prolog der Einleitung habe ich Zaimoğlus Antwort auf die Frage zitiert, warum er Schriftsteller geworden sei: »Ich war nicht zwischen zwei Kulturen, sondern ich habe zuhause Dinge erlebt und erfahren und gesprochen und ich wollte draußen weitersprechen «. ${ }^{233}$ Das Weitersprechen im Übergang von innen nach außen ist hier keine Befreiung, sondern macht erneut auf eine nicht funktionierende Öffentlichkeit aufmerksam, in der nicht gehört wird, was man sagt. Um ein Hören zu erzwingen, wenden Autoren und Filmemacher ästhetische Verfahren an, die es im Folgenden anhand der Werke Emine Sevgi Özdamars, Zafer Şenocaks, Feridun Zaimoğlus, der Filme von Thomas Arslan, Fatih Akın, Yüksel Yavuz und Buket Alakuş im Detail zu analysieren gilt.

Diese einleitenden Einblicke in Literatur, Theorie, Publizistik und Politik zeigen, dass wir es in den 1990er Jahren mit einer neuen Konstellation von eigen und fremd zu tun haben. Positiv gewendet sollen beide Bestimmungen nun Teil einer gemeinsamen Welt werden. Im Zentrum dieser neuen Konstellation von Migration und Integration steht eine Deplatzierung von öffentlich und privat, die sich nicht nur in Literatur, Film und Theorie abspielt, sondern auch im Kern der Entwicklung des türkischen Islams in Deutschland. ${ }^{234}$ Wir werden in diesem Zusammenhang sehen, dass in Literatur und Film volksreligiöse und mystisch-islamische Zugänge in die Herkunftskultur anstelle eines orthodoxen Islams favorisiert und bisweilen gegen letzteren ausgespielt werden. Auch wenn volksliterarische, volksreligiöse und mystische Autoren, Texte und Gedichte gegen religiöse Fundamentalisten und türkische Nationalisten in Stellung gebracht werden, entspringen beide Ausrichtungen einer neuen Grundlage des Auftretens und der Begegnung im

233 Zitiert nach: BRUNNER, Maria (2004): »'Migration ist eine Hinreise. Es gibt kein `Zuhauseく, zu dem man zurück kann`. Der Migrationsdiskurs in deutschen Schulbüchern und in Romanen deutsch-türkischer Autorinnen der neunziger Jahre«. In: Die andere deutsche Literatur, hg. v. Manfred Durzak, Würzburg: Königshausen \& Neumann, S. 71-90, S. 85.

234 NöKEL, Sigrid (2001): »Personal Identity and Public Spaces. Micropolitics of Muslim Women in Germany«. In: Jahrbuch 2000/2001, Kulturwissenschaftliches Institut Essen, S. 113-147, S. 145. 
privaten wie im öffentlichen Raum, die ebenfalls den »selbstbewussten« Auftritt der Muslime der zweiten Generation im öffentlichen Raum in den 1990er Jahren bestimmt. Wenn beispielsweise das Kopftuch in den 1980er Jahren als Ausdruck einer rückständigen, traditionell-religiösen Lebensauffassung begriffen wurde und dadurch Fortschrittlichkeit und Rückständigkeit voneinander trennte, arbeitet die Forschung in den 1990er und beginnenden 2000er Jahren neue Selbstbeschreibungen und neue Lesarten dieses Kleidungsstücks heraus. In ihren theoretischen und empirischen Arbeiten verstehen Nilüfer Göle, Gritt Klinkhammer und Sigrid Nökel das Kopftuch im öffentlichen Raum nicht mehr als ein Zeichen für Verdrängung, sondern für die Artikulation von »Selbstbewusstsein« und »Modernität«. ${ }^{235}$ Beliebte Bilder und Figuren sind für diese neue identitätspolitische Konstellation kopftuchtragende Frauen mit Abitur, im Studium, oder noch provokativer die kopftuchtragende Frau mit Jeans oder im Umgang mit den neuesten Telekommunikationsmedien. Und auch wenn Tomas Hammar bei seinem Konzept des Denizens von den Gastarbeitern ausgeht, die geblieben sind, skizziert er den Denizen als jemanden der sozialstrukturell angekommen ist. Denn sie stellen eine neue Kategorie des »foreign citizen « dar, »who hold such an honoured position as scientists, artist or sportsmen «. ${ }^{236}$ Auch in diesen Vorstellungen, die soziologische und publizistische Beiträge in den Vordergrund rücken, greift die Logik einer vorgestellten Verbundenheit mit der Welt, weil es um sozialstrukturelle Ähnlichkeiten geht. Doch als Grundlage steht auch erneut der öffentliche Raum, in dem sich die zweite Migranten-Generation artikuliert und durch eigenes erworbenes Wissen über ihre Religion selbst bestimmt, was sie ist. Dabei gilt als öffentlicher Raum alles, was nicht privat ist (Schule, Arbeitsplatz, öffentliche Plätze) ${ }^{237}$ Inwieweit diese unterschiedlichen Formen des Auftretens und der Anrufung in Literatur, Film und alltäglicher Praxis tatsächlich "gleichursprünglich autonom» (eine Grundlage des liberalen Rechtsstaats) sind, was den öffentlichen und privaten Raum betrifft, oder ob nicht vielmehr umgekehrt beide Räume von einem »displacement « durchzogen sind, das den einen Raum ohne den anderen nicht denken lässt, sind mitunter wichtige Leitfragen des gesamten Analyseteils des folgenden vierten Kapitels. In jedem Fall resultiert die kreative Explosion, wie sie in der deutsch-türkischen Lite-

235 Siehe hierzu: GöLE, Nilüfer (1995): Republik und Schleier. Die muslimische Frau in der modernen Türkei, Berlin: Babel. KLINKHAMmER, Grit (2000): Moderne Formen islamischer Lebensführung. Eine qualitativ-empirische Untersuchung zur Religiosität sunnitisch geprägter Frauen der zweiten Generation in Deutschland, Marburg: diagonal. NöKEL, Sigrid (2002): Die Töchter der Gastarbeiter und der Islam. Zur Soziologie alltagsweltlicher Anerkennungspolitiken. Eine Fallstudie, Bielefeld: transcript.

236 HAMmAR (1990): S. 13.

237 Siehe hierzu: NöKEL (2011). 
ratur und im Film in den 1990er Jahren stattfindet, nicht nur aus einer gesteigerten kulturellen Kompetenz, die sich darauf zurückführen ließe, dass ihre Regisseure und Autoren in Deutschland studiert und wie die Akteurinnen und Akteure des neuen »modernen« Islam deutsche säkulare Bildungsinstitutionen durchlaufen haben. ${ }^{238}$ Der Vorrang der Fiktion, der modischen, literarischen und filmischen Ästhetik vor der Dokumentation, hat mit dem Faktum einer »sedentären Bias« zu tun, damit, dass sie territorial zugleich dazu- und nicht dazugehören. Genau diese kontradiktorische Konstellation muss tatsächlich auch als eine nichtdargestellte soziale Wirklichkeit dieser Produktionen wahrgenommen worden sein. Nur so lässt sich erklären, warum mitunter surreale und offensichtlich überzogene Geschichten als Artikulationen der türkischen Community in der Bundesrepublik als die eigentlichen Wirklichkeiten begriffen werden konnten. So gibt es in den 1990er Jahren gegen die asymmetrische Gleichzeitigkeit von Inklusion und Exklusion nur die eine Möglichkeit der Integration, der Bindung von öffentlich und privat, von Person und Körper, von Innen und Straße, nämlich ausschließlich durch eine fiktionale Erzählung, die wirklicher ist als die Realität. Ihr Austragungsort und Umschlagplatz ist die ,Türschwelle‘.

\subsection{Vom Hören und Lachen in der multikulturellen Gesellschaft}

» Mutter, es ist Lüge, aber ich erzähle es dir.` Meine Mutter hörte mir zu, lachte und sagte: >Wie kannst du so viel Lügen aus dir herausholen. Oder liegt die auf der Straße?« «39 Tatsächlich entstehen die Geschichten, die die namenlose Ich-Erzählerin in Emine Sevgi Özdamars Roman Das Leben ist eine Karawanserei von 1992 erfindet, draußen, und nicht zu Hause. Jedes Mal, wenn sie in Stadtbussen unterwegs ist, vermisst sie ihre Mutter und erfindet dabei Geschichten, mit denen sie sie, wenn sie nach Hause kommt, zum Lachen bringen kann. ${ }^{240}$ Doch es geht nicht allein um die Unterhaltung und um die Aufmerksamkeit der Mutter, sondern auch um die Form der Begegnung zwischen Mutter und Tochter. Denn die Tochter will andere Interaktionen tunlichst vermeiden. Eines Tages öffnet die Mutter mit einer aufgeschlagenen Zeitung in der Hand und begrüßt ihre Tochter nicht einmal. Oder aber - und das ist die zweite Begegnungsvariante - sie ruft: »)Hey, meine Tochter ist da«" und übersäht sie dabei mit Küssen. Beides gefällt der von draußen kommenden Tochter nicht, die sich daraufhin beide Male in der

238 Siehe hierzu: TIESLER, Nina (2006): Muslime in Europa. Religion und Identitätspolitiken unter veränderten gesellschaftlichen Bedingungen, Münster: LIT, S. 212.

239 ÖZDAMAR (1992): S. 334.

240 Ebd., S. 333. 
Toilette einschließt. Sie ist auf einen Umgang aus, der vom Hören und Lachen bestimmt ist, von einem gemeinsamen Teilen der Situation. ${ }^{241}$ Letztlich geht es um eine Form der Geselligkeit, um eine Form der Soziabilität, die dem anderen, »dasjenige Maximum an geselligen Werten (von Freude, Entlastung, Lebendigkeit) [gewährt], das mit dem Maximum der von ihm selbst empfangenen Werte vereinbar ist «. ${ }^{242}$ Doch dafür muss sie alltagsfern entweder unerhört auftreten oder Unerhörtes erzählen.

Dass dieses Mitteilungsverlangen der Protagonistin und der Fokus auf Begegnungs- und Schwellensituationen, sich nicht allein auf die Mutter beschränken, zeigen viele Situationen im Roman: etwa Interaktionen mit den Nachbarn auf der Straße oder mit der Großmutter, die sich beispielsweise sehr um die Kinder und um die Frau Robinson Crusoes besorgt zeigt, als ihr die Enkelin Robinson Crusoe vorliest. Da sie glaubt, ihre Enkelin würde wichtige Teile der Geschichte weglassen, fragt sie nach, was denn die Kinder und die Frau von Robinson machen würden und wie sie vor allem überlebten. Was haben sie gegessen? Wer hat sie beschützt und was haben sie gemacht während Robinsons Abwesenheit? Auch wenn es in Defoes Geschichte entgegen der großmütterlichen Vermutung keine Beschreibungen dieser Art gibt, erzählt die Enkelin, was Frau und Kinder gegessen, getrunken, wer sie beschützt und wie sie dadurch alle überlebt hätten. ${ }^{243}$

241 ÖZDAMAR (1992): S. 334.

242 SimMel (2019): S. 58.

243 ÖzDAmar, Emine Sevgi (1992): Das Leben ist eine Karawanserei, Köln: Kiepenheuer \& Witsch, S. 117. Norbert Mecklenburg interpretiert diese Szene als eine Form der Kulturkomik. Siehe hierzu: MECKLENBURG, Norbert (2008): »Interkulturalität und Komik bei Emine Sevgi Özdamar«. In: Das Mädchen aus der Fremde. Germanistik als interkulturelle Literaturwissenschaft, hg. v. Norbert Mecklenburg, München: iudicium, S. 506-535, hier S. 518. Dass es hier und in vielen anderen Szenen des Romans nicht nur um Unterhaltung, sondern in erster Linie um einen glücklichen Umgang miteinander geht, erkennt Mecklenburg ebenso wenig wie andere Forscher, die sich mit Özdamars Komik beschäftigt haben. Denn Großmutter und Mutter erkennen diese Art der Ich-Erzählerin, Geschichten zu erfinden und sie »gewitzt« zu erzählen, als besondere Fähigkeit an. Auch in der pädagogischen Forschung zur Sprachkompetenz von Migranten und ihren Kindern beginnt sich in den 1990er Jahren die Erkenntnis durchzusetzen, dass sich bei Äußerungen nicht allein die Frage stellt, »ob sie wahr oder falsch sind; sondern vielmehr, ob sie glücken oder nicht glücken«. Dieses »Glücken« ist nicht allein eine Frage der Wahrheit oder der »technischen Sprachkompetenz«. Sie ist im Besonderen auch eine Frage von Intelligenz und Witz. Siehe zur pädagogischen Forschung: DIRIM, Inci/MecherIL, Paul (2010): Migrationspädagogik, Weinheim: Beltz, S. 102. Den Aspekt des gewitzten Erzählens als ein elementares narratives Mittel in Özdamars Karawanserei-Roman hat Julia Boog in ihrer Dissertation Anderssprechen. Vom Witz der Differenz in Werken von Emine Sevgi Özdamar, Felicitas Hoppe und Yōko Tawada überzeugend herausgearbeitet. Sieh hierzu: Boog, Julia (2017): Anderssprechen. Vom Witz der Differenz in Werken von Emine Sevgi Özdamar, Felicitas Hoppe und Yōko Tawada, Würzburg: Königshausen \& Neumann, S. 96-113. 
Aufgrund einer Vielzahl solcher Situationen bezeichnen Mutter und Großmutter unsere Erzählerin im Laufe des Romans manchmal belustigt, manchmal besorgt, als eine »Mundhure«: eine Person, »die mit der Zunge Hure ist «. ${ }^{244}$ Diese Zuschreibung gefällt der namenlosen Erzählerin, die im Übrigen auch über die interpersonalen Verhältnisse im Roman hinaus alles Mögliche erfindet, denn selbst wir als Leser wollen ihr ebenso wenig glauben, dass sie sich bis in ihre Zeit als Fötus im Mutterleib zurückerinnern kann; oder dass sie als fünf Tage alter Säugling uns auf dem Friedhof volksreligiöse Grabsteininschriften vorzulesen vermag. Auch bei diesen Erfindungen geht es nicht um eine verschönerte oder einfach nur verzerrte Darstellung einer Wirklichkeit zwischen zwei Kulturen, sondern um die Möglichkeit einer anderen Begegnung, auch zwischen Autorin und Lesepublikum, also zwischen Autorin und deutschsprachiger Öffentlichkeit.

Trotz dieser fiktionalen Besonderheit hat man Das Leben ist eine Karawanserei in Besprechungen und Aufsätzen der 1990er Jahre häufig als Özdamars Autobiografie gelesen oder als eine exemplarische Repräsentation einer türkischen Biografie in den 1950er und 1960er Jahren. ${ }^{245}$ An anderen Stellen wird der Roman als ein Bildungsroman begriffen, der die Vorgeschichte einer türkischen Gastarbeiterin erzählt oder als eine Auseinandersetzung zwischen Tradition und Moderne. ${ }^{246}$ Im Feuilleton hat man Özdamar attestiert, dass ihr Roman eine »gelungene

244 ÖZDAMAR (1992): S. 117.

245 Siehe hierzu: Konuk, Kader (1997): „Das Leben ist eine Karawanserei. Heimat bei Emine Sevgi Özdamar«. In: Kein Land in Sicht. Heimat - weiblich?, hg. v. Gisela Ecker, München: Fink, S. 143-158, S. 153-155. Dies zeigt nicht zuletzt der Urheberrechtsstreit um Feridun Zaimoğlus Roman Leyla dreizehn Jahre nach Veröffentlichung von Özdamars Roman. In seinem vielbeachteten Roman erzählt Zaimoğlu auf Grundlage der Lebensgeschichte seiner Mutter eine vergleichbare Geschichte wie Das Leben ist eine Karawanserei. Ein besonderer Streitpunkt während der Affäre 2006 war, wem diese Geschichte der türkischen Migration vor der Migration nach Deutschland eigentlich gehöre: Emine Sevgi Özdamar oder Feridun Zaimoğlus Mutter. Siehe hierzu: PfLITSCH, Andreas (2009): »Fiktive Migration und migrierende Fiktion. Zu den Lebensgeschichten von Emine, Leyla und Gül«. In: Wider den Kulturenzwang. Migration, Kulturalisierung und Weltliteratur, hg. v. Özkan Ezli, Dorothee Kimmich, Annette Werberger, Bielefeld: transcript, S. 231-252. Ausgangspunkt des Plagiatsstreits war der Aufsatz »Kulturelle Differenzen und Identifikationsräume in Feridun Zaimoğlus Roman `Leyla` und Emine Sevgi Özdamars `Das Leben ist eine Karawanserei««. Darin zeigt die Autorin anhand von 160 Beispielen Überschneidungen an Motiven und Bildern zwischen den Romanen. Siehe: BRunner, Maria E. (2009): »Kulturelle Differenzen und Identifikationsräume in Feridun Zaimoğlus Roman `Leyla und Emine Sevgi Özdamars `Das Leben ist eine Karawanserei««. In: Der deutschsprachige Roman im 20. Jahrhundert aus interkultureller Sicht, hg. v. László Szabo, Gabriella Rácz, Veszprem: Praesens, S. 31-52.

246 Siehe hierzu: JANkowsky, Karen (1997): »German` Literature Contested. The 1991 Ingeborg-Bachmann-Prize Debate. `Cultural Diversity« and Emine Sevgi Özdamar«. In: The German Quarterly Vol. 70, No. 3, S. 261-276. HorRocKs, David/KolinsKy, Eva (1996): »Living and Writing 
Mischung aus Naivität und Intellekt, orientalischem Märchen und abendländischem Bewußtsein « sei. ${ }^{247}$ Inwieweit ein Fötus über Selbstbewusstsein verfügt oder man diesen Zustand zumindest erinnern kann, war vor über zwanzig Jahren und ist bis heute eine ungeklärte Frage. Annette Wierschke hat befunden, dass Özdamars Roman in »einer Zeit immenser politischer und ökonomischer Umwälzungen bewußtseinsbildend « wirke, respektive »in der Auseinandersetzung mit Deutschlands faktischer multikultureller und multiethnischer Realität Entwürfe sanderer Realitäten«« aufzeige. ${ }^{248}$

Inwieweit diese Formen zeitnaher Interpretationen zumindest der poetischsurrealen Diktion von Özdamars Text und ihrem verfremdenden Stil gerecht geworden sind oder nicht, hat die neuere Forschung bereits eindrücklich gezeigt. ${ }^{249}$ Erste und viel zitierte Arbeiten, in denen vor allem die Poetologie Özdamars im Vordergrund steht und nicht die Frage nach der Repräsentation des Orients, haben Kader Konuk, Ottmar Ette und Hansjörg Bay vorgelegt. Mit ihrem Karawanserei-Roman dekonstruiere Özdamar die Vorstellung einer starren Heimat und Kultur durch ihre verfremdende Poetologie und setze an ihre Stelle eine Hybridität, die nicht einfach für eine Vermischung der Kulturen steht. Vielmehr ebnet nach Konuk ihr Erzählen einen Weg für den Leser, der »Polariäten, bzw. dualistische Prinzipien wie das der Heimat versus Fremde bzw. eingeboren versus eingewandert (oder Selbst versus Andere) auflöst «. ${ }^{250}$ Für den Romanisten Ottmar Ette steht Özdamars Roman zum einen für eine besondere Spielform des Literarischen, zum anderen ist sie zugleich ein Wissensspeicher für neuere Formen transkulturellen Lebens. ${ }^{251}$ Und für den Germanisten Hansjörg Bay praktiziert Özdamar in ihrem Karawansereiroman ein

in Germany«. In: Turkish Culture in German Society Today, hg. v. David Horrocks, Eva Kolinsky, Oxford: Berghahn Books, S. 45-54.

247 BRöCKERS, Mathias (1991): »Irgendwohin. Irgendwoher. Wir nicht. Zum diesjährigen Ingeborg-Bachmann-Wettbewerb in Klagenfurt«. In: die tageszeitung, 03.07.1991, S. 15.

248 WiERSCHKE, Annette (1996): »Auf den Schnittstellen kultureller Grenzen tanzend. Aysel Özakın und Emine Sevgi Özdamar«. In: Denn du tanzt auf einem Seil. Positionen deutschsprachiger MigrantInnenliteratur, hg. v. Sabine Fischer, Moray Mcgowan, Tübingen: Stauffenberg, S. 179-194, hier S. 190.

249 Siehe hierzu: Konuk (1998); Bay (1999); MAguiRe, Nora (2013): »Reading and Writing the Child's Voice in Emine Sevgi Özdamar's >Das Leben ist eine Karawanserei hat zwei Türen aus einer kam ich rein aus der anderen ging ich raus` (1992)«. In: Forum for Modern Language Studies Vol. 49, No. 2, S. 213-220. KAISER, Birgit Mara (2014): "A new German, singularly Turkish. Reading Emine Sevgi Özdamar with Derrida's `Monolingualism oft he Other«. In: Textual Practice Vol. 28, No. 6, S. 969-987.

250 KonuK, Kader (1998): »Das Leben ist eine Karawanserei. Heimat bei Emine Sevgi Özdamar«. In: Kein Land in Sicht. Heimat - weiblich?, hg. v. Gisela Erker, München, S. 143-158, S. 158.

251 Siehe hierzu: EтTE, Ottmar (2004): ÜberLebenswissen. Die Aufgabe der Philologie, Berlin: Kadmos, S. 227-252. 
Erzählen, indem »die Grenze zwischen Wahrheit und Lüge, Realismus und parodistischem Spiel, ,echter` Übersetzung und bloßem Sprachwitz nicht auszumachen « ist. ${ }^{252}$ Und wer in der Rezeption in ihrer Literatur eindeutige Fremdheit oder gar den Orient meint zu sehen, »verfällt [...] dem exotischen Klischee der fremden Fülle». ${ }^{253}$

Mich interessiert weniger, diese Lesarten erneut literaturwissenschaftlich zur Disposition zu stellen, als vielmehr an dieser Stelle zunächst festzuhalten, dass mit Özdamars Roman Anfang der 1990er Jahre eine besondere Konstellation von Fiktion und Wahrheit, von Sprechen und Hören deutsch-türkischer Provenienz, also eine neue Form der Verhandlung der Migration und ihrer Folgen in Literatur und Film ins Spiel kommt. Sie steht nicht nur für eine komplexe und hybride Poetisierung von Migration und Integration, wie viele Forschungsarbeiten von den 1990ern bis heute meinen. In ihrem Zentrum stehen mit der Ich-Erzählerin und der Autorin die Einsicht und Praxis, dass das Erzählen als Erfindung selbst die Grundlage jeder Partizipation, allen weitersprechens ist und nicht das gleichgültige oder liebevolle Empfangen auf der Schwelle. Letzteres ist den Begegnungen der 1980er Jahre eigen. ${ }^{254}$ Dieser besondere Akzent auf der Erzählung ist im Zusammenhang der Bearbeitung der deutsch-türkischen Migration neu und verlangt eine bestimmte Form der Kommunikation und Rahmung.

In Sten Nadolnys Roman Selim oder die Gabe der Rede von 1989 ist diese Struktur ebenfalls zu erkennen. Darin konstruiert der türkische Protagonist Selim, der wie Özdamars Erzählerin zur ersten Gastarbeitergeneration gehört, die Wahrheit durch sein Erzähltalent selbst. Zur Grundlage seiner Fabulier- und Erfindungskunst gehört, folgt man dem deutschen Erzähler Alexander, dass Selim in der Türkei ein erfolgreicher Ringer war. Mit solch einer Verbindung von körperlicher und kreativer Virtuosität kann der deutsche Protagonist und Erzähler nicht aufwarten. Er möchte aber das Reden lernen und erklärt in der erzählten Zeit des Romans Anfang 1970er Jahre Selim zu seinem Lehrer. ${ }^{255}$ Beide hatten sich auf einer Zugfahrt in Deutschland kennengelernt, ohne ein Wort miteinander gewechselt zu haben. Später treffen sich beide wieder, werden Freunde und Alexander beginnt, einen Roman über Selim zu schreiben und dabei zugleich von ihm die Redekunst zu erlernen. Gegen Ende des zweiten Drittels des Romans kehrt Selim nach einer abgesessenen Haftstrafe in Deutschland in den 1980er

252 BAY (2001): S. 45.

253 Ebd., S. 42.

254 Siehe in diesem Zusammenhang zum Film in den 1980er Jahren: HickETHIER, Knut (1995): »Zwischen Abwehr und Umarmung. Die Konstruktion des anderen in Filmen«. In: 〉Getürkte Bilder. Zur Inszenierung von Fremden im Film, hg. v. Ernst Zapf, Marburg: Schüren, S. 21-40.

255 Nadolny (1989): Selim oder die Gabe der Rede, München: Piper, S. 9. 
Jahren in die Türkei zurück. Im letzten Teil des Romans sterben Selim und sein Sohn bei einem Autounfall, sie waren unterwegs zum Flughafen, um Alexander abzuholen, der zur Hochzeit von Selims Schwester eingeladen ist. Alexander lässt ihn jedoch als Romanfigur weiterleben und die Hochzeit findet statt. Denn der Erzähler stellte im Laufe seiner Biografie und der deutschen Geschichte, genauer in den 1980er Jahren, fest, dass Selim ein Phantom war, das Alexander »mehr erdacht als verstanden« hatte. »Das stört mich nicht. Der Irrtum war vielleicht besser als die Wahrheit«, räsoniert Alexander. ${ }^{256}$ Reden, Erzählen und Erfinden tragen maßgeblich zum Gelingen einer Geschichte in Nadolnys Roman bei. Zugleich ermöglicht dieser Zugang aber auch, deutsche Geschichte und eine gesellschaftliche Wirklichkeit zu erfassen. Als Nadolnys Erzähler Alexander in den 1960er Jahren in sich hineinhorcht, hört er »nur Gefasel«, das er nicht herauslässt. Auch in seinem Studium während der 1960er und 1970er Jahre sei es nur um die »Verklemmungen der Gesellschaft « gegangen. ${ }^{257}$ Wenn in den Seminaren »einer etwas sagen wollte, mußte er energisch `Direkt dazu! « rufen, sonst kam er nicht durch. Was er dann lieferte, war meist nicht direkt, sondern so verzwickt, daß er auch wieder zu den Hosen paßte«, die der Sprecher trug. ${ }^{258}$ Der Erzähler liest damals Jürgen Habermas' Buch über den Strukturwandel der Öffentlichkeit. Worin dieser Strukturwandel besteht, gibt der Erzähler selbst nicht wieder. Vielmehr merkt er sich, dass diese Zeit aufgrund ihrer mangelnden Unmittelbarkeit dafür verantwortlich ist, dass er kein Erzähler ist. Als er sich eine Weile mit Selim über Politik unterhält, erkennt Alexander: »[D]ieser Mann hatte einiges, was ihm selbst fehlte «. ${ }^{259}$ Mit Selim entdeckt er, dass Konsens nur möglich ist, wenn man weiß, dass es ihn eigentlich gar nicht gibt. So entdeckt Alexander das Erzählen als die Substanz aller Rede, die er zu Beginn der 1960er Jahre an deutschen Universitäten und bei der deutschen Bundeswehr zu erlernen suchte. Die Universitäten waren zu verquast, und beim Bund hörte er nur von anderen deutschen Soldaten, dass es nach Adolf Hitler keinen deutschen Redner mehr geben könne. »Er war nämlich der beste darin. ${ }^{260}$ So ist Nadolnys Roman »nicht nur eine 500 Seiten starke Liebeserklärung an den Titelhelden [Selim, Ö.E.], sondern auch ein Zeitroman über ein Vierteljahrhundert deutscher Geschichte, der bis in die unmittelbare Gegenwart führt «. ${ }^{261}$ Das Gelingen dieser Geschichte ist wesentlich

256 NADOLNY (1989): S. 9.

257 Ebd., S. 31.

258 Ebd., S. 200.

259 Ebd., S. 204.

260 Ebd., S. 93.

261 TRAUB, Rainer (1990): »Ein türkischer Winnetou«. In: DER SPIEGEL, 2/1990, S. 153-155, hier S. 154. 
davon abhängig, dass Alexander zu reden, zu erzählen und zu erfinden lernt. Denn über den Türken Selim habe er erfahren, wie er ein anderer werden könne. Während des Rückflugs aus der Türkei nach Deutschland besteht für kurze Zeit die Gefahr eines Flugzeugabsturzes. Alexander fragt sich in diesem Moment, wie Selim in dieser Situation reagieren würde. ${ }^{262}$ Ein von Selim oft angebrachte türkische Redewendung kommt ihm in den Sinn: »takma kafana tokadan başka birşey«. Dieser fremde Satz beruhigt ihn so sehr, dass er ihn auch den anderen Passagieren mitteilt, die er damit ebenfalls beruhigt. Wörtlich übersetzt bedeutet die Redewendung, dass man sich nichts an den Kopf stecken sollte außer einer Haarspange. Alex übersetzt sich selbst diesen Satz mit dem englischen »never mind«, weiß aber genau, dass das nicht stimmt. Dass dieser Gedanke ihn und die anderen Passagieren dennoch beruhigt, zeigt ihm, dass er noch nicht alles über sich weiß und dass dieser Umstand eine Chance für sein zukünftiges Leben und indirekt auch allgemein für die Bundesrepublik bedeutet. ${ }^{263}$ Diese Chance speist sich daraus, dass im anderen das Eigene steckt und im eigenen das Andere. Man muss diesen Gedanken nicht verstehen, sondern ihn sich nur vorstellen können.

In den besprochenen Romanen von Nadolny und Özdamar begegnet uns eine besondere Form der Verständigung. Sie zeigt, dass mit Lebensläufen und Kulturen etwas passiert, wenn sie in einer Zeit erzählt und zu Gehör gebracht werden, deren Kommunikationszusammenhang sich immer wieder verschoben hat wie in der Geschichte der Deutschen, aber auch der Türken in der BRD. In den 1990er Jahren werden die türkische Migration nach Deutschland und ihre Folgen besonders energisch thematisiert. Özdamars Roman sowie andere Texte und Filme legen dabei nahe, dass die Unterscheidung zwischen wahr und falsch für die Lebenswirklichkeit der Migranten in Deutschland nicht mehr greift. Diese Verschiebung ist mir einer Kritik und einem spezifischen Mangel an Repräsentation verbunden. Denn mit dem Beginn der 1990er Jahre wird das bisherige Leitmotiv der türkischen Migranten, »Nächstes Jahr kehren wir zurück«, als wichtige Kategorie der Identitätsbestimmung äußerst fragil. Obwohl die Rückkehr zur Illusion wird, bleibt das Verhältnis zur Türkei konstitutiv - es ist nur von der lebenswirklichen Ebene auf eine poetisch-narrative gerutscht. ${ }^{264}$

262 Ebd., S. 474.

263 Ebd., S. 494-497.

264 Auf diese besondere Einwanderungssituation der Türken in Deutschland machen viele Publikationen und Aufsätze aufmerksam. Siehe etwa: MincIYAZGAN, Ursula (1989): »Rückkehr als Metapher. Die Bedeutung der Rückkehr in der Lebensplanung und -praxis türkischer Migrantinnen«. In: Informationsdienst zur Ausländerarbeit, H. 4. 1989, S. 39-42. Siehe auch: PAGENSTECHER, Cord (1996): „Die >Illusion` der Rückkehr. Zur Mentalitätsgeschichte von `Gastarbeit und Einwanderung«. In: Soziale Welt, 47 (2), S. 149-179, S. 168. Siehe auch: SCHIFfaUER (2004). 
Dieser Neuerung, die Deutsch und Türkisch nicht mehr voneinander trennt, sondern miteinander verbindet, wovon auch Nadolnys Roman handelt, fehlt wiederum integrationsbedingt eine Entsprechung im öffentlichen Raum. Die politisch repräsentative sowohl türkische als auch deutsche Seite hält diese Trennung aber weiter aufrecht; das zeigt sich schon in der Änderung des Ausländergesetzes. In den öffentlichen Debatten ist zwar von multikultureller Gesellschaft und Anerkennung die Rede, was aber genau anerkannt werden soll und um was für eine Kultur es sich dabei handelt, ist im Unterschied zu den 1980er Jahren theoretisch offen, weil diese Frage nicht mehr in die Vergangenheit, sondern in die Zukunft gestellt wird. Diese Ungenauigkeit und Offenheit ist auch in der Interpretation künstlerischer und dokumentarischer Werke deutsch-türkischer Provenienz zu erkennen.

Mich interessiert in den folgenden Analysen dieses Kapitel also erneut die Frage, warum deutsch-türkische Literatur und Film, die in den 1990er Jahren interessant bis sehr anspruchsvoll und in der Darstellung unterschiedlicher Kulturen ungemein irritierend sind und bewusst sunerhört duktionen eines Kulturdialogs auf unterschiedlichsten Ebenen gelesen werden; warum etwa in Buchbesprechungen von »westlichem Bewusstsein « oder »orientalischem Märchen « die Rede ist; oder warum man meint, das in Özdamars Roman deutsch geschrieben, aber türkisch empfunden werde oder dieser Roman über das türkische Volk und seine Lebensart ein besseres Zeugnis ablege als jede ethnologische Forschung, obwohl der Text augenscheinlich durchgehend mit surrealen Beschreibungen und "verfremdenden Übertreibungen « arbeitet. $^{265}$ Schon die ersten fünf Seiten in Özdamars Roman strafen diese kurz dargestellten zeitnahen Reaktionen auf Das Leben ist eine Karawanserei Lügen. Das übersetzbare Verhältnis, das wir zwischen Hark Bohms Film YASEMIN und der ethnologischen Forschung von Werner Schiffauer in den 1980er Jahren ausfindig machen konnten, scheint hier kein wechselseitiges mehr zu sein. Ohne Fiktion scheint es keine kulturelle >Wahrheit` mehr zu geben. Dass die kurz skizzierten Interpretationen keine Ausnahmen sind, zeige ich an den Interpretationen der Literatur Zafer Şenocaks und den Filmen Fatih Akıns und Thomas Arslans.

265 Siehe hierzu: AYTAÇ, Gürsel (1997): »Sprache als Spiegel der Kultur. Zu Emine Sevgi Özdamars Roman Das ist eine Karawanserei«. In: Interkulturelle Konfigurationen. Zur deutschsprachigen Erzählliteratur von Autoren nichtdeutscher Herkunft, hg. v. Mary Howard, München: iudicium, S. 171-177, hier S. 175 u. S. 176. BüsleR, Bettine (1992): »Ihr Deutsch klingt wie Türkisch«. In: BERNER ZEITUNG, 30.10.1992, zitiert nach: AYTAÇ (1997): S. 175. BACHMANN, Angela (1992): »Scheherezades Schwester«. In: Augsburger Allgemeine Zeitung, 02.02.1992, zitiert nach: AYTAÇ (1997): S. 175. 
Diesen Fokus auf die Übersetzung finden wir auch in den poetischen Reflexionen Yüksel Pazarkayas zu seinen Gedichten aus den 1990er Jahren. Er bezieht sich dabei besonders auf Walter Benjamins Text »Die Aufgabe des Übersetzers«, in dessen Zentrum die These steht, dass die Sprache sich selbst mit-teile, aber nicht wirklich etwas repräsentiere. ${ }^{266}$ Übersetzen und Sprechen vermitteln also nicht Gegebenes, sondern das Gegebene und Vorliegende ist der Akt der Mit-Teilung selbst. ${ }^{267}$ Denn was vermeintlich gegeben ist, scheinen ja alle genau zu wissen, nämlich wo die Grenzen zwischen Orient und Okzident verlaufen. Es geht nicht mehr darum, wie Spivak in den 1980er Jahren noch festgehalten hat, dem Individuum eine Stimme zu verleihen und ihm Gehör zu verschaffen, weil es etwas Vermittelndes von a nach b gibt. ${ }^{268}$

In jedem Fall führt die besondere Konstellation von Fiktion und Wahrheit zu einer neuen Rahmung der Begegnung von eigen und fremd. So hält etwa die Autorin Renan Demirkan in ihrem zeitgleich entstandenen Roman Schwarzer Tee mit drei Stück Zucker fest, nichts mehr "unausgesprochen zu lassen « ${ }^{269}$. Diese neue Konstellation ist Ausdruck einer neuen Struktur von Authentizität, die auf »verfremdende Übertreibung ${ }^{270}$ und Fiktion angewiesen ist. Im Widerspruch zu Multikulturalismus- und postkolonialen Theorien ist das Subjekt hier nicht Fix-, sondern Ausgangspunkt für einen Prozess sich verändernder Identifikationen. ${ }^{271}$ Vergleichbar konstatiert Yüksel Pazarkaya, dass es in der Sprache nichts gebe, das »nicht veränderbar« wäre. ${ }^{272}$ Man ist nur authentisch, wenn man offenkundig lügt, erfindet, Regeln bricht und übersetzt. Selbst die nationale Kollektivierung eines Phänomens wie der Muttersprache wird unter dieser Perspektive $\mathrm{zu}$ einem »Willkürakt«, denn Muttersprache könne nur »individuell bedeutungsvoll sein «. ${ }^{273}$ Denn das Verlangen nach einer neuen Begegnungsstruktur

266 Siehe hierzu: Pazarkaya (2000): S. 22; Benjamin, Walter (1972): »Die Aufgabe des Übersetzers«. In: ders., Gesammelte Schriften Bd. IV/I, Frankfurt a. M.: Suhrkamp, S. 9-21.

267 Siehe hierzu: NANCY, Jean-Luc (1994): »Das gemeinsame Erscheinen. Von der Existenz des `Kommunismus` zur Gemeinschaftlichkeit der `Existenz`. In: Gemeinschaften. Positionen des Politischen, hg. v. Joseph Vogl, Frankfurt a. M.: Suhrkamp, S. 167-204, hier S. 192.

268 Siehe hierzu: SPIVAK (2007): S. 53.

269 DEMIRKAN (1991): S. 35.

270 BAY (1999): S. 44.

271 Vgl. KAISER, Birgit Mara (2014): »A new German, singularly Turkish. Reading Emine Sevgi Özdamar with Derrida’s >Monolingualism of the Other«. In: Textual Practice Vol. 28, No. 6, S. 969-987, S. 973. Siehe hierzu programmatisch auch: Hall, Stuart (1996): »Who needs $>$ Identity«? «. In: Questions of Cultural Identity, London: Sage, S. 1-17.

272 PAZARKaya (2000): S. 45.

273 Ebd., S. 40. Die Literaturwissenschaftlerin Mary Howard hält in diesem Zusammenhang fest, dass nicht mehr der »Akt der Migration « oder die migrierenden Akteure im Zentrum stehen, 
gilt in unserem einleitenden Beispiel nicht nur der Mutter gegenüber, sondern der Begegnung, dem Lesen und Hören an sich. Diese neue Konstellation ist mit unterschiedlichen künstlerischen Herangehensweisen, die sich jedoch alle auf den Körper des Migranten konzentrieren, in Literatur und Film der 1990er Jahre ausschlaggebend. ${ }^{274}$ Dabei hat sie nicht nur mit einer neuen Künstler-Generation zu tun; sie findet sich etwa in den zu besprechenden Texten von Emine Sevgi Özdamar ( $\left.{ }^{\star} 1946\right)$ und Zafer Şenocak ( $\left.{ }^{\star} 1961\right)$. Vor der Materialanalyse möchte ich kurz den Inhalt des Romans Das Leben ist eine Karawanserei zusammenfassen.

Die erzählte Zeit des Romans erstreckt sich vom Sein als Embryo der Protagonistin und Ich-Erzählerin des Romans Mitte der 1940er Jahre in der türkischen Provinz bis zu ihrem 19. Lebensjahr, als sie von Istanbul in die Bundesrepublik aufbricht, wo sie als Gastarbeiterin arbeiten möchte. Dazwischen erzählt Özdamar eine Migrationsgeschichte innerhalb der Türkei, die

"sondern die Folgen des Übergangs in eine fremde Situation werden gezeigt, in der das erzählte Subjekt sich und die Welt in veränderter Sicht wahrnimmt«. Siehe hierzu: HowARD, Mary (1997): »Einleitung«. In: Interkulturelle Konfigurationen. Zur deutschsprachigen Erzählliteratur von Autoren nichtdeutscher Herkunft, hg. v. Mary Howard, München: iudicium, S. 7-15, S. 11.

274 Interessanterweise gibt es auch in den 1990er Jahren außer Sinan Çetins BERLIN IN BERLIN (der bekanntesten türkischen Reflexion jener Zeit) und zwei tatsächlich kaum nennenswerten Filmen im Unterschied zwischen den 1960er und 1980er Jahren keine türkische künstlerische Auseinandersetzung mit der türkischen Migration nach Deutschland und ihren Folgen. Neben BERLIN In BERLIN handelt es sich dabei um die Filme BIR UMUt uğRuna (Für eine Hoffnung, 1991) und KADERsiz DoğMuşum (Ohne Schicksal wurde ich geboren, 1991). Erst mit der Komödie BERLIN KAPLANI von 2012 ist türkische Migration nach Deutschland und ihre Folgen für das türkische Fernsehen und Kino wieder ein Thema. Obwohl Integration und Multikulturalismus in den 1990er Jahren in der Bundesrepublik äußerst virulent waren, führt Ersel Kayaoğlu als Hauptgrund für das fehlende türkische Interesse in den 1990er und 2000er Jahren an, dass das türkische Kino in den 1990ern komplexere Erzählformen entwickelt habe, »die das Heranziehen der Deutschlandmigration als bloßen Ausgangspunkt, als Auslösemechanismus für ein tragisches Ende bzw. als Dramatisierungsmittel nicht mehr zulassen «. Siehe hierzu: KAYAoğLU, Ersel (2012): »Figurationen der Migration im türkischen Film«. In: 51 Jahre türkische Gastarbeitermigration nach Deutschland, Türkisch-Deutsche Studien, Jahrbuch 2012, hg. v. Şeyda Ozil, Michael Hofmann, Yasemin Dayığlu-Yücel, Göttingen: V\&R unipress, S. 81-104, hier S. 101. Ich denke, dass der zentrale Grund eher darin liegt, dass die Kategorie der territorialen Herkunft in der Thematisierung von Migration in den 1990er Jahren obsolet wird und genau dieser Umstand für das türkische Desinteresse verantwortlich ist. Um der Bindung des Türkischen und Deutschen in den 1990er Jahren gerecht zu werden, müssen diese Reflexionen, wie in den deutsch-türkischen Film vor Ort in der Bundesrepublik stattfinden. Tatsächlich spielen auch die drei einzigen türkischen Filme zu Beginn der 1990er Jahre ausschließlich in Deutschland. Interessant an allen drei Filmen ist, dass sie sich wie in den 1980ern als zentrale Austragungsorte auf geschlossene Räume konzentrieren und nicht wie die Werke von Fatih Akın, Yüksel Yavuz oder Ayşe Polat auf den Straßen spielen. 
zeitlich die 1950er und 1960er Jahre umfasst. Denn die Familie der Ich-Erzählerin muss immer wieder umziehen, weil der Vater oft den Job verliert und immer von Neuem sein Glück und das der Familie suchen muss. ${ }^{275}$ Der erste Umzug führt die Familie von Istanbul in eine Kleinstadt, aus einem säkularen Umfeld in eine »religiöse Straße«. Die Erzählerin staunt darüber, dass die Mutter nun auf der Straße oder wenn sie zu Hause Besuch empfangen, ein Kopftuch trägt. ${ }^{276}$ Innerhalb dieser Stadt zieht die Familie erneut um, diesmal in ein Bürokratenviertel. Dort legt die Mutter das Kopftuch im öffentlichen wie privaten Raum wieder ab, da die Menschen, die hier leben, kemalistisch geprägte Laizisten sind. ${ }^{277} \mathrm{Als}$ der Vater seinen Job als Bauingenieur verliert, zieht es die Familie Anfang der 1950er Jahre nach Bursa, die erste Hauptstadt des Osmanischen Reiches. Dort lebt sie länger, sodass hier ein Großteil der Sozialisation der Ich-Erzählerin stattfindet - insbesondere auf den Straßen des neuen Viertels. Dieser Abschnitt im Migrationsleben der Familie nimmt mehr als ein Drittel der Erzählzeit des Romans ein. Darauf folgt ein erneut arbeitsbedingter Umzug der Familie in das steppenhafte Umland der Landeshauptstadt Ankara, wo sie nicht lange bleiben, sondern sich in der Stadt niederlassen, in einer Wohnung in der »unbarmherzige[n] Grabmalstraße zwischen Erdgeschoss und Keller «. ${ }^{278}$ Schon der Straßenname prophezeit, dass die Zeit in Ankara unglücklich verlaufen wird: Mutter und Erzählerin werden krank, beide unternehmen Selbstmordversuche. Nach einem neuen kurzen Arbeitsverhältnis des Vaters im äußersten Osten der Türkei zieht die Familie dann schließlich von Ankara zurück nach Istanbul in eine neue Wohnung, wo die Ich-Erzählerin dann erst beschließt, als Arbeiterin nach Deutschland zu gehen.

Zwei Aspekte des Romans fallen nun besonders auf: Binnenmigration und sozial-kulturelle Heterogenität. ${ }^{279}$ Interessant ist, wie expansiv und übergreifend Migration diesen Roman bestimmt und wie sie dargestellt wird. Allein die Umzüge der Familie von Stadtteil zu Stadtteil und von Stadt zu Stadt erfolgen für die Ich-Erzählerin, die Leserin und den Leser des Romans unvorbereitet und abrupt. Als sie von Istanbul in eine »religiöse Straße« ziehen, reden Eltern und Tochter noch über einen Kinobesuch, im nächsten Absatz kommt der Vater mit einem Taxi nach Hause und sie ziehen schon wieder um. Im Taxi fällt die Erzählerin »mit Benzingeruch in den Schlaf», und sie wacht »in einem anderen Holzhaus

275 Vgl. MeCKLENBurg (2008): S. 516.

276 Siehe: ÖZDAMAR (1992): S. 33.

277 Ebd., S. 42.

278 Ebd., S. 318.

279 Siehe hierzu auch: BAY (1999): S. 39. 
in der Kleinstadt auf «. ${ }^{280}$ Kommentiert und begleitet wird dieser Umzug während der Taxifahrt, der auf einer knappen Seite beschrieben wird, in hier noch widersprüchlichen Aussagen der Großmutter. Sie sei an dem Ort, den sie nun verlassen, nur »einmal gestorben«, in der Fremde werde sie aber »jetzt tausendmal sterben «. Sofort relativiert sie diese »schweren Sätze«: »Ach, was weiß ich, was ist der Mensch? Der Mensch ist ein Vogel, machst du die Augen auf, bist du da, machst du die Augen zu, bist du dort «. ${ }^{281}$ Auch beim nächsten Umzug werden die Augen einmal geschlossen, wieder geöffnet und der Umzug ist bereits vollzogen: »Ich bin wach geworden in einer Gasse in Bursa, im dritten Stock eines Steinhauses. ${ }^{282}$

Diese schlagartigen Szenenwechsel werden durch die Erzählweise und die Mobilität der Akteure zu fluiden Übergängen im Roman, die die ganze Familie betreffen. Sie bestimmen auch lange das Verhältnis der Ich-Erzählerin zum öffentlichen Raum. Sie hält sich entweder selbst oft auf den Straßen ihres Wohnviertels auf, beobachtet die Nachbarn, spricht mit ihnen, oder sie besucht mit ihrer Mutter und Großmutter die Grabstätten muslimischer Heiliger bzw. in Ankara das Mausoleum Atatürks. Die republikanisch-nationale Bestattung ist anders als die der Sultane. Die Räume und Zimmer der Sultane »waren wie für Nomaden gemacht. Wenn sie gestorben waren, standen ihre Särge einfach in einem Zimmer, mit sehr schönen grünen Tüchern bedeckt «. ${ }^{283}$ Atatürk bekam hingegen ein Mausoleum. Das regelrechte Ablaufen alltäglicher und zugleich historischer Topografien zeigt, dass auch Kulturen und Nationen sterben können oder wie die Protagonistin in einem Überlebenskampf stehen. ${ }^{284}$

Ausgangspunkt dieser kulturellen Fließbewegung ist, dass nicht nur Räume und Orte durchlässig und von Ambiguität geprägt sind, sondern auch die Körper der Akteure. ${ }^{285}$ In Özdamars Kunstsprache, die viele Begriffe aus der türkischen Alltagssprache - etwa Redewendungen - entlehnt, sagen die Frauen, sie würden »sich die Würmer« ausschütteln oder sich »lüften«, wenn sie nach draußen

280 ÖZDAMAR (1992): S. 65.

281 Ebd.

282 Ebd., S. 115.

283 Ebd., S. 315.

284 Tatsächlich kündigen in den 1990er Jahren viele Publikationen im Kontext von »Postmoderne« oder einer »Zweiten Moderne« das Ende des Nationalstaats an. Siehe für viele hierzu: ZüRN, Michael (1998): Regieren jenseits des Nationalstaates, Frankfurt a. M.: Suhrkamp. Der »finite Charakter« des Nationalstaats ist auch in Bhabas Hybriditätstheorie konstitutiv. Siehe hierzu: Внавна (2000): S. 225.

285 Siehe hierzu auch: BAY (1999): S. 33. In der Analyse der Ambiguität der Orte konzentriert Bay sich auf die Badehausszenen in Özdamars Roman. 
gehen. ${ }^{286}$ Als die Ich-Erzählerin am Ende des Romans nach Deutschland aufbricht, beruhigt die Großmutter die besorgte Mutter, dass sie »sich in Alamania ein bißchen lüften« und danach wieder zurückkehren werde. ${ }^{287}$ Deutschland scheint dabei nicht weiter entfernt zu sein wie eine in der Nähe liegende türkische Stadt, in die man rasch umziehen könnte. An anderer Stelle meinen ältere Frauen, dass die Ich-Erzählerin in der Pubertät zu unbekümmert mit ihrer "Schachtel« spazieren gehe. ${ }^{288}$ In diese Phase fällt auch die Beschreibung der Mutter über ihre Tochter, dass sie glaubt, einen Jungen und nicht eine Tochter in die Welt gesetzt zu haben. "Sie hat nur eins im Kopf: die Straße. $\aleph^{289}$ Dass die Lebenspraxis der Protagonistin ihrer biologischen Identität vermeintlich widerspricht, spielt in wesentlichem Maße auch bei den Protagonistinnen und Protagonisten in Der Mann im Unterhemd (1995), Abschaum (1997), in GEschwisTER (1997), Der Erottomane (1999), AusLANDTOURneE (1999), Lola UND BiLIDIKID (1999) sowie Gegen die WAND (2003) der Autoren und Regisseure Zafer Şenocak, Feridun Zaimoğlu, Thomas Arslan, Ayşe Polat, Kutlu Ataman und Fatih Akın eine entscheidende Rolle. ${ }^{290}$

Neben den Straßen, Gassen und Plätzen, die auf fast jeder Seite entweder als Begriff oder als Setting des beschriebenen Geschehens stehen, nehmen auch Schwellenbereiche wie die Wohnungs- oder Haustür, viele Brücken oder aber die Position der Erzählerin am Fenster wichtige topografische Funktionen ein. ${ }^{291}$ Sitzend beschreibt sie ihrer Großmutter, die sich innerhalb der Wohnung befindet, und letztlich dem Leser, was sie draußen in der »steinigen « und »seelenlosen Gasse« in Bursa sieht. Was Özdamar dabei entfaltet, ist in surreal-poetischer Diktion ein Kaleidoskop einer widersprüchlichen türkischen Alltagswelt. Sie

286 Sich »die Würmer ausschütteln«, türkisch kurtlarmı dökmek, heißt so viel wie »sich vergnügen«. Die sprichwörtliche Übersetzung von »lüften gehen« geht auf die Wendung »hava almak« zurück, was so viel bedeutet wie »hinausgehen« oder wortwörtlich »Luft zu sich nehmen«. Die wortwörtlichen und Lehnübersetzungen Özdamars in ihrem Karawanserei-Roman haben dazu geführt, dass die Reaktion türkischer Leser auf die türkische Übersetzung aus dem Deutschen enttäuschend ausgefallen ist; der Verfremdungseffekt fehlte. In der erzählerischen Praxis wie auch in der unterschiedlichen Rezeption zeigt sich eindeutig, dass der Ort der Auseinandersetzung und der Selbstverhandlung die deutsche Sprache ist, sozusagen die Ankunftsgesellschaft. Siehe hierzu: KuRUYAZICI, Nilüfer (1997): „Emine Sevgi Özdamars Das Leben ist eine Karawanserei im Prozess der interkulturellen Kommunikation«. In: Interkulturelle Konfiguration. Zur deutschsprachigen Erzählliteratur von Autoren nichtdeutscher Herkunft, hg. v. Mary Howard, München: iudicium, S. 179-188, S. 184. Siehe auch AYTAÇ (1997).

287 ÖZDAMAR (1992): S. 371.

288 Ebd., S. 220. Mit »Schachtel« ist die Vagina gemeint.

289 Ebd., S. 218.

290 Siehe hierzu: Polat (1999). ŞENoCAK (1995, 1998, 1999). KutLuCAN (1998). AKIN (2003/2004). 291 In APRILKINDER sehen wir sehr oft eines der Geschwister die Wohnung verlassen. Die Schwelle ist auch bei Sinan Çetin konstitutiv. Siehe hierzu: ÇETIN (1993); YAVUZ (1998). 
beobachtet muslimisch-konservative Frauen, die »kiloweiße wie Blei schwere» weiße Mäntel tragen, die sie nach ein »paar Schritten bis zum gegenüberliegenden Steinhaus zum Schwitzen« bringen. Auch wenn sie schon in ihren Häusern wieder verschwunden sind, bleiben »ihre Rockschatten, ihre langsamen Bewegungen, [...] vor meinen Augen auf der steinigen Gasse wie schlecht abgewischte Kreidezeichen «. ${ }^{292}$ Langsam und schwer tragen sie auch an den »sehr großen Wassermelonen in ihren Händen«. Dabei tragen sie ihre Einkäufe so, »daß die anderen Menschen das sehen und denken, wie schwer es für diese Frauen ist, diese Wassermelonen zu tragen«. Der Vater der Erzählerin meint, dies seien Frauen, die beim Sitzen »ihre Hände in ihren Händen und beide Hände über ihren Schachteln« halten. ${ }^{293}$ Die Erzählerin sitzt am Fenster und stellt sich vor: Wenn ein Schiff kommen würde, das »diese Frauen in sich aufnimmt und wegfährt, werden diese Frauen den Kapitän [...] nicht fragen, wohin «. ${ }^{294}$

Angekommen sind hingegen die »verrückten« Frauen in den Gassen Bursas. Sie treten im Unterschied zu den verschleierten Frauen freizügig und mit Eigennamen auf. Unter ihnen sind die »verrückte Saniye«, eine Emigrantin aus Jugoslawien, die »deli Ayten «95 $^{295}$ und Tante Sidıka, der es »ein bisschen besser geht als einem Schwiegersohn, der bei seinen Eltern leben muss «. ${ }^{296}$ Sie stehen der existenziellen Traurigkeit des Kollektivs der mit Kleidung und Einkäufen schwer beladenen Frauen entgegen. Die verrückte Saniye ist häufig lautstark zwischen der »steinernen« und »seelenlosen Gasse« unterwegs, und besonders in der "seelenlosen Gasse« zeigt sie den Reichen mit der Hand über dem Kopf als eine Geste des sich

292 ÖZDAMAR (1992): S. 120.

293 Ebd., S. 119.

294 Ebd. Das Herauskommen aus den gegebenen Lebensbedingungen ist eine Bewegung, die sich durch viele Texte und Filme der 1990er Jahre - ob deutsch-türkisch oder deutsch - zieht. In Akıns KuRz Und SCHMERzLos von 1998 möchte der deutsch-türkische Protagonist Hamburg verlassen. Obwohl er sich dort sicher und zugehörig im öffentlichen Raum bewegt, will er in der Türkei ein Strandcafé eröffnen. Von Paris an den Strand von Goa möchten in einer ähnlich widersprüchlichen integrativen Konstellation wie in Akıns Film auch die Protagonistinnen im französischen Film L'Honneur DE MA FAMILle (dt. Die EHRE MEINER FAMILIE), der ebenfalls 1998 in die Kinos kam. Und auch im deutschen Komödienhit LAммвоск von 2001 träumen die Protagonisten von einem Strandcafé im Süden. Doch keiner der Akteurinnen und Akteure landet in den drei Filmen dort, wo sie es sich vorgestellt haben. Sie bleiben bis zum Schluss wie die Protagonistin in Özdamars Roman, unterwegs zwischen Städten oder unterwegs in einer Stadt. Siehe hierzu: AKIN (1998); Bouchareb, Rachid (1996): L'honneur de ma famille, Frankreich: La Sept ARTE.

295 Deli bedeutet auf Türkisch »verrückt«; Ayten ist ein weiblicher, türkischer Vorname.

296 Ebd., S. 122 und 260. 
Schützens, was für einen Käse sie gekauft hat. ${ }^{297}$ Die »deli Ayten« fasst, nachdem sie einem Mann lasziv eine Zigarette abgerungen hat, in einer der Gassen »sein Ding an«, reckt ihm ihren Mund zu und sagt: »Lass mich dich einmal küssen «. ${ }^{298}$ Der Mann ist von dieser Situation eindeutig überfordert und ergreift die Flucht. ${ }^{299}$ Tante Sıdıka schließlich bohrt jeden Tag mit ihrem Zeigefinger »ein Loch in die Zeitung, wo das Bild von dem Ministerpräsidenten der Demokratischen Partei [Adnan Menderes, Ö.E.] abgedruckt ist«, und geht damit mit der Hand über ihrem Kopf in den Gassen spazieren, wie dieses Mal die Mutter der Ich-Erzählerin berichtet. ${ }^{300}$

Die Großmutter sieht diese »verrückten«, Grenzen überschreitenden Frauen der Straße als gerettet an, denn sie hätten unter »Allahs Flügeln« Asyl gefunden. ${ }^{301}$ Die anderen, schwer beladenen Frauen lösen zwar orientalische Assoziationen aus. Doch ihnen entgegen gesetzt sind nicht etwa modern gekleidete bürgerliche Frauen, die öffentlich von ihrer Vernunft Gebrauch machen würden und eine bestimmte Position im öffentlichen Raum innehätten. Den vermeintlich typisch muslimischen Frauen werden hier selbstbewusste, leicht bekleidete, aber zugleich »ver-rückte ${ }^{302}$, widerständige und die öffentliche Ordnung störende Frauen gegenübergestellt. ${ }^{303}$ So orientieren sich die Beobachtungen der Ich-Erzählerin, ob die Frauen sich »unterdrückt» durch die Schwere ihre Kleidung fühlen oder »frei« durch ihren erleichterten Körper werden, nicht an der großen unbestimmten Unterscheidung zwischen Orient und Okzident, sondern an der Frage, wie es sich in ihren Mänteln oder Häuten wohl lebt. Wie die Antwort auf diese Frage ausfällt, hängt sehr vom öffentlichen Auftritt der Frauen ab. Sind ihre Köpfe und Schultern gesenkt, wie bei den schwer beladenen Frauen oder nicht?

297 ÖzDAmar (1992): S. 170. Auch in Demirkans Romanen der 1990er binden die Protagonistinnen in öffentlichen Räumen durch ihr Sprechen und Handeln anfangs unbeteiligte Akteure in die jeweilige Situation ein. Siehe hierzu: DEMIRKAN (1991): S. 34-36.

298 In Rachid Boucharebs L'HONNEUR DE MA FAMILLE hat die Freundin der algerischstämmigen Protagonistin Nora zu Beginn des Films Sex beim Tanz mitten in einer Diskothek. Nora und ihre Freundin arbeiten heimlich in einer belgischen Diskothek, in die sie an Wochenenden immer fahren. Ihre Eltern denken, sie würden als Krankenschwestern in einem Pariser Krankenhaus arbeiten. Auch wenn es sich in Boucharebs Film um eine Komödie handelt, erzählt er doch von Identitätsstress. Die Protagonistin ist oft gereizt und fühlt sich am wohlsten im Bad ihrer Freundin. Siehe hierzu: Bouchareb (1996).

299 Ebd.

300 ÖZDAMAR (1992): S. 170.

301 Ebd., S. 136.

302 Siehe allgemein zu »verrückt« in Özdamars Roman BAY (1999).

303 In Andreas Dresens Film NACHTgestalten sind die Protagonisten ebenfalls randständige Figuren: Obdachlose, sich prostituierende drogenabhängige Jugendliche, ein farbiges Flüchtlingskind und ein von seinem Chef geplagter älterer deutscher Angestellter. Siehe hierzu: DRESEN (1999). 
Der lässige, coole oder außergewöhnliche Auftritt, den die »verrückten« Frauen bei Özdamar hinlegen, ist auch für die Darstellungsweise der kulturellen Bestimmung der Protagonistinnen und Protagonisten in den Filmen der 1990er Jahre elementar. ${ }^{304}$

Der Fokus auf den Körper sowie eine surreale Wahrnehmung der Realität bestimmen auch so manche Wege der Ich-Erzählerin, besonders in der Nähe von Brücken. »Als ich über die heilige Brücke in Richtung unserer steilen Gasse lief, gehörten meine Beine nicht mehr mir, ich hielt mich beim Gehen am Brückengitter fest, ich dachte, sonst werden meine Beine von der Erde fliegen und ich falle in den Bach. ${ }^{305}$ Die Unterscheidung zwischen schweren und leichten Körpern fällt auf. Konstitutiv ist auch, dass weder der eine noch der andere körperliche Zustand für ein Gleichgewicht oder einen Ausgleich zwischen Innen und Außen sorgen würde. Schwer wird die Protagonistin beispielsweise, wenn sie krank ist - und sie erkrankt bei fast jedem Umzug. Fast jedes Mal ist unklar, ob sie überleben wird. Wenn sie sich erholt, dann verlässt der Tod das Haus. ${ }^{306}$ Für die amerikanische Germanistin Nora Macguire zerschlagen die Krankheiten »the child's corporeal and subjective wholeness«, die »repeatedly collapses into fragmentary or plural states «. ${ }^{307}$

Eine andere wichtige Facette des Körperlichen ist in Özdamars Roman das Thema Sexualität, das von der Sprache über sexuellen Missbrauch bis zur isla-

304 Siehe hierzu exemplarisch folgende Filme von Fatih Akın, Matthieu Kassowitz, Thomas Arslan und die Romane von Feridun Zaimoğlu und Zafer Şenocak: AKIN (1998, 2003/4); KASsoWitZ (1995); ARSLAN (1997, 1999); ZAIMOĞLU $(1995,1997,1998)$; ŞENOCAK $(1995,1998)$.

305 ÖZDAMAR (1992): S. 207.

306 Siehe hierzu: Ebd., S. 113 u. S. 353.

307 MACGUIRE, Nora (2013): »Reading and Writing the Child's Voice in Emine Sevgi Özdamar's >Das Leben ist eine Karawanserei Hat zwei Türen Aus einer kam ich rein Aus der anderen ging ich raus «. In: Forum for Modern Language Studies Vol. 49, No. 2, S. 213-220. Auch in Polats Film AUSLANDSTOURNEE sind körperliche Dispositionen wie Menstruation und Krankheit der elfjährigen Protagonistin Şenay besondere Marker. Als sie mit ihrem »falschen« Onkel, dem homosexuellen Nachtclubsänger Zeki, auf der Suche nach ihrer »falschen« Tante Çiçek, Zekis Kollegin aus den 1980er Jahren, ist, bekommt sie in Paris ihre erste Menstruation. Sie glaubt zu sterben. Zeki organisiert daraufhin in Paris eine Prostituierte, die vor Şenay eine Ärztin spielt und ihr erklärt, was es mit der Menstruation auf sich hat. Als sie am Ende des Films in Istanbul Çiçek finden, die eigentlich Şenays Mutter ist, erkrankt Şenay im Hotel. Als Zuschauer haben wir Angst, sie könnte sterben, da auch ihre Mutter sich nicht um sie kümmern will. Doch Şenay genest und nachdem auch Zeki mit seiner Mutter, die er auf den Prinzeninseln besucht, keinen Frieden findet, machen sich Zeki und Şenay gemeinsam wieder auf den Weg nach Deutschland. Siehe hierzu: Polat (1999). 
mischen Geschlechterordnung entfaltet wird. ${ }^{308}$ Sogar die Ich-Erzählerin möchte einmal in ihrem Leben Prostituierte sein. ${ }^{309}$ Dieser Berufswunsch ist vollkommen anders motiviert als etwa Sibels Aussage in Fatih Akıns Film GEGEN DIE WAND, dass sie mit so vielen Männern wie möglich »ficken « wolle. ${ }^{310} \mathrm{Im}$ Gegenteil reizt sie die Beachtung und Anerkennung, die einer Prostituierten im Frauenbad, einem »Mösenplanet«, zuteil wird, in einem Alter, als sie noch nicht wissen kann, was es eigentlich bedeutet, eine Prostituierte zu sein.

Alle Frauen gingen hinter dieser Hure wieder in den Waschraum rein, setzten sich um den runden Marmorstein und schauten auf diese Hure, die sich in der Mitte des Marmorsteins legte und sich von zwei Badehausdienerinnen waschen ließ. Weder die Dienerinnen wurden satt sie zu waschen, noch die anderen Frauen, auf sie zu gucken. Wir gingen als lange Schlange hinter dieser Hure her aus dem Badehaus. Sie stieg in eine Kutsche, ohne Schleier, und der Kutschwagen spritzte Straßenschmutz auf uns Verschleierte, und ich schwor mir, eines Tages so wie diese Hure zu werden. ${ }^{311}$

308 Sex und Sexualität spielen auch in den Filmen und Texten Lebewohl, Fremde, Kurz Und Schmerzlos, gegen die Wand, L'Honneur de ma famille, Der Bewegte ManN, Lammbock, Nachtgestalten, Das Leben ISt eine Baustelle, Kanak Sprak, Abschaum, Die Prärie, Der Erottomane und vielen anderen eine wesentliche Rolle.

309 Deutsch-türkische, türkische und deutsche Prostituierte sind in vielen deutsch-türkischen Produktionen der 1990er Jahre positiv konnotiert. Nicht selten identifizieren die Protagonistinnen und Protagonisten sich mit ihnen. In Zaimoğlus Roman Abschaum (1997) bringt der Protagonist Ertan Ongun einer türkischen Prostituierten in Kiel Respekt entgegen, weil er sich in ihrer resilienten Art selbst gespiegelt sieht. Siehe hierzu: ZAIMOĞLU (1997): S. 34-39. Zafer Şenocaks Erzähler beschäftigt sich in mehreren Erzählungen in Der Mann im Unterhemd mit der deutschen Prostituierten Lisa, deren Mutter und Großmutter auch schon Prostituierte waren. Die Geschichte ihrer Profession geht bis in die Weimarer Zeit zurück. Der Erzähler, ein Privatdetektiv, sollte erst eine Türkin aufspüren - nun soll er Lisa finden. Für den Erzähler ist sie voller Geheimnisse, denn sie ist die erste Frau, die sich »mit Männern den Männern« entzieht, ein »weiblicher Mohammed«. Siehe hierzu: ŞENOCAK (1995): S. 54. In Yüksel Yavuz’ Film APRILKINDER verliebt sich der deutsch-türkische Protagonist Cem (Erdal Yıldız) auf den ersten Blick in die deutsche Prostituierte Kim (Inga Busch). Und er fühlt sich auch nur bei ihr wirklich wohl. Doch seine Eltern verlangen, dass er seine Cousine aus der Türkei heiratet, damit sie nach Deutschland kommen und Asyl beantragen kann. Denn ihr Leben als Kurdin ist in der osttürkischen Bürgerkriegsregion gefährdet. Die Eltern erfahren erst am Schluss des Films von Kim. Siehe hierzu: YAvUZ (1998). Einer vergleichbaren Konstellation zwischen Prostitution und Identifikation begegnen wir in Kutlu Atamans Film Lola und BiLIDikid (1999). Siehe hierzu: ATAMAN (1999).

310 Siehe hierzu: AKIN (2004): S. 39.

311 ÖZDAMAR (1992): S. 52. 
Während Elif in Tevfik Başers Film ABschied vom FALSCHEN PARAdIEs noch Busfahrerin werden will, ${ }^{312}$ zielt der Berufswunsch von Özdamars namenloser Protagonistin nicht auf gesellschaftliche Integration, sondern auf unerhörte Weise auf Aufmerksamkeit, Provokation und Anerkennung. Diese drei Aspekte sind Wirklichkeit und Ressource. ${ }^{313}$ So dominiert in Özdamars Roman auch nicht die Beschreibung von Geschlechtsverkehr, sondern vielmehr der häufige Gebrauch des Verbs »ficken«. Eine Verschiebung erfährt dieses Verhältnis in ihrem zweiten Roman, wobei das Verhältnis zwischen dem Gebrauch der ordinär sexualisierten Sprache und der Beschreibung sexueller Praxis weiterhin asymmetrisch bleibt. In Die Brücke vom Goldenen Horn, Emine Sevgi Özdamars zweitem Roman, versucht die Ich-Erzählerin unbedingt ihren »Diamanten« zu verlieren, denn ohne seinen Verlust kann sie - nach ihrer eigenen Einschätzung und der des sozialistischen türkischen Heimleiters des Berliner »Frauenwonayms« - keine richtig gute Schauspielerin werden. ${ }^{314}$ »Ficken« ist neben »Straße« und »Gasse« das

312 Im türkischen Film Postaci (Der Postbote) von 1984 ist es ein Postbote, der es mit dem türkischen Gastarbeiter Latif aus Deutschland aufnimmt. Letzterer möchte seine Schwester dem türkischen Postboten nicht zur Frau geben, weil er weder Haus noch Land besitzt. Siehe hierzu: ÜN, Memduh (1984): Postacl, Türkiye: Uğur Film.

313 Nachdem die Mutter der Protagonistin In Boucharebs Film von 1996 erfahren hat, dass sie in Wirklichkeit in einer belgischen Diskothek arbeitet, bezeichnet sie ihre Tochter scherzhaft immer wieder als Prostituierte. Wie in Özdamars Roman stört auch hier die Protagonistin diese Zuschreibung nicht. In Ayşe Polats deutsch-türkischem Film AuslandstourneE wird der Begriff Orospu (»Prostituierte«) zum Großteil eher positiv als negativ verwendet. Dort ist der Protagonist, Zeki, gespielt von Hilmi Sözer, ein homosexueller Nachtclub-Sänger, der versucht die Mutter der Tochter seines Kollegen Mahmut zu finden. Siehe hierzu: Polat (2000).

314 Siehe hierzu: ÖzDAmAR, Emine Sevgi (1998): Die Brücke vom Goldenen Horn, Köln: Kiepenheuer \& Witsch, S. 108, 122, 128, 138, 152, 163, 165. Die Ich-Erzählerin ist in diesem zweiten Roman, anders als im ersten, über Ländergrenzen hinweg unterwegs: in Deutschland, Frankreich und der Türkei. Beschriebenen Sex hat sie aber nur mit türkischen Männern, einmal mit einem jungen Nationalisten und ein anderes Mal mit einem älteren Sozialisten. Einem ähnlich asymmetrischen Verhältnis hinsichtlich der Nationalität der Sexpartner werden wir in GEGEN DIE WAND begegnen. In keiner Szene schläft die Protagonistin mit einem Nicht-Türken, obwohl sie davon redet und sie sie auch ,abschleppt'. Gezeigt wird gegen Ende allerdings, wie sie mit dem Türken Cahit schläft, was zugleich ein Liebesakt ist. Auch in Abschaum hat der türkische Protagonist Ertan Ongun ausgiebig Sex mit einer türkischen Prostituierten. Siehe hierzu: ZAIMOĞLU (1997): S. 34-39. Yavuz' Film APRILKINDER stellt in dieser Hinsicht eine Ausnahme dar. Doch ist Kim, die deutsche Akteurin in dem Film, wiederum eine professionelle Prostituierte, mit der eine Ehe per se ausgeschlossen ist, zumal Cem mit ihrem Beruf auch nicht mehr klarkommt, nachdem er sich in sie verliebt hat. Die ersten Filme, in denen Sex einer Deutsch-Türkin oder Türkin mit einem Deutschen gezeigt werden, sind die Komödien MEINE VERRÜCKTE TÜRKISCHE HochzeIT und EvET, ICH wILl von 2006 und 2009. In beiden Filmen sind die Sexpartner allerdings auch die späteren Ehepartner. 
meistverwendete Wort in Özdamars Roman. ${ }^{315}$ Dabei lehnt sich die Autorin an die türkische Vulgärsprache an, in der das Verb sehr häufig fällt. An einer Stelle wird sogar aufgelistet, dass es im Türkischen unendlich viele Synonyme für »Penis« gibt, mit »am« und »Schachtel« aber nur zwei für »Vagina «. ${ }^{316}$

Aber es gibt nicht nur ein Missverhältnis zwischen Sprechen und dargestellter Praxis, sondern auch ein sexuell missbräuchliches Verhalten älterer Männer gegenüber Mädchen. Kurz bevor unsere Erzählerin mit der Aussage nach Hause kommt, dass sie ihrer Mutter gleich eine Lüge erzählen werde, wird sie in einem Bus sexuell belästigt. »Es gab in den Bussen auch Männer, die meine Hüften zwickten und ihre Körper hinter mir an mir rieben. ${ }^{317}$ Auch ihr Vater hat Vorbehalte gegenüber fremden türkischen Männern. Als er einmal mit ihr in den Kinofilm PORKY AND BES gehen möchte, aber nur Karten für voneinander getrennte Sitzplätze bekommt, sagt er den gemeinsamen Kinobesuch ab. Denn er könne sie »nicht allein zwischen den hungrigen Wölfen sitzen lassen «. ${ }^{318}$ Die »Wölfe« gibt es aber nicht nur außerhalb der Familie. Selbst ihr Großvater, der die Familie nach zehn Jahren wieder besucht, macht die offensichtlich pubertäre Ich-Erzählerin darauf aufmerksam, dass sie beim Laufen zu Hause nicht so fest auftreten solle. Dabei wackelt »dein Schmuck, das gibt den Männern Wollust «. ${ }^{319}$ Großvater Ahmet verweist dabei auf die Verse zur Verschleierung im Koran und macht auf ihre Entstehung aufmerksam.

Interessant an dieser Unterweisung über das Geschlechterverhalten und die islamische Geschlechterordnung in Özdamars Roman ist, dass das spezifische Verhalten der Frau aus dem Koranvers nur gegenüber Männern ohne familiäre Blutsbande gilt und deshalb besonders im öffentlichen Raum einzuhalten ist, jedoch nicht in den eigenen vier Wänden. ${ }^{320}$ Und der Großvater selbst schiebt diese Interpretation zwar auch nach, doch zu Hause "sollte ich trotzdem auf die Erde nicht so fest mit meinen Füßen treten, daß mein Schmuck wackelt «. ${ }^{321}$ Offenbar ist sexuelle Erregung nicht nur auf der Straße ein Problem, sondern auch zu Hause. In vergleichbarer Diktion empfiehlt später die Großmutter der Mutter, dass sie ihre Tochter bald verheiraten sollte, weil sie »unbändig« geworden sei. »Ihr

315 Dasselbe gilt für den Roman Abschaum von Feridun Zaimoğlu und den Film GEgEN DIE WAND von Fatih Akın.

316 ÖZDAMAR (1992): S. 178f.

317 Ebd., S. 334.

318 Ebd., S. 351.

319 Ebd., S. 309.

320 Der Koran, Übersetzung von Adel Theodor Khoury (unter Mitwirkung von Muhammad Salim Abdullah), Gütersloher Verlagshaus 1987, S. 267.

321 ÖZdAMAR (1992): S. 310. 
Feuer sollte jemand löschen, vielleicht der Neffe des Obstladenbesitzers «. ${ }^{322}$ Und wie die Erzählerin beschreibt, hat zuvor tatsächlich ihre »Schachtel« zwischen ihren Beinen »wie der Körper des von Staatshand vergifteten Straßenhundes in Bursa « gezuckt. ${ }^{323}$ Das Verhältnis zwischen Drinnen und Draußen ist in Özdamars Roman sozial (Familie), kulturell (Religion) und besonders körperlich (Sexualität) ephemer. Dadurch gehören Gassen, Straßen und öffentliche Plätze zum Zuhausesein dazu. Wie bei der rechtlichen und politischen Figur des Denizens geht es hier um eine Praxis und zugleich um eine Form der Platzierung, die weder eindeutig formell noch eindeutig privat ist. Eine Sowohl-als-auch-Zugehörigkeit, die jedoch nicht von Ruhe, sondern im Gegenteil von Unruhe geprägt ist. Jede Form der Inklusion aktualisiert zeitgleich unter diesen Umständen Exklusion.

So ist Fremdheit nicht einfach eine kulturelle Kategorie, die vom Eigenen getrennt betrachtet werden kann und zwischenmenschliche Begegnungen bestimmt. Sie ist in besonderem Maße eine medial erst hervorgebrachte Kategorie. Sie verfremdet Herkunft, Ursprung, Ankunft und den »legal act of naturalisation « und wirkt daher deterritoralisierend. ${ }^{324}$ Durch die unruhigen Körper und die Schwelle als zentrale Topografie des Romans reicht das, was in den Gassen und Straßen sich ereignet bis ins eigene Heim. ${ }^{325}$ Integrationstheoretisch im Sinne der 1990er Jahre gesprochen, sind Desintegrationsdynamik und Exklusionsbereich in diesem Roman, wie auch in den Filmen APRILKINDER und BERLIN IN BERLIN sehr deutlich ausformuliert. Diese intensive Austauschzone der Verfremdung erstreckt sich bis in die verwendete Alltagssprache und selbst in die Wiedergabe der Geschichte der Türkei in Özdamars Roman.

Gleich zu Anfang des Romans versteht die Erzählerin die Worte nicht, die die Großmutter auf dem Friedhof spricht. Es handelt sich um die erste Sure, al-Fatiha (`Die Eröffnende $\triangleleft)$, aus dem Koran, die die Großmutter auf Arabisch rezitiert. Im Buch lesen wir die latinisierte und transkribierte Version als Zitat und kursiv gesetzt - wie die volksreligiöse Grabsteinschrift zu Beginn des Romans - und

322 Ebd., S. 330.

323 ÖZDAMAR (1992): S. 330.

324 Eine identische deterritoralisierende Funktion übt nach Soysal die Anrufung der universellen Menschenrechte in nationalstaatlichen Politiken und Ordnungen aus. Siehe hierzu: SoysAL (1994): S. 3 u. S. 157.

325 Wir werden in der Analyse von Zafer Şenocaks Tetralogie sehen, dass darin die Schwelle ebenfalls konstitutiv ist. Wie in den Filmen APRILKINDER und BERLIN IN BERLIN finden die meisten Aktivitäten zwischen Wohnung und Straße statt. In Yavuz’ Film sehen wir häufig eines der Geschwister die Wohnung verlassen, während die Eltern nie auf die Straße gehen. In BERLIN IN BERLIN entscheidet schließlich der Bereich zwischen Wohnung und Treppenhaus sogar über Leben und Tod des deutschen Protagonisten Thomas (Armin Block). Siehe hierzu: YAVUZ (1998); ÇETIN (1993). 
können sie nur mit einer arabistischen Ausbildung verstehen. Dieses Nicht-Verstehen gilt aber ebenso sehr für den potentiellen türkischen Leser des Romans. ${ }^{326}$ Selbst die eigene Enkelin versteht kein Wort. Diese sprachlich-kulturelle Spaltung und identitätspolitische Spannung wird mit der von Özdamar gewählten Literatursprache, nämlich dem Deutschen, um eine weitere Sprache ergänzt und befremdlich gespalten: »Indem Özdamars Geschichten eine dreigespaltene Zunge in den Diskurs einführen, machen sie die herkömmliche Sicht unmöglich. «27 So ist auch die Geschichte der Türkei von Fremdheit geprägt. Diese erzählt der Großvater auf äußerst surreal-poetische Weise Soldaten im Zug, als er mit seiner Enkelin während ihrer ersten Schulsommerferien von Istanbul wieder unterwegs in die Provinz nach Malatya ist. Unsere Protagonistin begegnet zwar wie auf ihrer ersten Zugfahrt erneut Soldaten. Dieses Mal hat sie es dabei allerdings gemütlicher: Sie ist nicht mit Eisenstangen im Bauch der Mutter umzäunt. Sie sitzt wohlig warm in einem Gepäcknetz, hört dem Großvater zu und beobachtet die Soldaten. ${ }^{328}$ Er erzählt den Übergang vom Untergang des Osmanischen Reiches zur Neuordnung der türkischen Republik, indem er einen Teppich webt: »Großvater sprach, und sein unrasierter Bart wuchs auf seinem Gesicht, und der Bart fing an, einen Teppich zu weben. Die Soldaten machten Feuer, um die Bilder des Teppichs zu sehen. « ${ }^{329}$ Eine Geschichte erzählt er wie folgt.

Bismarck schleppte alle Steine aus der Stadt Pergamon nach Berlin, dann kam Bismarck wieder zum Teppich und brachte deutsche Eimer, mit denen er das Öl von Bagdad mit nach Hause schleppen wollte. Die Engländer und Franzosen und Italiener hörten es und kamen mit ihren eigenen Eimern in die Türkei. Deutsche, Engländer, Franzosen, Italiener kehrten ihre Eimer um, setzten die Eimer als Helme auf ihre Köpfe, zogen ihre Handgranaten und Waffen aus ihren Hosentaschen, und in der Türkei fand der Öleimerkrieg statt. ${ }^{330}$

326 Siehe hierzu auch: BAŞER (1990); ZAIMOĞLU (1995, 1998); ŞENOCAK (1998). Ähnlich werden auch in Sinan Çetins Film BERLIN IN BERLIN von 1993 der deutsche wie auch der türkische Rezipient an manchen Stellen im Film bewusst im Unklaren gelassen. Doch irritiert diese Technik der Auslassung nicht die Erzählung selbst, denn der Film arbeitet insgesamt mit sehr vielen und unterschiedlichen Geräuschquellen. Diese Besonderheit zeigt auch in diesem Film, dass es mehr um das Hören als um das Verstehen geht. Lapidar und zugleich mehrdeutig hält Zafer Şenocak zeitnah in einem Interview Anfang der 1990er Jahre fest, dass es für die Integration besser sei, wenn man nicht alles verstehe, was die Türken in Deutschland sagten, denn dies würde die Deutschen "gänzlich überfordern«. Siehe hierzu: ŞENOCAK, Zafer (1993): Atlas des tropischen Deutschland, Berlin: Babel, S. 89.

327 BoA, Elisabeth (1997): "Sprachenverkehr. Hybrides Schreiben in Werken von Özdamar, Özakın und Demirkan«. In: Interkulturelle Konfigurationen, hg. v. Mary Howard, München: iuidicium, S. 115-137, hier S. 122.

328 Siehe hierzu: MAGUIRE (2013): S. 218.

329 ÖZDAMAR (1992): S. 38.

330 Ebd., S. 39. 
Die Anfänge der türkischen Republik werden in derselben Diktion weitererzählt, muten aber nicht als heroische Ursprungserzählung an, wie sie beispielsweise in den türkischen Grundschulbüchern zum türkischen Unabhängigkeitskrieg (1919-1922) zu finden ist. Dieser Mangel an emotionaler und kultureller Bindung Steine, Eimer und Öl sind in ethnisch-kultureller Hinsicht keine besonderen Gegenstände -, zeigt sich auch darin, dass die Großonkel der Protagonistin die arabische Schrift lesen können, aber nicht die türkische, die wiederum sie lesen kann. So schlägt ihr Vater im Roman zwar des Öfteren den Koran auf, kann ihn aber nicht lesen. Er ist schon in der türkischen Republik aufgewachsen. Die Geschichte, die der Großvater den Soldaten erzählt, handelt nicht von der Wiederherstellung einer verloren geglaubten sozial-kulturellen Einheit, wie sie beispielsweise die Sprachpolitik Mustafa Kemals ab den 1930er Jahren anvisierte. ${ }^{331}$ Es ist vielmehr die Geschichte eines Bruchs, die sich im Roman an den unterschiedlichen Sprachen Türkisch und Arabisch und ihren Verwendungsweisen zeigt, die die verschiedenen Generationen in ihrem Alltag und in ihrer Lebenspraxis voneinander trennt.

Von Brüchen, Widersprüchen und Verfremdungen ist aber nicht nur die national-kulturelle Identifikation in Das Leben ist eine Karawanserei geprägt, sondern auch die soziale Praxis. Man denke nur an die Prostituierte im Frauenbad, im »Mösenplanet«, die die meiste Aufmerksamkeit auf sich zieht und Anerkennung erntet. In einer islamischen und auch konservativ-moralischen Auffassung sozialer Ordnung ist dies eigentlich unerhört. Bemerkenswert ist in dieser Hinsicht auch, dass der Vater fremde, unanständige Männer im Kino befürchtet und die Großmutter und andere Frauen sich um die sexuelle »Unbändigkeit« der Protagonistin sorgen, sie jedoch am Ende des Romans Enkelin und Tochter

331 Siehe hierzu: LaUt, Jens-Peter (2000): Das Türkische als Ursprache? Sprachwissenschaftliche Studien in der Zeit des erwachenden Nationalismus, Wiesbaden: Harrassowitz. Dagegen tauchen in Özdamars Text an mehreren Stellen transnationale Verweise auf, die im Zentrum der Analysen von Azade Seyhan und Cornelia Zierau stehen. Mitunter stellt Seyhan anhand von Özdamars Roman ein Schreiben »outside the national canon « fest: Die Migrationsliteratur arbeite mit inter-, paranationalen und globalen Bezüge, nicht mit nationalen. Siehe hierzu: SEYHAN, Azade (2000): "Writing outside the Nation«. In: dies.: Writing outside the Nation, Princeton: Princeton University Press, S. 125-150. Siehe hierzu auch: ZIERAU, Cornelia (2004): »Story and History - >Nation-Writing in Emine Sevgi Özdamars Roman Das Leben ist eine Karawanserei«. In: Die andere Deutsche Literatur. Istanbuler Vorträge, hg. v. Manfred Durzak, Nilüfer Kuruyazıc1, Würzburg: Königshausen \& Neumann 2004, S. 166-173. Der Turkologe Jens-Peter Laut zeigt in seiner Arbeit, wie sehr das nationalidentitätspolitische Konstrukt und die Idee, Türkisch sei die Ursprache der Menschen, über die »Sonnensprachtheorie« von europäischen Gedanken des 19. und 20. Jahrhunderts beeinflußt war. Eine herausragende Rolle spielten nach Lauts Forschung hierbei die Arbeiten des Wiener Orientalisten H. F. Kvergic. 
einer Prostituierten, Tante Pakize, anvertrauen, die ebenfalls als Gastarbeiterin nach Deutschland reisen will. Dies geschieht, weil Mutter und Vater die Huren als die eigentlichen »Prophetinnen « der Menschen verehren. ${ }^{332}$ Das ständige Unterwegs-Sein der Familie ist keinesfalls immer nur positiv konnotiert. Die Großmutter, »die eine leitende Funktion in der Familie hat (333 $^{33}$, meint, dass das Böse in die Welt nur daher komme, dass der Mensch »in einem Zimmer nicht auf seinen Knien ruhig sitzen kann «. ${ }^{334}$ Sich andeutende Oppositionen, wie die Trennung von Mann und Frau, die die Entstehung erogener Zonen verhindern soll, von schweren und leichten Körpern, in diesen gefangen oder durch sie befreit, von Bewegung, Begegnung und Stillstand, werden im öffentlichen Raum in konkrete Verhältnisse und Zusammenhänge gebracht, die ihre vermeintlich stabilen Positionen unterlaufen und die Ordnung der öffentlichen Repräsentation auf den Kopf stellen. ${ }^{335}$

Emine Sevgi Özdamars Roman ist hinsichtlich der sozialen Ordnung von Widersprüchen, mitunter Spaltungen und einer Unsicherheit der Akteure geprägt, die sich bisweilen über das interkulturelle Verhältnis zwischen deutsch und türkisch hinaus erstreckt. Sie wirkt sich auch auf den Bezug zu Amerika aus, mit dem wir unsere Kulturgeschichte begonnen hatten - als es noch hieß: »Wir wollten alle Amerikaner werden«. Die soziale Ordnung hat sich geändert, an die Stelle der Fabrikbesitzer sind Politiker getreten. Wenn auf der mikropolitischen Ebene viele Akteurinnen und Akteure die Verhaltensweisen von amerikanischen Schauspielern wie »Humprey Pockart«, »Pürt Lancester« und »Ava Kartener» in ihren Alltag übersetzen und sie gerne nachahmen, immer wieder ins Kino gehen, um amerikanische Filme $\mathrm{zu}$ sehen, die Kinder am liebsten die Comics von »Tom Mix« und »Jane Kalemiti« lesen, wird auf der makropolitischen Ebene das ökonomische Abhängigkeitsverhältnis zu Amerika von denselben Akteuren scharf kritisiert. ${ }^{336}$ Die demokratische Partei des türkischen Ministerpräsidenten der 1950er Jahre, Adnan Menderes, habe »das Land, ohne unsere Mütter zu fragen, Amerika in einer Nacht als Nutte serviert, auf dem Tablett «. ${ }^{337}$ Oder man

332 ÖZDAMAR (1992): S. 375. Als Şenay und Zeki am Ende von AuSLANDSTOURNEE ihre Mütter nicht finden bzw. nicht gewollt werden, verlassen sie am nächsten Morgen ihr Hotel in Istanbul und steigen in ein Taxi. Zeki sagt Şenay auf Türkisch, dass sie nun gemeinsam zu den türkischen Huren Zübeyde und Naciye in Deutschland zurückkehren, bei denen Zeki Şenay abgeholt hatte, als sie sich auf die Suche nach ihrer Mutter machten. Siehe hierzu: Polat (1999).

333 KuRUYAZICI (1997): S. 181.

334 ÖZDAMAR (1992): S. 54.

335 Siehe hierzu auch: BAY (1999): S. 33.

336 Siehe hierzu: ebd., S. 28, S. 181 und 187f.

337 Siehe hierzu: Neumann/Kreiser (2009): S. 426f. 
hört auf den Straßen rufen: »Kinder, eure Ärsche bereithalten, es wird alles von Amerika gefickt «. ${ }^{338}$

Wie gelingt es Özdamar, die dargestellten nationalen, sozialen und kulturellen Widersprüche zu greifen und sie in einen Zusammenhang zu bringen? Kann ihr Roman politisch sein, wo doch der Politik als System misstraut und sie ausgeschlossen wird? Schafft ihre Form der Erzählung einen Ort, mit dem vielfältige Lebensentwürfe koordiniert und ihre Diskurse und Handlungen mit einem Rahmen versehen werden können? Vollzieht ihre Erzählung einen Prozess, »durch den eine menschliche Gruppierung, die als solche eine bloße >Bevölkerung ‘ darstellt, allmählich das Aussehen einer wirklichen Gemeinschaft annimmt «. ${ }^{339}$ Özdamars Vorgehen besteht aus vier Elementen. An erster Stelle steht ihr surrealistisch geprägter Stil, der jegliche vorhergehende Vorstellung einer geordneten Realität des Lesers unterminiert: ${ }^{340}$ So beginnt nicht nur die Erzählerin bereits im Mutterbauch zu beobachten und zu sprechen, sondern auch Züge und Schiffe scheinen Bewusstsein zu haben, denn sie »schreien « aus Ungeduld und lassen Dampf ab. ${ }^{341}$ Eine Abendstimmung wird folgendermaßen in Worte gefasst: »die Welt starb, aus der nur eine kurz weinende Babystimme und der Abendezan aus den Minaretten wie die letzten Wörter der Sterbenden in unsere Zimmer kamen und wieder weggingen. Die Welt schrumpfte zu einer Walnussschale, das war unser Zimmer. « ${ }^{342}$ Hier verbinden sich Ästhetik und ein Sein-in-der-Gemeinschaft. ${ }^{343}$

Eng mit dem surrealistischen Zugang und der Erfindung ihrer Geschichten verbunden ist die Vorstellung, dass eine multikulturelle Gesellschaft besser funktioniert, wenn man sich nicht richtig, sondern am besten sogar falsch versteht und Geräusche macht. Nach dem Besuch eines öffentlichen türkischen Schattenspiels erklärt die Mutter der Erzählerin:

338 ÖZDAMAR (1992): S. 171.

339 Rosanvallon, Pierre (2011/2012): »Für eine Begriffs- und Problemgeschichte des Politischen. Antrittsvorlesung am Collège der France«. In: Mittelweg 36, S. 43-65, hier S. 46.

340 Den französischen Surrealismus lernte Özdamar über türkische Studenten kennen. Sein Einfluss zeigt sich in ihrem zweiten Roman Die Brücke vom Goldenen Horn. Siehe hierzu: ÖzDAMAR (1998): S. 200.

341 ÖZDAMAR (1992): S. 15.

342 Ebd., S. 125.

343 Siehe hierzu: NANCY, Jean-Luc (1988): Die undarstellbare Gemeinschaft, Stuttgart: Edition Patricia Schwarz. Ein Gefühl von einem Sein-in-der-Gemeinschaft vermitteln auch die Kneipenabende in Aras Örens Berlin Savignyplatz in der »Paris-Bar«, »Zur dicken Wirtin« und am Ende des Romans im »Zwiebelfisch«. Dieses Sein-in-der-Gemeinschaft findet jedoch nicht öffentlich als Teil der deutschen Wiedervereinigung statt. Siehe hierzu: ÖREN (1995). 
Diese Männer im Schattenspiel heißen auch Karagöz und Hacivat. Karagöz ist ein Zigeuner oder Bauer, Hacivat ist ein Stadtmann, Lehrer vielleicht, und sie sprechen und verstehen sich immer falsch. Dann lachen die Menschen. Im Schattenspiel gibt es Juden, Griechen, Armenier, Halbstarke, Nutten, jeder spricht einen anderen Dialekt, jeder ist ein anderes Musikinstrument, redet nach seiner eigenen Zunge und versteht die anderen nicht, jeder macht an sich tın, tın, tın. Das ist unser Land $[\ldots]^{344}$

Soziale Interaktionen aus der türkischen Volksliteratur, zu der das Schattenspiel gehört, finden sich an vielen Stellen des Romans als Gegenentwurf zu einer orthodoxen gesetzestreuen Lebensweise. Wie wir später noch sehen werden, nehmen das türkische Schattenspieltheater und andere osmanisch-türkische Theaterfiguren, wie beispielsweise die Zenne ${ }^{345}$ in Zafer Şenocaks letztem Band seiner Tetralogie oder der Schattenspieler Mahmut in Ayse Polats Film AusLAndstournEE wichtige Rollen und Funktionen ein. ${ }^{346}$ In Özdamars Roman stehen sie als dritte Form neben den laizistisch-bürokratischen Figuren, deren Frauen kein Kopftuch tragen, und den bekennenden Religiösen, die an ihrer schweren Kleidung zu erkennen sind. Auch das Leitmotiv des Romans, dass das Leben zwei Türen hat, man durch eine hineinkam und aus der anderen wieder heraustritt, entstammt der Feder eines türkischen Volksdichters. Mit derlei Anleihen will Özdamar mehr veranschaulichen als nur einen innertürkischen Konflikt. 1996 erläutert die Autorin, dass sie mit ihrem ersten Roman vor allem gegen die damals geläufige Ethnisierung der Herkunft Ende der 1980er und Anfang der 1990er in der Bundesrepublik habe anschreiben wollen. Das im Diskurs des Multikulturalismus gesellschaftlich und wissenschaftlich aufkommende Thema der Ethnie sei in dieser Zeit für sie

344 Ebd., S. 157.

345 Die Zenne ist im türkischen Volkstheater (Orta Oyunu) die weibliche Hauptfigur, die von einem Mann gespielt wird.

346 Siehe hierzu: ŞEnocaK (1999). Äußerst bemerkenswert ist, dass in den Filmen AusLANDSTOURNEE und APRILKINDER die bekannten und sehr beliebten türkischen Sänger Zeki Müren und Bülent Ersoy gewissermaßen identitätskonstitutive Rollen spielen. Müren trat oft mit Glitzeranzügen, besonderen Bühnenkostümen, Plateaustiefeln, Minikleidern und Netzstrümpfen auf, wurde jedoch von seinen türkischen Anhängern, die sozialstrukturell aus allen Schichten kamen, mit dem maskulin konnotierten Titel »Pascha« bedacht. Dieses besondere Phänomen spiegelt sich auch in Yavuz' Film APRILKINDER wieder. Dort kleidet sich der türkisch-kurdische Sänger und Bordellbesitzer Palla wie Zeki Müren und versucht auch, wie dieser aufzutreten. In seinem Zimmer hängt auch ein großes Plakat von ihm. Pallas kriminelle Machenschaften widersprechen jedoch vollkommen der medialen Darstellung von Mürens Figur, der stets höflich und dezent gezeigt wurde. In Polats Auslandstournee tragt der Protagonist sogar den Namen Zeki und ist ein homosexueller Varietesänger. Siehe hierzu: Polat, Ayşe (1999): Auslandstournee. Siehe zu Müren: AsAN, Emine (2003): Rakipsiz Sanatkar Zeki Müren, Boyut Yayın Grubu. 
ein ausgesprochen »deformierender Moment « gewesen. ${ }^{347}$ Als sie in den 1960er Jahren nach Deutschland gekommen sei, habe die ethnische Zugehörigkeit überhaupt keine Rolle gespielt. Diesen Punkt habe sie in ihrem Roman verdeutlichen wollen, und das haben uns bereits die in dieser Kulturgeschichte analysierten Texte und Filme der 1960er und 1970er Jahre gezeigt; allerdings mit einer ganz anderen Diktion, nämlich einer Mischung aus Dokumentation und Fiktion, deren Ziel es war, Realität abzubilden und damit die herrschenden gesellschaftlichen Mechanismen aufzuzeigen. Doch nicht nur der surrealistisch-poetische Stil Özdamars steht mit seiner inhaltlich volksliterarischen Grundierung im Kontrast zu den Reflexionen und Produktionen der 1960er und 1970er Jahre, sondern auch die Verwendung ironischer und komischer Stilmittel in Das Leben ist eine Karawanserei.

Neben ihrem surrealistischen Stil und dem gewollten Nicht-Verstehen ist Özdamars Einsatz von Ironie und Komik als das dritte Kennzeichen ihres Romans anzusehen: als Bearbeitungsmodus sozialer und kultureller Differenz im Kleinen (die Begegnung mit der Mutter auf der Türschwelle), und in großen sozialen Zusammenhängen. ${ }^{348}$ Man denke nur an die Erfindungen im Zusammenhang mit Robinson Crusoe. Einmal schwört der Vater auf den Koran, dieser solle ihm den Mund schief machen, wenn er seine Frau betrügt. Am Abend hat er einen schiefen Mund, den seine Mutter mit aller Kraft wieder gerade zu biegen versucht. ${ }^{349}$

Für den tschechischen Philosoph Vilém Flusser ist die Entscheidung für Ironie eine Bewegung der Emigration, der Auswanderung, wie er in seiner Essaysammlung Von der Freiheit des Migranten Anfang der 1990er Jahre festhält. Mit dieser "Auswanderungsbewegung" geht eine Empörung über die gegebenen Bedingungen und Umständen einher. »Wenn sich der Mensch in die Ironie stellt, kann er seine Bedingung überblicken. ॥ $^{350}$ Wichtig für die Freiheit des Migranten ist nach Flusser jedoch die Bewegung aus der Ironie, aus der geschaffenen Distanz wieder hinaus, die er als eine Bewegung der Immigration, der Einwanderung begreift. Diese zweite Bewegung sei engagiert, weil der Mensch »in seine Bedingung zurückkehrt, um sie zu ändern «. ${ }^{351}$ Diese zweite Bewegung der Migration - die

347 Zitiert nach: ZIERAU, Cornelia (2009): Wenn Wörter auf Wanderschaft gehen ... Aspekte kultureller, nationaler und geschlechtsspezifischer Differenzen in deutschsprachiger Migrationsliteratur, Tübingen: Stauffenburg, S. 186.

348 Siehe hierzu: Mecklenburg (2008); Seyhan, Azade (1996): »Lost in Translation. Re-Membering the Mother Tongue in Emine Sevgi Özdamar's >Das Leben ist eine Karawanserei<. In: The German Quarterly Vol. 69, No. 4, Special Issue on Culture Studies, S. 414-426, hier S. 424.

349 ÖZDAMAR (1992): S. 30.

350 FLUSSER (2007): S. 31.

351 Ebd., S. 32. 
Einwanderung - zeigt sich bei Özdamar besonders im vierten Kennzeichen ihres Romans, das über den gelingenden Multikulturalismus des Nicht-Verstehen-müssens noch hinausgeht. Die Bedingungen, über die Özdamar sich mit ironischen Mitteln empört, sind nicht der Multikulturalismus des Nicht-Verstehens, sondern seine Zerschlagung, für die im Roman der Militärputsch vom 27. Mai 1960 in der Türkei steht. Völlig unerwartet wird der Leser mit einer politischen Gewalterfahrung konfrontiert, die das ästhetisch-politische Credo herausfordert, das sie in der früheren Erzählung Mutterzunge entfaltet hatte. ${ }^{352}$

Der erste von vier Militärputschen erfolgt in der jungen Geschichte der türkischen Republik am 27. Mai 1960, als die Streitkräfte die Verwaltung des Landes übernehmen. ${ }^{353} 15$ Todesurteile werden ausgesprochen, eines davon über den damaligen Ministerpräsidenten Adnan Menderes, der am 17. September 1961 erhängt wird. Folgt man der Interpretation des Romans, dann steht dieser Putsch in enger Korrelation zum widersprüchlichen Verhältnis zwischen gewollter Nachahmung und Ablehnung der Vereinigten Staaten von Amerika. Eine besondere Stellung nimmt der Militärputsch in Özdamars Roman deshalb ein, weil alle genannten erzählerischen und sozialen Elemente nach dem Putsch verschwunden sind: Allen geht es »schlecht, ihre Gesichter lachen nicht« «. ${ }^{354}$ Und wenn dieser Roman bis zu diesem Punkt vom surreal komisch-ironischen Einsatz von Aberglaube, Volksreligiosität und Gebeten geprägt war, so verlassen nun die Geister die Menschen und auch ihre Häuser. ${ }^{355}$ Selbst die Tiere und die Dinge ziehen sich zurück, sprechen nicht mehr, und die Zeit steht still:

Keine Spinnen gingen an den Wänden zu ihren Häusern, keine Fliegen flogen über das Gesicht dieses Abends, das Holz knarrte nicht, sprach nicht mit dem anderen Holz. Der Tag ist ein Dienstag, der Abend ist ein Juliabend, es wird ein paar Jahre Dienstagabend bleiben. Hier. Die Armut hat diesen Juliabend gut erzogen. Er hat keine Zunge im Mund..$^{356}$

Das Erzählen stockt, die sozialen Bindungen verlieren ihre Kraft, weil der öffentliche Raum für die Bürger nun verschlossen ist. Das Militär beginnt das öffentliche Leben zu bestimmen und nicht mehr das Mädchen, die verschleierten und »verrückten« Frauen. ${ }^{357}$ Der Militärputsch schlägt einen Bogen zurück zum ersten

352 ÖzDAmar, Emine Sevgi (1990): Mutterzunge, Berlin: Rotbuch, S. 9.

353 Siehe hierzu: KreIser/Neumann (2009): S. 428f. Siehe auch: Ahmad, Feroz (1977): The Turkish Experiment in Democracy 1950-1975, London: C. Hurst \& Company, S. 147-176.

354 ÖZDAMAR (1992): S. 285.

355 Ebd., S. 288.

356 ÖZDAMAR (1992): S. 289.

357 Für eine feministische Interpretation des Karawanserei-Romans siehe: GHAUssy, Sohelia (1999): »Das Vaterland verlassen: Nomadic Language and `Feminine Writing` in Emine Sevgi 
Satz des Romans zurück, wo Soldaten das erste waren, das die Ich-Erzählerin aus dem Bauch ihrer Mutter heraus sah. Doch ist diesem spannungsgeladenen ver- und entfremdenden Anfang im Roman auch ein Ausweg eingeschrieben, den die Mutter der Protagonistin im Roman später weist - in Form von Sätzen, die die Familie nach der Geburt des Kindes hätten sprechen und ins Ohr des Säuglings hätten flüstern können. Stattdessen legten sie ihn in ein frischausgehobenes Grab, weil er ohne Unterlass schrie. Spät geben Mutter und Großmutter der Protagonistin Sätze mit auf den Weg, deren Gültigkeit sie bis dahin selbst schon auf der Straße erfahren hat.

'Siehst du, meine Tochter, siehst du, das ist die Welt. Denke dir, dass die Welt ein offener Platz ist, alle Menschen stehen dort und waschen sich und sprechen miteinander.` Dann sagte sie wie meine Großmutter: > Das Fleisch von Menschen kann man nicht essen, die Haut von Menschen kann man nicht anziehen. Hat ein Mensch mehr als seine süße Zunge?^Dann sagte sie: `Aber der Himmel hat kein Gewölbe, deswegen vergessen die Menschen, daß sie nackt von ihren Müttern geboren sind. ${ }^{358}$

Die Welt steht nach oben offen und kann erst dadurch für die Protagonistin zu einer Art Wohnung werden. Dies zeigt sich für die Ich-Erzählerin in dem Moment, als sie in der Republikshauptstadt Ankara auf einem öffentlichen Platz die Straßen Bursas, der ersten osmanischen Hauptstadt, wiederentdeckt. ${ }^{359}$ Ihre Beschreibung ähnelt den Worten der Mutter und Großmutter sehr und deren

Özdamar’s Das Leben ist eine Karawanserei«. In: The German Quarterly 72.1, S. 1-16.

358 Ebd., S. 263f. Der Verweis auf den Himmel ist in den Erzählungen der 1990er Jahre äußerst prominent. In Doris Dörries Film KeINER LIEBT MICH kommunizieren gleich mehrere Akteure auf dem Dach eines Hochhauses über Tanz und Beschwörungsformeln mit dem Himmel. Auch Andreas Dresens NACHTGESTALTEN endet mit einem Blick zum blauen Himmel, wobei der Film zuvor ausschließlich nachts in Berlin spielt. In Tevfik Başers einzigem Film aus den 1990er Jahren ist die Kamera ebenfalls häufig auf den Himmel ausgerichtet. Hussi Kutlucans Film IcH CHEF, Du TuRnschun endet, obwohl der armenische Flüchtling Dudi am Ende abgeschoben wird, mit einer Himmelsaufnahme. Siehe hierzu: BAŞER (1991); DöRRIE (1994); DRESEN (1998); KUTLUCAN, Hussi (1998): Ich Chef, Du Turnschuh, Berlin: Margarita Waskanian Filmproduktion. Und last but not least trägt die Literatur-Anthologie von Deniz Göktürk und Zafer Şenocak von 1991, in der dem deutschsprachigen Leser mit Übersetzungen türkischer Erzählungen die vielfältige Kultur der Türkei zugänglich gemacht werden soll, den Titel Jedem Wort gehört ein Himmel. Siehe hierzu: GöKTÜRK, Deniz/ŞENOCAK, Zafer (1991): Jedem Wort gehört ein Himmel, Berlin: Babel.

359 Es ist bezeichnend, dass viele Akteurinnen und Akteure in Film und Literatur der 1990er Jahre zu den Folgen der Migration, die größte Ruhe ausströmen, wenn sie sich wechselseitig als nackt wahrnehmen und es mitunter auch sind. Siehe hierzu die deutsch-türkischen Filme APRILKINDER, GEgEN DIE WAND und den französisch-maghrebinischen Film Die EHRE MEINER FAMILIE. 
Interpretation des türkischen Schattenspiels. Wenn die Welt wieder offensteht, bringt sie alle zum Sprechen, die der Putsch verstummen ließ.

Es waren die ersten Menschen, die ich nach Bursas Menschen sah. Ich wußte, daß wir in der Republikshauptstadt Ankara sind, aber dieser Luna-Park war für mich Bursa. Diese mit dem Riesenrad hopphochgehenden Herzen, hoppruntergehenden Herzen, diese wie aus einer schönen Nacht heruntergekommenen Sterne, die aufgeregt dort laufenden Menschen, diese alten Frauen mit ihren Strickjacken über ihren Schultern, diese Kinder, die im Chor Kürbiskerne aßen, cit cit cit cit, dieser Teegeruch aus den Samowaren der Cafés, diese kleinen Jungen, die auf ihre älteren Schwestern aufpaßten, die singenden Stimmen aus den Casinos, die aus ihren Körpern mit so tiefer Schwermut die Sehnsucht rausholten, das war für mich Bursa. ${ }^{360}$

Interessant an der Beschreibung dieser öffentlichen Szenerie ist, dass auch hier die Verhältnisse zwischen Innen und Außen, zwischen Körper und Platz - wie so oft in diesem Roman - durchlässig sind. Diese Menschen scheinen weniger aus ihrer Kultur als vielmehr aus ihren Herzen und Häuten Energie zu beziehen, denn »der Himmel hat kein Gewölbe«; für Zafer Şenocak findet in den 1990er Jahren die Auseinandersetzung nicht zwischen differenten Kulturen, sondern zwischen Herz und Haut statt - vor allem, weil die Kategorie »Gesellschaft" paradox geworden ist. ${ }^{361}$ Soziale Interaktionen - dafür steht der offene Himmel - geschehen nicht unter einer schützenden Haube, sondern nur an einem Ort, der aufgrund des fehlenden Rahmens unspezifisch wird. Die Anrufung und Beschreibung des Menschseins mit Sprache, Herz und Haut sind hier die bindenden Aspekte.

Die Verbindung von Endlichkeit und Gemeinschaft, wie sie in den letzten beiden Zeilen und dem Schattenspiel-Zitat aufscheint, setzt kein vorgängiges, gemeinsames ‘Wesen der Akteurinnen und Akteure voraus. Vielmehr steht die Mit-Teilbarkeit auf artikulatorischer (Sprechen, Singen) und körperlicher (Herzen, Essen, Aufregung) Ebene im Vordergrund. Der Gebrauch der Ironie erfüllt dabei im Sinne von Paul de Man eine performative Funktion: »Ironie wird dadurch zu einer ästhetischen Trope par excellence: Sie gibt der ästhetischen Erfahrung eine ,Wendung ins Unbestimmte, ja, Unbestimmbare, widersetzt sich jedem abschließenden Verständnis «. ${ }^{362}$ Auf eine vergleichbar performative Verhandlung der Migration und ihrer Folgen macht Yüksel Pazarkaya hinsichtlich seiner Literatur der 1990er Jahre aufmerksam. Auch für ihn teilt sich darin die Sprache selbst mit. ${ }^{363}$

360 ÖZDAMAR (1992): S. 292.

361 NASSEHI (1997): S. 135.

362 WiRTH, Uwe (2017): »Ironie«. In: ders.: Komik. Ein interdisziplinäres Handbuch, Stuttgart: Metzler, S. 16-20, hier S. 17.

363 PAZARKaya (2000): S. 22. 
Während seine Literatur der 1980er Jahre noch von Diskriminierungen durch die anderen bestimmt war - Ende der 1970er Jahre konstatiert er noch, dass die Fremde dort sei, wo man gekränkt wird -, steht nun weniger »der Sachverhalt an sich, als vielmehr der Prozess des Schreibens « im Zentrum. ${ }^{364}$ Für gewöhnlich versteht man Integration als die Wiederherstellung einer verloren geglaubten Einheit. Hier wird sie vielmehr im und durch den Akt des Schreibens generiert, durch das sichtbar und hörbar machen einer gemeinsamen Gegenwart. Dies geschieht in Situationen und Szenen, die ganz klein in eine »Walnussschale « passen oder sich auf Straßen oder Luna-Parks entfalten. »Ich liebte [...] diese Frauen, die ich am Fenster sah, die mich immer fragten, wie es meiner Mutter ging. « ${ }^{365}$ Gerade diese Topografie und Struktur der Präsenz in Özdamars Roman, von der Walnussschale über den Tür- und Fensterbereich bis zum offenen Platz in der Welt, führt voneinander getrennte Menschen wieder zusammen, weil alle »ursprünglich« aus einem geteilten Körper gekommen sind. Beispielsweise teilen sich von Anfang an Mutter und Tochter einen Körper. Das Volk ist in kultureller und sozialstruktureller Hinsicht ebenfalls geteilt; auch die Türkei. Umso wichtiger werden dadurch der öffentliche Raum und das Erzählen, weil sie Verbindungen und Bindungen ermöglichen. Der Motor der Erzählung ist die Vorstellung einer Verbundenheit, einer gemeinsamen Gegenwart.

Die individuelle und soziale Spaltung hat nicht nur mit der Reihe von Widersprüchen und Unsicherheiten zwischen den Akteurinnen und Akteuren zu tun, die Özdamar aufzeigt. Sie rührt auch daher, dass die Autorin die Begriffe »Türkei « und »türkisch« im Gegensatz zu den 1980er Jahren überhaupt nicht verwendet. Es gibt zwar Emigranten aus Jugoslawien und Albanien, und Jugoslawien wird im letzten Satz des Romans als erste Etappe der Zugfahrt nach Deutschland genannt. Ferner wird die Ich-Erzählerin wegen ihres kurdischen Akzents in der Schule in Istanbul diskriminiert. Insgesamt lässt sich jedoch keine wirksame nationale oder ethnische Kategorie ausmachen, die das ganze heterogene soziale Panorama in Özdamars Roman rahmt. Diskriminierungen sind ohnehin nebensächlich; auf sie wird mit einer erzählerischen Haltung und mit einem Möglichkeits- und Fantasiesinn reagiert. Viele türkische und deutsch-türkische Figuren reagieren in den 1990er Jahren souverän auf Diskriminierungen und unterminieren damit das Verhältnis zwischen Täter und Opfer. Dabei sind die Akteurinnen und Akteure keineswegs psychisch oder physisch unversehrt. Die Ursachen und Herkünfte ihrer Verletzungen werden nur nicht mehr so genau wie in den 1980er Jahren beschrieben, sondern bleiben eher unbestimmt bzw. werden am Körper, durch

364 Ebd., S. 19.

365 ÖZDAMAR (1992): S. 168. 
Narben oder hyperaktives Auftreten sichtbar. ${ }^{366}$ So ist die nächstgrößere vereinheitlichende Referenz neben den häufig auftauchenden Topografien wie Gasse, Straße und Stadt nicht die Nation, die eine klare Grundlage und Erklärung für negative wie auch positive Diskriminierungen geben könnte, sondern die Welt. Hier sammelt sich alles und wendet sich zugleich ins Unbestimmte. Letztlich sind es Ironie, Körper und Plätze, die die Spaltungen und Trennungen in einen Dialog miteinander bringen.

Den universellen, transnationalen und globalen Zugang zur multikulturellen Demokratie und Gesellschaft, wie ich ihn Publizistik und Theorie aufgezeigt habe, finden wir auch in Özdamars Roman. Das heißt, nicht nur dort werden national-gesellschaftliche Geschichten in inhärente Migrationsgeschichten uminterpretiert, die von inneren Fremdheiten, Verfremdungen und von Transnationalismus geprägt sind. Auch Özdamar vollzieht diese Bewegung und erzählt sie surreal gebrochen mit Steinen, Eimer und Öl für die Türkei, die Türken und die Gastarbeiter. ${ }^{367}$ Dasselbe gilt für eine gelingende und funktionierende multikulturelle Gesellschaft, die anhand der Resilienz, der Durchsetzungsfähigkeit von Akteuren oder am Überlebens- und Gestaltungspotential von Kulturen aktuell oder in der Vergangenheit gemessen wird: Am Anfang als Säugling, später wenn sie erkrankt, die Gefahren des Militärputsches und schließlich, als sie sogar versucht, an sich selbst Hand anzulegen, weil der Vater ihr den Kinobesuch verweigert. Doch sie überlebt, ist beharrlich und zäh. ${ }^{368}$ Diese beiden poetischen Verfahren, die Verfremdung des Eigenen und die unterschiedlichen Formen des »Überlebens«, minimieren die Prägekraft einer sich kausal entwickelnden Geschichte. An die Oberfläche dringt die Situation als konkrete Begegnung im öffentlichen Raum. Die Aufhebung der Geschichte macht diese Situationen unberührt und unbelastet. Mit Şenocak gesprochen, wird es bei der Integration

366 Siehe hierzu: BAŞER (1991); DöRRIE (1992); AKIN (1998); KutLUCAN (1998); DRESEN (1998); Polat (1999); AKIN (2003).

367 Für Homi Bhabha und Charles Taylor sind individuelles und kulturelles »Überleben « zentrale Themen des Multikulturalismus. Einen »Öleimerkrieg« gab es während der Entstehung von Özdamars Roman 1991: den Krieg zwischen den Vereinigten Staaten von Amerika und dem Irak, der als Zweiter Golfkrieg in die Geschichte einging. Sadam Hussein marschierte in Kuwait ein, woraufhin die Vereinigten Staaten als Verbündete Kuwaits militärisch eingriffen. Hans Magnus Enzensberger verglich damals Sadam Hussein mit Adolf Hitler, worauf mitunter Zafer Şenocak kritisch-polemisch mit seinem Essayband War Hitler Araber? reagierte. Siehe hierzu: EnzENSBERGER, Hans Magnus (1991): »Hitlers Wiedergänger«. In: DER SPIEGEL, 04.02.1991, 6/1991, S. 26 28. ŞENOCAK, Zafer (1994): War Hitler Araber, München: Babel.

368 Siehe zum Motiv der Beharrlichkeit in Özdamars Roman: JoHnson (2001): S. 43f. 
nicht darauf ankommen, ob die Türken und Deutschen sich werden verstehen, sondern, ob sie sich werden berühren können. ${ }^{369}$

Von der Idee eines gemeinschaftlichen Neuanfangs ist Özdamars zweiter Roman Die Brücke vom Goldenen Horn von 1998 geprägt. Darin erzählt sie die Geschichte der Ich-Erzählerin aus der Karawanserei weiter, wie sie nun in Deutschland arbeitet, dort andere Gastarbeiterinnen, Gastarbeiter, aber auch Studentinnen und Studenten kennenlernt. Nach zwei Jahren kehrt sie für vier Jahre in die Türkei zurück, weil angeblich ihre Mutter erkrankt ist. Dort stellt sie fest, dass sie nicht mehr zu ihrer Familie, zu Istanbul und zur Türkei gehört, sondern nach Berlin. Zwei Jahre in Deutschland haben ihr für diese Erkenntnis und die neue Zugehörigkeit ausgereicht. ${ }^{370}$ Im weiteren Verlauf des Romans erklärt sie die linke und intellektuelle Community in der Türkei und in der Bundesrepublik zu ihrer Gemeinschaft; Gemeinschaften, die sich ähnlich sind. Mit der Aufhebung spezifischer Geschichten und spezifischer kultureller Prägungen geht auch die Bedeutung der Eltern verloren, was bereits im Karawanserei-Roman so angelegt war. ${ }^{371}$

369 Siehe hierzu: ŞENOCAK, Zafer (1993): Atlas des tropischen Deutschland, Berlin: Babel, S. 14. Die Protagonisten Thomas und Dilber geben sich in der letzten Einstellung von Çetins Film BERLIN IN BERLIN gegenseitig auf der Straße die Hände. Sie berühren sich hier das erste Mal körperlich, obwohl sie vorher über Wochen gemeinsam in einer Wohnung lebten. Der Film beginnt damit, dass Thomas Dilber auf einer Baustelle, auf der ihr Mann arbeitet, mehrmals heimlich fotografiert. Es sind allesamt Portraitaufnahmen. In der letzten Einstellung des Films sehen wir beide hingegen von hinten, nicht ihre Gesichter. Auch hier geht es nicht mehr darum, nach draußen zu gelangen, sondern darum, dass Körper zu sich und zueinander finden. Siehe hierzu: ÇETIN (1993). Eine vergleichbare `Berührungskultur`scheint auch Andreas Dresen in seinem Film NACHTGestalten zu pflegen. Denn Peschke, ein älterer Herr, nimmt wider Willen ein afrikanisches Flüchtlingskind auf. Lange bleibt das Verhältnis zwischen beiden distanziert, mitunter weil Peschke sehr viele Vorurteile gegenüber Flüchtlingen und Ausländern hat. Doch widersprechen seine immer fürsorglicheren Handlungen seinen Sprechweisen, so dass am Ende, als er den für das afrikanische Kind verantwortlichen Verwandten in Berlin findet, der Junge Peschke umarmt. Siehe hierzu: DRESEN (1999).

370 In Metin Gürs, Dursun Akçams, Jeanine Meerapfels und Paul Geiersbachs Dokumentationen leben die Türken bereits seit zwischen 10 und 15 Jahren in Deutschland, doch hält keiner und keine unter ihnen eine ansatzweise vergleichbare Nähe zu den Deutschen fest wie in Özdamars Literatur.

371 In fast jedem literarischen Text und in jedem Film der 1990er Jahre sind es immer nichtfamiliäre Angehörige, die den Protagonisten helfen, und obwohl sie keine Familienangehörigen sind, werden sie in den Filmen von Polat, Akın und auch Yavuz mit verwandtschaftlichen Bezeichnungen wie »Bruder« und »Onkel« angesprochen. Der bekannteste ist sicher der falsche Onkel Şeref in Akıns GEgEN DIE WAND, der mit Cahit um die Hand Sibels anhält. Später ist er auch derjenige, der es Cahit finanziell ermöglicht, nach seiner Haftstrafe, nach Istanbul zu Sibel zu fliegen. Interessant an dieser Gesamtkonstellation ist, dass es nicht die eigentlichen Familienangehörigen sind, die für Gemeinschaft und Verantwortung stehen, sondern Fremde. Siehe hierzu: 
Für diese neu zu rahmende Begegnung zwischen Deutschen und Türken ist ein weiterer Aspekt entscheidend. Denn im Unterschied zu vielen Interpreten der Literatur von Özdamar, aber auch von Werken anderer Deutsch-Türken in den 1990er Jahren, sehe ich darin nicht nur das Potential für neue transnationale und transkulturelle Gemeinschaften ${ }^{372}$ oder Bereicherungen der Nationalliteratur. ${ }^{373}$ Özdamars Werke und die der folgenden Autoren und Filmemacher sind von sozialen und kulturellen Konflikten durchsetzt, die sie zu lösen versuchen, was in der Regel durch »verfremdende Übertreibungen« und mit einem »Witz der Differenz« auch gelingt. ${ }^{374}$

Während in den 1960er und 1970er Jahren der Konsumkapitalismus ein System ist, das Integration nicht möglich macht und in den 1980er Jahren an dessen Stelle die Herkunfts- oder Ankunftskultur rückt, ist in den 1990er Jahren das Individuum mit der Austragung sozialer und kultureller Konflikte auf sich allein gestellt. Als der Vater der Ich-Erzählerin im Karawanserei-Roman den Kinobesuch verbietet, gibt sie weder ihm noch der puristischen Vorstellung einer islamischen Geschlechterordnung im öffentlichen Raum die Schuld dafür. In den 1980er Jahren wäre das eine klare Sache gewesen: Der Vater ist das Medium und Schuld ist die Kultur dahinter. Bei Özdamar scheint sich die Protagonistin selbst schuldig zu fühlen: Zumindest reagiert sie darauf völlig überzogen mit einem Selbstmordversuch. Diese Nichtadressierbarkeit der Verantwortung an sozialen und kulturellen Konflikten wird uns in diesem Kapitel immer wieder beschäftigen. Beispielsweise hält auch der deutsch-türkisch-jüdische Protagonist in Zafer Şenocaks Tetralogie fest, dass er für seine Existenz zwischen den Kulturen keinem anderen die Schuld zuschieben könne als sich selbst. ${ }^{375}$ Der Protagonist wird sich zwar durchweg fremd in Deutschland fühlen, besonders nach der deutschen Wiedervereinigung, wie Şenocak in die Gefährliche Verwandtschaft zeigt. ${ }^{376}$ Er kann

AKIN (2003). Der homosexuelle Zeki nimmt in Polats Film AuSLANDSTOURNEE eine vergleichbare fürsorgliche Funktion als falscher Onkel ein. Siehe hierzu: Polat (1999).

372 Siehe hierzu: Seyhan, Azade (2001): Writing outside the Nation, New Jersey: Princeton University Press, S. 14. KAISER, Birgit Mara (2014): »A new German, singularly Turkish. Reading Emine Sevgi Özdamar with Derrida’s Monolingualism of the Other«. In: Textual Practice, Vol. 28, No. 6, S. 969-987, S. 973; ZIERAU (2009): S. 184.

373 Siehe hierzu: Hofmann, Michael (2006): Interkulturelle Literaturwissenschaft, München: Fink, S. 213. AdELson, Leslie (2005): The Turkish Turn in Contemporary German Literature, New York: Palgrave Macmillan, S. 24.

374 Siehe hierzu: Boog (2017).

375 ŞENoCAK, Zafer (1997): Die Prärie, Hamburg: Rotbuch, S. 5.

376 Diese identitätspolitische Konstellation entwirft auch der Roman Berlin Savingyplatz von Aras Ören. Obwohl der Platz konkret bezeichnet ist, gibt sich der Roman insgesamt labyrinthartig. Zwar ist der Erzähler in den Straßen Berlins unterwegs, wie so viele Akteure in den 1990er 
sich jedoch für seinen heimatlosen Zustand bei niemandem beklagen und niemanden anklagen.

Die Schuld an Konflikten nicht mehr zuweisen zu können, ist ein äußerst häufig auftretendes und konstitutives Element der Akteurinnen und Akteure in Erzählungen und Filmen in dieser Dekade. Auch Fatih Akın konstatiert für seinen deutsch-türkischen Hauptakteur Gabriel in seinem ersten abendfüllenden Spielfilm KuRz UND SchMERzLos von 1998, dass er sich mit der Idee, der Held »fühlt sich immer schuldig“, sehr gut identifizieren könne. ${ }^{377}$ Die Protagonisten sind Verursacher und Opfer der Konflikte, wie es auch der verbreitete Akt des selbstverschuldeten Todes oder des Selbstmords nahelegt.

Nicht zuletzt aufgrund dieser hier kurz angerissenen Schuldfrage gibt es trotz der Überschneidungen von theoretischen und künstlerischen Verfahren von Multikulturalismustheorien und deutsch-türkischer Ästhetik, zwei entscheidende Unterschiede. Sie betreffen zum einen offensichtlich die Verbindung von Kultur und Gesellschaft, zum anderen weniger offensichtlich die Frage nach der eigenen Ökonomie. Zunächst ist evident, dass in Das Leben ist eine Karawanserei das multikulturelle Setting der Türkei weitaus existenzieller und körperlicher beschreiben wird, als in den im Kern kulturell-ökonomisch (Cohn-Bendit), politisch-repräsentativ (Habermas) und schließlich kulturdialogisch (Taylor) ausgerichteten Theorien. Während der politische Ausgangspunkt in den Multikulturalismustheorien lautet, mögen sie sich an ein Kollektiv oder an ein Individuum richten, wie man es mit der Kultur als Gruppe oder als Subjekt hält, stellt sich die Ausgangsfrage in Özdamars Roman mit unserer Leitfrage für die 1990er, »wie lebt es sich in Deiner Haut?«, nach dem »bloßen« Leben. Während Cohn-Bendit mit den selbstständigen und zähen Akteuren Kultur und Ökonomie, während Habermas mit dem Individuum Kultur und Politik und während Taylor Kultur und Anerkennung verbindet, führen Özdamar und andere Autoren und Filmemacher deutsch-türkischer Herkunft in ihren Produktionen der 1990er Jahre kulturelle Eigenheiten mit der Existenz zusammen. Mit dieser Verbindung steht nicht die Frage nach der Organisation multikultureller Gesellschaften durch die Verwirklichung spezifischer

Jahren. Doch ist es weniger der Savignyplatz als vielmehr das Gemeinsam-Sein in den Kneipen und Restaurants mit Freunden, das dem romantischen Gefühl des Wohlseins nahekommt. Dieses Gefühl stellt sich aber an keiner Stelle im Roman ein. Entweder liegt es daran, dass die Liebesbeziehungen des Erzählers zu deutschen Frauen nicht gelingen, oder aber seine eigene literarische Figur, der Gastarbeiter Ali Itir, sucht ihn heim. Am Ende stirbt Ali in diesem Roman erneut. Von seinem Tod berichtet dieses Mal nur eine Zeitungsmeldung im Roman. Im Unterschied zur Ali Itir-Figur aus Bitte nix Polizei trägt hier niemand die Schuld für seinen Tod. Siehe hierzu: ÖREN (1995).

377 Behrens, Volker/TöteBerg, Michael (2011): Fatih Akn. Im Clinch - Die Geschichte meiner Filme, Reinbek bei Hamburg: Rowohlt, S. 65. 
Rechte im Vordergrund. Wenn man Kultur mit Existenz verbindet, dann geht es in der Kulturanalyse nicht in erster Linie um die Gesellschaft, sondern um die politische Gemeinschaft. ${ }^{378}$

Genau an dieser Stelle zeigt sich auch, dass die Bearbeitung der Migration und ihrer Folgen im ästhetisch-politischen Zusammenhang jenseits der Frage der Integration im klassischen Sinn erfolgt. Die Protagonistinnen und Protagonisten sind Arbeitslose, Prostituierte, Kleinkriminelle oder Taxifahrer, wie wir noch oft in diesem Kapitel sehen werden. Mit einem möglichen beruflichen Aufstieg ist keine ihrer Arbeiten verbunden. Dennoch sind die Akteure alles andere als passiv oder depressiv, sondern bis zur körperlichen Erschöpfung im öffentlichen Raum äußerst aktiv. Dieses hohe Maß an Aktivität stellt die Frage nach einer neuen Begegnung und Gemeinschaft, die interessanterweise auch im Mittelpunkt einer politischen Philosophie steht, die Ende der 1980er und Anfang der 1990er Jahre zeitgleich mit dem Multikulturalismus eine Konjunktur erfährt. Im Kern dieser politischen Philosophie, die sich von der Politik als System und Verfahren grundlegend unterscheidet, steht die Frage nach neuen möglichen Gemeinschaften. $\mathrm{Zu}$ ihren wichtigsten Publikationen gehört zunächst die Arbeit La communauté désœvrée (1986, Die undarstellbare Gemeinschaft, dt. 1988) des französischen Philosophen Jean-Luc Nancy. Darin geht es darum, nach dem Ende des systemischen Kommunismus durch ein »Zusammen-Erscheinen « der Menschen ohne soziale Unterschiede wieder einen Ort für die Gemeinschaft $\mathrm{zu}$ finden. ${ }^{379} \mathrm{Um}$ diesen Ort durch ein »gemeinsames Erscheinen « zu schaffen, sei es notwendig, von der Existenz des »Kommunismus« zur Gemeinschaftlichkeit der »Existenz« $\mathrm{zu}$ finden. Eine Politik, die

ihren Kosmopolitismus nicht im Weltmarkt der Welt-Bürger, sondern in der Gemeinsamkeit all der Fremden, der Flüchtlinge, Heimatlosen, Immigranten und Asylanten aufsucht; einer Politik schließlich, die in kein gemeinsames - deutsches, europäisches, westliches - Haus einziehen will, sondern sich als Instandsbesetzung einer bloßen Baustelle versteht. ${ }^{380}$

378 Auch wenn ein Großteil der deutschen Filme der 1990er Jahre, die unter der Bezeichnung des »Konsens-Kinos« in der Filmwissenschaft firmieren, keiner explizit politischen Rhetorik folgt, ist ihnen die soziale Form der Gemeinschaft ohne Gesellschaft sehr wichtig. Man erkennt sie etwa in Abgeschminkt (1990), Go Trabi Go (1991), Der Bewegte ManN (1994) über ZugvöGEL, EINMAL NACH INARI (1998) bis DeR CAMPus (1998). Siehe hierzu: DöRRIE (1991, 1994); GARNIER (1991); SCHMID (1995); BECKER (1955-1997); DRESEN (1998).

379 Siehe hierzu: NANCY, Jean-Luc (1988): Die undarstellbare Gemeinschaft, Stuttgart: Edition Patricia Schwarz, S. 11.

380 VoGL, Joseph (1994): S. 25. Die Baustelle taucht in den literarischen und filmischen Erzählungen deutsch-türkischer wie auch deutscher Herkunft dieser Jahre häufig auf. Siehe hierzu: KLIER (1991); ÇETIN (1993); DöRRIE (1994); BECKER (1995-1997); KUTLUCAN (1998). 
Der Ausgangspunkt ist hier - nach einer sehr nationalistisch geprägten Dekade in den 1980ern und mit dem Zusammenbruch des Kommunismus - die Frage, wie »kann man die politische Dichotomie zwischen ursprünglicher Gemeinschaft und organisierter Gesellschaft unterlaufen? « Und weiter: Wie lässt sich nach dem faktischen Ende des Kommunismus politisch wieder soziale Wärme herstellen, die in Opposition zu »machtgestützten Rituale[n] politisch-sozialer Identitätsstiftungen « steht? ${ }^{381}$ Nach Ansicht der Theoretiker Michel Foucault, Jean-Luc Nancy, Gilles Deleuze und Giorgio Agamben ist dies nicht von der Mitte oder aus einem bestimmten System, wie dem der Ökonomie oder einer repräsentativen Partei, möglich, sondern nur vom äußersten Rand der Gesellschaft. Dort, wo der Einsatz, den jeder erbringt, das Leben selbst ist. ${ }^{382}$

Ein politisches Leben lässt sich allerdings nie nur als »bloßes Leben« denken, das plötzlich von »Gewalt, Fremdheit, Krankheit und Unfall« bedroht werden kann. Denn auf dieser Grundlage und »in seinem Namen« regiert »der unsichtbare Souverän hinter [...] stumpfsinnigen Masken der Mächtigen «. ${ }^{383}$ Tatsächlich brechen sämtliche Gefahren in Özdamars Roman und den anderen bislang genannten Werken sehr unvermittelt über die Körper der Protagonisten herein: Umzüge, sexuelle Nötigung im Bus, Krankheiten, Selbstmordversuch oder Militärputsch. Vor diesen Gefahren für das »bloße« Leben schützen weder Staat noch Gesellschaft einen, sondern das »gemeinsame Erscheinen« im öffentlichen Raum und die erfundenen Geschichten gegenüber der Mutter, Großmutter und dem Leser. Leb- und verhandelbar werden existenzielle Unsicherheiten durch Ästhetik, Ironie und Humor. Oder wie sie es in ihrem zweiten großen Roman Die Brücke über dem goldenen Horn programmatisch festhält, ist ihr zentrales Anliegen, ihr passives Leben durch ein poetisches zu aktivieren. ${ }^{384}$ Auch in diesem Text Özdamars ist das "gemeinsame Erscheinen« zentral. Der Unterschied hier ist, dass Özdamar mit der Bundesrepublik und der Türkei ähnlich politisierte Länder und multikulturelle Gesellschaften in den 1960er Jahren wiederum aus einer exis-

$381 \mathrm{Zu}$ diesen Ritualen gehört auch das selbstbestimmte souveräne Individuum, wie es beispielsweise Charles Taylor oder Jürgen Habermas als Grundlage für ihre Multikulturalismustheorien beschreiben.

382 Agamben, Giorgio (1994): »Lebens-Form«. In: Gemeinschaften. Positionen zu einer Philosophie des Politischen, hg. v. Joseph Vogl, Frankfurt a. M.: Suhrkamp, S. 251-258, hier S. 253.

383 Ebd.

384 Siehe hierzu: ÖzDAmaR (1998): S. 200. Das erzählerische Aktivieren des Politischen ist in Die Brücken vom Goldenen Horn deshalb auch notwendig, weil der Militärputsch von 1970 das städtisch-öffentliche Alltagsleben lahmgelegt hat. Am 12. März 1970 reißt das türkische Militär, dieses Mal durch ein Referendum, die Staatsmacht für zwei Jahre an sich. Linksgerichtete Studierende werden inhaftiert und verfolgt. Wie im Karawanserei-Roman setzen erneut die Grundlagen des Erzählens aus. Siehe hierzu: ebd., S. 309-329. 
tenziellen Perspektive aufzeigt. Die erste Hälfte des Romans spielt in Berlin und kurze Zeit in Paris, die zweite in Istanbul und in der türkischen Provinz.

Trotz dieser topografischen Unterschiede ist in beiden Romanen die Frage der Integration keine nationale oder kulturelle, sondern eine Frage der öffentlichen Teilhabe. Denn auch hier gilt, dass es jenseits des Existierens nichts gibt. Eine Existenz, die sich durch das Zwischen im öffentlichen Raum konstituiert. ${ }^{385}$ Nach den Reflexionen Linda Hutcheons zu Beginn der 1990er Jahre ist dieses »Zwischen « genau der Ort, wo »irony >happens« « und sie ist in ihrer Praxis »always different - other than and more than the said «. ${ }^{386}$ Und um dieses Existieren zu betonen, gilt es im ersten Schritt Grenzen zu überschreiten und vor allem Regeln zu brechen. Im zweiten Schritt neue mögliche Bindungen aufzuzeigen. Die Mit-teilung, die auch Yüksel Pazarkaya für seine ästhetischen Reflexionen und Schreibpraxis in den Vordergrund rückt ${ }^{387}$, ist hier eine »doppelte Bewegung von Assoziieren und Dissoziieren, die das `Soziieren` begründet «. ${ }^{388}$ Dadurch entsteht ein »inkonsistentes $>$ Wir « $^{389}$, das nicht von einer gemeinsamen Kultur, sondern von einem gemeinsamen Teilen bestimmt ist. Es geht dabei um eine Gemeinschaft, die ihre eigene Grundlage ausschließt.

Im Kern dieses nicht-systemischen politischen Verfahrens taucht nach Nancy eine doppelte Kernfrage auf: »Wie ausschließen, ohne Figuren zu bilden? Und wie Figuren bilden, ohne auszuschließen? Ausschließen, ohne Figuren zu bilden, heißt, das Fehlen eines Grundes oder einer Voraussetzung des Seins-in-der-Gemeinschaft anzuerkennen «. ${ }^{390}$ Es fehlen gewollt Zeichen zur Bezeichnung eines kulturellen Kerns und es ist der körperlich-energetische Überschuss in beiden Romanen Özdamars, denen die Zeichen und mit ihnen die Definitionen nicht nachkommen. Und es ist gerade dieser Überschuss an Bewegung und Körperlichkeit, die das »Unerhörte [...] nicht nur wieder möglich, sondern in irgendeiner Weise Gewißheit« werden lässt. ${ }^{391}$ Dass dieser Überschuss aber nicht ziellos agiert und um sich schlägt, liegt besonders auch am Willen und am "gewitzten« Erzählen, ${ }^{392}$ die Mutter zum Lachen, die Großmutter und den deutschsprachigen Leser zum Staunen bringen zu wollen und dadurch Bedingungen für ein Weiter-

385 NANCY (1994): S. 194.

386 Zitiert nach: WiRth (2017): S. 19. Siehe hierzu auch: Hutcheon, Linda (1994): Irony's Edge. The Theory and Politics Irony, New York: Routledge, S. 12 u. 19.

387 Siehe hierzu: PAZARKAYA (2000): S. 22.

388 Ebd., S. 195.

389 Vogl (1994): S. 21.

390 NANCY (1994): S. 195.

391 Ebd., S. 196.

392 Boog (2017). 
sprechen und eine besondere Form der Integration schaffen. Darin zeigt sich ein "politisches Leben, das sich an der Idee der Glückseligkeit orientiert und versucht eine Lebens-Form « ${ }^{393}$ mit künstlerischen Mitteln zu entwickeln. »Ich will poetisch leben«, antwortet die Ich-Erzählerin in Özdamars Die Brücke vom Goldenen Horn auf die Frage, warum sie Schauspielerin werden möchte. In der Erzählzeit des Romans befinden wir uns in der hochpolitischen Phase linker Bewegungen in der Türkei Ende der 1960er Jahre.

Allerdings braucht die Gemeinschaft mehr als nur die passenden Umstände, mehr als das Wissen, das sie keinen gemeinsamen Ursprung hat, und mehr als eine erwachte Intelligenz, wenn sie überleben will. Das hohe Maß an körperlicher Energie und Bewegung in Özdamars Romanen der 1990er Jahre verweist auf eine Lebens-Form, in der das Leben als Möglichkeit entworfen ist, die es erst noch umzusetzen gilt. Die Frage nach der sozialen Konstellation drängt sich in der Analyse von Özdamars Literatur deshalb auf, weil das Subjekt darin immer in verschiedenen Beziehungen steht. Es ist einzigartig, kann aber nur im Beisein von anderen sichtbar werden. ${ }^{394}$ Inklusion bedeutet bei Özdamar zugleich Exklusion. Ähnlich beschreibt Armin Nassehi in Anlehnung an Luhmann die Grundlagen der Inklusion: Interaktionen von Akteuren, ihre Teilhabe am gesellschaftlichen Geschehen, lassen sich nicht mehr durch eine "fremdreferentielle Beobachtung" sichern. Dieser paradoxe Zustand des drinnen und zugleich draußen Seins, konterkariert die von Habermas vorausgesetzte »Gleichursprünglichkeit privater und öffentlicher Autonomie«. Er gibt auch die beschriebene Beobachtungsposition der Ich-Erzählerin vom anfänglichen Erzählen aus dem Mutterbauch bis zur topografischen Struktur des Romans wieder und zeigt sich ebenso in der Spannung, die sich aus einem Erzählen im Präteritum des Romans bei gleichzeitiger Dominanz der erlebten Rede ergibt. Es gibt kaum auktoriale Erzählerpositionen. ${ }^{395}$ Diese besondere Bindung von Vergangenheit und Gegenwart, von Distanz und unbedingter Nähe wird uns auch in Zafer Şenocaks Roman Gefährliche Verwandtschaft wieder begegnen.

Um die Verbindung von Kultur und Existenz zu stabilisieren, sind Stilmittel und ästhetische Verfahren nur die eine Seite. Auf der anderen Seite hat in Özdamars ersten beiden Romanen ein zentraler Kategorienwechsel stattgefunden, der die klassischen Integrationstheorien, die bis in die späten 1980er Jahre hinein äußerst wirkmächtig waren, aus den Angeln hebt. Ihre Literatur hat an die Stelle der Herkunft und Ankunft, an die Stellen der Assimilation und Binneninte-

393 AgAmben (1994): S. 254.

394 Siehe hierzu: KAISER (2014): S. 972.

395 Siehe hierzu: BAY (1999): S. 36. 
gration das Wohnen gesetzt - und das nur mit der Begründung, dass man ohne eine Heimat sehr wohl leben könne, aber nicht ohne eine Wohnung im weitesten Sinne: ${ }^{396}$ »Die Pariser Clochards wohnen unter Brücken, die Zigeuner in Karawanen, die brasilianischen Landarbeiter in Hütten, und so entsetzlich es klingen mag, man wohnte in Auschwitz. Denn ohne Wohnung kommt man buchstäblich um. ${ }^{397}$ Und es ist diese besondere Verschiebung der Perspektive vom Ankommen zum Überleben, die über sozialstrukturelle Fragen hinaus die Literatur und den Film der 1990er inhaltlich und konzeptionell bestimmt. Das macht aus der Frage nach der alten und neuen Identität eine Frage der Identifikation. Diese Verschiebung steht in enger Korrelation zum verblassten Narrativ der Rückkehr in die vermeintliche Heimat. Sie ist ebenfalls eng verbunden mit der Wohnsituation der Türken in Deutschland: In Deutschland lebten sie vor allem zur Miete, kauften aber Wohnungen und Sommerhäuser in der Türkei, die sie bis heute nur in den Sommerferien benutzen, weil sie weiterhin in Deutschland leben. Das Wohnen ohne Heimat ist also die alltägliche Praxis.

Heimatlosigkeit in dieser Zeit, die nicht mehr als solche erzählt wird, zeigt den Migranten als Migranten, nicht als Arbeiter, nicht als Türken, nicht als Mitbürger und schon gar nicht als Einwanderer. Zumindest, was die Türken in Deutschland betrifft, gehen Migration und Integration in den 1990er Jahren getrennte Wege. Integration kann unter diesen Bedingungen ohne Gesellschaft, wie in der »Paris-Bar« von Ören, nur ein Sein-in-der-Gemeinschaft sein. ${ }^{398}$ Ein Sein, in das der Gastarbeiter der ersten Generation nicht hineinpasst, denn dafür bräuchte es einen aufrufbaren Verweis auf eine Gesellschaft. Aus diesen analytisch wie auch theoretisch zusammen getragenen Erkenntnissen, wundert es nicht, dass die erste Generation, sozusagen die Eltern-Generation, keine bestimmende performative Funktion in den meisten ästhetischen Produktionen der 1990er Jahre hat.

Wenn nach Flusser Heimat eine von Geheimnissen umwobene Wohnung ist, dann ist der Migrant geheimnislos. Er lebt nicht in einem Geheimnis, sondern in der Evidenz. ${ }^{399}$ Und gibt es eine überzeugendere Evidenz, als wenn offen erfunden wird? Die Frage der Integration ist in den 1990er Jahren keine sozialstrukturelle,

396 Interessanterweise wird die Frage des Wohnens auch in den bekannten deutschen Filmen der 1990er Jahre wie DeR Bewegte Mann (1994), NaChtgestalten (1999), Lola RENNT (1998) und DAS LEBEN IST EINE BAUSTELLE (1998) behandelt.

397 FLUSSER (1994): S. 27.

398 Nicht zufällig beginnt die Erfolgsgeschichte der Vorsilbe »Trans« im Zusammenhang mit kulturellen und nationalen Thematisierungen in dieser Zeit. Siehe zu transnationalen und transstaatlichen Theorien zu Migration und Integration: GLICK-SCHILLER (1994) und FAIST (2000). 399 Siehe hierzu: FLUSSER: S. 30. 
sondern eine formal-konstitutive Frage, eine Frage der Erzählung und des Weitersprechens. Diese scheint eine geteilte, aber eine unausgesprochene Erkenntnis in den 1990er Jahren gewesen zu sein. Denn wie sonst konnten übertriebene Geschichten und Sprachen als multikulturelle Realität wahrgenommen werden? Doch nur, wenn diese Erkenntnis vom Narrativ bestimmt war, dass die einzige gültige Frage an die deutsch-türkischen Migranten der 1990er Jahre nur noch die sein konnte, nicht mehr nach ihrer Heimat oder nach ihrer Ankunft in Deutschland $\mathrm{zu}$ fragen, sondern nur noch, wie es sich nach dieser ganzen Geschichte in der Bundesrepublik in ihrer Haut lebt.

Ihre Antwort ist, folgen wir zunächst Özdamar, eine ironische. Eine Ironie, die sich mit Humor über die multikulturellen Bedingungen in der Bundesrepublik empört, dass man Ethnien zugewiesen wird, gleich wo man seit Dekaden schon wohnt. Auch bei Hammer und Soysal ist die Grundlage der Denizenship weder eine kulturelle Identität noch die Staatsbürgerschaft, sondern vielmehr das Faktum ihres Wohnens und Daseins im öffentlichen Raum. Jedoch ist dieses Wohnen und die öffentliche Präsenz der Akteure in Özdamars Literatur nicht auf Dauer zu stellen. ${ }^{400}$ Sie ist ohne das unterwegs sein, nicht zu denken. So endet auch ihr zweiter Roman Die Brücke vom Goldenen Horn wie auch der erste mit einer erneuten Zugfahrt nach Deutschland, diesmal wegen dem zweiten Militärputsch in der Türkei 1971. Und auch hier trifft sie wieder einen Fremden im Zug, den sie um eine Zigarette bittet. ${ }^{401}$ Am Ende des Karawanserei-Romans ist es ihr Vater, mit dem sie eine Zigarette raucht, bevor sie nach Deutschland migriert. Im zweiten Band ist es ein Fremder.

Wir begegnen im Kern von Özdamars Literatur dem Überleben, dem Wohnen und der Integration als Erzählung und all diese Komponenten zusammen irritieren den Multikulturalismus der 1990er Jahre in seinen Grundlagen. Sie heben die Prägekraft kultureller Hintergründe durch Verfremdungen auf. Dabei bleibt die Frage nach dem Zusammenleben touchiert, aber nicht ausbuchstabiert. Denn die verfremdende Ästhetik bedarf eines hohen Aufwands, wenn es darum geht, den Wunschvorstellungen der Gemeinschaft der Ich-Erzählerin durch Beschreibungen von öffentlichen Plätze, auf denen wir Akteurinnen und Akteure in ihren

400 Dies gilt interessanterweise auch für das Konzept der Denizenship. Nach Daniel Thym haben die Reflexionen zur Denizenship über die Zeit an Breite nicht gewinnen können, weil es nach seiner Interpretation an einer diskursiven Verbreitung mangelte. Siehe hierzu: Тнум (2018). Ich denke jedoch, dass das Problem der Denizenship vielmehr wahr, dass mit den Folgen des 11. September, die Anrufung der universellen Menschenrechte nicht mehr genügt, um ein auf Sicherheit abgestelltes gemeinsames Leben und Wohnen zu gewährleisten.

401 ÖZDAMAR (1998): S. 330. 
körperlichen Bedingungen und dem Schlagen ihrer Herzen begegnen, Grundlagen zu geben, die keiner zuvor vorgestellten Identität entspricht. Wie diese sich aber verhalten, welche Interaktionen stattfinden und was auf die gezeigte körperlich-innere Wärme, auf die Begegnungen, auf dieses »Zusammen-Erscheinen « als Praktiken, Handlungen und welche geregelten Sprechweisen folgen können und sollen, sehen und ahnen wir nicht. Einen Prozess zu einer inklusiven (Parsons) oder zu einer sozialen Verflechtungsordnung (Elias) sehen wir hier nicht angebahnt, jedoch die Erzählung einer gemeinsamen Gegenwart, deren Ziel es mitunter ist, die Unterscheidung der Fort- und Rückschrittlichkeit zu unterminieren. Der Fokus wiederum auf soziale Handlungen, dann als Praktiken, wird hingegen erst mit dem Narrativ »Was lebst Du?« mit der Literatur und den Filmen ab den 2000er Jahren folgen. Da wird mit den Debatten um das Zusammenleben in einem Einwanderungsland ein Narrativ an die Oberfläche steigen, das die Bewegungen der Migration und Integration wieder enger, jedoch anders als zuvor, zusammenführen wird. Aber auch da wird es zu neuen desintegrativen Dynamiken kommen. Neben diesem Wandel findet auch Anfang der 2000er Jahre ebenfalls ein markanter Wechsel in der Politik statt, was Fragen der Integration der Türken in Deutschland betrifft.

Bevor wir uns diesem Wandel in der vorliegenden Kulturgeschichte zuwenden, gilt es im nächsten Schritt zunächst durch die Literatur und Essayistik von Zafer Şenocak und der Kanak Sprak von Feridun Zaimoğlu die Breite der Wirkung und der Varianz unseres Narrativs "Wie lebt es sich in Deiner Haut? « aus zu buchstabieren. Anhand von Filmanalysen zum Werk von Fatih Akın, von Thomas Arslan, Ayşe Polat und Yüksel Yavuz werden wir sehen, welche neuen bewegten Bilder dieses Narrativ ermöglichen wird und wo sie aber auch ihre Grenzen zieht. Die folgende Analyse der Tetralogie Şenocaks wird uns zeigen, dass unser Narrativ nur vordergründig für eine Kritik am Orientalismus oder am Multikulturalismus steht. In Wirklichkeit ist sie eine Kritik an der Integration in einem weitaus allgemeineren Sinne, die die Migration von der Integration trennt. Die Intensität der Trennung ist bei Şenocak zwischen dem Sozialen und Ästhetischen so vehement, dass die soziale Frage in seiner Literatur regelrecht an den Rand gedrängt wird. Noch stärker als bei Özdamar stehen bei ihm das Problem, Infragestellung der Identität und der Konnex von Mobilität und Subjektivität im Vordergrund. So ist Zafer Şenocak noch mehr ein Autor, dessen Werke in den 1990er Jahren vieles von dem nicht lieferten, was die deutsche Rezeption als Multikulturalismus oder als Orientalismus erwartete und verlangte.

In der Forschung wird gerne zwischen der Literatur Emine Sevgi Özdamars und Zafer Şenocaks unterschieden, besonders was den Umgang und die Verhandlung des Orientalismus betrifft. Zwar wird beiden Autoren attestiert, dass sie 
den Orientalismus in Frage stellen ${ }^{402}$, doch wird mitunter für Özdamars Literatur zugleich auch konstatiert, dass sie den Orientalismus umgekehrt mit Gebrauch türkischer und islamischer Marker in Alltagszusammenhängen in ihrer Literatur wieder reterritorialisiert habe. ${ }^{403}$ Auf den ersten Blick kann bei einem Vergleich der Texte dieser beiden Autoren dieser Eindruck entstehen. Jedoch greift diese Interpretation, wie ich zeigen werde, zu kurz. Nicht allein deshalb, weil in Özdamars Literatur der gezeigte Kategorienwechsel von Heimat und Ankommen zum Überleben und Wohnen stattgefunden hat. Sondern besonders deshalb, weil die Literatur Şenocaks diesen in den 1990er Jahren ebenfalls vollzieht. Denn auch er rückt in seiner Literatur wie Özdamar an die Stelle der Heimat, der Zugehörigkeit das Wohnen und den Körper. Und auch bei ihm ist die Frage der Integration eine Frage der Erzählung, die den Protagonisten seiner Tetralogie, Sascha Muhtesem, umtreibt. Im Unterschied zu allen Figuren bei Özdamar, auch zu denen in Zaimoğlus Literatur und in Akıns Filmen bis GEGEN DIE WAND, hat Sascha Muhtesem überhaupt keine finanziellen Probleme. Er ist in deutscher Sprache Journalist, Detektiv, Romanautor und tritt in Gefährliche Verwandtschaft ein Erbe an, das ihn existenziell absichert. Was Sprache und Finanzen betrifft, müsste er als ein Angekommener oder als Integrierter beschrieben werden. Doch ist Sascha Muhtesem das Gegenteil davon. Und nicht einfach deshalb, weil er mehrere Identitäten hat. Vielmehr stehen auch hier am Anfang und am Ende ein deplatziertes Verhältnis zwischen öffentlichem, privatem Raum, ein asymmetrisches zwischen Inklusion und Exklusion und ein Problem der Kommunikation, wie in Özdamars Karawanserei-Roman.

\section{4 «Nicht aus der Haut kommen können« oder die Unmög- lichkeit des »third space»}

Es gebe Tage, da schwebe man »vor der eigenen Haustür und traut sich nicht hinein«, meint der Erzähler am Anfang von Zafer Şenocaks Roman Die Prärie (1997). Man bilde sich ein, »drinnen habe sich alles verändert«, und weil man dies glaube, sei jetzt kein »Zutritt [...] mehr möglich«. Aber eigentlich »ist dort alles genau so, wie es immer gewesen ist, alles an seinem Platz, nur man selbst

402 Siehe hierzu: KonUK (1998). BAY (1999).

403 Cheesman, Tom (2007): Novels of Turkish-German Settlement. Cosmopolite Fictions, Columbia: Camden House, S. 100. Diesem orientalisierenden Gebrauch versucht sich Zaimoğlu in der Kanak Sprak ebenfalls zu widersetzen, in dem er übliche alltägliche Verwendungsweisen von türkischen Begriffen wie Gözüm (»Mein Auge«, »mein Augenlicht«) oder Canm (»mein Herz«, »meine Seele«) vermeidet. Siehe hierzu: ZAIMoĞLU (1995): S. 14. 
ist sonstwo, schwebt ortlos vor der eigenen vertrauten Welt «. ${ }^{404}$ Dies mögen der Protagonist und der Erzähler zwar einsehen, sie beide werden aber über alle vier Bände der Tetralogie hinweg dennoch kein Vertrauen zu den Räumen aufbauen, die sie real und imaginär bewohnen. Das verkehrte Verhältnis zwischen öffentlichem und privatem Raum - draußen ist es sicher, drinnen unsicher - fällt nicht nur im zweiten Band von Şenocaks Tetralogie auf. Bereits im ersten Band Der Mann im Unterhemd (1995) steht der Erzähler draußen vor der Tür. Dieses Mal tut er jedoch so, »als würde ich das Haus von außen betreten, als säße ich nicht hier, hinter meinen Fenstern im Verborgenen, sondern wäre einer, der hereinkommt, für jeden im Haus sichtbar«. Diese Sichtbarkeit liefert den Erzähler wie jeden anderen, der ein unbekanntes Gebäude betritt, den Blicken der Bewohner aus, heißt es im nächsten Satz. ${ }^{405}$ Und der letzte Band der Tetralogie, Der Erottomane (1999), beginnt mit der Beschreibung eines Schwellenbereichs, der hier jedoch überschritten wird: »Ich bin aus unserer Wohngemeinschaft ausgezogen. Man kann nicht auf Dauer mit zwei Frauen zusammenleben «, lautet der erste Satz. ${ }^{406}$

Unwohlsein, weil die eigene Wohnung sich verändert haben könnte im zweiten, weil die anderen einen anschauen, im ersten, oder weil das gemischtgeschlechtliche Zusammenleben zu dritt in einer Wohnung nicht gelingt, im vierten Band, stehen jeweils nicht am Ende, sondern am Anfang, als Ausgangspunkte für die Ich-Erzähler. ${ }^{407}$ Den vermeintlich unwohnlichen Zustand in Gefährliche Verwandtschaft, dem dritten Band der Tetralogie, werde ich später noch ausführlich analysieren. Während die deutsche, die öffentliche Seite in den 1980er Jahren noch als ein getrennter, unbeteiligter und konturloser Dritter dargestellt wurde wie in der Zwei-Zimmer-Wohnung von Dursun und Turna in 40 QM DEUTSCHLAND oder in Uwes Figur in YASEMIN -, zeigen uns diese ersten Sätze in den 1990ern schon, dass man sich nun selbst als unbekannter Beobachter von draußen wahrnimmt. Wenn der Ort der Begegnung zwischen Deutschen und Türken in den

404 ŞENOCAK (1997): S. 5.

405 ŞENoCAK, Zafer (1995): "Das Haus«. In: ders.: Der Mann im Unterhemd, Berlin: Babel, S. 23-30, hier S. 23. Auch in Sinan Çetins Film BERLIN IN BERLIN gibt es keinen Akteur, der nicht beobachtet wird. Siehe hierzu: ÇETIN (1993).

406 ŞENOCAK (1999): S. 5.

407 Auch am Anfang von Michael Kliers Film OstKreuZ von 1991 sind eine Mutter und eine Tochter im Jahr der Wiedervereinigung zu Fuß auf Wohnungssuche. Sie sind aus der DDR über Ungarn nach Westdeutschland geflohen und wohnen zunächst in der Nähe einer Baustelle in einem Berliner Randgebiet in einem Container. In Sönke Wortmanns äußerst erfolgreicher Komödie Der Bewegte Mann sucht der Protagonist Axel (Til Schweiger) im ersten Drittel des Films ebenfalls eine Wohnung. Siehe hierzu: KLIER, Michael (1991): Ostkreuz, Spielfilm, Michael Klier Film, Deutschland. Wortmann, Sönke (1994): Der bewegte Mann, Spielfilm, Neue Constantin Film Produktion, Deutschland. 
1980er Jahren geschlossene Räume waren, haben wir es nun mit einer Verschränkung im öffentlichen Raum zu tun.

Zentraler Bestandteil von Şenocaks Erzählungen sowie seiner Thematisierung der Folgen der türkischen Migration nach Deutschland ist wie auch bei Özdamar die Türschwelle. Sie ist auch in Sinan Çetins Film BERLIN IN BERLIN von 1993 heiß umkämpft. In diesem Film lebt der Deutsche Thomas im Flur einer türkischen Familie in Berlin, deren Verwandten er aus Versehen auf einer Baustelle tötete. Als er aus großem Reueempfinden sich bei der Frau des Getöteten auf der Straße vor der Wohnung der türkischen Familie entschuldigen möchte, flieht er vor Mürtüz, dem Bruder des Getöten, aus Versehen in deren Wohnung. Dort wird er dann von den Eltern des Getöten, weil für sie jeder flüchtende Mensch ein von Gott geschickter Gast ist (»Tanrı Misafiri«), vor ihren nach Rache sühnenden Kindern beschützt, solange er ihre Wohnung, ihr Domizil in Berlin nicht verlässt. Die Türschwelle entscheidet hier über den Täter (Mürtüz) und das Opfer (Thomas). ${ }^{408}$ Die Betonung der Schwelle macht die Begegnung ausschlaggebend bei Özdamar, Çetin und auch bei Şenocak. Doch zugleich sind die Akteure oft in Bewegung. Dieser Zusammenhang erfordert einen hohen narrativen Aufwand. So bestimmen auf der einen Seite topografische Komponenten wie Wohnungen, Schwellen, Hotelzimmer, Autos, Straßenbahnen, Busse und öffentliche Räume die Tetralogie und die anderen Erzählungen. ${ }^{409}$ Auf der anderen Seite gibt es einen Ich-Erzähler, dessen Wünsche im Widerspruch zu seiner Präsenz als Erzähler stehen.

Gleich in der ersten Erzählung »Fliegen « im ersten Band Der Mann im Unterhemd interessiert sich der Ich-Erzähler sehr für das Unsichtbar-Werden. ${ }^{410}$ Von Beruf ist er Journalist und Detektiv für multikulturelle Kriminalität; ${ }^{411}$ Er soll Menschen mit mehreren Identitäten aufspüren. Eine in Frankfurt verschwundene Deutsch-Türkin wird etwa in Istanbul vermutet: ${ }^{412}$ Ihr säkular-laizistisch geprägter Vater glaubt, dass sie von islamischen Fundamentalisten verführt und dorthin gebracht worden ist. Die Recherchen des Erzählers vor Ort sind erfolglos. Zufällig

408 Siehe hierzu: ÇETIN, Sinan (1993): Berlin in Berlin, Türkei: Plato Film Production.

409 Dieser Wandel von Topografien bestimmt auch den Film AusLandstourneE von Ayşe Polat. Denn Zeki und Şenay sind zu Fuß, im Taxi, im Zug, im Auto, auf dem Dampfer, mit dem Pferdewagen unterwegs und bewegen sich dabei in Städten wie Paris, Wuppertal, Stuttgart, München, Istanbul, wo sie sich in den unterschiedlichsten Hotelzimmern, Nachtclubs oder auf den Prinzeninseln in Istanbul aufhalten. Siehe: PoLAT (1999).

410 ŞENoCAK, Zafer (1995b): »Fliegen«. In: Der Mann im Unterhemd, München: Babel, S. 9.

411 Ebd., S. 11. Auch Doris Dörries Kemal Kayankaya in HAPPY BIRTHDAY TÜRKE ist Privatdetektiv. Siehe hierzu: DöRRIE (1992).

412 Kayankaya wird in Dörries Film ebenfalls von einer deutsch-türkischen Familie beauftragt, ein verschwundenes Familienmitglied aufzuspüren. Siehe hierzu: DöRRIE (1992). 
erkennt er die Vermisste auf seinem Rückflug nach Deutschland: Sie arbeitet als Flugbegleiterin und wäre, wie der Erzähler selbst, am liebsten unsichtbar, um der kulturellen Enge zu entkommen und sich im Gegenteil nicht noch mehr in sie $\mathrm{zu}$ verstricken, wie ihr Vater befürchtet hatte. ${ }^{413} \mathrm{Ihr}$ Beruf sei dafür ideal. Anders formuliert, entspricht ihr Beruf unserem Befund der vorgestellten Verbundenheit: Viele Städte der Welt werden miteinander verbunden, es stellt sich aber kein längerer Aufenthalt an diesen Orten ein. Im zweiten Band der Tetralogie, Die Prärie, verschwindet der in diesem Band als Schriftsteller gewordene Erzähler Sascha (es ist derselbe wie im ersten Band). Denn gegen Ende des Bandes tritt ein neuer Erzähler auf, der sagt, dass Sascha sich einfach so »selbstständig« gemacht habe. "Er hat sich davongeschlichen, ungefragt, ohne ein Wort zu hinterlassen. Er war eine Figur im Zentrum. Jetzt ist er an der Peripherie. ${ }^{414}$ In Gefährliche Verwandtschaft ist Sascha wieder der Erzähler der Geschichte und in diesem Roman möchte er endlich seiner »wurzellosen « Existenz ein Ende setzen. ${ }^{415}$ Eine zentrale Rolle nimmt bei dieser Suche die Übersetzung der Tagebücher seines türkischen Großvaters ein, die jedoch in einer Mischung aus Arabisch, Türkisch und Osmanisch-Türkisch verfasst sind. Weder er noch ein professioneller Übersetzer können die Tagebücher verständlich übersetzen. ${ }^{416}$ Der Großvater war am Genozid der Türken an den Armeniern von 1915 beteiligt. Da die autobiografischen Texte des türkischen Großvaters für Sascha kaum übersetzbar sind, wählt er für die Darstellung des Lebens seines Großvaters nicht eine lückenlose, rein faktuale Dokumentation, sondern - wie der Erzähler Alexander in Nadolnys Selim oder die Gabe der Rede als Zugang zu Selim - einen Roman im Roman. »Kann man heute überhaupt irgendetwas finden, was nicht erfunden ist? «, fragt sich der Ich-Erzähler selbst. ${ }^{417}$ Die Fakten folgen hier den Erzählungen nach. Wie bereits erwähnt, wird auch in keinem Film der 1990er Jahre das gefunden, wonach man eigentlich gesucht hat. Dass man mit einem derart inhaltsbezogenen Blick auf die hier behandelten Werke nicht weiterkommt, hat damit $\mathrm{zu}$ tun, dass stets die Erzählform am wichtigsten ist; ein Auseinanderklaffen von Inhalt und Form, das erneut die Entkopplung der Integration von der Migration in diesem Jahrzehnt verdeutlicht.

Sascha wird erst am Ende von Gefährliche Verwandtschaft, auf den letzten zwei Seiten, anfangen, den Roman im Roman zu schreiben, von dem er sich Wurzeln erhofft. Im nachfolgenden Band Der Erottomane, der auf die Gefährliche

413 ŞENOCAK (1995b): S. 16.

414 ŞENOCAK (1997): S. 98.

415 ŞENOCAK (2009): S. 118.

416 ŞENOCAK (2009): S. 118.

417 Ebd., S. 21. 
Verwandtschaft folgt, wird dieser Roman im Roman allerdings nicht fortgesetzt. Denn darin geht es nicht um eine einzige Geschichte, sondern um mehrere sich abwechselnde fiktionale historische Zugänge, die am Ende nicht $\mathrm{zu}$ ihm selbst, sondern zu einer Inszenierung des Selbstmords des Erzählers führen. ${ }^{418}$ $\mathrm{Zu}$ Anfang, in der Mitte und am Ende der Tetralogie möchte der Erzähler verschwinden oder sich selbst finden, unsichtbar sein oder tot. Doch trotz dieser Widersprüche bleibt er in der Erzählung. Erzähltheoretisch und mit der Großmutter von Özdamars Ich-Erzählerin könnte man fragen: Was hält ihn denn noch in der Erzählung und wie überlebt er eigentlich?

Mit Aras Örens Berlin Savignyplatz und Kemal Kurts Der Chinese von Schöneberg gehört Şenocaks Werk aus den 1990er Jahren sicherlich zu den komplexesten Fiktionen deutsch-türkischer Herkunft. Obwohl seine Figur Sascha Muhtesem gewissermaßen der unzuverlässigste Erzähler von allen ist, ziehen sich die erzählerischen Komponenten des Erzählens im und durch das Ich, des Wohnens, der Schwelle und der Begegnung durch alle vier Prosabände. Wie bereits erwähnt, zieht der Erzähler in Der Erottomane schon im ersten Satz aus einer WG mit zwei Frauen aus. Daran wird bereits deutlich, wie wichtig ihm Begegnungen mit Frauen sind. ${ }^{419}$ Im Unterschied zu Özdamar und Ören ist die Frage der Gemeinschaft in Şenocaks Literatur etwas anders gelagert. Dort, wo sich Akteure im Sinne einer Soziabilität verbinden könnten, sind die Beziehungen viel komplizierter und fragiler. ${ }^{420}$ Zuerst sollen in unserer Analyse jedoch die ersten beiden Bände der Tetralogie im Mittelpunkt stehen.

Der in Die Prärie wie Özdamars Erzählerin zunächst namenlos eingeführte Ich-Erzähler stellt sich nach einem Drittel des Romans das erste Mal mit Namen, Alter und finanzieller Situation vor; er hat viele Beziehungen mit Frauen hintereinander. Bevor wir ihn namentlich kennenlernen, wissen wir schon, dass er

418 ŞENOCAK (1999): S. 115. Auch Kemal Kurt äußert in der Erzählung »Die Lösung« über seinen Erzähler, dass er das aristotelische Grundprinzip der Erzählung (Anfang, Mitte, Ende) vergessen habe. Die Figuren in der Erzählung sind froh darüber, dass ihr Erzähler nicht damit betraut wurde, die Brandanschläge von Mölln und Solingen aufzuklären. Siehe hierzu: KURT, Kemal (2000): »Die Lösung«. In: ders., Der Chinese von Schöneberg, Berlin: Hitit, S. 27-31, S. 31.

419 In Aras Örens Roman Berlin Savignyplatz erinnert sich der Erzähler zwar an seine Romanfigur Ali Itir aus der Kriminalerzählung »Bitte nix Polizei« von 1981 und lässt ihn in diesem Roman gewissermaßen über- und weiterleben. Doch stehen neben diesen Erinnerungen an Ali Itir, mit dem er sich auf komplizierte Art und Weise identifiziert, auch die Beziehungen des türkischen Erzählers zu den deutschen Frauen, Elfie und Maria, im Vordergrund des Romangeschehens. Siehe hierzu: ÖREN (1995).

420 Siehe hierzu auch: Dollinger, Roland (2003): „Stolpersteine. Zafer Şenocaks Romane der 1990er Jahre«. In: Multikultur. Gegenwartsliteratur. Ein germanistisches Jahrbuch. A German Studies Yearbook, hg. v. Paul Michael Lützeler, Stephan K. Schindler, S. 1-28, hier S. $6 \mathrm{f}$. 
Schriftsteller ist, Essays für Zeitungen verfasst, den türkischen Pass hat und ohne Abschluss von der Schule abgegangen ist, um die Frauen zu studieren. Anfangs »nur so zum Spaß, dann für Geld, später als Partner, darin nur mit mäßigem Erfolg«. Er hat sogar ein Buch über seine Freundin Veronika geschrieben, die wir am Anfang von Die Prärie kennenlernen. Bis dahin ist er bereits dreimal geschieden worden. ${ }^{421}$ Aber auch die Beziehung mit Veronika hält nicht an: entweder, weil sich »hinter ihren gekünstelten Formulierungen nichts anderes verbirgt als ihre Impotenz«, oder weil ihr schlanker Körper keinen Platz für Sentimentalitäten habe; sicher ist sich der Erzähler da selbst nicht. ${ }^{422}$ Dabei sei gerade er für Sentimentalitäten anfällig, "wie alle Menschen, die ihre Herkunft leugnen« - und andernfalls zynisch würden. ${ }^{423}$ Denn zynisch werde man dann, wenn man nicht mehr wissen wolle, woher man kommt. ${ }^{424}$

Die nächste Frau, die unser Erzähler trifft, lernt er in der Straßenbahn kennen. ${ }^{425}$ Sie spricht ihn an. Er verbringt die Nacht mit ihr und verlässt das Haus im Morgengrauen, weil er Abschiedsszenen »nach einer solchen Nacht hasst . Danach läuft er »meistens [...] in der Stadt herum, bis die Geschäfte aufmachen« und deckt »sich dann mit neuen Klamotten ein «. ${ }^{426}$ Wie schon der Ich-Erzähler im ersten Band, Der Mann im Unterhemd, festhält, ist sein »Körper « sein »Haus«, sein »Fahrzeug « und sein »Geräteschuppen «. ${ }^{427}$ Denn das »Leben gründet sich auf weiterleben $« .{ }^{428}$ Erst nach diesen Beschreibungen stellt sich unser Erzähler als der 35-jährige Sascha Muhtesem vor. Durchschnittlich an ihm ist nicht nur sein Alter. "Auf was bin ich stolz? Ich habe keine Schulden, keinen Beruf und keine Frau. ${ }^{429}$ Auf der nächsten Seite lernt er schon Klara, die nächste Frau

421 ŞENOCAK (1997): S. 9.

422 Ebd., S. 10.

423 Ebd., S. 11.

424 Ebd.

425 Zur Bedeutung der Verkehrsmittel in Şenocaks Literatur der 1990er Jahre siehe auch: DOLLINGER (2003): S. 8.

426 ŞENOCAK (1997): S. 19.

427 ŞENOCAK, Zafer (1995c): »Betrachtungen eines Müßiggängers«. In: ders.: Der Mann im Unterhemd, Berlin: Babel, S. 71-74, hier S. 74. Doris Dörries Film HAPPY BIRTHDAY, TÜRKE! beginnt auch mit einer Sequenz, in der der Protagonist des Films Kemal Kayankaya (Hansa Cypionka), ein türkeistämmiger Detektiv, der kaum noch Türkisch spricht, seinen One Night Stand am nächsten Morgen loswerden möchte. Kayankaya stellt sich schlafend, als die Frau sich anzieht. Siehe hierzu: DöRRIE (1992).

428 ŞENOCAK, Zafer (1995d): »Die Erzählerin«. In: ders.: Der Mann im Unterhemd, Berlin: Babel, S. 79-84, hier S. 79.

429 ŞENOCAK (1997): S. 37. Leslie Adelson macht in The Turkish Turn in Contemporary German Literature darauf aufmerksam, dass die Figuren in Şenocaks Literatur in ihrer komplexen Konstruktionsstruktur bewusst jeglicher realistischer Grundlage entbehren. Sie repräsentieren nicht 
kennen, die »es gewagt hat «, ihn in der U-Bahn anzusprechen. ${ }^{430}$ Danach sind sie »monatelang [...] unterwegs, obwohl sie ein hochverschuldetes Brautkleidergeschäft übernommen hatte, das ihre Zeit sehr in Anspruch nahm. [...] An mich verschwendete sie nicht nur ihre Mittel, sondern sich selbst «. ${ }^{431}$ Aber auch diese im Buch sich auf 1,5 Seiten erstreckende Beziehung geht auseinander. Am Ende verlässt sie ihn, weil sie sich im Büro »den Arsch aufreiße«, während er den ganzen Tag seinen »Pimmel« rubbele. Das sind Klaras letzte Worte, und sie knallt die Haustür zu. So schnell könne der »Kaffee kalt werden«, kommentiert der Ich-Erzähler diese Trennung lapidar und teilnahmslos. Gleich darauf fragt er sich, wie lange wohl eine »lebenslange Bindung« dauere: eine Woche, drei Monate, ein Jahr, sieben Jahre oder vielleicht doch »lebenslang «. ${ }^{432}$ Bis er diese Frage beantwortet habe, werde seine Tür jedem offen stehen; auch denen, die kommen, um bei ihm »ihren seelischen Sondermüll endzulagern«. Nach neuesten wissenschaftlichen Erkenntnissen helfe gegen Trauer Geschlechtsverkehr, weil er das Gedächtnis schwäche. „Wenn eine Frau zu mir kommt, um sich auszuweinen, wird sie natürlich in dieses Geheimnis eingeweiht. ${ }^{433}$ Frauen, die auf diese »Einweihung« empört reagieren, versteht er nicht. Am liebsten würde er über diese »Ungereimtheiten« ein Buch schreiben.

Aber das Thema, über das er schreiben soll, ist der Islam: ${ }^{434}$ einen Text zur Fatwa gegen Salman Rushdie. ${ }^{435}$ Was ihn dazu prädestiniert, ist seiner Einsicht

und sind ausschließlich als Figurationen und textuelle Zeichen zu sehen. Siehe hierzu: AdELSON (2005): S. 77.

430 In Thomas Arslans Film Geschwister lernen sich der türkische Vater und die deutsche Mutter der Geschwister auch in einer Straßenbahn kennen. Siehe: ARSLAN (1997).

431 ŞENOCAK (1997): S. 38.

432 Ebd., S. 39. Auch die Protagonistin in Özdamars zweitem Roman Die Brücke vom Goldenen Horn wechselt ohne einen nennenswerten emotionalen Aufwand die männlichen Partner, nachdem sie, wie oben erwähnt, in Paris die Unschuld verloren hat. Siehe hierzu: ÖzDAMAR (1998): S. 169.

433 ŞENOCAK (1997): S. 40.

434 Ebd.

435 Am 14. Februar 1989 erließ der damalige iranische Ayatollah, Ruhollah Khomeini, eine Fatwa zum satirischen Roman Die satanischen Verse von Salman Rushdie, den er darin der Apostasie bezichtigte und ein Kopfgeld für seine Tötung aussprach, da sich der Roman gegen den Propheten, gegen den Islam und den Koran richte. Die Figur Mahound (alias Mohammed) wird in Rushdies Buch zum businessman. Er wird im Roman durchgehend als Mahound, der Geschäftsmann, bezeichnet. Der Koran ist nicht Gottes Wort, sondern die Erfindung eines umtriebigen, lüsternen und herrschsüchtigen arabischen Geschäftsmannes. Vgl. RushdIE, Salman (1989): Die satanischen Verse, Artikel 19 Verlag, S. 368f. Ende der 1980er Jahre begreift Rushdie diese Figur explizit als eine fiktive und nicht etwa als Darstellung oder Dokumentation der tatsächlichen historischen Person. Damit impliziert sein Roman allgemein die Aussage, dass jede Religion vom 
nach weder ein Studium der Islamwissenschaft noch eine andere Form des Spezialwissens, sondern sein türkischer Pass und sein Großvater, der Muslim war. ${ }^{436}$ Auf Anfrage der Redaktion schreibt er den Rushdie-Artikel; davon, dass er eigentlich ein Experte in Frauenfragen ist, wissen die Kollegen nichts. In der Redaktion sitzen »zu viele gehemmte Nachkommen prüder Protestanten, die lieber den Islam zum Thema machen wollen als die interkulturelle Geilheit «. ${ }^{437}$ Die interkulturelle Spannung besteht für ihn nicht zwischen den Kulturen, sondern zwischen Mann und Frau, auch wenn heute niemand mehr über das andere Geschlecht schreiben möchte: »Heute schreibt jeder über sein eigenes Geschlecht, als handelte es sich dabei um das Vaterland, dessen Verteidigung ansteht. Ein obskurer Geschlechtspatriotismus macht sich breit«. ${ }^{438}$ Zwischen Mann und Frau gibt es eine Differenz, die fernab einer national codierten körperlichen Identität oder eines Dialogs der Kulturen den Menschen sehen oder nicht sehen lässt: »Durch die Haut einer Frau schimmert ihr Inneres. [...] Die Männer haben mindestens

Menschen erfunden ist. Knapp 30 Jahre später skizziert Abdelhamad Samad ein vergleichbares Bild von Mohammed. Im Unterschied zu Rushdie geht es ihm aber dabei keineswegs darum, eine allgemeine Aussage über die Entstehung von Religionen zu fällen. Im Zentrum seiner Publikation steht, den Islam in seinen Anfängen und in seiner Gegenwart als eine mitunter mafiös und faschistoid strukturierte Religion zu beschreiben, die auf die psychopathische Person ihres Begründers Mohammed zurückgeht. Siehe hierzu: HAMAD, Abdel-Samad (2015): Mohamed. Eine Abrechnung, München: Droemer Knaur.

436 Ebd.

437 ŞENOCAK (1997): S. 42.

438 Ebd., S. 9. Şenocak nennt weder Beispiele für diese Konjunktur noch entfaltet er sie argumentativ. Doch tatsächlich wird seit den 1990ern im Bereich des deutschen Films die Frage von Geschlecht und Zugehörigkeit, besonders im Unterhaltungskino, dem in der Forschung so genannten »Konsenskino«, postfeministisch verhandelt. Hierzu gehören Filme wie EIN MANN FÜR JEDE TONART (1992), FRAUEN SIND WAS WUNDERBARES (1993), ABgESCHMinKT (1993), DER BEWEgte MANN (1994), IRREN IST MÄNNLICH (1995), STADTGESPRÄCH (1995) und DAS SUPERWEIB (1996). Im Gegensatz zum »Neuen deutschen Film« der 1960er und 1970er Jahre wird hier auf einen "profitablen Kompromiss zwischen künstlerischen und kommerziellen Interessen« gesetzt. Siehe hierzu: HAKE, Sabine (2004): Film in Deutschland. Geschichte und Geschichten seit 1895, Reinbek bei Hamburg: Rowohlt, S. 311. Katja Nicodemus konstatiert, dass der deutsche Film der 1990er Jahre im Unterschied zum »Neuen Deutschen Film« weder ein Manifest hervorgebracht noch eine vergleichbare gesellschaftliche »Angriffsfläche« vorgefunden habe. Der `Neue deutsche Film` habe die gesellschaftlichen Verdrängungsstrategien von »Papas Kino« der 1950 und 1960er Jahre aufgezeigt - und damit auch die Spuren der Vergangenheit in der Gegenwart. Im deutschen Film der 1990er Jahre erkennt Nicodemus hingegen eine Verbindung von Kommerz und Kunst, die sich zwischen gefälligem »Konsenskino« und kreativen Neuentwicklungen, wie beispielsweise der Entstehung der Creative X Pool bewegt. Siehe hierzu: NicodEmus (2004): S. 359. 
zwei Häute, manche stecken sogar in Kapseln. Die Frauen dagegen sind transparent. Man muß nur den Blick für ihre Transparenz haben. « ${ }^{439}$

Im Binnenroman Veronika beschäftigt den Autor die zwischengeschlechtliche Frage, wo die Liebe beginnt. Es ist bereits zu spät, darauf eine "gehaltvolle, bleibende, dem Thema angemessene und allseits zufriedenstellende Antwort zu geben «. ${ }^{440}$ Zugleich ist für den Erzähler des Rahmenromans aber genau dieses Verlangen, das Rätsel um die Liebe lösen zu wollen, das eigentliche Problem. Denn man wolle »gerade aufgrund seiner Rätsel « geliebt werden. Sascha wundert sich selbst darüber, »daß Menschen überhaupt noch zur Liebe fähig sind, obwohl sie sich permanent enträtseln«. Trotz dieser Erkenntnis, dass man eine »eigene Sprache« brauche, die »ohne Verständnis auskommt und dabei unvergeßlich» und individuell bleibt, ist es der Autor selbst, der nach diesen Reflexionen das Scheitern seiner nächsten Beziehung sehr trocken kommentiert. Bei Elvira, Veronikas Nachfolgerin, die er auf dem Markt kennenlernt, stellt er ebenfalls nüchtern fest, dass er sie wahrscheinlich zu sehr mit seiner »Geilheit genervt habe «. ${ }^{441}$ Woher diese kommen könnte, führt er in einem Zeitungsartikel aus. Sein Großvater habe einmal gesagt, dass seine Familie schon immer »unersättlich « gewesen sei. Diese Unersättlichkeit habe Tradition und gelte wahrscheinlich für das ganze Volk. »Wie hätte es sich sonst über drei Kontinente ausbreiten können. Doch nur, weil es unersättlicher war als alle anderen Unersättlichen. « ${ }^{442}$

Der Ich-Erzähler beschließt, »diese Welt zu verlassen « und geht nach Amerika, um sich zu verändern. Ob dies individuell-beziehungstechnische Gründe hat oder an den nervenden Anfragen aus der deutschen Redaktion liegt, ist an dieser Stelle des Romans nicht klar. Beide Themen sind von Widersprüchen aus unterschiedlichen Richtungen geprägt. Die intimen Beziehungen, die am besten von Geheimnissen umwoben bleiben sollten, dabei aber immer an der »Geilheit» oder am Drang des Protagonisten, Geheimnisse preiszugeben, scheitern, stehen im eklatanten Widerspruch zu den Anfragen von draußen. Beide Erzählstränge werden in dieser beziehungslosen Bindung auch im weiteren Verlauf des Romans fortgeführt. Auf der individuellen Ebene merkt der Erzähler etwa an, dass er in die USA geht, um sich zu verändern. Dabei nimmt er direkten Bezug zur deutschen Kulturgeschichte, indem er darauf verweist, dass man früher nach Italien

439 ŞENOCAK (1997): S. 10.

440 ŞENOCAK (1997): S. 27.

441 Ebd., S. 52. Auch in den Filmen Lola Und BILIDIKID (1998) und AUSLANDSTOURNEE (1999) sind die Protagonisten häufig sexuell erregt; das gilt auch für die erfolgreichen deutschen Filme Das Leben ist eine Baustelle, Der Campus, Lammbock, Der Bewegte Mann und viele weitere. 442 ŞENOCAK (1997): S. 55. 
gegangen sei, um sich zu verändern. »Heute geht man nach Amerika. ${ }^{443}$ Wie es die Verstrickung zwischen Zuschreibung und Selbstbeschreibung schon andeutet, ist die erwünschte Veränderung alles andere als einfach. So zieht es ihn auch nicht einfach in eine bestimmte Metropole wie New York oder Los Angeles, sondern in die Prärie, wo es nur »Bäume und meilenweit unbebaute Erde« gibt. Wenn man sich verändern will, »muß man erst einmal die Orientierung verlieren «. ${ }^{444}$ Später wird Sascha präziser, warum er gerade in Amerika die Orientierung verlieren müsse. Begriffe wie »Inländer« und »Ausländer« treffen für die Türken in der Bundesrepublik für die 1990er Jahre einfach nicht mehr zu. Sie haben kein Territorium, das ihnen gehört oder zu dem sie gehören. Wie bereits erwähnt, verläuft die Grenze zwischen dem Deutschen und Türkischen nicht mehr außen und sondern innen, durch den eigenen Körper. Und es sind politische Ereignisse und die mediale Berichterstattung darüber, die die Wirkmächtigkeit und Kommunikation dieser innen liegenden Grenzen steigern. Die Migration nach Amerika erfolgt auch, um dieser inneren Spannung zu entkommen.

In Amerika konnten mich die Ereignisse nicht mehr einholen. In der Türkei, ich hatte es auch dort einmal versucht, war mir die Flucht mißlungen, da die Türkei, wie Italien, ein unbedeutender Ort in Deutschland ist. Täglich werden die Grenzen zwischen der Türkei und Deutschland von Tausenden von Menschen aufgehoben. Bei diesen Aktivitäten zwischen zwei Ländern verlagern sich die Grenzen nach innen. In jedem menschlichen Körper gibt es einen Grenzverlauf, der mit den Staatsgrenzen korrespondiert. Diese Grenzen werden dort für immer aufgehoben. Man wird sie weder durch Staatsverträge noch durch Gedächtnisschwund los. Wenn Sie Deutschland meiden wollen, müssen Sie die Türkei loswerden und umgekehrt. ${ }^{445}$

Sie kommunizieren miteinander, doch ihre Form der Kommunikation ist nicht kompatibel mit den Anfragen aus den Redaktionen, wenn sie auch in Beziehung zu ihnen steht. Würde der Erzähler gebeten, über »interkulturelle Geilheit« zu berichten, müsste er vielleicht gar nicht in die amerikanische Prärie auswandern. Wie im ersten analytischen Kapitel dieses Buches geht es wieder nicht darum, wirklich Amerikaner werden $\mathrm{zu}$ wollen, wenngleich die Vereinigten Staaten hier als Orientierung erneut ins Spiel kommen. Es geht aber auch nicht darum, Amerika in sozialstruktureller oder konsumistischer Form nachzuahmen, wie

443 Ebd., S. 68.

444 Ebd., S. 69.

445 Ebd., S. 73. Retrospektiv fügt der Erzähler im dritten Band der Tetralogie einen weiteren Grund hinzu, der die implizite kulturelle Spannung um eine narrative ergänzt: Er sei nach Amerika gegangen, weil Deutschland »ein Land von Märchenerzählern und Bittstellern geworden« sei. Im Unterschied zu anderen erfolgreichen Kollegen könne er sich zudem an seine eigene Herkunft nicht gut erinnern. Siehe hierzu: ŞENOCAK (1998): S. 129. 
es noch Örens Niyazi in den 1970ern tat. Denn für Şenocaks Ich-Erzähler ist die amerikanische Prärie ein Raum ohne Ort, von dem er sich erhofft, sich dort selbst jenseits des Türkischen und Deutschen begegnen zu können.

Während in den 1970er Jahren durch Waren und Produkte wie Auto, Fernseher und echten Whiskey die kulturelle Koordination klar markiert ist, steht im Zentrum von Şenocaks Text die Kommunikation, nach innen wie nach außen, die ganz ohne soziale Beziehungen natürlich nicht möglich ist. In Der Mann ohne Unterhemd hält der Erzähler am Ende zum eigenen Lebenslauf fest, dass er mit sieben Jahren zusammen mit vielen anderen gebetet habe. In der Moschee war es »laut, staubig« und es »roch nach Schweiß«. Zu dieser Zeit las er Robinson Crusoe und »wunderte [sich] darüber, wie dieser Mann es ganz einsam auf einer Insel ausgehalten hatte, ohne zu sterben $« .{ }^{446}$ Doch ist er in den USA auch nicht wirklich allein. Dort lernt er die Kneipenwirtin Sue kennen, mit der er eine sexuelle Beziehung eingeht, für die er ihr manchmal sogar Geld gibt.

Sein eigenes Geld verdient er als writer in residence irgendwo im Norden der USA. Außerdem lehrt er amerikanischen Studierenden deutsche Literatur und deutsche Sprache. Dabei fragt er sich, wofür amerikanische Studierende in dieser Prärie eigentlich Deutsch lernen. Er weiß wenig über Sue, verliebt sich aber trotzdem in sie, weil die Distanz zwischen ihnen stimmt und sie seinem Körper Luft zum Atmen gibt: „Sie hat Stellen an mir entdeckt, die mir unbekannt waren. Ich spüre ihren Atem, wie er sich mit meinem vermischt, ohne daß einer von uns erstickt. ${ }^{447}$ Zwischen ihm, Sue und den anderen Amerikanern entsteht eine Zone, in der es dem Erzähler gut geht. »Die Gelassenheit hier bedeutet mir sehr viel. In Deutschland habe ich nichts so sehr vermißt, wie diese gelassene Art. « ${ }^{448}$ Eine Gelassenheit, sich in Gegenwart unterschiedlicher Menschen wohlzufühlen. ${ }^{449}$ Trotz dieses Wohlbefindens unternimmt der Erzähler mit einem türkischen Bekannten aus New York und Sue eine Reise nach Istanbul, um seinen Vater zu

446 ŞENOCAK (1995): S. 137.

447 ŞEnocaK (1997): S. 84f. Ähnlich schildert der Autor Selim Özdoğan den Sex seines deutsch-türkischen Ich-Erzählers mit seiner deutschen Freundin in seinem Roman Mehr (1999): »Später war ich völlig außer Atem, mein Hals war trocken, wahrscheinlich hatte ich doch noch geschrien, wir lagen da und kamen langsam wieder zur Besinnung. Haut an Haut, angenehm ineinander verknotet, mit pochenden Herzen, die sich langsam beruhigten, unsere Gerüche, die sich zu einem vereint hatten." Siehe hierzu: ÖzdoğAN, Selim (1999): Mehr, Berlin: Aufbau, S. 20. Genauso wirkt es auf den Zuschauer, wenn Cem aus APRILKINDER das erste Mal mit der deutschen Prostituierten Kim in ihrem Zimmer im Bordell sexuell verkehrt. Siehe hierzu: YAvUZ (1998).

448 Ebd., S. $80 f$.

449 Siehe hierzu: GoRdon, Milton (1964): Assimilation in American Life, Oxford: Routledge, S. 69. 
besuchen. Der Ich-Erzähler hält davon nur einen einzigen Dialog mit Sue fest. Sue findet die Stadt so furchtbar wie Los Angeles, wobei Istanbul noch etwas »dunstiger « sei. Er ärgert sich darüber, wie sie eine zweitausend Jahre alte Stadt derart mit L.A. vergleichen könne. »L.A. ist eine Mißbildung. Kann man in L.A. vielleicht so gut träumen wie hier?« Sue entgegnet, dass sie abreisen werde. Er komme »natürlich mit«, ohne sie bleibe er nicht hier, »ich weiß gar nicht, warum ich hier bin«. Weder seine türkische Staatsbürgerschaft noch sein Vater, der Grund für die Reise, spielen in diesem Dialog eine Rolle.

Warum? Die Antwort des Erzählers ist verwirrend. Denn kaum ist er zurück in den USA angekommen, wacht er aus einem Traum auf. Hinsichtlich der Beschreibungsfolge wird zwischen Realität und Traum nicht unterschieden, und auch die nachfolgenden Sätze liefern keine Anhaltspunkte. Wenn wir davon ausgehen, dass der Istanbul-Trip ein Traum war, wirkt dieser doch so sehr nach, als sei der Ich-Erzähler wirklich weg gewesen. Was Traum ist, was Einbildung und was äußere Realität, ist in diesen Passagen nicht zu entscheiden. Auf jeden Fall braucht der Erzähler eine Weile, um sich wieder an den alltäglichen Rhythmus in den USA zu gewöhnen - an die Gelassenheit. ${ }^{450}$ Doch selbst als er sie wiedergefunden hat, ist er irritiert. Auf dem Nachhauseweg vom College fragt sich der Ich-Erzähler, „was mir hier fehlt, um mich hier zu Hause zu fühlen. Mut, Trieb, Lebenswille? « Obwohl das Leben in der eigenen Haut mit Sue gut war und ist, habe er sich dafür doch das »Jagen abgewöhnt«. »Vielleicht sollte ich jetzt zu den Tieren, um meine verlorenen Instinkte wiederzuerlangen. ${ }^{451}$ Sein deutscher Redakteur ruft an und fragt, ob er nicht Türken in den USA zu Mölln interviewen könne. Er gibt dem Redakteur eine unerhörte Antwort, woraufhin dieser auflegt. Nach Niklas Luhmann ist der Exklusionsbereich in einer Gesellschaft »vor allem an der Unterbrechung von Reziprozitätserwartungen zu erkennen «. ${ }^{452}$

Sascha wird trotzdem nach Deutschland zurückkehren. Diese letzte widersprüchliche Konstellation erzählt aber nicht mehr er selbst, sondern sein amerikanischer Autor, der sich erst gegen Ende des Romans dem Leser zu erkennen gibt, weil er ein Problem mit seiner Erzählung bekommt, denn »Sascha hat sich selbstständig gemacht «. ${ }^{453}$ Er befürchtet, dass Sascha, mitunter weil er die »langweilige« deutsche Sprachwissenschaftlerin Marianne in der Bibliothek kennenlernt, mit ihr nach Deutschland zurückkehren wird. Dabei wähle man gerade deshalb einen amerikanischen Autor, um Identitätskonflikte zu vermeiden, wie der neue Erzähler konstatiert. Denn jeder, der wie Sascha »hierherkommt, trägt

450 ŞENOCAK (1997): S. 82.

451 Ebd., S. 85.

452 LuHMANN (1998): S. 623.

453 ŞENOCAK (1997): S. 93. 
eine unerträgliche Spannung in sich «. ${ }^{454}$ Trotz der integrativen Gelassenheit und Soziabilität, die Sascha in der amerikanischen Provinz und Prärie kennenlernt, entgleitet er seinem Erzähler. »Saschas Glanz und Elend als Figur hing früher von seiner Zugehörigkeit ab. Seit er sich abgesetzt hat, hat er niemanden mehr um sich, der seiner Sprache vertraut. ${ }^{455}$ Dem amerikanischen Autor fehlt der Schluss: »Sascha lässt sich irgendwie nicht beenden «. ${ }^{456}$

Im letzten Kapitel »Der Übersetzer« aus Die Prärie stellt der amerikanische Autor einen Kollegen mit dem Kürzel A. C. vor, der kreatives Schreiben am College unterrichte. Da ihm seine Gedichte so gut gefielen, habe er ein Kapitel aus dessen Gedichtband Holzwege übersetzt. Das letzte Gedicht handelt vom Traum eines Jungen, der sich in seinem Zimmer eingesperrt hat und die Wand anstarrt.

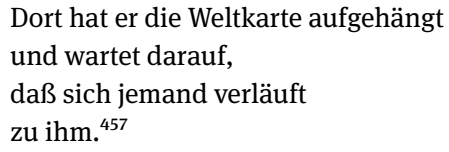

Während Die Prärie damit begann, dass der Erzähler nicht mehr in seine Wohnung kommt, endet der Roman damit, dass jemand mit einer Weltkarte an der Wand auf einen Fremden wartet. ${ }^{458}$ Wie in Özdamars Romanen, in Çetins Film und vielen anderen Erzählungen dieser Dekade kommen hier der Schwelle und der Referenz „Welt« Schlüsselpositionen zu. Es geht um einen neuen Kontakt, um eine neue Form der Soziabilität jenseits kultureller Zuschreibungen und um die Skizzierung

454 Ebd., S. 102. Von dieser Spannung berichtet auch der Erzähler in Örens Roman Berlin Savingyplatz: Er erkennt sie für sich und seine fiktive Figur Ali Itir ebenfalls. Denn beide versichern ihren wechselnden deutschen Gegenübern von Dr. Anders bis Elfie, dass sie nicht die seien, die sie in ihnen sähen. Nach diesem Bruch der Reziprozität, leitet Ören seinen Roman mit den rätselhaften Sätzen ein, dass er (wer auch immer) den Mut aufgebracht habe, »die Bedeutung der geheimen, undankbaren Aufgabe [...] unzweifelhaft« auf sich zu nehmen. Doch trotz einer Aufgabe »war sein Verhalten dadurch nicht ruhiger, sondern eher hektisch geworden«. Siehe hierzu: ÖREN (1995): S. 11.

455 ŞENOCAK (1997): 98.

456 Ebd., S. 103. Vgl. ZAimoĞLU (1997); AKIN (2003).

457 ŞENOCAK (1997): 112.

458 Interessanterweise stellt sich auch Martin Heidegger 1950 in seiner Textsammlung Holzwege, auf die Şenocak implizit Bezug nimmt, für die Öffnung seiner Theorie den Gegenwartsfragen der Technik und Globalisierung. Der Begriff und Titel der Sammlung steht nach dem Autor selbst für neue Wege, die im sprichörtlichen Sinne zwar in die Irre führen, »aber sie verirren sich nicht", sie führen zu einer Begegnung. Siehe hierzu: HeIDEgGer, Martin (1950): Holzwege, Frankfurt a. M.: Klostermann. Siehe auch: DER SPIEgEL (1950): »Philosophie - Heidegger. Rückfall ins Gestell«. In: DER SPIEGEL, 06.04.1050, S. 35f. 
eines neuen postnationalen Bürgers. Mit dem Konnex von Türschwelle und Welt wird hier gegen nationale und kulturelle Fixierungen das Menschsein angerufen, die auf den Bedarf einer »intensified world-level interaction« verweist. Diese ist zugleich auch die Grundlage für die Reflexionen Soysals für eine »postnational membership «. ${ }^{459}$

In seinem 1994 veröffentlichten Essayband War Hitler Araber? erläutert Zafer Şenocak anhand einer Passage aus Salman Rushdies Die Satanischen Verse, wie sich das multikulturelle Leben verwirklichen lässt. Rushdie skizziert in seinem Roman ein von Migration geprägtes London, in dem sich neuartige Kontakte ergeben. "Freunde fangen an, einander spontan $\mathrm{zu}$ besuchen ohne sich vorher anzukündigen. Seniorenheime werden geschlossen, die Großfamilie gefördert. Schärfer gewürzte Speisen kommen auf den Tisch. In englischen Toiletten wird sowohl Wasser als auch Papier benutzt. ${ }^{460}$ Die Übernahme familiärer und freundschaftlicher Verhaltensweisen, mitunter auch die körperhygienischen Praktiken von Zugewanderten werden in den 1990er Jahren immer wieder thematisiert. ${ }^{461}$ Außerdem sehen die damaligen Integrationstheorien, ob transnational oder multikulturell, Integration als einen global vernetzten oder wechselseitigen Prozess an, der sich von den Ansprüchen und Erwartungen der Assimilation gelöst hat

459 SOYSAL (1994): S. 144.

460 ŞENOCAK, Zafer (1994): War Hitler Araber? Irreführungen an der Rand Europas, München: Babel, S. 25.

461 Siehe hierzu: Hunn (2005): S. 546. Beispielsweise schreibt die Journalistin Dilek Zaptcıŏlu, die zwischen den Jahren 1988 und 1998 Deutschlandkorrespondentin der türkischen Tageszeitung Cumhuriyet war, dass $» z$ u hoffen [ist], dass manche menschlichen Werte der vorkapitalistischen Welt, die [die Türken] [...] mitgebracht und ihren Kindern weitergegeben haben, wie Gastfreundschaft und Respekt vor den Älteren, wie Solidarität mit den Schwachen und Benachteiligten [...] nicht verloren gehe«. ZAPTcıoĞLU, Dilek, in: Der Tagesspiegel, 20.06.1993, zitiert nach ebd. Einem vergleichbaren Credo folgten auch die Interkulturellen Wochen in den 1990er Jahren. Im Zentrum der Wochen stand beispielsweise in Jena und in Erfurt der Gedanke, über dargestellte und beim Essen, tanzen und Fußball spielen gelebte Multikulturalität die Stadt und seine Bevölkerung »weltoffener « zu machen. Paradigmatisch dafür ist vielleicht die Aussage der Erfurter Märchenerzählerin Gisela Zimmermann, die in den 1990er Jahren bei den Interkulturellen Wochen auf dem Erfurter Anger Märchen aus aller Welt in einer Straßenbahn erzählte. Sie verband damit einen besonderen kulturellen Auftrag. «Das Wahrnehmen der Elemente um uns herum ist so heilsam. Leider geht die Fähigkeit hierzu in der zivilisierten Welt mehr und mehr verloren. Die Afrikaner können das noch. Darum brauchen wir diese Kultur, um wieder heil zu werden.« Siehe hierzu: LANDESBEAUfTRAgTE FÜR AUSLÄNDERFRAgEN DES FrEISTAATS THüRINGEN (1995): ... und sie feierten vierzig Tage und vierzig Nächte lang. Märchen aus aller Welt in einer Straßenbahn auf dem Erfurter Anger erzählt, In: Offene Grenzen. Offener Sinn. Fünf Jahre der ausländischen Mitbürger in Thüringen, dokumentiert von Elisabeth Garbe, Stadt Erfurt, S. 122-123. 
- dessen klare gesellschaftliche Rahmungen dadurch jedoch auch verloren gegangen sind. So gibt es für die Transnationalisten und Multikulturalisten auf die zentrale Frage der Integration (wohinein integrieren?) schon allein deshalb keine Antwort, weil die globalisierte Welt von einem gleichzeitigen Hier und Dort geprägt ist. ${ }^{462}$ Ein Konzept, das nur auf der Verbindung von Hier und Dort oder auf einer Logik des Sowohl-als-auch basiert, ist letztlich unbrauchbar. ${ }^{463}$ Wie in Özdamars Literatur fungiert hier die Ironie als Trope, durch die mit einer immer wieder eintretenden Verstellung (dissimilatio) auf ästhetischem Weg eine >Wendung ins Unbestimmte erreicht werden soll. Diese Unbestimmtheit ergreift auch konkrete soziale Interaktionen: Bei Rushdie heißt es zwar, dass schärfere Speisen im multikulturellen London auf den Tisch kommen, aber wie in vielen anderen Produktionen der 1990er Jahre wird das gemeinsame Essen dann nicht beschrieben; oder es wird begonnen, aber nicht beendet. Das Beisammensitzen am Tisch ist in den 1990er Jahren niemals frei von Störung.

Wie in Zafer Şenocaks Romanen der 1990er wird auch in Emine Sevgi Özdamars Das Leben ist eine Karawanserei nicht drinnen gewohnt. Bei beiden Autoren gibt es zwei Türen, die von außen nach innen und von innen nach außen führen. Und beide entkoppeln auf eine spezifische Art die Migration von der Integration und unterminieren die Unterscheidung von Fiktion und Realität. Dies soll ein »Fiktivitätsbewusstsein« dafür schaffen, dass die Realität eigentlich anders ist als man meint oder sie wahrnimmt. ${ }^{464}$ Grundlage ist bei beiden Autoren eine unbestimmbare, sich entziehende Erzählerfigur. Es ist ebenso unmöglich, vor die Geburt zu treten, wie in Şenocaks Roman den eigentlichen Erzähler auszumachen: Ist es Sascha, ist es der amerikanische Autor oder ist es am Ende der Auftragnehmer eines deutschen Chefredakteurs? Einen »unmarked space«, von dem aus alles beobachtet werden kann, was geschieht, gibt es nicht. Bevor der amerikanische Autor auftritt, hält einer der Erzähler in Şenocaks Roman fest, dass er von einem Versteck aus alles beschreibe und »keiner geregelten Arbeit « ${ }^{465}$ nachgehe. Die Großmutter aus Özdamars Roman würde an dieser Stelle fragen, wie er es denn schaffe, ohne geregelte Arbeit zu überleben. Doch sozialstrukturelle Fragen spielen bei Şenocak kaum eine Rolle. Vielmehr geht es in seiner insgesamt erzählerisch labyrinthartigen Tetralogie - mit Ausnahme von Gefährliche Verwandtschaft - mit den zentralen Themen der Körperlichkeit, der Beziehung

462 Siehe hierzu: GLICK-SCHILLER (1994) und FAIST (2000).

463 Siehe hierzu: LANGENoHL/RAUER (2011): S. 10.

464 Siehe hierzu: WIRTH (2017): S. 18.

465 Ebd., S. 91. 
zwischen den Menschen, besonders zwischen Mann und Frau, um die universellmenschliche Rahmung seiner kulturellen Unbestimmtheit. ${ }^{466}$

Niklas Luhmann hat die moderne Gesellschaft als ein Labyrinth beschrieben, in dem ein Beobachter nur beobachten kann, was der andere beobachtet. Auf ganz ähnliche Weise wechseln in Şenocaks Roman die Erzählerpositionen, nur dass dabei die Differenz zwischen einer Beobachtung erster und zweiter Ordnung fehlt. Dasselbe passiert in Berlin Savignyplatz von Aras Ören, in dem eine alte Figur anders neu erzählt wird und der Ich-Erzähler selbst viele Positionswechsel vornimmt, ohne dabei wirklich aus seiner Haut herauszukommen. Denn Ali bleibt ihm bis zum Schluss auf den Fersen, so wie das Türkische und Deutsche bei Sascha stets im Spiel bleiben. So ist das Beobachten der Beobachtung bei Şenocak von einem Spiel geprägt, das unklar werden lässt, was genau passiert. Trotz der Dominanz des öffentlichen Raums, der Schwelle und der Mobilität gibt es in der Prärie keine realistische Passage, weil sich die Akteurinnen und Akteure nie lange dort aufhalten. Bei Şenocak, Özdamars Romanen der 1990er Jahren und in Örens Berlin Savignyplatz üben Sprache und Literatur eine verfremdende, verstellende und performative Funktion aus. Sie sammeln Wörter und Sätze und stellen den Schreibprozess in den Vordergrund. ${ }^{467}$ Die Heimat oder die verlässlichste Referenz von Şenocaks Erzähler ist kein Haus, keine Wohnung, kein Land, keine Straße, keine Frau, sondern ein Notizheft, das er von Veronika geschenkt bekommen hat: »Meine Gedanken haben jetzt ein Zuhause. Da macht es mir nicht mehr so viel aus, daß ich selbst kein Zuhause habe ${ }^{468}$ Um den Mangel an verlässlichen Referenzen ${ }^{469}$ auszugleichen, setzt Şenocaks wie Özdamars Poetologie auf das Surreale. In Özdamars erstem Roman spricht die Großmutter den Leitsatz der öffentlichen Begegnung aus; das poetologische Konzept Şenocaks wird mit den Worten des türkischen Großvaters wiedergegeben. ${ }^{470}$ Es zeugt von einem Misstrauen gegenüber gesichertem, positivistischem Wissen und gegenüber dem, was man »alltägliche Realität« nennt:

Von meinem Großvater, dem ich meinen türkischen Nachnamen und somit meinen Status als Islamkenner verdanke, wird folgender Gedanke überliefert: »Wenn man ein Wort nicht kennt, soll man nicht nur in ein Lexikon schauen, sondern auch aus dem Fenster, besser

466 Darum geht es auch in Örens Berlin Savignyplatz. Siehe hierzu: ÖREN (1995).

467 Siehe hierzu auch: PAZARKAYA (2000): S. 19.

468 ŞENOCAK (1997): S. 10.

469 Leslie Adelson nennt dies in Bezug auf Şenocaks Literatur auch »riddle of referentiality«. AdELSON (2005): S. 88.

470 Auch in Selim Özdoğans Roman Mehr spielt der türkische Großvater im Unterschied zu den Eltern eine besondere Rolle. Siehe hierzu: ÖzDoğAN, Selim (1999): S. 9. Siehe auch: ÖzDAMAR, Emine Sevgi (1991): »Großvaterzunge«. In: dies.: Mutterzunge, Köln: Kiepenheuer \& Witsch. 
noch, man soll sich das Wort vor dem Schlafengehen dreimal aufsagen, denn im Lexikon steht nur seine lexikalische Bedeutung und nicht sein Lebenssinn, draußen kann man schon eher enträtseln, wozu ein bestimmtes Wort existieren darf, die endgültige Entschlüsselung von Sinn und Bedeutung aber liegt im Traum verborgen. « ${ }^{471}$

Sowohl Özdamar als auch Şenocak haben einen verfremdenden surrealen Zugang zum Multikulturellen gewählt, der versucht, eine andere Wirklichkeit aufzuzeigen, als die in den Debatten verhandelte multikulturelle Gesellschaft, die es womöglich nur in der Theorie gibt. Dieser Zugang ist besonders in Zeiten beliebt, in denen nach Ansicht vieler Autoren »the State takes reality into its own hands, and sets about distorting it«. Nach Salman Rushdie, auf den sich Şenocak in seinen Essays häufig bezieht, müsse man gegen die vom Staat erzeugte Realität »alternative realities of art« setzen, die in diesem Zusammenhang unbedingt als politische zu verstehen sind. ${ }^{472}$ Wie eng die Ästhetik mit Fragen der Integration und Desintegration in Şenocaks Literatur zusammenhängt, zeigt sich bereits in der zweiten Erzählung »Das Haus« des ersten Bandes seiner Tetralogie Der Mann im Unterhemd (1995).

Die kurze programmatische Erzählung spielt in einem Haus, in dem alteingesessene Deutsche, unser Erzähler und eine Deutsch-Türkin wohnen. Der Ich-Erzähler unterhält sich oft mit der Deutsch-Türkin im Treppenhaus, die ihm allerdings unheimlich ist, weil sie sich vollkommen assimiliert hat. Das sei sie auch deshalb, weil sie ihre Eltern verlassen habe, obwohl diese »verhältnismäßig liberal« seien und ihr etwa eine Beziehung mit jedem Mann außer einem Deutschen zugestanden hätten. Doch im Fokus der Literatur und des Films stehen in den 1990er Jahren das Handeln gegen Vorstellungen, das Brechen von Regeln und Erwartungen und das Überschreiten von Grenzen.

Melike brach die Lehre ab, zog vom Elternhaus hierher in die Donaustraße. Es war eine ungeheure Provokation, dass sie nur ein paar hundert Meter weiter zog, ohne das Viertel zu wechseln, in Atem- und Augennähe zu den Eltern, zu Verwandten und Bekannten. Sie war die erste, die von einem deutschen Freund verlassen wurde und aus Rache zwei deutsche Freunde verließ, die sich tödlich in sie verliebt hatten. Sie begann zu studieren. Da hatte sie schon die deutsche Staatsbürgerschaft angenommen und den Namen gewechselt. ${ }^{473}$

471 ŞENOCAK (1997): S. 41.

472 Rushdie, Salman (2010): Imaginery Homelands. Essays and Criticism 1981-1991, London: Vintage, S. 14.

473 ŞENOCAK (1995a): S. 25. Tatsächlich ist die Einstellung der türkischen Eltern zum Auszug ihrer Töchter auch in den Debatten Anfang der 1990er Jahre ein Thema. Siehe hierzu: WiEsSNER, Irina (1994): »Konservativ und manipuliert. Viele türkische Einwanderer können sich mit der deutschen Gesellschaft nicht identifizieren, der Einfluß der staatstreuen Medien ist groß. Plädoyer für nur eine Staatsbürgerschaft«. In: taz, 15.10.1994, http://www.taz.de/!1538443/ (11.07.2018). 
Melike heißt nun Michaela, ist eine »Superdeutsche«, eine »unerträgliche Identität«. ${ }^{474}$ Trotz des Konflikts zwischen Ich-Erzähler und Michaela, der sich am Assimiliert- oder Nicht-Assimiliert-Sein entzündet, sind sich beide hinsichtlich ihrer neuen Nachbarn, einer Gruppe von drei Männern, einig: Es sind »finstere Gestalten«, die unzivilisiert wirken. ${ }^{475}$

Sie kommen aus dem Osten des Landes, das sie beide vergessen möchten. Weder Michaela noch der Ich-Erzähler beschreiben, worin die neuen Nachbarn in Wirklichkeit unzivilisiert sind. Im Treppenhaus sagen sie nur: „»Das ist so üblich, dort wo die herkommen.` Wir streiten über den Namen der Provinz, wo keiner von uns war und von deren Menschen wir so viel wissen, oder sollte ich besser sagen: ahnen. ${ }^{476}$ Wenn einen Moment zuvor sich der Ich-Erzähler noch von Michaela distanzierte, fühlen sie sich angesichts der drei neuen Nachbarn einander zugehörig - weil ihre Eltern aus demselben Land eingewandert sind.

Treppenhäuser kommen auch in Fassbinders Filmen vor, besonders im oben besprochenen ANGST ESSEN SEelE AUf. Die Unterschiede zu Şenocaks Treppenhausszene sind bemerkenswert. Auf den ersten Blick fällt auf: Wenn in Fassbinders Film alteingesessene deutsche Frauen als Teil einer Mehrheitsgesellschaft über Frau Kutzer und ihren neuen marokkanischen Freund im Treppenhaus reden und beide sich beobachten, so sind es bei Şenocak nun die Minderheiten selbst, die diese Grenzen ziehen. Noch zwei weitere Unterschiede fallen auf: Fassbinder markiert die alteingesessenen deutschen Frauen Emmi gegenüber als kalt und unzivilisiert. Solche Szenen der Diskriminierung sind als Kritik an der bestehenden gesellschaftlichen Sozialstruktur zu verstehen. Treppenhäuser spiegeln bei Fassbinder gewissermaßen die Gesellschaft, von oben und unten.

In Şenocaks Treppenhaus gibt es keine Unterscheidung zwischen oben und unten oder zwischen Besitz und Nicht-Besitz. Wie in Die Prärie geht es auch hier um ein deplatziertes Verhältnis zwischen Innen und Außen, um die eigene Positionierung, die sich durch die Spiegelung in der assimilierten Deutsch-Türkin und den neuen türkischen unzivilisierten Nachbarn ergibt. Aspekte des Verhaltens und der Sozialstruktur treten zugunsten von ästhetischer Verfremdung, Vorstellung, Artikulation, Position und »unerhörtem « Erzählen oder Tun in den Hintergrund. Dennoch wird auch in Şenocaks Treppenhaus Kritik geübt. Er unterscheidet in dieser Passage - ähnlich wie damalige Theorien - zwischen Assimilation und individueller Desintegration und zeigt, dass selbst die süberintegrierte Akteurin

474 Ebd.

475 Als Motiv begegnet uns dieses gefährliche türkische Dreier-Kollektiv, das die deutsch-türkischen Individuen bedroht, auch in Emine Sevgi Özdamars Roman Die Brücke vom Goldenen Horn und in Fatih Akıns Spielfilm GEgEN DIE WAND.

476 ŞENOCAK (1995a): S. 30. 
keineswegs frei von verallgemeinernden und diskriminierenden Aussagen ist. In seinem Hauptwerk Die Gesellschaft der Gesellschaft konstatiert Luhmann hinsichtlich Exklusion und Inklusion Ende der 1990er Jahre, dass heute Situationen typisch seien,

in denen man erklären muß, wer man ist; in denen man Testsignale aussenden muß, um zu sehen, wie weit andere in der Lage sind, richtig einzuschätzen, mit wem sie es zu tun haben. Deshalb wird »Identität«, wird »Selbstverwirklichung« ein Problem. Deshalb unterscheidet die Literatur körperlich-psychische Existenz und »soziale Identität«. Deshalb kann man nicht eigentlich wissen, wer man ist, sondern muß herausfinden, ob eigene Projektionen Anerkennung finden. ${ }^{477}$

In dieser Konstellation ist die türkische Minderheit heterogen und widersprüchlich, die mit ihr verbundenen Akteure sind gemäßunterschiedlicher Vorstellungen Opfer und Täter zugleich. Dieses kritisch-differenzierende Potential in Şenocaks Treppenhaus-Szene wird noch deutlicher, wenn wir sie mit Bhabhas Treppenhausmetapher in Location of Culture von 1994 vergleichen. Denn Bhabha hält das Treppenhaus für die Grundlage der Entstehung des von ihm positiv besetzten »third space ${ }^{478}$

Das Treppenhaus als Metapher ist nach Bhabha eine »interstitial passage«, eine Zwischenräume bildende Einheit aus fixen Identitäten, die »opens up the possibility of a cultural hybridity that entertains difference without an assumed or imposed hierarchy«. ${ }^{479}$ Die Begegnung im Treppenhaus versinnbildlicht für ihn weder soziale Hierarchie noch neue komplexe Grenzziehungen oder Bedrohungen, sondern die Möglichkeit des »Hin- und Hergehens« der Bewohner. Sie sind nicht auf ein Schwarz- oder Weiß-sein fixiert, sondern in Bewegung. ${ }^{480}$ Der Raum, die Bewegung und die Begegnungen im Treppenhaus ermöglichen ein »beyond of fixed identities« und verhelfen auf diese Weise hybriden Identitäten zum Ausdruck. Diese Möglichkeit deutet Şenocak im Der Mann ohne Unterhemd und in Die Prärie nicht an. Denn seine Akteure sind zwar auch in Bewegung und gehen hin und her, doch stehen sie dabei auch oft vor verschlossenen Türen und Räumen, in die sie nicht hinein- oder herauskommen, werden beobachtet und mitunter von "politischen Ereignissen« und Zuschreibungen »eingefangen«. Zudem werden sie selbst zu Tätern und Opfern von Diskriminierungen, die in Form einer Autokommunikation geschehen.

477 Luhmann (1999): S. 627, Hervorhebung im Original.

478 Siehe hierzu: BHABHA (1994): S. 5.

479 Ebd., S. 4.

480 Ebd., S. 5. 
Nicht nach »drinnen« oder nach »draußen« zu gelangen, führt bei Şenocak und Özdamar dazu, dass ihre Protagonisten nicht aus ihrer eigenen Haut herauskommen. Auch der Ich-Erzähler in Örens Berlin Savignyplatz verlässt in Erinnerung an Ali Itir die »Paris Bar« mit den Worten, dass er »staunend, schutzlos und neugierig hinaus in einen Raum [geht], in dem ich ein Fremder bin und dennoch nicht fremd«. Er wechselt dabei mühelos aus »Ali Itirs Zeit in eine andere Zeit«. ${ }^{481}$ Tatsächlich verlässt er die Bar gar nicht - wie Şenocaks Erzähler auch womöglich gar nicht nach Istanbul gereist ist. Denn es folgt ein Gespräch mit seinem Bekannten Max, bei dem er den Eindruck hat, dass er ihm gar nicht zuhört.

Die Erzähler, Akteure und Akteurinnen der 1990er Jahre vermischen sich nicht, sie bilden kein stabiles Kollektiv hybrider Identitäten. Ören und Ali Itir sind getrennt, bleiben aber bezogen aufeinander. Melike (Michaela) und Şenocaks Ich-Erzähler beziehen sich auf- und trennen sich zugleich voneinander. Beide unterscheiden sich zudem von den neu zugezogenen Türken. Der Ich-Erzähler wendet sich nach der Erzählung »Das Haus« auch von Melike/Michaela ab und widmet sich in mehreren folgenden Erzählungen in Der Mann im Unterhemd der deutschen Figur Laura. Nicht die Konvertiten, die Assimilierten oder die vermeintlich Integrierten interessieren ihn, sondern die, die wie er selbst in ihrer Haut stecken bleiben. Lisa ist wie ihre Mutter und Großmutter eine deutsche Prostituierte, doch grenzt sie der Erzähler klar von ihren deutschen Vorfahren ab. Auch Feridun Zaimoğlu grenzt die >Kanaken « in der Kanak Sprak und im Roman Abschaum vom »Schmuse-Ali« der ersten Generation ab, der sich vermeintlich angepasst hatte und immer still war, und vom integrierten »Abi-Türken « der zweiten Generation ab. ${ }^{482}$ Die >Kanaken`, die Bastarde, die weder über Vaterland noch »Mutter Erde« verfügen, bilden für ihn die Grundlage einer ernstzunehmenden Integration. »Erst die Existenz nichtintegrierbarer Personen oder Gruppen läßt soziale Kohäsion sichtbar werden und macht es möglich, Bedingungen dafür zu spezifizieren. ${ }^{483}$ Der Ausgangspunkt für die Bestimmung der eigenen Position ist in den 1990er Jahren die Desidentifikation mit der gesellschaftlich zugeschriebenen eigenen Herkunft, um aus dieser Abspaltung heraus eine eigene Form der Identifikation und des Sozialen zu setzen. Dieses Anliegen und diese poetische Praxis stehen im Missverhältnis zu multikulturellen, transnationalen Theorien und $\mathrm{zu}$ Integrationsdebatten der 1990er Jahre, die Kultur oder internationale Mehrfachzugehörigkeiten einfach voraussetzen und nach den Grundlagen und Bedingungen

481 ÖREN (1995): S. 55f.

482 Siehe hierzu: ZaimoĞLU (1997): S. 14.

483 LuHMANn (1999): S. 621. 
ihres Überlebens fragen. In den ersten beiden Bänden von Şenocaks Tetralogie wird dies zunächst nur als Problem angezeigt. Man muss dieses Missverhältnis aber entfaltend aufzeigen, um darauf bauend zwischen eigen und fremd übersetzen zu können. Es ist für den öffentlichen Diskurs notwendig, aber auch für den Erzähler, Sascha Muhtesem, der sich in den Vereinigten Staaten von Amerika in seiner Haut zwar wohlfühlt, aber aus ihr auch nicht herauskommt und sich deshalb auch nicht integriert. So wie er sich zwischen der assimilierten Türkin und den Türken als Kollektiv nicht positionieren kann, braucht er eine über die eigene Haut hinausgehende integrierende ästhetische Erzählung, an der er sich mit dem dritten Band der Tetralogie Gefährliche Verwandtschaft versucht.

\subsection{Anrufung der Welt statt transcultural community}

In Die Prärie lebt ein Mann gewissermaßen auf der Schwelle, weil er sich nicht in seine Wohnung traut. Özdamars Protagonisten ergeht es ganz ähnlich; die besprochenen Romane beginnen und enden mitten in Zugfahrten. In Sinan Çetins BERLIN IN BERLIN ist die Schwelle, der Wohnungsflur der Türken in der neuen deutschen Hauptstadt, der Ort der Begegnung und des Überlebens zugleich. Und Yüksel Pazarkaya hält in seinen poetologischen Reflexionen Odyssee ohne Ankunft als seinen Ausgangspunkt fest, dass er von »nirgendsher gekommen « sei und »nirgendshin zurückkehren ${ }^{484}$ könne. Doch in eben dieser »Zwickmühle« besinnen sich das lyrische und epische Ich »auf einmal [ihrer] alten Jurte, die nichts anderes als Odyssee bedeutet. Der Weg als Zuhause? Das Zuhause des Nomaden ist der Weg. ${ }^{485}$

Die Prärie in Amerika wird in Şenocaks Roman nicht zum dauerhaften Wohnort, obwohl sie den Erzähler weder an Deutschland noch an die Türkei erinnert. Daher bleibt die Frage des Wohnens im bisher bekanntesten Roman von Zafer Şenocak Gefährliche Verwandtschaft weiter ein wichtiges Motiv. Zu ihr gesellt sich aber als weiteres Motiv die Bedeutung der Übersetzung. Denn damit Spaltungen nicht bestehen bleiben, muss das im Inneren nicht zu lösende deutsch-türkische Verhältnis übersetzt werden. Durch diese Form der Übersetzung erweitert sich auch das surreal-poetologische Konzept. Zum Übersetzer wird nun der IchErzähler selbst, während der amerikanische Erzähler, der die innere Spannung des türkeistämmigen Deutschen hätte aufheben sollen, verschwindet. Sascha

484 Pazarkaya (2000): S. 95.

485 Ebd., S. 122. 
definiert nun selbst den Sinn und die Funktion der Übersetzung im letzten Drittel von Gefährliche Verwandtschaft. Dabei muss er, wenn er

eine Wahrheit erkennt, die nicht der Wahrheit der anderen entspricht, [...] sie für sich behalten. Gäbe er diese Wahrheit preis, würden sich die anderen nur über den schlechten Übersetzer ärgern. Ohne den Übersetzer würde die Welt an vielen Stellen auseinanderfallen. Durch ihn werden viele Nähte unsichtbar. Nur die, die zu nahe an den Nähten sind, spüren den Schmerz, das Jucken und Brennen an der Naht. ${ }^{486}$

Der Übersetzer reagiert also auf eine desintegrierte Welt, weil ein jeder seiner eigenen Wahrheit oder der seiner Gruppe nachgeht. Auch Wilhelm Heitmeyer geht in seinen Schriften zur Integration ab Mitte der 1990er Jahre von der Desintegration aus. Dort jedoch, wo Heitmeyer gegen das Bedrohungsszenario der Desintegration auf Integration, auf die Gesellschaft in einem größeren Zusammenhang setzt, ${ }^{487}$ liegt für Şenocak die einzige mögliche Form der Bearbeitung von Differenz und der Entstehung sozialer Bindungen, von Soziabilität, in der Praxis der Übersetzung. Şenocaks Beschreibung sowie die Funktion der Übersetzung und des Übersetzers erinnern an die erfundenen Geschichten von der Straße der kleinen Ich-Erzählerin in Özdamars Roman. ${ }^{488}$ Diese spezifisch ironisch gewendete Form der Authentizität macht deutlich, dass es je nach Perspektive und Gruppe unterschiedliche Wahrheiten gibt. Und der Erzähler muss erfinden, wenn er ein Weitersprechen unterschiedlicher Welten und Systeme für alle Beteiligten jeglicher Herkunft aufrechterhalten und nicht als Lügner vor dem einen oder anderen dastehen will.

Das Geheimnis dieses Übersetzungsprozesses liegt darin, dass er nicht genau das wiedergeben kann, was er gesehen oder gehört hat; und das muss der Übersetzer eigentlich für sich behalten. Doch gibt Sascha entgegen dieses Codex in der Gefährlichen Verwandtschaft dies nicht nur theoretisch zu, sondern Seiten später auch praktisch, indem er seine Operation sichtbar macht. Als er mit seiner neuen deutschen Freundin Marie ${ }^{489}$ aus den USA zurückgekehrt ist, erhält Sascha Muhtesem wieder eine Anfrage aus einer Zeitungsredaktion. Dieses Mal soll er eine Reportage über die muslimischen Gebetshäuser in Berlin schreiben. Anders als noch in der Prärie lehnt der Erzähler diese Anfrage nun nicht ab. Und anders

486 ŞENOCAK (2009): S. 95.

487 Siehe hierzu: HeitmeyeR, Wilhelm (1997): „Gesellschaftliche Integration, Anomie und ethnisch-kulturelle Konflikte«. In: Was treibt die Gesellschaft auseinander?, hg. v. dems., Frankfurt a. M.: Suhrkamp, S. 629-653.

488 Emine Sevgi Özdamars Ich-Erzählerin in ihrem zweiten Roman wird ebenfalls zu einer Übersetzerin: im Berliner Frauenwohnheim. Dort muss sie nicht nur zwischen Deutschen und Türken übersetzen, sondern auch zwischen Türken und Türken. Siehe hierzu: ÖzDAMAR (1998): S. 115. 489 Im Roman Die Prärie trägt die deutsche Freundin aus den USA den Namen Marianne. 
als in der Prärie stellt er seine Eignung für diesen Auftrag nicht mehr in Frage. Ganz im Gegenteil sieht er es jetzt als seine Aufgabe an, »die Welt der Migranten, der Randgänger « zu beschreiben. »In der Welt, die ich zu beschreiben habe, ist man auf Instinkte angewiesen. [...] Meine Aufgabe besteht darin, diese Logik zu übersetzen. ${ }^{490}$ Es handelt sich also um keine gewöhnliche Übersetzung, die der Erzähler hier leisten will.

Sein persönlicher Eindruck der Berliner Moscheen ist, dass der Islam, wie er sich dort zeigt, »eine perfekte Glaubensgemeinschaft für Männer [sei], die ihr Leben lang nur Fußgeruch, Bärte und Sperma produzieren ${ }^{491}$ Doch seine Reportage schlägt einen ganz anderen Ton an und eine ganz andere Richtung ein: Er fasst darin zusammen, dass die Moscheen in der Großstadt Berlin sich aus Gebetshäusern zu sozialen Einrichtungen entwickelt hätten. Sein Fazit lautet daher: Die Moscheen »sind muslimische Häuser und deutsche Vereine zugleich. Sie beanspruchen einen Platz in der Mitte dieser Gesellschaft «. ${ }^{492}$ Seinen eigenen Titelvorschlag »'Freitags zum Beten, Sonntags zum Tischtennisı« ändert die Redaktion zwar in »»Bedrohen Muslime den Kiez? « und setzt als Hintergrundbild fälschlicherweise die Kuppel der Berliner Synagoge, doch der Inhalt bleibt so, wie er ist. Was genau die Reportage über die Entwicklung und das Soziale im Leben der Moschee und der Türken in Berlin berichtet, erfahren wir als Leser des Romans Gefährliche Verwandtschaft nicht. ${ }^{493}$ Wir wissen über den Übersetzer und die Redaktion nur, dass unterschiedliche heterogene Vorstellungen über den Islam bestehen: für den Übersetzer ist er eine Religion für Männer; für die deutsche Redaktion eine Gefahr für die Gesellschaft. Auch der Verweis darauf,

490 ŞENOCAK (2009): S. 94.

491 Ebd., S. 110.

492 Ebd., S. 112.

493 Im Zentrum der Arbeiten zur Entwicklung des Islam in Deutschland stehen von Mitte der 1990er bis Anfang der 2000er Jahre zum einen die Entstehung und Entwicklung islamischer Vereine in der Bundesrepublik, zum anderen und sehr prominent die individuelle Interpretation der Religion. Zum zweiten Punkt merkt Levent Tezcan an, »dass die Thematisierung des Islam weitgehend im Rahmen der Fragestellung erfolgt, wie er im Verhältnis zur Moderne zu positionieren ist «. Siehe hierzu: TezCAN, Levent (2003): »Das Islamische in den Studien zu Muslimen in Deutschland «. In: Zeitschrift für Soziologie, Jg. 32, Heft 3, Juni 2003, S. 237-261, hier S. 237. Siehe zu den Analysen der Vereine: SCHIFFAUER, Werner (2000): Die Gottesmänner. Eine Studie zur Herstellung religiöser Evidenz, Frankfurt a. M.: Suhrkamp. JoNKER, Gerdien (2002): Eine Wellenlänge $z u$ Gott. Der ,Verband der islamischen Kulturzentren in Europa`, Bielefeld: transcript. SEUfERT, Günter (1999): „Die `Türkisch-Islamische Union` (DITIB) der türkischen Religionsbehörde. Zwischen Integration und Isolation«. In: Turkish Islam and Europe. Türkischer Islam und Europa, hg. v. Günter Seufert, Jacques Waardenburg, Stuttgart: Steiner, S. 261-265. 
dass die Moschee für einen sozialen Ort steht, wirkt in diesem Zusammenhang wie eine weitere Zuschreibung, wie eine weitere referenzlose Konstruktion, denn die Beschaffenheit und die Bedingungen dieses Ortes werden nicht näher ausgeführt. Im Vordergrund dieser literarischen Einbettung einer gesellschaftspolitischen Kommunikation steht eine ironische Reaktion. Einzig, dass es sich bei der Moschee um einen eingetragenen Verein handelt, lässt sie Assoziationen aufkommen, dass neben dem Gebet dort wahrscheinlich auch Tischtennis gespielt wird.

Indem die Reportage von der Religion zum Verein wechselt, vermittelt sie zwischen den beteiligten Parteien, zwischen Türken und Deutschen, was sich auch als Übersetzungsleistung deuten lässt. Damit verweist der Autor Sascha auf eine postnationale Citizenship, auf die bereits skizzierte Denizenship, die Soysal ins Zentrum ihrer These der Integration als Inkorporation Anfang der 1990er Jahre gestellt hatte. ${ }^{494}$ Die nationale Staatsbürgerschaft gehört nun der Vergangenheit an. Maßgeblich für die Integration sind nun transnationale Verbindungen in Form von Körperschaften. Doch ist dies nur die eine Seite der Übersetzung. Die andere schafft eine »unerhörte« Verbindung zwischen spermaproduzierenden Männern und sozialer Einrichtung. Da fragt sich der nach Authentizität und Identifikation verlangende Leser doch, warum nicht erklärt wird, warum gerade der Islam eine Religion für Bärte und Sperma produzierende Männer ist. Nach Saschas eigenem, oben dargelegtem Verständnis wäre er ein »schlechter Übersetzer« würde er diese »Wahrheit« preisgeben. Seine Einschätzung des Islam würde den multikulturellen Erwartungen der Mehrheit zuwiderlaufen und die Grenzen von Religion und Kultur auf Fragen von Geschlecht und Körper reduzieren. Aus Inklusion würde Exklusion werden. Denn wo es auf die Körper ankommt, verlieren »symbolische Mechanismen [...] ihre spezifische Zuordnung «. ${ }^{495}$ Bedürfnisbefriedigungen würden freigesetzt und »unmittelbar relevant werden«. Aber genau auf diesem Wege, über den Körper werden in Literatur und Film der 1990er Jahre der Inklusions- und Exklusionsbereich der Gesellschaft als heterogene Ordnungen zusammengebracht. Die Übersetzung ermöglicht das Weitersprechen als Bindung von innen und außen, so prekär ihre Bedingungen auch sein mögen.

Hätte sich der Erzähler in Gefährliche Verwandtschaft dazu entschlossen, seinen persönlichen Eindruck mitzuteilen und ihn anhand von sozialen Praktiken auszubuchstabieren, hätte er eine transkulturelle Pointe gesetzt, die die Idee der postnationalen Bürgerschaft tatsächlich in eine a-nationale Konstellation überführt hätte. Denn nicht nur türkische Männer produzieren Sperma, Fußgeruch und Bärte, sondern auch deutsche, jüdische und alle anderen Männer auf dieser

494 SOYSAL (1994): S. 3.

495 LuHMANN (1997): S. 633. 
Welt. Religion wäre dann eine allgemeine Körper- und Geschmacksfrage. Für Pierre Bourdieu zeigt gerade der Geschmack die kulturelle Integration in eine Gesellschaft an. ${ }^{496}$ Şenocaks Sascha deutet eine solche Bindung von Körpern unterschiedlicher nationaler Herkunft über die Kategorie des Geschmacks natürlich nur an, er führt sie nicht aus. Geschmack und Praktiken interessieren Sascha nicht, sondern der ästhetische Bruch und die damit einhergehende produktive - ein Weitersprechen initiierende - Provokation, wie sie für viele ästhetische Produktionen der 1990er Jahre gilt. So verbindet Sascha etwa das Deutsche mit dem Türkischen über das Jüdische bzw. das Thema des Genozids.

In den 1980ern kam die Autorin Aysel Özakın in ihrer Literatur auf ihren Lesereisen einfach nicht dazu, als Literatin aufzutreten und ihre Texte als solche vorzutragen. Immer musste sie über die vermeintlich kulturelle Realität der Türken und der türkischen Frau in Deutschland sprechen. Es waren mitunter diese Umstände, die zu ihrer Emigration von Deutschland nach England Ende der 1980er führten, wo sie bis heute lebt. Bei Şenocak ist die Abfolge umgekehrt. ${ }^{497}$ Viel erfahren wir über seinen literarischen und theoretischen Zugang, viel über unterschiedliche Vorstellungen oder von Reflexionen, was Übersetzung ist, doch kaum etwas über die soziale Disposition der türkischen und der deutschen Seite. ${ }^{498}$ Sie wird mit dem Titel Beten und Tischtennis-Spielen als soziale Praktiken nur angedeutet.

Die lose Kopplung von biologischen und abstrakten Körpern (Vereinen) lädt jedoch zu einer zugleich existenziellen und allgemeinen Beobachtung von Integration ein, die das Ziel des Übersetzers schlechthin ist, um die oben zitierten Nähte der Welt unsichtbar zu machen. Saschas Fokus auf den Körper ermöglicht uns, eine solche Perspektive auf diese allgemeineren Fragen einzunehmen. Neben Religion und Mehrheitsgesellschaft wird der Körper in den 1990er Jahren zur dritten Kategorie der Integration. Diese Überführung von einer dichotomischen Zweier- zu einer Dreierkonstellation ist das eigentliche Sujet in Gefährli-

496 Siehe hierzu: Bourdieu, Pierre (1982): Die feinen Unterschiede. Kritik der gesellschaftlichen Urteilskraft, Frankfurt a. M.: Suhrkamp.

497 Die Umstände unter denen Aysel Özakın in Deutschland geschrieben und ihre Lesereisen unternommen hat, haben sie nach eigener Aussage dazu gebracht, die Bundesrepublik Ende der 1980er Jahre Richtung England zu verlassen, zur gleichen Zeit als die fiktive Figur in Şenocaks Tetralogie Deutschland nach Amerika in die Prärie geht. Özakın ist im Unterschied zu Şenocaks fiktiver Figur Sascha Muhtesem nicht mehr zurückgekehrt. Siehe hierzu: WiERSCHKE (1996): S. 142.

498 Auch Selim Özdoğan skizziert seinen Erzähler, einen Endzwanziger mit türkischem Hintergrund, in seinem Roman Mehr als jemanden, der »aufs Schreiben verfallen « ist, "weil er keine Lust [hatte] zu arbeiten und ein nützliches Mitglied dieser [der deutschen] Gesellschaft zur werden«. Siehe hierzu: ÖzDOGAN (1999): S. 31. 
che Verwandtschaft. Denn für Sascha liegt die eigentliche Frage der Integration in der Bundesrepublik nicht im Verhältnis zwischen Islam und Ankunftsgesellschaft, wie es in den 1990er Jahren national und international zunehmend unter die Lupe genommen wird. Nilüfer Göle, Reinhard Schulze, Sigrid Nökel, Werner Schiffauer, Günter Seufert und Gritt Klinkhammer interpretieren in den 1990er und beginnenden 2000er Jahren - im Unterschied zu Wilhelm Heitmeyer - den neu entstehenden Islam der zweiten Generation in Deutschland oder der gleichaltrigen Generation von Türkinnen und Türken in der Türkei als eine emanzipatorische moderne Bewegung. ${ }^{499}$ Grundlage ist nach den Forschern dafür der öffentliche Raum, in dem sich die zweite Migranten-Generation artikuliert und anhand von selbst erworbenem Wissen über ihre Religion selbst bestimmt, was sie ist. Dabei gilt als öffentlicher Raum alles, was nicht privat ist (Schule, Arbeitsplatz, öffentliche Plätze). Interessanterweise wollen diese Forschungen auch Privates und Öffentlichkeit verschieben, ${ }^{500}$ wobei sie sich dabei ausschließlich auf die Individuen und nicht auf die veränderten sozialen Strukturen konzentrieren. ${ }^{501}$ Diese Perspektive soll die integrationsspezifische Unterscheidung zwischen Mehrheit und Minderheit auflockern und die eigentlich gemeinsame Kultur hervorheben. Ein bestimmtes Verhältnis zwischen Mehrheiten und Minderheiten hat auch Şenocaks Übersetzer nicht im Sinn, denn sonst hätte er seine Form der Übersetzung nicht offengelegt. Für ihn verfestigt die Unterscheidung von Mehrheit und Minderheit, von Religion und Gesellschaft, dichotomische Zuschreibungen und Wahrheitsansprüche.

Wie Homi Bhabha versucht auch Şenocaks Übersetzer fixierte, bipolar zueinander ausgerichtete Identitäten aufzubrechen und Kultur auf eine allgemeine Ebene zu heben. An einer Stelle hält Şenocak fest, dass es in ästhetisch-kultureller Hinsicht in Wirklichkeit nur eine einzige Kultur gebe - die jedoch erschrie-

499 Siehe hierzu: Göle (1995); Heitmeyer (1996); SChulze (1996); Seufert (1999); NöKel (2001); SCHIFFAUER (2002).

500 Siehe hierzu: NöKEL, Sigrid (2001): S. 145.

501 Tatsächlich ist die »Stimme« eine wichtige Kategorie in der Verschiebung von öffentlichen und privaten Verhältnissen in der politikwissenschaftlichen Theorie. In seinem instruktiven Aufsatz The Theory and Politics of the Public/Private Distinction von 1997 konstatiert Jeff Weintraub, dass es die importierte Kategorie der "Stimme« der Bürgerinnen und Bürger war, die das vorbereitete, was sich als Zivilgesellschaft, als »Public sphere« in den 1980er und 1990er Jahren durchsetzt. Davor ist die Öffentlichkeitsstruktur der 1960er und 1970er Jahre als eine der Unterscheidung zwischen öffentlichem Bereich als Staat und privatem Bereich als Wirtschaft aufgeteilt. Siehe hierzu: Weintraub, Jeff (1997): »The Theory and Politics of Public/Private Distinction«. In: Public and Private in Thought and Practice. Perspectives on a Grand Dichotomy, hg. V. Jeff Weintraub und Kirshan Kumar, Chicago/London: The University of Chicago Press, S. 1-42, S. 10. 
ben werden müsse. ${ }^{502}$ Dies gelingt wiederum nicht einfach, wenn man sich einen neuen, aus Zwischenräumen entstehenden, dritten Raum denkt. Stattdessen müssen neue identitätspolitische Verhältnisse und Sprechweisen in Deutschland entwickelt werden. Die Lösung liegt für Şenocak also weder in einem Dialog zwischen Deutschen und Türken noch in einem neuen Raum, den selbst die amerikanische Prärie nicht eröffnen konnte. Nötig ist vielmehr ein dritter Akteur, der die Logik der zwei Seiten eines Dialogs unterläuft. ${ }^{503}$ Für Sascha besteht ein solcher anerkennender Trialog zwischen Deutschen, Juden und Türken. Davon würden alle Parteien profitieren und sich von ihren traumatischen Erfahrungen lösen. Voraussetzung dafür wäre, dass die Deutschen und die Juden in der BRD zuerst »die Türken in ihre Sphäre aufnehmen«.

Und die Türken in Deutschland müßten ihrerseits die Existenz der Juden entdecken, nicht nur als ein Teil der deutschen Vergangenheit, an der sie nicht mehr teilhaben können, sondern als Teil der Gegenwart, in der sie leben. Ohne die Juden stehen die Türken in einer dichotomischen Beziehung zu den Deutschen. Sie treten in die Fußstapfen der deutschen Juden einst. Solche Phantasien habe ich nur, wenn ich gut gelaunt bin. Die Wirklichkeit gibt mir keinen Anlaß zu solch konkreten optimistischen Überlegungen. ${ }^{504}$

Die Wirklichkeit trennt weiterhin Identitäten und behandelt sie getrennt voneinander. Dagegen setzt Şenocak mit dem türkischen, deutschen und jüdischen Hintergrund seines Protagonisten und Ich-Erzählers Sascha Muhtesem, der erst im dritten Band der Tetralogie bekannt wird, eine erzählte biografische und individuelle Wirklichkeit. Doch dieser Hintergrund ist alles andere als stabil und soll es auch nicht sein.

Der Ich-Erzähler in Gefährliche Verwandtschaft wird aber zunächst im Unterschied zu Die Prärie mit weitaus mehr biografischen und körperlichen Koordinaten

502 Siehe hierzu: KonzeTt, Matthias (2003): »Zafer Şenocak im Gespräch«. In: The German Quarterly, Vol. 76, No. 2 (spring, 2003), S. 131-139, hier S. 135.

503 Diese Erfahrung macht auch der Erzähler in Aras Örens Berlin Savignyplatz auf unterschiedlichen Ebenen: Zum einen scheitert seine Beziehung zu Elfie, als der Spanier Franco nicht mehr da ist. Er war, so stellt er fest, paradoxerweise sein Konkurrent um Elfie und zugleich die Grundlage für seine Beziehung mit ihr. Dasselbe gilt für sein Verhältnis zu Ali Itir. Gäbe es seine Freunde vom Savignyplatz nicht, die ihn ironisch als den "großen Türken « bezeichnen, hätte er nicht unbedingt eine Verbindung zur Gastarbeitergeneration. Siehe hierzu: ÖREN (1995).

504 ŞENOCAK (2009): S. 90. Zwanzig Jahre nach Die Gefährliche Verwandtschaft ist für Zafer Şenocak jedoch nicht mehr die geteilte gemeinsame Gegenwart integrativ, sondern im Gegenteil das Aufarbeiten einer gemeinsamen kulturellen Herkunft. Siehe hierzu: ŞENOCAK, Zafer (2018): Das Fremde das in jedem wohnt. Wie Unterschiede unsere Gesellschaft zusammenhalten, Hamburg: Koerber Stiftung, S. 175. 
eingeführt. ${ }^{505} \mathrm{Er}$ ist blond und blauäugig. ${ }^{506}$ In einem Nebensatz erfahren wir, dass er in Istanbul gezeugt, aber in München geboren wurde. ${ }^{507}$ Angedeutet, aber nicht ausgeführt wie bei Özdamar, ist der Ich-Erzähler im Bauch der Mutter von Istanbul aus unterwegs im Zug. Neben der Geburt steht auch die Frage des Überlebens ganz am Anfang des Romans. Dabei spinnt Şenocak die Ununterscheidbarkeit zwischen Traum und Realität aus Die Prärie noch weiter. Der erste Satz in Gefährliche Verwandtschaft lautet: »Als ich aufwachte, hatte ich im Gesicht an der Stelle, wo mich die Kugel getroffen hatte, einen Pickel«. ${ }^{508}$ Darauf schildert der Ich-Erzähler realistisch und eindrücklich die Fahrt in einem Bus, der überfallen wird. ${ }^{509} \mathrm{Ihn}$ trifft ein tödlicher Schuss. »Aber statt zu sterben bin ich aufgewacht. Als erstes fiel mir auf, wie ordentlich das Zimmer war. ${ }^{510}$

Dieser bewegungsreiche, rätselhafte und mitreißende Einstieg in Şenocaks Roman zwischen Bus, Kopfschuss und Hotelzimmer, der den Leser in ähnlichem Maße irritiert wie Özdamars Einstieg ähnlich irritiert, bleibt nicht, wie es in Die Prärie der Fall war, allein auf die Gegenwart bezogen. Denn der Ich-Erzähler hält sich in München in einem Hotel auf, weil er einen Termin beim Notar hat. Seine Eltern sind bei einem Autounfall ums Leben gekommen, und er ist der einzige Erbe. Ihm werden ein Haus in München-Grünwald, mehrere Wohnungen und viele Aktien vermacht. ${ }^{511}$ Wie in Die Prärie ist der Erzähler also finanziell unabhängig. Doch neben dem ganzen materiellen Besitz erbt er auch einen silbernen Kasten mit Tagebüchern seines türkischen Großvaters. An diesen individuell-familiären Besitz schließt Sascha Muhtesem gleich großkollektivistische Überlegungen zum Zusammenhang von Geld, Zugehörigkeit und Selbstbewusstsein an, geht also rasch vom »Ich « zum "man« über. Denn in dem Land, in dem er geboren wurde (Deutschland), stehe »Geld zwar im Zentrum aller Dinge«, doch spreche man nicht darüber. Wer es hat, gehört dazu, wer nicht, der nicht. Deshalb machten es die »gescheiten Einwanderer « in Deutschland richtig, wenn sie sich nicht mit »wertlosen Dingen« wie dem deutschen Pass, sondern sich mit der deutschen

505 Er bleibt auch bis zum Schluss der Erzähler der eigenen Geschichte. Am Ende scheint er darauf aufbauend, sogar der Erzähler einer anderen Figur werden zu können.

506 Vgl. HaLL, Katharina (2003): »Bekanntlich sind Dreiecksbeziehungen am kompliziertesten`. Turkish, Jewish and German Identity in Zafer Şenocak’s Gefährliche Verwandtschaft «. In: German Life and Letters 56:1, S. 72-88, S. 73. Siehe hierzu auch: CHEESMAN, Tom (2006): S. 102.

507 ŞENOCAK (2009): S. 11.

508 ŞENOCAK (2009): S. 8.

509 Zur äußerst realistischen Schilderung dieser Traumsequenz im Roman siehe: CHEESMAN (2007): »In Quarantine: Zafer Şenocak«. In: ders.: Novels of Turkish German Settlement. Cosmopolite Fictions, New York: Camden House, S. 98-112.

510 Ebd.

511 Ebd., S. 11. 
Mark beschäftigten. Und tatsächlich erfolgte mit dem Ausländergesetz von 1990, das am 1. Januar 1991 in Kraft trat, eine gleichzeitige aufenthalts- und sozialrechtliche Gleichstellung, die aber die Frage der Zugehörigkeit außen vor ließ. Zynisch ergänzt der Erzähler, dass in Deutschland die deutsche Mark die Frage der Zugehörigkeit regele, die hier eine »Existenzfrage ${ }^{512}$ sei.

Ganz anders sieht es im Land des Großvaters aus. Dort redet man nur über das Geld, weil es zu viel davon gibt und es durch die hohe Inflation kaum noch etwas wert ist. Bei seinen kurzen Türkeiaufenthalten, die mehr »touristischen als familiären Charakter hatten«, war es seiner Ansicht nach den Menschen dort anzumerken, »daß mit dem dahinschwindenden Wert ihres Geldes auch ihr Selbstbewusstsein schwand «. ${ }^{513}$ Das Geld mag zwar gesellschaftliche Zugehörigkeit regeln, die Identität regelt sie, wie in Die Prärie und auch im dritten Roman Gefährliche Verwandtschaft der Tetralogie, jedoch nicht. Dafür sind nun die Tagebücher des Großvaters konstitutiv. Leider kann sie der Übersetzer nicht lesen. Denn der Großvater hat seine Tagebücher zwischen den Jahren 1916 und 1936 in zum Großteil arabischer und zu einem geringen Teil kyrillischer Schrift und Sprache verfasst. Der Erbe spricht nur bruchstückhaft Türkisch und gar kein Arabisch. Dennoch wird die Dechiffrierung der Tagebücher im Laufe des Romans für ihn zu einer existenziell identitätspolitischen Aufgabe, da er aus früheren Andeutungen seines Vaters weiß, dass sein türkischer Großvater am Völkermord an den Armeniern beteiligt war und später, 1936, Selbstmord beging. Im Unterschied zum Erzähler in Die Prärie will Sascha Muhtesem im dritten Band nicht mehr »wurzellos« leben, nicht unverantwortlich für alles sein, »was länger als zwanzig Jahre her war«. So scheint plötzlich das Geheimnis seines Großvaters zwischen ihm und seiner Herkunft zu stehen: »Ich mußte sein Geheimnis lüften, um zu mir selbst zu kommen «. ${ }^{514}$ Nach Weintraub sind zwei Überlegungen zentral, um dem multiplen und mehrdeutigen Charakter der Unterscheidung öffentlich/privat nachkommen zu können. Erstens geht es darum, »what is hidden or withdrawn versus what is open, revealed, or accessible«. Zweitens geht es um die Frage, was ist individuell, »or pertains only to an individual, versus what is collective, or affects the interests of a collectivity of individuals «. ${ }^{515}$ Wie in Weintraubs-Konzept finden wir die Verschränkung von öffentlich und privat, von Visibilität und Kollektivität auch in Şenocaks Literatur.

512 Ebd., S. 12.

513 Ebd. Dass die zweite Migranten-Generation das Herkunftsland der Eltern und Großeltern nun als Tourist bereist, taucht als Motiv in vielen Filmen, literarischen Texten der 1990er Jahre auf. Siehe hierzu: AKIN (1998); ders. (1999); KURT (1995); ÖZDoğAN (1999); ZAIMOĞLU (1999).

514 ŞENOCAK (2009): S. 118.

515 Weintraub (1997): S. 5. 
Denn Zeitgeschichte und individuelle Biografie führt Şenocak in der weiteren Erzählung mit der Mobilität, Rätselhaftigkeit des Anfangs und der Zerbrechlichkeit sozialer und intimer Bindungen wieder zusammen. Denn so, wie die Eltern des Erzählers in den 1960er Jahren aus der Türkei nach Deutschland migrierten, waren zuvor schon seine deutsch-jüdischen Großeltern mütterlicherseits aus dem faschistischen Deutschland in den 1930er Jahren in die Türkei migriert. Dort lernt die Mutter seinen Vater kennen, der Türke ist. Doch nach der Geburt des Erzählers trennen sich seine Eltern in Deutschland, und sein Vater, der ebenfalls »nicht an Geldmangel litt«, lebt daraufhin seine Ungebundenheit aus. »Er stieg in den besten Hotels ab, lebte aus dem Koffer, reiste einmal um den Globus. Am Ende landete er in Istanbul. ${ }^{516}$ An ein Treffen mit seinem Vater in Istanbul kann sich der Erzähler erinnern. Bei dieser Gelegenheit erfuhr er, dass sein Großvater sich von 1919 bis 1920 unter falschem Namen in Istanbul versteckte und überlebte. So wie jetzt der Vater habe auch der Großvater niemandem vertrauen können. Istanbul war zwischen 1918 und 1923 von Briten, Franzosen und Italienern besetzt. Warum sich der Vater des Erzählers ebenfalls in Istanbul verstecken muss, ist nicht klar - anders die Gründe des Großvaters: Da er im Jahr 1915 Namenslisten zur Deportation von Armeniern zusammenstellte, war er als Täter in den Genozid involviert. Da war er 25 Jahre alt. Zehn Jahre danach und fünf, sechs Jahre nach dem Leben im Istanbuler Untergrund kandidiert er als Bürgermeister in der türkischen Republik Mustafa Kemal Atatürks. Er ist ein Mann, kommentiert sein Enkel, »den seine Schuld mächtig gemacht hat «. ${ }^{517}$

Während also der Großvater väterlicherseits beim Genozid an den Armeniern mithalf, fiel seine jüdische Familie mütterlicherseits dem Holocaust zum Opfer. Diesen Teil seiner Familiengeschichte hält seine Mutter geheim, denn sie fürchtet, dass das Wissen darum, was die Deutschen der Familie antaten, der Integration des Sohnes in die deutsche Gesellschaft im Wege stehen könnte. Der einzige Weg der Integration, den sie für ihren Sohn sah, war die Assimilation. Obwohl uns der Erzähler über diese familiengeschichtlichen Zusammenhänge aufklärt, erfahren wir Leser letztlich nur wenig über diese Vergangenheiten. Dieser Weg ist ihm selbst versperrt, und er vermag nur zu begreifen, dass er »ein Enkel von Opfern und Tätern « ist. ${ }^{518}$

Der Ich-Erzähler entscheidet mit Marie von München nach Berlin zu ziehen, wo er einen Roman über seinen Großvater schreiben möchte. In diese Suchbewegung des Ich-Erzählers ziehen auch Eindrücke von der Gemütslage deutscher

516 Ebd., S. 25.

517 Ebd.

518 ŞENOCAK (2009): S. 40. 
Bürger nach der Wiedervereinigung ein. Sascha und Marie kehren im Jahr 1992, also nach dem Fall der Mauer, aus den USA nach Deutschland zurück. Zu dieser Zeit konnte man in Berlin »überall [...] auf unsichtbare Mauern stoßen, die nach dem Fall der Mauer errichtet worden waren. Die Welt war komplizierter geworden, die Wege labyrinthischer «. ${ }^{519}$ Früh erkennt der Ich-Erzähler, dass er das Leben seines Großvaters - in Form eines Romans - erfinden muss. Das liegt einerseits an seinen eigenen sprachlichen Mängeln. Weder Sprachkurse in Türkisch und Arabisch noch ein engagierter Orientalist helfen ihm bei der Übersetzung der Tagebücher seines Großvaters weiter, der außerdem hin und wieder in einer Geheimschrift schrieb. Andererseits meint Sascha, dass man nichts finden könne, das nicht schon erfunden sei - wie auch Salman Rushdie festhält, dass es keine »precisely description « mehr gebe, sondern nur noch die Form der »create fiction «. ${ }^{520}$ Saschas Glaube an die Ästhetik reicht weit. Denn für ihn hätte der "große Führer« Mustafa Kemal Atatürk besser auch ein Stück oder einen Roman wie den Mann ohne Eigenschaften von Musil verfasst, um sein Volk zu zivilisieren und damit zu retten. Hinterlassen hat er aber nur die $>$ Marathonrede $N_{N u t u k}{ }^{521}$ So sieht Sascha auch das Filmprojekt seiner deutschen Freundin Marie, einen Dokumentarfilm und keinen Spielfilm zu Talat Paşa zu drehen, äußerst kritisch. ${ }^{522}$

519 ŞENOCAK (2009): 47. Michael Kliers Spielfilm OstKREUZ spiegelt diese politische Wende und Stimmung in Berlin eindrücklich wieder. Seine Aufnahmen wirken tatsächlich äußerst labyrinthisch. Es gibt keinen zentralen Platz, die Protagonistin ist in unterschiedlichen öffentlichen Räumen wie Baustellen, Nebenstraßen, wenig besuchten, halbdunklen Kneipen, verlassenen Plätzen, nicht fertig gebauten Häusern und nicht mehr im Betrieb stehenden Bahnhöfen im Osten Berlins unterwegs. Siehe hierzu: KLIER (1991). Und obwohl sich Örens Roman von 1995 nur um Orte und Straßen um und am Savignyplatz dreht, verlieren wir schnell die Orientierung, wo wir eigentlich genau sind. Dies liegt vor allem an der unzuverlässigen Erzählweise: Waren wir an einer Stelle noch mit dem Erzähler in einer Kneipe, bringt uns die Erzählung mit Ali Itir unvorbereitet in das Wartezimmer von Dr. Anders und von dort auf eine türkische Hochzeit, auf der sich der Doktor und Ali Itir unterhalten. Orientieren kann man sich letztlich nur anhand der Figuren. Siehe hierzu: ÖREN (1995): S. 108-118.

520 RuSHDIE (1991): S. 10.

521 Bei der Nutuk handelt es sich um eine Rede, die Mustafa Kemal Paşa (Atatürk) vor den Delegierten seiner Republikanischen Partei (CHP) zwischen dem 15. und 20. Oktober 1927 im damaligen Angora, heute Ankara, hielt. Sie hat zwei Abschnitte: Im ersten geht es um den Befreiungskampf von 1919 bis 1920, den Weg in die republikanische Unabhängigkeit und im zweiten um die Zukunft der jungen Republik. Die Rede dauerte über 36 Stunden. Die etwa 900 Buchseiten umfassende Nutuk wurde mehrfach veröffentlicht, übersetzt und wird bis heute jährlich neu aufgelegt, insbesondere im Jubiläumsjahr 2017. Siehe hierzu: ATAтÜRK, Mustafa Kemal (2015): Nutuk. 1927, Istanbul: Yapi Kredi Yayınları. Siehe für die deutsche Version: http://menadoc. bibliothek.uni-halle.de/landau/content/titleinfo/214006 (20.12.2017).

522 Talat Paşa, bürgerlich Mehmed Talaat Bey, lebte von 1874 bis 1921 und war zwischen den Jahren 1909 und 1917 bis zur Besetzung Istanbuls Großwesir und Innenminister im Osmanischen 
Die Dokumentation orientalisiere. ${ }^{523}$ Auf ähnliche Weise kritisiert Dr. Anders in Örens Berlin Savignyplatz, dass wir alle in Klischees denken würden, »aber in der modernen Gesellschaft gibt es dazu noch keine Alternative «. ${ }^{524}$

Nach Sascha lassen sich mittels Fiktion neue Beziehungen knüpfen und Heterogenes verbinden. «Nicht theoretische oder praktische Ausführungen machen das Multikulturelle erfahrbar, sondern literarische Werke [...], die die persönlichen und subjektiven Erfahrungen von Grenzüberschreitungen in Sprache formen. «25 So basiert Saschas Erzählung seiner Familiengeschichte, die ebenso nationale Geschichten von Schuld erzählt, nicht etwa auf Dokumenten oder Berichten zu den Genoziden, sondern auf einer Liebesgeschichte zwischen seinem Großvater und einer Armenierin - deren Name auf einer Deportationsliste durchgestrichen war. Zugleich ist dieses das einzige Dokument, welches für Sascha verifizierbar ist. Von dieser Beziehung erfährt Sascha in einem Brief, den sein Großvater von dieser Armenierin erhalten hat. Darin fragt sie ihn vor allem danach, wie er nach dem, was passiert sei, noch weiterleben könne. Saschas Großvater begeht als türkischer Sportattaché bei den Olympischen Spielen 1936 in Berlin Selbstmord. Ob dieser Brief oder sein schlechtes Gewissen ausschlaggebend waren, bleibt offen.

Reich. Er ordnete am 24. April 1915 unter dem Vorwand eines Aufstandes in einer osttürkischen Provinz die Verhaftung von 235 armenischen Intellektuellen in Istanbul an. Diese Verhaftungswelle gilt allgemein als der Beginn des Völkermords an den Armeniern. Am 15. März 1921 wurde Mehmet Talat Paşa in Berlin auf offener Straße von dem Armenier Salomon Teilirian erschossen. Siehe hierzu: Аксам, Taner (2004): Armenien und der Völkermord. Die Istanbuler Prozesse und die türkische Nationalbewegung, Hamburg: Hamburger Edition, S. 52-76. Siehe auch: GuST, Wolfgang (1993): Der Völkermord an den Armeniern, München: Hanser, S. 18-25.

523 In seinem Essayband War Hitler Araber? Irreführungen an den Rand Europas kritisiert Zafer Şenocak an mehreren Stellen die deutsche Orientalistik und die mit dem ersten Irakkrieg sich neu formierende Expertenkultur in den Medien. Bei den Interpretationen dieser Experten sieht er einen positivistischen Orientalismus am Werk, der den Orient als eine fixierbare homogene Einheit begreift. Auch islamische Fundamentalisten würden sich durch einen positivistischen Zugang zur Welt und zur Religion auszeichnen. Dem stünde eine mystisch geprägte Volksreligiosität entgegen, die es für den Westen, aber auch für die Türken in Deutschland, neu zu entdecken gelte. Denn der »orthodoxe Islam räumt der Fiktion keinen Raum ein, begreift nicht einmal ihre Notwendigkeit«. Zafer Şenocak übersetzte selbst Gedichte des bekannten türkischen Volksdichters und Derwischs Yunus Emre, der für ihn einen aufgeklärten Islam repräsentiert. Siehe zu beidem: ŞENoCAK (1994): S. 9, 18, 39, 50 u. 72; EmRE, Yunus (1986): Das Kummerrad/Dertli Dolap, übers. v. Zafer Şenocak, Frankfurt a. M.: Dağyeli, S. 90. Eine vergleichbare Kritik äußert auch Werner Schiffauer in Fremde in der Stadt. Siehe hierzu: SchIFfaUER (1997): S. 33. Siehe hierzu auch: SCHULzE (1996).

524 ÖREN (1995): S. 108.

525 ŞENOCAK, Zafer (1994a): "Der Dichter und die Deserteure«. In: ders.: War Hitler Araber? Irreführungen am Rand Europas, München: Babel, S. 21-29, hier S. 27. 
Dass es in seiner Kultur - hier identifiziert er sich offensichtlich mit der türkischen Kultur - keinen Begriff von Schuld gebe, merkt Sascha in diesem Zusammenhang kulturvergleichend nur an: »Wir kennen nur die Sünde. Sie umreißt unsere Verantwortung einem göttlichen Wesen gegenüber. Aber wir haben keine Verantwortung vor uns selbst. Schuld ist eine persönliche Frage. Man ist mit seiner Schuld immer allein. Wir sind es nicht gewohnt, allein zu sein. ${ }^{526}$ Aufgrund dieses äußerst individuellen und bedarfsorientierten Einsatzes von Kultur ist Şenocaks Roman unter anderem mit dem aphoristischen und mitunter glossenartigen Stil von Alfred Polgar verglichen worden. ${ }^{527}$ Gefährliche Verwandtschaft umfasst nur 144 Seiten, auf denen er so gewichtige Themen der Geschichte wie den Genozid an den Juden und an den Armeniern in einer Figur als eine Frage des Opfers und der Schuld zusammenbringt. Und trotz des literarischen Zugangs zu diesen Themen fühlt sich der Erzähler erst ganz am Ende von Gefährliche Verwandtschaft dazu bereit, einen Roman über seinen Großvater, der am Genozid an den Armeniern beteiligt war, zu schreiben. Als Person hat er sich dabei noch nicht gefunden, vielmehr seine Position, aus der heraus er schreiben möchte. Er hofft, während des Schreibprozesses und indem er das Geheimnis seines Großvaters lüftet, zu sich selbst zu finden - aus der Exklusion in die Inklusion. Warum hier die Person der Position nachfolgen muss, zeigt uns der Schluss des Romans. Denn um diese Geschichte zu schreiben oder sie »so zu erzählen, wie sie sich ereignet hat «, bedarf es noch einer weiteren Grundlage. Sascha musste zuerst in eine »leere Wohnung ziehen«. Bisher hatte er noch nie in seinem Leben »eine eigene Wohnung bewohnt «. ${ }^{528}$ Bis dahin ist Sascha jemand, der den öffentlichen Raum zwar bewohnt und mit seinem türkisch-jüdischen Hintergrund auch auf die Dauer seiner Existenz in der Bundesrepublik verweist. Doch seine trans- oder postnationale Identität ist und bleibt bis zum Ende der Erzählung ortlos.

Anders interpretiert Leslie Adelson Şenocaks Gefährliche Verwandtschaft. Hinsichtlich der Zusammenführung von »cultural contact and historical narrative« markiert dieser Roman für sie nicht nur einen besonderen Moment in der deutsch-türkischen Literatur, sondern auch in der zeitgenössischen deutschen Literatur. ${ }^{529}$ Andernorts heißt es, er sei ein deutschsprachiger Wenderoman, ${ }^{530}$ in dem auch die Türken in Deutschland nun Teil dieser deutschen Geschichte seien und würden. Oder man konstatiert umgekehrt, dass Şenocaks Roman eine sehr wichtige und notwendige Kritik am Prozess der deutschen Wiedervereinigung

526 ŞENOCAK (2009): S. 119.

527 Siehe hierzu: Polgar, Alfred (2004): Das große Lesebuch, Reinbek: Rowohlt.

528 Ebd., S. 137.

529 AdELSON (2005): S. 100.

530 Hofmann (2005): S. 208. 
darstelle. ${ }^{531}$ In Sachen »Multikulturalismus« setze er an die Stelle einer konfusen multiethnischen Genealogie transkulturelle Kompetenz. ${ }^{532}$ In jedem Fall spielen in diesen unterschiedlichen Einschätzungen die Begriffe des Transnationalen und Kosmopolitischen eine größere Rolle als das Multikulturelle. Besonders betont wird der Befund, dass durch die individuelle Verstrickung des deutschen Genozids an den Juden mit dem türkischen Genozid an den Armeniern eine Transnationalisierung des Holocausts erfolgt sei. Die Erfahrung des Holocaust erzeugt hier eine neue Form der Solidarität jenseits jeglicher Grenzen. Dass seine deutsche Freundin Marie bei den Dreharbeiten zur Dokumentation über Talat Paşa in Thessaloniki sich sehr überrascht zeigt, als sie vom griechischen Antisemitismus erfährt, kommentiert Sascha ironisch distanziert. ${ }^{533}$ Zafer Şenocak schreibt sich mit seinem Roman, wie Adelson richtig anmerkt, in das in den 1990er Jahren und Anfang der 2000er allseits beliebte Themenfeld der kulturellen Erinnerung, des kulturellen Gedächtnisses, ein. ${ }^{534}$

Theorien des kulturellen Gedächtnisses gehen davon aus, dass Realität relational entsteht und die Erzählung, etwa in Form eines Rituals, also letztlich die Art des Gedenkens, das Bewusstsein bestimmt und die Erinnerung prägt. Identität ist nur zeitweise möglich und kann sich nur in der erzählten Zeit stabilisieren. ${ }^{535}$ Auf dieser besonderen Stellung der Fiktion beruht auch das poetologische Konzept der Übersetzung in Gefährliche Verwandtschaft. Wie in Der Mann im Unterhemd, in Die Prärie, in Örens Berlin Savignyplatz und in Özdamars Literatur wird auch in Gefährliche Verwandtschaft »die epistemologische Sicherheit [des Lesers] über die Grenzen von Realität und Fiktion« unterminiert. ${ }^{536}$ Auch wenn die Vergangenheit dabei eine Rolle spielen kann, steht im Fokus eine Verlebendigung der Gegenwart, wie sie auch Bhaba als ein Anliegen postkolonialer Kritik äußert. Diese »Suche nach der Gegenwart« findet auch in Örens Romanen Berlin Savignyplatz und Sehnsucht nach Hollywood statt. ${ }^{537}$ Mit Blick auf dieses Ziel einer Verlebendigung der Gegenwart wird Saschas Vorschlag, Integration für alle Beteiligten durch einen Trialog zwischen Deutschen, Juden und Türken in Deutschland zu ermöglichen, plausibel. Denn im Unterschied zu den Deutschen können die

531 LITTLER, Margret (2013): »Guilt, Victimhood, and Identity in Zafer Şenocaks `Gefährliche Verwandtschaft ««. In: The German Quarterly Vol. 78, No. 3, S. 357-373, S. 359.

532 CHEESMAN (2007): S. 107.

533 ŞENOCAK (2009): S 73.

534 Siehe hierzu: Assmann, Aleida (1999): Erinnerungsräume. Formen und Wandlungen des kulturellen Gedächtnisses, München: Beck.

535 Siehe hierzu: AdELSON (2005): S. 30. Als ebenso temporär begreifen Nassehi und Stichweh die Integration in den 1990er Jahren, die auf der Systemtheorie Niklas Luhmanns beruht.

536 DOLLINGER (2003): S. 3.

537 Siehe hierzu: ÖREN (1995); ders. (1999): Sehnsucht nach Hollywood, Berlin: Espresso. 
Türken keine Schuld gegenüber den Juden weitertradieren. Ein Verhältnis dazu ist nur über einen Vergleich möglich, mit dem Genozid als tertium comparationis.

Diese Transkulturalisierung des Genozids schafft auf allen Seiten »halbe Inländer«, postnationale Zustände. Als Modell integrativer Zustände entspricht sie dem Integrationsmodell der Inklusion, wie es etwa Rudolf Stichweh und Armin Nassehi formuliert haben. Die Verfremdung des Eigenen ist dafür eine notwendige Voraussetzung. Dass Integration wie Erinnerung und Anerkennung nur zeitweise gelingen kann, verdeutlicht Sascha Muhtesem in Gefährliche Verwandtschaft, wenn er meint, dass er nichts »Ganzes sei« und auch nicht ein Teil einer »Schicksalsgemeinschaft« sein wolle. Als »halber Inländer« wie der »Denizen« würde er sich auch nicht wohlfühlen. ${ }^{538}$ »Ich ersetze die fehlende Hälfte mit einer prothesenartigen Identität, etwas Geborgtem«, wozu die Geschichte des Großvaters und mit ihm das Thema des Genozids gehört. In Entliehene Erinnerung. Geschichtsbilder junger Migranten in Deutschland untersucht die Erziehungswissenschaftlerin Viola Georgi, wie junge Migranten in der Bundesrepublik ihr Verhältnis und ihre Position zur deutschen Geschichte und besonders zum Holocaust beschreiben. Wie in der Literatur von Özdamar, Ören und Şenocak steht auch in dieser Studie die spezifische »Geschichtsaneignung einzelner Subjekte« im Mittelpunkt von elf ausgewählten Fallstudien. ${ }^{539}$ Georgi hat insgesamt 55 Interviews geführt. Die eigene Selbstverortung hängt für sie mit der historischen Selbstreflexion Einzelner sowie mit einer sozialgruppenspezifischen Bestimmung zusammen. Denn ein wesentliches Motiv dafür, sich mit der deutschen Geschichte intensiver auseinanderzusetzen, sei die Teilhabe am kommunikativen Gedächtnis der deutschen Gesellschaft, ${ }^{540}$ also am öffentlichen Raum, die bei Şenocak gerade nicht gegeben ist. Denn »im Innersten« empfindet Sascha »gegen jede Art von Solidarität « Abneigung. ${ }^{541}$ Identifikationen mit einer ethnischen Gruppe oder der Mehrheitsgesellschaft sind nicht nur hier in der Literatur, sondern auch im Film, wie wir sehen werden, äußerst zerbrechliche Angelegenheiten. Nicht zuletzt stehen derartigen sozialen Bestimmungen und Positionierungen, wie in Selim Özdoğans Literatur und den bereits genannten deutsch-türkischen Filmen der 1990er Jahre, die körperlichen Triebe und Verausgabungen im Wege.

Die auffallend körperliche Dimension von Şenocaks und Zaimoğlus Literaturen hat Adelson dazu geführt, dass in ihnen deutsche und türkische Geschichten gewissermaßen körperlich, nicht interkulturell, miteinander kommunizieren.

538 ŞENOCAK (2009): S. 121.

539 GEoRgI, Viola B. (2003): Entliehene Erinnerung. Geschichtsbilder junger Migranten in Deutschland, Hamburg: Hamburger Edition, S. 63.

540 Ebd., S. 302.

541 Ebd. 
Getragen würden diese Geschichten und letztlich der »Turkish Turn in German Literature« nach Adelson vom Subjekt, das in Gefährliche Verwandtschaft zu verstehen sei als »figure of historical accountability that speaks to us from a dark hole where breath resonates «. ${ }^{542}$ Dass hinsichtlich dieser Kontaktaufnahme zumindest bei Şenocak Geschichte und soziale Interaktion kaum eine Rolle spielen, und dass aufgrund dessen eine stabile Bindung zwischen einem »dark hole« und einer »historical accountability« kaum möglich erscheint, hat in der Forschung bislang keine Berücksichtigung gefunden.

Adelsons Sprung aus einem »schwarzen Loch« hin zur »historischen Rechenschaftspflicht" erinnert an den Sprung, den Şenocak in Die Prärie vom »ich" zum »man« vollführt, ohne ein »Du« oder ein »Wir« dazwischen zu setzen. Oder daran, wie Soysal allein mit der Anrufung des Menschseins und der universellen Menschenrechte eine neue Form des Sozialen, nämlich eine transnationale im Gegensatz zu einer nationalen aufkommen und entstehen wird. Der Grund dafür mag darin liegen, dass besonders Adelson und Şenocak gegen eine positivistische Soziologie Stellung beziehen wollen - eine Soziologie, die nach Ansicht von Wissenschaftlern wie Adelson, Göktürk und Malik, Film, Literatur und die Reflexion darüber in den 1970er und 1980er Jahren bestimmt hat. ${ }^{543}$ Auch Zafer Şenocak thematisiert die 1980er Jahre in Gefährliche Verwandtschaft dahingehend: Helmut Kohl habe für seinen Protagonisten 1982 eine "geistig-moralische Wende« eingeleitet, die den antiautoritären Trend der 1970er »begradigte«, der den Autor, als er 1970 in Deutschland ankam, wie Kemal Kurt, so beeindruckt hatte. ${ }^{544}$ Mit dem Regierungswechsel wurden Grenzen gezogen, anhand derer nun genau bestimmt werden sollte, wer wohin gehört. ${ }^{545}$ Anfang der 1980er Jahre bekommt Sascha die Anthologie Als Fremder in Deutschland mit dem Kommentar, dass das ein Buch für ihn sei, von einem Freund geschenkt. Der sehr an einer Reflexion über »Fremdheit« interessierte Erzähler ist von der Anthologie enttäuscht. Denn darin stehen ausschließlich Berichte, Erzählungen und Gedichte von Ausländern aus einer Perspektive, die nur sie als die Fremden markiert. Es war ein »Angebot an die Fremden, ihre Fremdheit zu akzeptieren«. Er konnte dieses Buch nicht ernstnehmen, weil auch keiner der Beiträge eine ästhetische Qualität besaß. Später

542 AdELSON (2005): S. 100.

543 Adelson (2003); GöKTÜRK (2000, 2003); MALIK (1996). Dass diese Positionen aber selbst in den 1980er Jahren nicht so einfach waren, habe ich im dritten Kapitel dieses Buches gezeigt. 544 An dieser Stelle geraten Saschas biografische Koordinaten mit denen Şenocaks aneinander. Denn Sascha muss nach der Logik der Erzählung 1960 im Bauch seiner Mutter nach Deutschland gekommen sein, während Zafer Şenocaks Eltern 1970 von Ankara mit ihm als Neunjährigem nach München zogen; dorthin also, wo auch Sascha geboren wird.

545 ŞENOCAK (2009): S. 108. 
muss er feststellen, dass dieses Buch hinsichtlich seiner Positionsbestimmung wegweisend war. ${ }^{546}$ Das lag wohl daran, dass die Deutschen wie in Başers und Bohms Filmen sowie den Büchern von Dikmen und Tekinay kein aktiver Kommunikationspartner waren, sondern nur als unbeobachtete Beobachter auftauchten. In der narrativen Struktur von Gefährliche Verwandtschaft folgt auf diese Reflexionen die erwähnte Anfrage an den Erzähler, ob er nicht eine Reportage zu den Berliner Moscheen schreiben möchte.

Wie die Völkermorde wird auch der Umgang mit der Geschichte der Migration in nur wenigen Sätzen beschrieben. Emine Sevgi Özdamars narrativer Zugang zu Migration, Politik und Geschichte in der Türkei zeichnet sich ebenfalls durch einzelne Sätze, genauer türkische Redewendungen, aus, die sie eins zu eins in die deutsche Sprache übersetzt. Die Verfremdungseffekte, das Problem und die Irritation in Zafer Şenocaks und Emine Sevgi Özdamars Werken der 1990er Jahre haben also in erster Linie weder mit der Zeitgeschichte noch mit dem Individuum zu tun. Beide bemühen sich kaum um historische Quellen, ihre Aufbereitung und Interpretation. Aras Örens Erzähler begegnet Ali Itir in Berlin, Savignyplatz nur auf der Straße, in Kneipen oder bei einer türkischen Beschneidungsfeier. ${ }^{547}$ Es geht hier nicht darum, »turkish thoughts« durch »touching tales« in die deutsche Geschichte einzubringen oder subnationale Verhältnisse in transnationale umzuschreiben. Vielmehr schreiben sich die Autoren in das fragile Gebilde der civil society der Bundesrepublik Deutschland der 1990er Jahre ein. Wohnen, Beziehungsprobleme und Konflikte bestimmen schließlich auch das deutsche kommerzielle und das anspruchsvollere Kino jener Zeit. ${ }^{548}$ Doch besonders die deutsch-türkischen literarischen und filmischen Werke stellen etablierte Vorstellungen vom Eigenen und Fremden in Frage, gerade nicht die Praktiken des gesellschaftlichen Anstands. Anders als bei Başer, Tekinay und Bohm werden hier nicht die eigene Modernität oder Fortschrittlichkeit nachgewiesen. So lasen wir bei Aysel Özakın, dass sie Französisch spreche und schon zivilisiert gewesen sei, bevor sie nach Deutschland kam. Daher führen die sichtbaren Marker der Integration wie Sprachkompetenz (Melek/Michaela), alleine Wohnen, unabhängig Sein (Michaela; Sascha) und beruflicher Aufstieg (Sascha) nicht zu Entspannung

546 Ebd. Ich selbst habe im Jahr 2000 während meines Studiums der Islamwissenschaften an der Universität Freiburg in einem Seminar von einem damaligen deutschen Kommilitonen das gleiche Buch Als Fremder in Deutschland (1982) mit der identischen Aussage geschenkt bekommen, dass es ein Buch für mich sei. Heute sitzt der ehemalige Kommilitone der Islamwissenschaft nach den Landstagswahlen von 2016 im sächsischen Landtag als Abgeordneter für die Alternative für Deutschland (AfD).

547 Siehe hierzu: ÖREN (1995).

548 Siehe hierzu die Filme: KLIER (1991); DöRRIE (1994); BECKER (1995-1997); DRESEN (1998). 
oder Zufriedenheit. Spivaks Frage des Sprechens und Re-Präsentieren-Könnens bzw. die Vorstellung einer weiterentwickelten Kultur, die ein Für-, Gegen- oder Nichtsprechen als Orientierung evoziert, rücken in den Hintergrund. Stattdessen hat die kulturelle Gemengelage die äußeren Grenzen in Grenzen im Körperinneren verwandelt. Die Akteurinnen und Akteure konservieren diese innere Spannung, die in jedem von ihnen zu erkennen ist und sich nicht entladen lässt. Der zu erreichende Ort oder der unmarked space, wie er sich in den Produktionen der 1980er zeigte, ist nicht mehr die deutsche Mehrheitsgesellschaft, sondern der Raum der Übersetzung.

Diese Praxis der Übersetzung ist nicht mehr auf ein Verstehen aus, sondern auf Verunsicherung und Irritation. ${ }^{549}$ Für Werner Schiffauer gerät die civil society, nicht nur in Deutschland, sondern auch in Frankreich, Großbritannien und in den USA mit dem Beginn der 1990er Jahre in Schwierigkeiten. Das Konzept der Zivilgesellschaft sei zwar »bemerkenswert effizient, aber auch eine sehr schwierige Form der Vergesellschaftung«. Dies gelte in besonderem Maße für Deutschland, wo man das Verhältnis von Individuellem und Allgemeinem nicht zwischen den Individuen ausagiere, sondern es »tendenziell in das Individuum verlagert «. ${ }^{550}$ Doch auch über die BRD hinaus wird die zivilgesellschaftliche Vergesellschaftungsform seit Beginn der 1990er Jahre zum Problem und die alltägliche multikulturelle Praxis von Debatten eingeholt und gestört. Den Anfang bildeten Affären um das Kopftuch im französischen Creil 1989. ${ }^{551}$ Die Debatte stellte die strikte Trennung von Religion und Öffentlichkeit in Frankreich in Frage und damit auch das zentrale französische Vergesellschaftungsprinzip der Gleichheit. In Großbritannien war es die Rushdie-Affäre, die das Prinzip der Unantastbarkeit der Person grundlegend irritierte. ${ }^{52}$ In den Vereinigten Staaten hat der Fall einer Vergewaltigung einer erfolgreichen jungen Investment-Bankerin im New Yorker Central Park

549 Siehe hierzu: Schiffauer, Werner (1997a): Fremde in der Stadt, Frankfurt a. M.: Suhrkamp, S. 10.

550 SChIFFAUER, Werner (1997b): »Die >civil society< und der Fremde. `Grenzmarkierungen in vier politischen Kulturen««. In: ders.: Fremde in der Stadt, Frankfurt a. M.: Suhrkamp, S. 35-49, hier S. 47.

551 Sie gilt als »die Mutter aller Kopftuchaffären«. In der Kleinstadt Creil weigerten sich damals drei Schülerinnen maghrebinischer Herkunft, das Kopftuch in der Schule abzulegen. Sie wurden der Schule verwiesen. Siehe hierzu: JoppKe, Christian (2009): Veil. Mirror of Identity, Cambridge: Polity Press, S. 27. Siehe auch: Pioch, Roswitha/Rother, Stefan/Hunger, Uwe (2014): Migrations- und Integrationspolitiken im europäischen Vergleich, Berlin: LIT, S. 235f.; KORTEWEG, Anna C./YuRdAKul, Gökce (2016): „Republikanismus, Laïcité und Geschlechtergerechtigkeit. Das Kopftuchverbot in Frankreich«. In: dies.: Kopftuchdebatten in Europa. Konflikte um Zugehörigkeit in nationalen Narrativen, Bielefeld: transcript, S. 35-88.

552 SCHIFFAUER (1997b): S. 41. 
am 19. April 1989 durch fünf Jugendliche afroamerikanischer und hispanischer Abstammung besonders in New York zu gesellschaftlichen Spaltungen geführt, das sich in seinem »Selbstverständnis angegriffen fühlte «. ${ }^{553}$

Ein Vorbild zeigt sich für Schiffauer in keinem dieser Länder, da selbst das vielversprechende amerikanische Modell der individuellen Assimilation, die nur ihre Zeit brauche, keine Zeit mehr habe: ${ }^{554}$ »[D]as Spannungsverhältnis von Heterogenität und Einheit [wurde] zeitlich aufgelöst. Die kollektive Integration von nationalen Gruppen war möglich, weil sie mit dem Versprechen der individuellen Assimilation in der zweiten, besonders aber der dritten Generation verbunden war «. ${ }^{555}$ Allerdings stiegen die später immigrierten Ostasiaten sozialstrukturell schneller auf als die Afro- und Hispanoamerikaner und machten ihnen dadurch Platz und Position streitig. In Deutschland sei die civilité zu »schwach ausgeprägt «, weshalb eine Kultur vorherrsche, »in der die Identifikation mit dem Ganzen als Voraussetzung für gesellschaftliche Partizipation gewertet wird«. Der Fremde hat es sehr schwer, weil gleich nach seiner Ankunft »Aufrichtigkeit« von ihm gefordert wird.

Kann man demjenigen, der in einer anderen Kultur aufgewachsen ist, diese innere (und deshalb unsichtbare) Bejahung abnehmen? Identifiziert sich >der Fremde` vielleicht doch nur äußerlich, fühlt er sich wirklich dem Gemeinwesen verpflichtet? Der nationalsozialistische antisemitische Diskurs scheint mir gerade auch dadurch gekennzeichnet, daß für ihn noch der >assimilierteste Jude im >Inneren Kosmopolit, vaterlandsloser Geselle etc. war. ${ }^{556}$

Welcher kulturwissenschaftliche Zugang vermag diese deutsche »Realitätsblindheit» zu irritieren? Schiffauer setzt wie Şenocaks Erzähler auf den Prozess der Übersetzung. Selbst seine Ausgangsbedingungen sind mit denen von Şenocak, Ören und Özdamar vergleichbar: Kultur lässt sich weder als System noch als Struktur begreifen, weil derartige Vorstellungen zu identitätspolitischen Festschreibungen führen. Kultur ist »ein offenes Diskursfeld«, in dem nicht das im Vordergrund steht, »was ihre Angehörigen miteinander teilen, sondern das, worüber sie sich auseinandersetzen und streiten«. Es geht nicht um Normen und Werte, sondern um Konflikte, Debatten und Deutungen. ${ }^{557}$

553 Siehe hierzu: Didion, Joan (1991): Überfall im Central Park. Eine Reportage, München Hanser. 2002 stellte sich heraus, dass die zu langjähriger Haft verurteilten Jugendlichen unschuldig waren.

554 Vgl. SCHIFFAUER (1997b): S. 44f.

555 Ebd., S. 44.

556 SCHIFFAUER (1997b): S. 48.

557 Siehe hierzu auch: CoHN-BENdit (1993). Für den Soziologen Albert O. Hirschman besteht der Unterschied zwischen einem Streit und einem Konflikt darin, dass es beim Streit (etwa beim 
Diese Form der Kultur soll »Latentes« und »Unhinterfragtes« hervorbringen, so wie Zafer Şenocak in Gefährliche Verwandtschaft neben den »spermaproduzierenden« Körper die identitätspolitische Festschreibung in Form eines religiösen Vereins stellt. Dieser Ansatz richtet sich besonders gegen sozialstrukturelle Erklärungsmodelle. Denn nach Schiffauer entstehen Krisen hauptsächlich nicht aus einer bestimmten materiellen Situation heraus, sondern erst, »wenn die Verschiedenheit der Parameter [...] durch einen definitorischen Akt sauf den Punkt gebracht ist«. Erst danach wird »eine Konstruktion als Ursache genommen«. Aufgrund dieses Befunds schlägt Schiffauer vor, den sozialstrukturellen Erklärungsversuch umzudrehen. »Der Verweis auf Sozialstruktur erklärt nicht die Krise - sondern umgekehrt, in und durch die Krise wird Sozialstruktur geschaffen, weil Klassen und Beziehungen im Akt der Mobilisierung definiert werden. ${ }^{558}$ Dass der Erzählung, der Form vor Fakten und sozialstruktureller Realität der Vorrang gewährt wird, kennzeichnet die Literatur und den Film, aber auch ihre Analysen in der literatur- und filmwissenschaftlichen Forschung. Diese Vorrangstellung von Erzählung und Irritation ist die Grundlage für den Paradigmenwechsel von der Integration in eine Nation zu einer Trans- oder Postnation, für die Einschreibung in die deutsche Geschichte oder Erzählung eines empowerment von subnationalen zu transnationalen Beschreibungen und Selbstbeschreibungen. Auch Salman Rushdie hält für die gelingende Erzählung der Migration ein paradoxes Verhältnis zwischen der Form und dem Inhalt der Erzählung fest. Am Beispiel seiner eigenen Texte beschreibt er, dass ihr Inhalt oft von Verzweiflung bestimmt sei, aber ihre Akteure und Erzähler dafür äußerst resistent seien und Talent hätten für eine nicht endende Selbstregeneration. Die Erzählung produziere neue Geschichten, indem sie sstrotze ${ }^{559}$

So wird auch im vierten Band der Tetralogie Der Erottomane von Zafer Şenocak die Krise nicht beseitigt. Dabei hätte man am Ende von Gefährliche Verwandtschaft mit dem Einzug in die eigene Wohnung, der mit dem Beginn des Romans im Roman zusammenfällt, glauben können, dass jetzt die Erzählung tatsächlich $\mathrm{zu}$ einer Geschichte werde, zu einem konsisten Zusammenhang von Form und Inhalt. Doch am Anfang von Der Erottomane steht erneut ein deplatziertes Verhältnis von Innen und Außen. Wie schon erwähnt, zieht der Erzähler aus einer

Tarifstreit) darum geht, am Ende eine teilbare Ressource oder teilbare Werte zu haben. Auch Georg Simmel hat in seiner Schrift zum Streit diesen vergesellschaftenden Aspekt hervorgehoben. Beim Konflikt hingegen gehe es gerade um nicht teilbare Ressourcen und Werte, die in teilbare übersetzt werden müssten. HIRschman, Albert O. (1994): »Wieviel Gemeinsinn braucht die liberale Gesellschaft?«. In: Leviathan, Vol. 22, No. 2, S. 293-304.

558 SCHIFFAUER (1997a): S. 20.

559 RUSHDIE (1991): S. 16. 
WG aus. ${ }^{560}$ Wohin er von dort umzieht, bleibt bis zum Schluss des vierten Bandes der Tetralogie unbeantwortet. Stattdessen träumt er gleich nach dem Auszug aus der WG, wie zu Beginn des ersten Bandes der Tetralogie Der Mann im Unterhemd, "vom Wegkommen, vom Sichselbstverlieren, vom Verwischen der eigenen Spuren «, die er - nicht als Tourist - mit einer "großen Reise« schaffen möchte. ${ }^{561}$ Doch wird dieser Roman damit nicht enden, sondern mit einem Gewaltakt gegen den eigenen Körper. Vom anfänglichen Traum der Selbstauflösung bringen den Erzähler etwa eine Zeitungsmeldung und der Anruf eines Staatsanwalts ab. Der Staatsanwalt heißt Tom, trug früher den türkischen Namen Tayfun und streitet sich immer wieder mit dem Erzähler zu Beginn von Şenocaks Roman Der Erottomane. ${ }^{562}$ Wie die Deutsch-Türkin in Der Mann im Unterhemd macht Tom auch keine »halben Sachen «. In der erwähnten Zeitungsnachricht steht, dass aus dem Berliner Landwehrkanal eine Leiche geborgen wurde. ${ }^{563}$ Man vermutet, dass der Tote von einer Prostituierten ermordet wurde.

Der Erzähler trifft sich mit Tom, der ihm den Anfang einer von ihm selbst verfassten Erzählung über eine männliche Figur zu lesen gibt, die das gleiche Schicksal ereilt, wie den Toten aus der Zeitung. Wie in Şenocaks gesamten prosaischen Werk kehrt sich auch die Unterscheidung zwischen Fiktion und Realität um. ${ }^{564}$ Tom hat noch mehr Geschichten über die Figur geschrieben, die sich in der Erzählung selbst als »Erottomanen« bezeichnet, weil er eine »unabschüttelbare Herkunft« und ein »verwegenes Schicksal« habe. »Den anarchischen Zustand seines Körpers hatte er als miniaturhafte Abbildung des anarchischen Zustandes der Gesellschaft wahrgenommen, ohne daß ihm dabei das Wort Freiheit in den Sinn gekommen wäre. ${ }^{565}$ Der lesende Ich-Erzähler versieht den Text des Staatsanwaltes ebenfalls mit dem Titel Der Erottomane. Ein Findelbuch. In den weiteren zueinander sehr heterogen stehenden Geschichten, die durch »verfremdende

560 Auch Aras Örens Roman Berlin Savignyplatz beginnt mit einem Unbehagen zu Hause; wir werden dem Ich-Erzähler nur noch in der »Paris Bar«, dem Gasthaus »Zur dicken Wirtin« oder auf der Straße begegnen. Siehe hierzu: ÖREN (1995).

561 ŞENOCAK (1999): S. 7.

562 Ebd., S. 8.

563 Der Landwehrkanal spielt auch in Örens Berlin Savignyplatz eine wichtige Rolle. Doch im Unterschied zu seiner Kriminalerzählung Bitte nix Polizei nicht als eine wirkliche Lokalität, sondern als Erinnerungsraum für Ali Itir, der im Roman von 1995 weiterlebt. Siehe: ÖREN (1995).

564 Ören gibt in Berlin, Savignyplatz auch ein Gespräch in einer Kneipe wieder, das der Erzähler später als eines bezeichnet, das er nicht in der Kneipe geführt habe, sondern aus einem Theaterstück kenne. Siehe hierzu: ÖREN (1995): S. 37.

565 ŞENOCAK (1999): S. 11. 
und widerständige Details $\aleph^{566}$ zusammengehalten werden, entwirft Şenocak ein Kaleidoskop von der Suche nach dem Ich und dem Körper. Am Ende übernimmt wieder der Rahmenerzähler und berichtet davon, dass Tom seinen eigenen Ritualmord in Auftrag gegeben habe.

Davor erzählt aber erst einmal Toms erste Erzählung mit dem Titel »Der Antiquar« die Geschichte des Erottomanen. Dieser ist, ganz dem Wunsch des Rahmenerzählers entsprechend, auf Reisen und landet in einer Hafenstadt, in der er einen Buchladen erwirbt, um damit die »Zeiten« und »die Geschichte [...] in Ordnung [zu] bringen«. Der einzige Ort, an dem ein solches Vorhaben für ihn möglich ist, ist dieser Buchladen. Er will, »daß das Mittelalter die Antike ablöst und die Neuzeit das Mittelalter, und [...] daß die Uhren überall auf der Welt richtig gehen. Deshalb reise ich durch alle Länder und kümmere mich um die Zeit«. ${ }^{567}$ Doch wird in der Erzählung an nur drei Stellen kurz etwas Geografisches, Soziales und Historisches eingefügt: Die Stadt liegt am Meer, mit seinem eigentlichen Monatsgehalt würden die Menschen in dieser Stadt ein ganzes Jahr leben können, und im Jahr 1913 »war die Stadt voll mit Flüchtlingen «. ${ }^{568}$ Kurz darauf will der Erottomane nicht mehr die Zeiten oder die Geschichte ordnen, sondern sein eigenes Leben. «Wenn ich nebenbei auch das Leben dieser Stadt ordnen werde, so ist das nur ein willkommener Nebeneffekt meiner eigentlichen Absicht. ${ }^{569}$ Als aber eine Frau den Laden betritt und ein für ihn unverkäufliches Buch erwerben möchte, passiert das, was er eigentlich vermeiden wollte. Seinem Ordnungswillen kommt der »Geschlechtstrieb [...] in die Quere«, der die Ordnung des eigenen Selbst in Frage stellt. ${ }^{570}$ Wenn Integration für gewöhnlich die Wiederherstellung einer Ordnung meint, so hindert den Erzähler eine attraktive Frau daran, die Ordnung im historischen oder autobiografischen Sinn zu gewinnen. In Sinan Çetins BERLIN IN BERLIN zieht die ebenfalls attraktive, hier kopftuchtragende Protagonistin Dilber, gespielt von Hülya Avşar, die beiden männlichen Hauptakteure Thomas und ihren Schwager Mürtüz in ihren Bann. Diese Anziehungskraft scheint sich dadurch noch zu steigern, dass sie beim Masturbieren gezeigt wird - wobei Mürtüz sie heimlich beobachtet. ${ }^{571}$

566 Koschorke, Albrecht (2012): Wahrheit und Erfindung. Grundzüge einer allgemeinen Erzähltheorie, Frankfurt a. M.: Suhrkamp, S. 53.

567 ŞENOCAK (1999): S. 23.

568 Ebd., S. 29.

569 Ebd., S. 32.

570 Ebd., S. 37.

571 In der türkischen Presse wurde zu diesem Film besonders diese Sequenz hervorgehoben. Siehe hierzu: KaYAoğLu, Ersel (2012): »Figurationen der Migration im türkischen Film«. In: 51 Jahre türkische Gastarbeitermigration in Deutschland, hg. v. Şeyda Ozil, Yasemin Dayığlu-Yücel und Michael Hofmann, S. 81-104, hier S. 99. 
In Şenocaks Roman beendet der Erzähler nach dem erwähnten Anflug des sexuellen Begehrens sein Projekt und begibt sich auf eine imaginäre Reise über Konstanza nach Odessa und Batumi. Wie in der Prärie nach dem Geschlechtsverkehr empfindet er auch hier nach jedem Ankommen in einer neuen Stadt den Zwang, sich neu einkleiden zu müssen. ${ }^{572}$ Die Reise endet in Baku, wo Nazim Hikmets erstes Buch Das Buch der Sonnentrinker erschien. Wie in vielen literarischen und filmischen Erzählungen der 1990er Jahre herrschen schlechte Lichtverhältnisse. Die Sonne scheint kaum und »[m]odriger Geruch « dringt »aus dem ölverpesteten Meer «. ${ }^{573}$ Während bisher Bewegung in Form einer Reise thematisch und erzählerisch die heterogen strukturierte Erzählung bestimmte, ist von nun an, der Körper des Protagonisten zentraler Ausgangspunkt von Reflexion und Erzählung. Denn der Erottomane stellt fest, dass er eine Zenne ist. Die Zenne ist im klassischen türkischen Volkstheater (Orta Oyun) der männliche Schauspieler, der Frauenrollen spielt, weil Frauen selbst nicht auf der Bühne stehen durften. Beim Auftritt ist die Figur nun Mann und Frau zugleich, vergleichbar mit der Aussage der Mutter der Erzählerin in Özdamars Roman, die nicht mehr genau weiß, ob sie ein Mädchen oder einen Jungen in die Welt gesetzt hat. Şenocaks Erzähler fühlt sich auf jeden Fall gehäutet. ${ }^{574}$ In der auf die »Zenne« folgenden Erzählung »Durst« lernt er bei einer Autopanne Isabella kennen. Er fragt sie, ob in ihrem Herzen ein Mann wohne, und wenn nicht, dann würde er einziehen. ${ }^{575}$

Auf »Durst« folgt mit »Tom und Robert« die nach »Der Antiquar« längste Binnenerzählung in Der Erottomane; eine Geschichte, die vermeintlich von zwei Männern erzählt, sich am Ende aber als eine entpuppt, in der es nur um eine Person geht. Während Tom rational ist und sich nachts gewissermaßen den Tag vom Leib schreibt, glaubt Robert an den Schmerz. ${ }^{576}$ Robert setzt sich für eine Weile durch und lernt Alexandra kennen, mit der er eine sadomasochistische Beziehung eingeht. Alexandra schreibt ihre Gedanken, die nur er lesen kann, auf Roberts Körper. Er bemitleidet die anderen für ihren Analphabetismus. Alexandra nennt Robert den Erottomanen. Er überlegt, ob das an dem roten Ottomanen - der einzigen Sitzgelegenheit in einem dunklen Zimmer - oder an

572 Siehe hierzu: Şenocak (1997): S. 23.

573 ŞENOCAK (1999): S. 44.

574 ŞENOCAK (1999): S. 47.

575 Eine ähnliche Hoffnung hegt Örens Erzähler in Berlin Savignyplatz, als Franco, der Spanier und Konkurrent im Buhlen um Elfie, sich eine Weile in Frankreich herumtreiben will. Der Erzähler freut sich über sein Verschwinden »in der sternlosen Dunkelheit der kalten Nacht«. Wider Erwarten bedeutet das Verschwinden des Konkurrenten nicht den Beginn der wahren Liebe zwischen Elfie und dem Erzähler: »[O]bwohl wir uns von Angesicht zu Angesicht anblickten, sah sie mich auch jetzt nicht«. Siehe hierzu: ÖREN (1995): S. 71-75.

576 Ebd., S. $60 f$. 
seiner Herkunft liegt. Was ihn jedoch am meisten fasziniert, ist, dass sie ihn von hinten »fickt«. »Er glaubt, vor Schmerzen das Bewusstsein zu verlieren. Sie hatte die Festung des Erottomanen erobert. « ${ }^{577}$ Tom, der abends schreibt und tagsüber seinen Arbeitsterminen nachgeht, versucht Robert von Alexandra abzubringen, doch ohne Erfolg. Am Ende gesteht der Erzähler dieser Geschichte, dass Tom und Robert identisch seien. Warum der Erottomane derart aufgespalten ist, gibt die letzte Binnenerzählung »Fährtenleser« des Staatsanwalts Tom preis. Darin freunden sich zwei Männer auf Reisen an. Sie haben ihre Ängste und mitunter Feindschaft in »körperliche Nähe und geistige Verschmelzung « umgewandelt. Eines Tages stößt ein unbekannter Reporter zu ihnen, der ihre abgeschiedene Zweisamkeit stört: »Durch den Dritten [...] hatten sie das Gefühl, einander durch einen Filter zu sehen. Dieser Filter verwandelte sie. Er stellte sie nach außen hin ruhig, konnte aber die innere Unruhe, die beide erfasst hatte, nicht besänftigen «. ${ }^{578}$

Hier endet das Manuskript, das der Staatsanwalt Tom dem Rahmenerzähler gegeben hatte, der nun anmerkt, dass er von Anfang an geahnt habe, »daß Tom Robert war und es Robert nie gegeben hat «. ${ }^{579}$ Tom hieß früher, wie zu Beginn des Romans Der Erottomane festgehalten, noch Tayfun und hatte einen türkischen Pass. Am Ende von Der Erottomane übergibt der Rahmenerzähler Sascha nun dem Binnenerzähler Tom die ersten beiden Kapitel seines neuen Romans. Im ersten Kapitel stirbt ein Schriftsteller, der keine nennenswerten Publikationen vorzuweisen hat, aber eine Eigentumswohnung besitzt, bei einem sexuellen Ritualmord, den er angeblich selbst inszeniert hat. Der Erzähler beschreibt zwar, dass der besagte Autor eine Domina aufsucht und sich auf einem Tisch fesseln lässt. Vom plötzlichen Auftritt einiger Männer, die ihn mit Hilfe der Frau hinrichten, ist er jedoch äußerst überrascht. Es kommt zur Gerichtsverhandlung, bei der der Richter der Prostituierten abnimmt, dass es sich bei diesem Tod um eine »Art Selbstaufgabe« gehandelt habe. Schon vor zwanzig Jahren habe sich das Opfer einbürgern und »einen anderen Namen geben lassen«. Vor Gericht wird kommentiert, dass dies jedem zustehe, »der die deutsche Staatsbürgerschaft annimmt und keine

577 ŞENOCAK (1999): S. 65. Am Ende des Films APRILKINDER verliert der Protagonist das Bewusstsein, weil es für seine identitätspolitische Position ebenfalls keinen Ort gibt. Siehe hierzu: YAVUZ (1998).

578 Ebd., S. 104.

579 Dieser Plot um die erzählende Person erinnert sehr an den des im gleichen Jahr erschienenen Kinofilms Fight Club von David Fincher. Auch dort sind die eigentlich antagonistischen Akteure, deren Präsenz sich ebenfalls in ein Nacht- und ein Tagleben aufteilt, eine einzige Person. Und auch dort erfahren wir dies erst am Ende der Erzählung. Siehe hierzu: FinCHER, David (1999): Fight Club, USA. Siehe ähnliche Plotstruktur in The SiXth Sense. Shyamalan, M. Night (1999): The Sixth Sense, USA. 
halben Sachen mag«. In der einen Person verbergen sich also gewissermaßen zwei Personen, in etwa so, wie in Örens Erzähler auch Ali Itir steckt. ${ }^{580}$

Nach der Gerichtsverhandlung fragt der Erzähler weiter, ob »Selbstzerstörer in unserer Gesellschaft nicht auch aggressiv« seien. »Was wäre, wenn einer sich in der Öffentlichkeit in die Luft sprengt, etwa in einem Hochhaus?« Das Opfer hier folge aber keiner Ideologie. »Im Mittelpunkt seines Lebens stand die Inszenierung des eigenen Todes. ${ }^{581}$ Der Nachlass des verstorbenen Autors fällt an einen Professor, der sich auf Schriftsteller dieser Art spezialisiert hat. Diesem Professor fällt auf, dass der Autor seine Texte nicht datiert hat. Daher müsse er sich an Figuren orientieren, »die immer wieder auftauchen. Es sind dieselben Figuren, wenn auch mit unterschiedlichen Namen, Berufen, Lebensorten und Situationen «. ${ }^{582}$ Zum Schluss trifft der Professor sich mit seiner Hilfskraft zum Abendessen in einem Restaurant, um »wieder über das Opfer zu sprechen «. Sie freuen sich über das neue "gemeinsame Thema «. ${ }^{583}$

Weder historische noch sozioökonomische Motive treiben die Erzählung in Şenocaks gesamter Tetralogie von 1995 bis 1999 an. Vielmehr ist das erzählerische Konzept geprägt von Spiegelungen, Identifikationen und deren Zerschlagung als eine kulturell gebrochene und deshalb eine nie $\mathrm{zu}$ abschließende Transformation. Diesen Zugang erläutert uns der Autor sogar selbst anhand der Kurzinterpretation des Professors am Ende des Romans. Allerdings handelt es sich bei Sascha Muhtesem nicht um ein Opfer. Stattdessen liegt hier eine enge Kopplung von Subjekt und Objekt, von Täter und Opfer in einer Figur vor, die die Grundlage unseres Narrativs in diesem vierten Kapitel bildet; eine Gleichzeitigkeit von Person und Nicht-Person, Inklusion und Exklusion. Inklusion ist nicht möglich, wenn sich keine nicht-integrierbare Gruppe bestimmen lässt. Und Exklusion kann nicht geschehen, wenn die mit sich in Einklang stehenden Personen fehlen. ${ }^{584}$ Beide Bewegungen werden in Form der inneren Spannung ihres Erzählers zusammengeführt, aber nicht nach außen entladen.

580 Siehe: ÖREN (1995): S. 76.

581 Ebd., S. 120.

582 Ebd., S. 123. Einen vergleichbaren Erzählmodus finden wir in Aras Örens Berlin Savignyplatz. Siehe hierzu: ÖREN (1995).

583 ŞENOCAK (1999): S. 124.

584 Vergleichbar lose und fragil sind auch die Beziehungen zwischen Elfie, Franco, Maria und Örens Erzähler in Berlin Savignyplatz. Als sich der Spanier Franco, wie bereits erwähnt, nach Frankreich absetzt, verliert die Beziehung des Erzählers zu einer deutschen Frau ihr Geheimnis. Nur über den Nicht-Türken und Nicht-Deutschen war diese Beziehung am Leben, über ein gewisses Verbundenheitsgefühl. Sobald sich dieses auflöst, zerfällt auch das soziale Gefüge. Siehe hierzu: ÖREN (1995). Eine vergleichbare Beziehungskonstellation finden wir in Emine Sevgi Özdamars zweitem Roman Die Brücke vom goldenen Horn. Insgesamt durchzieht alle literarischen 
Ein gutes Beispiel hierfür ist, als Sascha über eine Dekade später denjenigen Bekannten trifft, der ihm die Anthologie Als Fremder in Deutschland geschenkt hatte. Beide haben sich verändert. Während Sascha nun davon überzeugt ist, dass Grenzen notwendig seien, ist der deutsche Bekannte überrascht, dass er selbst einmal so gedacht hat. Es bleibt also eine nicht entladbare und nicht kommunizierbare innere Spannung bestehen, die der Frage nach der möglichen oder unmöglichen Repräsentation eine andere Stoßrichtung gibt, wie sie sich noch Gayatri Spivak in den 1980ern vorstellte. Wenn es bei ihr vor allem um die Fragen der Darstellung und Vertretung ging, stehen nun Vorstellungen bei der Arbeit der Übersetzung im Mittelpunkt. Der Blick der anderen ist immer Bestandteil der eigenen Wahrnehmung. Als ein Autor dieser Dekade hält auch Mark Terkessidis mit seiner Lektüre von Franz Fanons Die Verdammten dieser Erde für die 1990er fest, dass Darstellung und Vertretung von der Vorstellung umschlossen seien. Vertretung und Darstellung haben sich auf »komplizierte Weise in das Feld des Imaginären verwickelt«. »Tatsächlich ist der `Gegner` der antirassistischen Kämpfe nicht einfach außen, sondern das scheinbare Gegenüber ist in die Konstruktion der eigenen Identität verwickelt. « ${ }^{55}$

Aufgrund der Dominanz der Rede von Mehrheitsgesellschaften und Minderheiten in Reflexion und Argumentation und des Bemühens, diese Unterscheidung über postkoloniale Unterschiede zum Verschwinden zu bringen, hat man häufig übersehen, dass es nicht immer die Mehrheit sein muss, die diskriminiert. Diskriminierung kann es auch innerhalb von vermeintlich homogenen Minderheitengruppen geben. Diese Form der gewissermaßen internen Diskriminierung sind wir schon bei Şenocak begegnet. Im Film dieser Zeit ist sie noch weitaus stärker und intensiver vorhanden: äußerst prominent und eindringlich etwa durch Cahit in Akıns GEGEN DIE WAND oder durch die türkischstämmige Jugendgruppe in Thomas Arslans Film GESCHWISTER. Als der Protagonist beispielsweise in GEGEN DIE WAND ein halbes Jahr nach der Hochzeit, der Scheinehe mit Sibel, seine Schwiegereltern besucht, äußert er sehr gereizt und laut während der Autofahrt dorthin, dass er "auf diesen Kanakenfilm« - gemeint ist der Besuch der Schwiegereltern - »keinen Bock« habe. ${ }^{586}$ Dort provoziert er Sibels Bruder

und filmischen Erzählungen der 1990er Jahre ein internationales und transnationales Setting, das weniger als eine "social practice« beschrieben werden kann, denn als ein Verbundenheitsgefühl.

585 TERKESSIDIs, Mark (2011): „Vertretung, Darstellung, Vorstellung. Der Kampf der MigrantInnen um Repräsentation«. In: Transit Deutschland. Debatten zu Nation und Migration, hg. v. Deniz Göktürk, David Gramling, Anton Kaes, Andreas Langenohl, Konstanz: Konstanz University Press, S. 667-670, hier S. 670.

586 AKIN (2003). 
und seine Freunde, als diese darüber reden wieder »in den Puff« zu gehen. Er fragt sie, was sie dort verloren hätten und warum sie nicht »ihre eigenen Frauen ficken « würden. ${ }^{587}$ Als Cahit sich schließlich immer mehr in Sibel verliebt, wird er in einer türkischen Disko von anderen Türken brutal zusammengeschlagen, weil er sie vor ihnen verteidigte. Während Sibel ihn verarztet, kommentiert er den Vorfall damit, dass diese Typen »Scheiß Kanaken« gewesen seien. »Du bist doch selber einer «, erwidert Sibel. ${ }^{58}$ In Arslans Film GESCHWISTER wird der deutsch-türkische Protagonist Erol von seinen türkischstämmigen Freunden als Bastard beschimpft und er kein bisschen besser als ein Asylant sei. Zuvor hat sich Erol im Beisein seiner Freunde über Asylanten aufgeregt, dass die das letzte seien. ${ }^{589}$ Wie in Akıns Film wird auch hier die Sequenz in einer Mischung aus Tragischem und Komischem dargestellt, die die Frage der Form auch hier in den Vordergrund rückt als allein die inhatliche Ebene der Sequenz.

Als Dursun Mitte der 1980er Jahre in 40 QM DEUTSCHLAND seine Wutrede an ein nicht anwesendes Gegenüber richtete, hat er nicht mit sich selbst gesprochen, denn der adressierte Andere hatte einen bestimmten Ort in der Gesellschaft. So benennt Dursun auch ganz konkrete Akteure wie die deutsche Bürokratie, deutsche Frauenvereine und deutsche Männer, die ihm seine Frau wegnähmen, wenn er sie aus der Tür ließe. ${ }^{590}$ Ebenso wenig spielt die Vorstellung bei Spivak Gayatri eine besondere Rolle, vielmehr die Frage, ob man als Subalterner sprechen und in Kommunikation treten kann. Fragen, die latent auch Tevfik Başer bewegten, als er einen so umständlichen Weg wählte, um eine türkische Frau auf eine

\section{Ebd.}

588 Ebd.

589 Siehe hierzu: ARSLAN, Thomas (1997): Geschwister, Mainz: Zweites Deutsches Fernsehen.

590 Wie Ali Itir in Örens Erzählung von 1981 sucht auch der Erzähler, der sich an Ali erinnert, in Berlin Savignyplatz nach »Persönlichkeit«. Doch die Suchbewegungen der 1990er Jahre unterscheiden sich wesentlich von denen der 1980er. Ali Itirs unbedingtes Ziel war die Arbeits- und Aufenthaltserlaubnis: »Wenn ich erst einmal Arbeiter bin, dann werde ich euch zeigen, wie man in Deutschland eine Persönlichkeit wird, wie Ali Itir zu einem geachteten Mann wird, an dem ihr euch alle ein Beispiel nehmen könnt«, heißt es in der Erzählung von 1981. Eine Dekade später ist von dieser Form persönlicher Entwicklung und dem dazugehörigen Selbstbewusstsein Vorbild für die anderen nicht mehr die Rede. In Berlin Savignyplatz schreibt Ören, dass Ali unbedingt eine »Persönlichkeit« aus Untertänigkeit und ökonomischen Nutzen habe werden wollen. »Deutschland war für ihn ein stetiger Dienst. >Ich leiste diesen Dienst für mich selbst und für die Sachen, die ich kaufen werde`, dachte er.« Dabei beschäftigt auch den Erzähler im Roman aus den 1990ern das Thema »Persönlichkeit«, allerdings jenseits von Entwicklung und Ökonomie. »Das Thema, eine >Persönlichkeit` zu werden, beschäftigte mich unentwegt; diese unberechenbare Obsession bereitete mir schlaflose Nächte und endlose Tage, stürzte mich in Delirien, Halluzinationen, Krankheiten und stellte mir unglaubliche Fallen«. Zitate aus ÖREN (1981): S. 27; ÖREN (1995): S. 23 u. S. 60. 
deutsche Straße zu schicken. Diese Fragen der Repräsentation und Nichtrepräsentation werden in den 1990er Jahren nicht mehr diskutiert, sondern der Bruch von Repräsentation durch Artikulation, durch Lautstärke, durch Stille, durch Körperlichkeit, durch Erzählung und besonders durch Bewegungen und mitunter nicht enden wollenden, weil die gefühlte und vorgestellte Wirklichkeit nicht die wirkliche Wirklichkeit ist.

Diese Verwicklung im Inneren sorgt auch im öffentlichen Raum dafür, dass der Migrant selbst außerhalb der eigenen vier Wände nicht nach draußen kommt, weil er nicht aus seiner Haut kann. ${ }^{591}$ Der öffentliche Raum ist von Bewegungen geprägt, nicht von Verortungen. Wie in Thomas Arslans Film GesCHWISTER fühlen sich die >Kanaken in Zaimoğlus Roman Abschaum auf der Straße immer angesprochen, ${ }^{592}$ egal wo und wann. Jeder Blick der vermeintlich Anderen (besonders der Deutschen), versucht sie nach ihrer eigenen Wahrnehmung als die Türken zu fixieren. Dabei sind sie in der Regel fast immer unter sich. ${ }^{593}$ Sie treffen sich oft an ihrem Stand auf dem Flohmarkt, verweilen dort aber nie. Sie sind in Bars, Kneipen, Imbissbuden, in Bordellen oder am Flughafen. Einen einzigen Ort für sich alle haben sie nicht. ${ }^{594}$ In der eigenen Wohnung steht Ertan Ongun, der Protagonist in Abschaum, oft unter Drogen. Er isst dort nie etwas, und als Leser bekommen wir kaum einen Einblick, wie es darin aussieht oder wie er lebt. Ähnliche Erfahrungen machen wir als Leser auch in den oben besprochenen Romanen von Zafer Şenocak. Der Unterschied zwischen Innen- und Außenräumen ist nicht nur in Özdamars, Şenocaks, Örens und Zaimoğlus Literatur der 1990er Jahre ausschlaggebend. Wir werden sehen, dass die Filme zur Migration in dieser Zeit ebenfalls davon bestimmt sind. Die Akteurinnen und Akteure sind fast immer draußen, bewegen sich jedoch kaum koordiniert.

Wie gezeigt, ist das Schreiben und Arbeiten gegen etablierte Vorstellungen ein Leitmotiv in der Literatur. Diese Vorstellungen sind dabei aber in einem selbst verankert und nicht mehr, wie in den 1980er Jahren, ausschließlich in ältere deutsche Frauen oder türkische Väter und Männer ausgelagert. Dass diese erste Generation keine entscheidende Rolle mehr spielt, werden wir auch in den Filmen sehen. Sie geben, wie die zeitgleich entstehende Literatur, Aufschluss darüber,

591 Siehe hierzu auch: ÖzDoğAN (1999): S. 23.

592 ZAIMoĞLU, Feridun (1997): S. 23.

593 Siehe hierzu: ZAimoĞLU (1998): S. 43 u. S. 71.

594 In Paul C. P. Sius Studie aus den 1950er Jahren zu den chinesischen Migranten der 1920er Jahre in New York spielt dagegen die Wäscherei als integrativer Ort eine äußert konstitutive Rolle. Bestimmend für die chinesischen Arbeitsmigranten war auch, dass sie irgendwann in ihr Herkunftsland zurückkehren. Sie stellten für Siu die klassischen Gastarbeiter dar. Siehe hierzu: SIU (1954): S. 294-303. 
welchen Aufwand es kostet, diese komplexe Gemengelage zu erzählen, um damit kulturelle Zuschreibungen zu unterminieren, und wie wenig Kraft und Energie für Beziehungen und sozialen Aufbau bleiben. Dabei sind letztere Formen der Soziabilität das eigentliche Ziel der Akteure. Bemerkenswerterweise widmen sich in dieser >Dekade der Vorstellungen` vor allem die Filme dem Thema der Migration. Die deutsche Kritik sieht diese Filme als besonders authentisch an, weil sie bis auf ganz wenige Ausnahmen ausschließlich von deutsch-türkischen Regisseuren stammen. In der Türkei entstehen zur selben Zeit lediglich drei Filme zur Thematik, von denen wiederum nur der schon mehrfach genannte Film BERLIN IN BERLIN von Sinan Çetin nennenswert ist. In den beiden anderen, BIR UMUT UğRunA (»Für eine Hoffnung«) und KADERSIZ DoğMUŞUM (»Mein dunkles Schicksal«) von 1991, stehen vor allem die Arabesk-Sänger Ceylan Avcı und Gökhan Güney im Vordergrund. ${ }^{595}$ In den 1990er Jahren und 2000er Jahren interessiert man sich in der Türkei kaum noch für die Folgen der türkischen Migration nach Deutschland. Anders formuliert wirken die neueren deutsch-türkischen Filme dort oft irritierend, wobei ihr Erfolg auf Anerkennung stößt. ${ }^{596}$ Der türkische Film, der sich nach BERLIN IN BERLIN explizit mit den Folgen der türkischen Migration in der Bundesrepublik auseinandersetzt, ist die Komödie BERLIN KAPLANI von Hakan Algül aus dem Jahre 2012. ${ }^{597}$ Die deutsch-türkischen Filme der 1990er Jahre werden als das neue deutsche Kino verhandelt. ${ }^{598}$ Dabei spielen deutsche Figuren in Literatur und Film der 1990er kaum noch eine Rolle; anders als in den 1970er und 1980er Jahren, wie wir an Frau Kutzer, Emmi Kurowski oder Jan in YASEMIN gesehen haben. Alle Protagonisten zeichnen sich nun durch eine Bindestrich-Identität aus.

Bei der aufwendigen Recherche für seinen Film GESCHWISTER von 1997 ist Thomas Arslan bei der zweiten Einwanderer-Generation eine äußerst spannende Kombination aufgefallen. Bei all den Interviews, die er mit deutsch-türkischen Jugendlichen und Heranwachsenden für den Film geführt hat, ist ihm trotz aller Differenzen zwischen ihnen eine Gemeinsamkeit aufgefallen: ein enger Zusammenhang von Lebhaftigkeit und Fatalismus. Die Jugendlichen sind äußerst agil,

595 Siehe hierzu: Güney, Gökhan (1991): Bir Umut uğruna, Spielfilm, Em-Ra Film, Türkei; GözEN, Oğuz (1991): Kadersiz doğmuşum, Spielfilm, As Film, Türkei.

596 Auf einer Tagung der Bilkent University in Ankara vom 22. bis 24. März 2009 erfuhr ich, dass türkische Intellektuelle besonders die Filme der 1970er und 1980er Jahre als repräsentativ einschätzen; nicht diejenigen, die in den 1990er und 2000er Jahren in Deutschland entstanden. 597 Siehe hierzu: KAYAOğLU (2012): S. 101.

598 Siehe hierzu: LEwEKE, Anke (1998): »Der neue deutsche Film ist da!«. In: TIP-Magazin Berlin 22 (1998). Siehe auch: KulaoğLU, Tuncay (1999): »Der neue `deutscheく Film `türkisch`?. Eine neue Generation bringt Leben in die Filmlandschaft«. In: Filmforum 16 (Feb./März 1999), S. 8-11. 
voller Energie und Sprachwitz, doch haben sie alle nach seinem Eindruck eine fatalistische Einstellung zum Leben. Sie können sich bemühen wie sie wollen, nur wenn sie Glück haben, werden sie ankommen. Dieser Kombination sind wir auch in Şenocaks Tetralogie, in Zaimoğlus Kanak Sprak, in Örens Berlin Savignyplatz und in den Romanen Özdamars begegnet. Sie ist auch deshalb interessant, weil sie auf besondere Weise mit Saids Orientalismusnarrativ bricht, es aber nicht vollkommen unterminiert. Passivität, Fatalismus und Mangel an individuellem Bewusstsein der Orientalen sind nach Said zentrale Elemente des Orientalismus, die er in seinem wirkmächtigen Buch vom beginnenden 19. Jahrhundert bis in die zweite Hälfte des 20. Jahrhunderts als politische Erzählung in der englischen und amerikanischen Wissenschaft und Literatur über den Orient ausmacht. ${ }^{599}$ Lebhaftigkeit und die Darstellungen innerer Spannungen als Selbstbeschreibungen widersprechen diesem Bild, wobei der Fatalismus, wie ihn Arslan ins Spiel bringt, dazu verleiten mag, von einem neuen Orientalismus zu sprechen. Doch ist der Orientalismus, wie ihn Said beschreibt, ohne eine von Entwicklung und Wachstum geprägte Geschichte gar nicht möglich. Bei einem derart verstandenen Orient muss der Westen umgekehrt diszipliniert, modern, selbstbewusst und aufgeklärt sein, und er muss für sozialstrukturellen Aufstieg, Entwicklung, Freiheit, Konsum und Selbstbewusstsein stehen. Diese Einheiten und Aspekte moderner Integration, die in den 1960er und 1970er Jahren Gastarbeiter aus den südlichen europäischen Ländern zur Assimilation reizten, sind in keiner der bislang behandelten deutsch-türkischen oder deutschen Produktion der 1990er zu erkennen.

Amerikaner sind in Das Leben ist eine Karawanserei höchstens noch in Form von Schauspielern im Fernsehen vorhanden, die man im eigenen Alltag nachahmt. Die Verbindung von amerikanischem Kino, seinen Helden und ihre Nachahmung spielt auch in den Filmen der 1990er eine besondere Rolle. Doch sind ziellose Nachahmungen ohne einen Wandel der Identifikationen ein schwieriges Unterfangen, wenn der eigene Ort sich immer wieder verschiebt. Dasselbe gilt für Entwicklungen, ob zu, mit oder postkolonial gegen den Westen. Die Verbindung und Verschmelzung von Ost und West bleibt auf diese Weise eine innere Angelegenheit; sie versetzen die Akteure in Film und Literatur in Spannung und in Bewegung. Diese Bewegung führt aber nicht einfach in den transnationalen oder kosmpolitischen Raum, wie es unzählige Forschungsbeiträge zum deutsch-türkischen Film vom Ende der 1990er bis heute konstatieren oder es sich so wünschen. ${ }^{600}$ Denn weder ist jemand wirklich frei am Ende der Spielfilme noch kommt der eine oder die andere irgendwo an. Dasselbe gilt für die deutschen Filme HAPPY BIRTH-

599 SAID, Edward (2011): Orientalismus, Frankfurt a. M.: Fischer, S. 274. 600 Für viele: GöKTÜRK (2000, 2003); MENNEL (2004); BURNS (2006). 
DAY, TÜRKE (1991) von Doris Dörrie und Lars Beckers KANAK ATTAK (2000) über Deutsch-Türken in Deutschland. Auch wenn auf einen dritten Raum verwiesen wird, stellt er nicht die eigentliche Grundlage des deutsch-türkischen Kinos der 1990er Jahre dar. Im Zentrum steht wie in der Literatur jener Zeit das Verhältnis von innerer Spannung und Mobilität. Natürlich sind Filmemacher wie Thomas Arslan oder Fatih Akın vom italienischen Neorealismus, vom französischen Kino der Nouvelle Vague oder vom amerikanischen Gangsterkino à la Martin Scorsese und Brian De Palma geprägt. ${ }^{601}$ In ihren und anderen Filmen sind nationale und kulturelle Vermischungen im Einsatz der Musik, der Sprachen, der Orte und der Auswahl ihrer Figuren evident. Diese Einheiten stehen in einer globalen Kommunikation. Doch symbolisieren diese Verknüpfungen nicht einfach den Übergang von einem vermeintlichen »cinema of duty" zu einem "pleasure of hybridity", wie Sarita Malik und Deniz Göktürk zu jener Zeit konstatieren. ${ }^{602}$ Identitätspolitische Spannungen lösen sich nicht einfach auf, wenn man Kulturen miteinander vermischt. Durch ihre kulturelle Unbestimmtheit zeigen sie vielmehr den existenziellen Grad der Konflikte auf. In diese Richtung weist auch die Relektüre des Gastarbeiters Ali Itir in Örens Berlin Savignyplatz: »Gewißheit herrscht nur über die Existenz einer Person names Ali Itir, deren wahre Identität unbekannt ist. [...] Ali Itir ist also eine existierende Person, die es nicht gibt, oder das Gegenteil davon: eine nichtexistente Person, die es dennoch gibt ${ }^{603}$ Diesen Konflikt als eine positive »imagination as social practice « $\mathrm{zu}$ lesen, die für eine neue Form der Verbundenheit, der Zusammengehörigkeit und für eine neue globale Ordnung steht oder stehen wird, wie es einige Forscher in der Folge der Arbeiten von Arjun Appadurai tun, ist eine grobe Verkürzung und zeugt von einer blinden Globalisierungseuphorie. ${ }^{604}$

601 Siehe hierzu: Löser, Claus (2004): »Berlin am Bosporus. Zum Erfolg Fatih Akıns und anderer türkischstämmiger Regisseure in der deutschen Filmlandschaft«. In: Apropos: Film. Das Jahrbuch der DEFA-Stiftung, Berlin, S. 129-147, hier S. 129f.

602 Siehe hierzu: MALIK (1996); GöKTÜRK (2000b).

603 ÖREN (1995): S. 30.

604 Siehe hierzu: ApPADURAI, Arjun (2005): »Die Kraft der Imagination«. In: Projekt Migration, hg. v. Dokumentationszentrum und Museen über die Migration in Deutschland e.v., Köln: Dumont, S. 794-796, hier S. 795. In einer vergleichbaren Globalisierungseuphorie hält der Schweizer Intellektuelle Roger De Weck für die doppelte Staatsbürgerschaft in Deutschland fest, dass es in 20 Jahren selbstverständlich und politisch alltäglich sein würde, wenn ein Politiker von Paris nach Berlin wechsele, wie es heute keinen irritiere, wenn einer vom Landtag in Schleswig-Holstein zu dem in Nordrhein-Westfalen wechsele. Siehe hierzu: DE WECK, Roger (1999): „Pro: Zwei Pässe«. In: DIE ZEIT, 7. Januar 1999. Siehe hierzu auch: GöKTÜRK u. a. (2010): S. 234-235, hier S. 235. 
Dass in den Filmen hingegen mehr Auseinandersetzung, Kampf und Konflikte stecken als einfach nur transnationale Verweise, Referenzen und Mobilität, zeigt allein die Tatsache, dass Fatih Akın für seinen ersten abendfüllenden Spielfilm KuRZ UND SCHMERZLOS sich wie Sylvester Stallone in RockY eine eigene Hauptrolle schreiben wollte; nicht weil er Amerikaner werden, sondern weil er wie Şenocak für die deutschen Zeitungen nicht mehr länger »»Der Türke vom Dienst « in den Fernsehkrimis sein wollte. ${ }^{605}$ In der ersten Hälfte der 1990er Jahre haben einige der genannten deutsch-türkischen Regisseurinnen und Regisseure Film und Regie studiert, waren als Schauspielerinnen und Schauspieler in Nebenrollen aktiv, haben Kurzfilme und ihre Abschlussfilme an den Filmhochschulen gedreht. So wurden in den ersten Jahren dieser Dekade die Voraussetzungen für eine Entwicklung geschaffen, die mitunter zum Goldenen Bären für GEGEN DIE WAND im Jahre 2004 führte. ${ }^{606}$ Dass es Akın bei dieser Entwicklung um mehr als nur um die Adaption von bereits vorhandenen erfolgreichen und populären Filmfiguren und Imaginationen geht, macht eine Szene in seinem ersten Film KuRz UND SCHMERzLOs besonders deutlich. Am Anfang wird einer der drei Protagonisten aus dem Gefängnis entlassen. Auf der Hochzeit seines älteren Bruders stellt sein enger Freund Bobby ihn seiner neuen Freundin vor: «Vergiss die ganzen Motherfucker aus dem Fernsehen. Das hier, Alice, ist die Legende. Der Mohammed Ali von Altona «. ${ }^{607}$ Um was für eine besondere Form der Nachahmung es sich dabei handelt, erläutert Akın selbst. Im Audiokommentar hält er fest, dass seine Schauspieler Aleksander Jovanovič (Bobby) und Oscar Ortega Sanchez (1. Waffendealer) zwar alle Fans von Tony Montana in ScARFACE (1983) seien, sie aber nicht direkt seinen Habitus in diesem Film nachahmten. Vielmehr ahmten sie die Kriminellen aus Altona nach, die wiederum Al Pacino als Tony Montana nachahmten. ${ }^{608}$ Diese spezifische Form der Übersetzung, eine kämpferische Auseinandersetzung vor Ort mit dem eigenen Körper, steht im Vordergrund der Filme aus den 1990er Jahren. ${ }^{609}$ Es ist eine Form der Übersetzung, die wie bei Şenocak nah an der »Naht« vollzogen wird. Auch das Verhältnis von Örens Erzähler in Berlin Savignyplatz zu seiner fiktiven Gastarbeiterfigur ist eines an der »Naht«.

605 BEHRENS/TÖTEBERg (2011): S. 36.

606 LÖSER (2004): S. 134.

607 Auch das erste von zwei Kapiteln in Berlin Savignyplatz führt den Begriff "Legende« im Titel: »Die Legende von Ali Itir«. Siehe ÖREN (1995): S. 8-123.

608 AKIN, Fatih (1997/98): »Audiokommentar zu >Kurz und schmerzlos««. In: Kurz und schmerzlos, Universal Germany GmbH, Deutschland, DVD.

609 So werden in Şenocaks letztem Band der Tetralogie sehr viele Orte erwähnt, die von einer langen und bewegten Reise berichten, obwohl die Erzählung ausschließlich in Berlin spielt. Siehe: ŞENOCAK (1999). 
So stehen Mohammad Ali oder Al Pacino in Kurz und Schmerzlos, Bruce Lee in GeSchWISTER von Thomas Arslan, Ali Itir in Berlin Savignyplatz und Kemal Kayankaya in HAPPY BIRTHDAY, TÜRKE! in erster Linie nicht für eine andere erwünschte Identität oder ein Vorbild für eine andere idealisierte Community, sondern für ein hohes Maß an Resilienz, an Selbstbehauptung, an dem Wunsch, anerkannt zu werden, an Selbstständigkeit, für körperliche Energie und für einen besonderen Auftritt und Bewegung im naheliegenden öffentlichen Raum. Auch in Örens Berlin Savignyplatz steht die Zugehörigkeit des Erzählers zu einem Berliner Stadtteil im Zentrum; eine Gegenwärtigkeit, zu der jedoch auch die fiktionale Figur Ali Itir gehört.

Es geht in den 1990ern also nicht darum, erfolgreiche Aufstiegsgeschichten oder, negativ gewendet, die Unsichtbarkeit der türkischen Gastarbeiter in der BRD zu kopieren oder zu wiederholen. Stattdessen will man zeigen, wie man selbst, ohne soziale oder kulturelle Stützen, Teil der Gegenwart ist. Man tritt also genau so auf, wie man es für Akteure aus der türkischen Kultur nicht für möglich halten würde, weil sie doch nach Edward Said zwischen den Kulturen stehen und ihre Herkunftskultur mehr von Phlegma als von Aktivität bestimmt ist. ${ }^{610}$ Darin ähneln sie den positiv beschriebenen Selbstständigen aus Daniel Cohn-Bendits Heimat Babylon auf türkischer Seite wie auf deutscher Seite in ihren jeweiligen Geschichten der Migration. Sie haben sich aus ihren kulturellen Kontexten gelöst und müssen sich selbst um ihre Integration kümmern.

Diese vermeintliche Unabhängigkeit hat in der Literatur und für die deutschtürkischen Figuren im Film einen besonderen Preis, nämlich den, dass immer wieder die Exklusion einbricht. Dies rührt nicht zuletzt daher, dass die Integration der Türken zu Beginn der 1990er Jahre im Unterschied zu den neuen Bürgern aus dem Osten Deutschlands »nicht im Namen einer ethnischen Nation vollzogen werden « kann. ${ }^{611}$ Wie und mithilfe welches Narrativs sie vollzogen werden kann, sind Fragen, die nicht nur der Historiker Rudolf von Thadden nicht stellt und nicht beantwortet. Auch Publizistik, Literatur und Film setzen sich nicht mit der Geschichte der Migration in der Bundesrepublik auseinander, in die sowohl Türken als auch Deutsche verwoben sind. Eine Schlussfolgerung aus diesem Umstand könnte lauten: Wenn sie es nicht schaffen, sich $\mathrm{zu}$ integrieren, sind sie selbst schuld. Genau das sagt sich diese Generation selbst, um ihre Selbstständigkeit trotz schwerer Bedingungen zu wahren. Wie Zafer Şenocaks Erzähler setzt sich die 1 1/2. und 2. Generation auf der einen Seite dabei von kulturellen Kollektiven, zu denen ihre Figuren vermeintlich gehören, beleidigend und dis-

$610 \mathrm{Zu}$ diesem Aspekt des Orientalismus siehe: SAID (2011): S. 237.

611 Zitiert nach: DIRKE (1994): S. 532. 
kriminierend ab, während sie auf der anderen Seite vom Modell der Assimilation an die deutsche Gesellschaft geprägt sind. ${ }^{612}$ Aus dieser Zwischenposition ergibt sich eine andere Frage des Überlebens, der Widerstandskraft, die sich sowohl vom gesellschaftlichen (Deutsche Einheit) als auch vom multikulturellen (»Türke sein in Deutschland«) Überleben unterscheidet, allerdings nicht ohne Bezüge zum Multikulturalismus oder zur Assimilation artikuliert werden kann. Dieses vielschichtige Kommunikationsgeflecht zeigt sich vor allem in den Filmen der Migration. Und weil die Kommunikation als Verknüpfung, Verbindung, als Verknüpft-Sein und Verbunden-Sein in unterschiedlichsten Varianten thematisiert wird, tritt das Verstehen als Koordinate des Kulturellen zurück, aber nicht die soziale Interaktion, das Verlangen nach Soziabilität. Die besonderen Stärken der Literatur und der Filme der 1990er Jahre liegen darin, dass sie sehr viele Grenzen überschreiten, Regeln brechen, auf Ästhetik und Körperlichkeit setzen, jedoch als einzigen Kanal für diese Artikulationsformen, und das ist ihre besondere Schwäche, nur auf die Kommunikation, auf eine rein imaginierte Verbundenheit über die Anrufung des Menschseins setzen. Anders und negativ formuliert lassen sich anhand der deutsch-türkischen Produktionen dieser Dekade die besonderen Folgen der deutschen Einheit ablesen: dass nämlich die Türken keine Türken mehr sind, aber auch keine Deutschen. Ebenso wenig existiert ein postnationales Konzept, obwohl kulturelle Marker im Spiel bleiben. Es handelt sich dabei jedoch um ein ernstes Spiel zwischen Komödie und Tragödie, weil die Übersetzungsarbeit unter den geschilderten gesellschaftspolitischen Bedingungen viel Kraft und viel Aufwand erfordert, um die zwei Seiten in einen Dialog zu bringen, der aufrechtzuerhalten ist. Die zentralen konstitutiven identitätspolitischen Aspekte in den 1990er Jahren sind nicht die »Gesellschaft« oder »Welt«, sondern das Weitersprechen, sich Weiterbewegen und Weitermachen.

Aysel Özakın wollte in den 1980er Jahren mit ihrem Auftritt und ihrer Literatur als Türkin zeigen, auch wenn es ihr eigentlich lächerlich vorkam, dass sie wie die gebildete Schicht in der Türkei und in Deutschland Teil des Westens ist. Diese Form der Repräsentation gibt es in den 1990er Jahren nicht mehr. Denn die »kulturelle Verschmelzung «, die der Publizist und Filmkritiker Georg Seeßlen in seinem vielzitierten Artikel zum deutsch-türkischen Kino der 1990er Jahre nennt, sei unumkehrbar. ${ }^{613}$ Auch wenn es Seeßlen selbst so nicht intendiert hat, ist der Begriff der Verschmelzung in den klassischen Assimilationstheorien der 1960er

612 Mit der 1 1/2 Generation sind im Unterschied zur zweiten Generation, die Personen gemeint, die im Herkunftsland geboren wurden, aber die schulischen Einrichtungen des Ankunftslandes durchlaufen haben. Zu ihnen gehören Zafer Şenocak, Feridun Zaimoğlu und Thomas Arslan. 613 SeEsslen, Georg (2000): »Das Kino der doppelten Kulturen. Erster Streifzug durch ein unbekanntes Kino-Terrain«. In: epd Film 12 (2000), S. 22-29, hier S. 25. 
Jahre zentral. ${ }^{614}$ Wie in den obigen Literaturanalysen ist zwar auch im Film das Türkische vom Deutschen nicht zu trennen. Doch die ästhetische Ausbuchstabierung dieser spezifischen Bindung, deren Ort ausschließlich der Körper der Akteure ist, erfolgt weder sozial endogen wie in den 1960er und 1970er Jahren, wo Kultur nicht Teil der Auseinandersetzung war, noch kulturell emisch wie in den 1980er Jahren, wo Kultur zum ersten Mal als eingegrenzte absolute Entität auftritt. Auf diese Geschichte folgend ist die Überschreitung von Grenzen der Artikulationsmodus der 1990er Jahre. Und aufgrund der entwickelten und entstandenen Vorstellungen von und über Kultur und den kulturellen Markern in der multikulturellen Realität der deutschen Gesellschaft ist das Überleben in Literatur und im Film ein existenzielles und zugleich auch kulturelles. In den 1990er Jahre steht die Frage des Überlebens am Anfang. Kultur und Existenz sind sowohl getrennt als auch zusammen - verbunden über einen globalen Rahmen mit einem jenseitigen Bezug durch eine Praxis der Anrufung des Menschseins.

\subsection{Vom Überleben im Film}

»Da war eben so ein junger Typ und hat ein Drehbuch abgegeben. Er macht einen ziemlich energetischen Eindruck«, meint Stefan Schubert, der Geschäftsführer der Filmproduktionsgesellschaft Wüste Film, im November $1993 \mathrm{zu}$ seinem Kollegen und Gesellschafter der Firma Ralph Schwingel und übergibt ihm die erste Fassung des Drehbuchs von KuRz Und schmerzlos. Schwingel findet den Titel des Films »verquast«, aber auch »toll«. Er entdeckt im Drehbuch viele Szenen, die »kaum umsetzbar waren«. Aber eine dieser Szenen hat ihn »umgehauen«. Am Ende des Drehbuchs liegt ein »angeschossener Albaner blutend auf der Straße«. Zwei andere Jungs, ein Türke und ein Grieche, »streiten sich, der eine sterbend, der andere rettend. Bis der ebenfalls sterbende Albaner fragt: ১Wie geht es denn jetzt weiter? « ${ }^{615}$

Tatsächlich wird diese Schlusssequenz vier bis fünf Jahre später auch anders gedreht, als Fatih Akın sie in der ersten Drehbuch-Fassung vorgesehen hatte,

614 RAUER, Valentin (2014): »Assimilation«. In: Das neue Deutschland. Von Migration und Vielfalt, hg. v. Özkan Ezli, Gisela Staupe, Konstanz: Konstanz University Press, S. 203-205, hier S. 203. 615 AKIn, Fatih/Behrens, Volker/TöteBerg, Michael (2011): Im Clinch. Die Geschichte meiner Filme, Reinbek: Rowohlt, S. 38. Auch in Ayşe Polats Film AusLAndSTOURnEE von 1999 steht der Tod des Schattenspielers Mahmut im Zentrum, der Anfang der 1980er Jahre mit einem türkischen Varieté-Ensemble in die Bundesrepublik gekommen war. Sein homosexueller Kollege und Travestiekünstler Zeki übernimmt die Aufgabe und Verantwortung, Mahmuds Tochter zu ihrer Mutter, der Dritten im Bunde des Ensembles, zu bringen. Siehe hierzu: Polat (1999). 
wobei Sterben und Überleben zentral bleiben. ${ }^{616}$ Die von Schubert wahrgenommene körperliche Energie des Regisseurs bestimmt auch den gesamten Film. Am stärksten ausgeprägt ist das Motiv des Überlebens in Akıns bislang bekanntestem und erfolgreichstem Film GEGEN DIE WAND, auf den später noch genauer einzugehen sein wird. Zunächst ist noch eine andere Ausgangsgeschichte zu KURZ UND ScHMERzLOS zu erwähnen, die es nach Jahren der Überarbeitung ebenfalls nicht in den Film geschafft hat, aber ebenso wie die oben genannte Sequenz die Grundstruktur des Films mitbestimmt.

KURZ UND SCHMERZLOS aus dem Jahr 1998 erzählt die Geschichte von drei engsten Freunden: dem Türken Gabriel, dem Serben Bobby und dem Griechen Costa. Alle sprechen reinstes Hamburger Kiez-Deutsch, wie die Protagonisten in Yüksel Yavuz' Film APRILKINDER. Gabriel wird am Anfang von KURZ UND SCHMERZLOS aus dem Gefängnis entlassen und möchte mit Taxifahren »ein wenig Geld bunkern und dann ab in die Türkei«. Dort sieht er sich als Strandcafébesitzer mit einem Bootsverleih am Meer. ${ }^{617}$ Bobby will hingegen bei der albanischen Mafia einsteigen und bezeichnet diesen Wunsch als das heutige Multi-Kulti in Deutschland. Costa ist ein Dieb und hat ein Beziehungsproblem mit seiner Freundin Ceyda, Gabriels Schwester. Im weiteren Verlauf des Films wird sie sich von ihm trennen und Bobby wird bei den Albanern einsteigen. Gabriel wird Taxi fahren und sich in Bobbys deutsche Freundin verlieben. Bobby und Costa scheitern an einem Waffendeal für den Albaner Muharem, dessen Rache sowie Gabriels Rache an ihm zur oben beschriebenen Schlusssequenz des Films führen.

Zwölf Jahre nach dem Kinostart des Films hält Fatih Akın trotz des Erfolgs, der Preise und der positiven Resonanz in Kritik und Forschung zu diesem Film fest,

616 In Hussi Kutlucans anarchischer Komödie ICH CHEF, Du TuRnschuH von 1998 wird die deutsche Frau, mit der der armenischstämmige Asylant und Protagonist des Films Dudie eine Scheinehe eingeht, von ihrem deutschen Exmann ermordet. Dudie kümmert sich als nicht-biologischer Vater um den 11-jährigen Sohn der Frau. Sie schlafen anfangs auf öffentlichen Plätzen oder in Parks, bis sie einer alten deutschen Dame vorgaukeln, dass die Berliner Ausländerbehörde sie zu ihr geschickt habe, da sie als alleinlebende Frau genug Platz in ihrer Wohnung habe, ihn und seinen Sohn als Asylanten aufzunehmen. Am Anfang noch fremdenfeindlich fügt sich die alte Dame der vermeintlichen Order der Stadt und nimmt die beiden auf. Mit der Zeit entwickeln sie sich zu einer sich respektierenden und solidarischen Gemeinschaft, die sogar in die Hochzeit von Dudie und der alten Dame mündet. Doch dazu kommt es nicht, weil die Betrüger von einer Nachbarin bei der Polizei angezeigt werden. ICH CHEF, Du TuRnschuH endet mit der Ausweisung von Dudie und seinem Wahlsohn, weil dieser, um von Dudie nicht getrennt zu werden, so tut, als sei er wirklich ein Flüchtlingsjunge. Sie hierzu: KutLuCAN (1998).

617 Den gleichen Traum haben die Protagonisten im erfolgreichen deutschen Film LAммвоск. ALLES IN HANDARBEIT (2001) von Christian Zübert. Auch in Rachid Boucharebs Film L'HONNEUR DE MA FAMILLE ist der Wunsch, irgendwo anders als in Frankreich am Strand zu leben, sehr präsent. 
dass er ihn hätte anders machen sollen. KURZ UND SCHMERZLOS erhält 1998 beim Filmfestival Locarno den Spezialpreis Bestes Darstellerensemble, im gleichen Jahr den Adolf-Grimme-Preis und 1999 den Bayrischen Filmpreis. ${ }^{618}$ Dennoch meint Akın im Jahr 2010, ein gescheiterter Waffendeal gehöre in eine »Vorabendserie«, sei »Möchtegern-Hollywood «. ${ }^{619}$ Er hätte lieber die reale Geschichte erzählen sollen, auf der die Idee zu diesem Film basiert: Akın, Adam Bousdoukos (Costa im Film) und Tommy (Bobby) sind Anfang der 1990er Jahre beste Freunde und besuchen dieselbe Schule in Hamburg-Altona. Adam bleibt sitzen und kommt in die Klasse von Tommy. Letzterer wollte wie die Figur Bobbys im Film ein Gangster werden, wie in den italienisch-amerikanischen Filmen ScARFACE oder DER PATE. Statussymbole waren ihm wichtig. An einem Tag, so erinnert sich Akın, wurde ihm seine teure »Versace-Jacke« auf einer »Jugo-Party [...] abgezockt«. Tommy wollte seine Jacke zurückhaben und wendete sich an »Geldeintreiber«, um die Jacke zurückzubekommen. Die brachten sie ihm zerfetzt zurück und verlangten danach von Tommy noch mehr Geld, "um ihn zu beschützen«. Denn der andere, der die Jacke gestohlen hatte, überlebte und war nun hinter Tommy her. Tommy flieht darauf nach Belgrad und als ein Jahr später die Jugoslawien-Kriege (1991-1995) beginnen, wird er zum serbischen Militär eingezogen. 1998 kehrte er nach Deutschland, nach Hamburg zurück. Zur Premiere von KuRZ UND SCHMERzLOS ist er da und Akın erinnert sich, dass er »erst einmal ziemlich beeindruckt [war], dass sein Leben verfilmt wurde«. Doch nach dem Film war er »sauer« auf Akın, »weil er meinte, dass er nicht sonderlich gut wegkommt im Film «. ${ }^{620}$ Realistisch wäre es nach Fatih Akın also gewesen, »wenn es um die Versace-Jacke von Tommy gegangen wäre«. Und genau so würde er den Film heute drehen, schließt Akın seine Erinnerungen an die Entstehung des Films. Ein junger Mann, der wegen einer Jacke, die ihm »abgezogen wird«, nach Jugoslawien flieht und als »Cetnik« ${ }^{621}$ zurückkommt. ${ }^{622}$

Wäre ein solcher Film von der deutschen Filmkritik und den deutschen Feuilletons in den 1990er Jahren wirklich als realistisch wahrgenommen worden? Eine Geschichte um eine geklaute Jacke, in die Türken, Serben, Griechen und Albaner verstrickt sind? Wenn es in solch einem Film einen Konflikt gibt, dann

618 Siehe hierzu: https://www.filmportal.de/film/kurz-und-schmerzlos_1e65902d2d3a4b66b35 95422503dc303 (zuletzt 15.05.2021).

619 BEHRENS/TÖTEBERG (2011): S. 66.

620 Ebd., S. 36f.

621 Während des Jugoslawienkriegs nannte man »Cetnik« die Soldaten serbischer Militärgruppen. Ihnen werden die genozidalen Kriegsverbrechen während des Bürgerkriegs angelastet. Die Verwendung des Begriffs geht bis in die Mitte des 19. Jahrhunderts zurück.

622 BeHRENS/TötEBERg (2011): S. $66 \mathrm{f}$. 
hätte es doch um die verletzte kulturelle Ehre eines seiner Akteure gehen müssen. Kurz gesagt: Wie mit der ersten Fassung der Sterbesequenz am Ende des Drehbuchs hätte es auch mit der Jackengeschichte ein Übersetzungsproblem gegeben. Denn es wäre schwierig gewesen, die Komik der Situationen zu unterdrücken, in der beispielsweise ein sterbender albanischer Krimineller einen schwer verwundeten und ebenfalls sterbenden Griechen fragt, wie es denn jetzt weitergehe; und das alles am Ende nur wegen einer Jacke. Entgegen Akıns eigener Einschätzung, dass sein erster abendfüllender Spielfilm unrealistisch sei, sah die Filmkritik vor zwölf Jahren und mitunter auch die Forschung in ihm eine realistische Sicht auf das multikulturelle Milieu Altonas dargestellt, während man ihn andernorts als das MEAN STREETs von Hamburg-Altona beschrieb. ${ }^{623}$ Ist diese Mischung aus Realität, Fiktion und Verbundenheitsgefühl als »Realität von heute« nun eine Fehleinschätzung? Mitnichten. KURz UND SCHMERzLOs musste sich wie viele andere Filme der 1990er Jahre mit bestimmten Vorstellungen von Multikulturalität und Wirklichkeit auseinandersetzen. So äußert auch Thomas Arslan zur Entstehungszeit von Akıns Film: »[W]enn es schon nicht möglich ist, völlig an den Klischees vorbeizugehen, dann kann man vielleicht versuchen, durch sie hindurchzugehen, d. h. von ihnen auszugehen, sie zu benutzen, um sie dann nach und nach aufzulösen, so daß etwas anderes sichtbar werden kann «. ${ }^{624}$ Auch Dr. Anders bringt in Örens Berlin Savignyplatz auf den Punkt, dass man in modernen Gesellschaften ohne Klischees nicht leben könne. Um einen Umkehrprozess einzuleiten, war es für Arslan daher wichtig, »bei der Darstellung der Personen türkischer Herkunft auf jedes folkloristische Detail, auf jede Behauptung oder Problematisierung einer 〉Fremdartigkeit $\mathrm{zu}$ verzichten $«{ }^{625}$ »Wirklichkeit« ist sozusagen nicht nur auf der begrifflichen Ebene dehnbar, sondern rückt auch inhaltlich das »fait social« in ein anderes Licht.

Feridun Zaimoğlu versucht Mitte der 1990er Jahre ebenfalls durch seine »Nachdichtung« der Sprache der »Kanak Kids« der »Folklore-Falle« zu entgehen: »Weil sich die Kanak Kids in den Straßen bewegen, sprechen sie einen sich laufend weiterentwickelnden symbolischen Jargon, der häufig als blumige Orientalsprache mißverstanden wird.« Daher hat Zaimoğlu beispielsweise die unter Freunden üblichen türkischen Anreden wie gözüm (»mein Auge«) oder gözümün

623 VoIgt, Claudia (1998): „Es war einmal in Altona«. In: DER SPIEGEL, 43/1998, S. 260-262, S. 260. Siehe auch: Stern, 14.02.2004. BEYER, Tom (1998): »Kurz und Schmerzlos«. In: Schnitt. Das Filmmagazin, Nr. 12 April 1998. HAMdoRF, Wolfgang M. (1999): „Die neue Alltäglichkeit. Multikultureller Realismus im jungen deutschen Kinofilm«. In: Film-Dienst, fd 12/1999. MEAN STREets (dt. HeXENKESSEL) ist ein Gangsterfilm von Martin Scorsese aus dem Jahr 1973.

624 Filmheft zu DEALER.

625 Ebd. 
nuru (»mein Augenlicht «) in das weniger blumige »Bruder« übersetzt. ${ }^{626}$ In seiner »Nachdichtung " geht er dennoch von Klischee und Differenz aus; zum einen, um den Erwartungen des Lesepublikums zu entsprechen, diese aber zugleich auch zu unterminieren, da die neue Generation weder Opfer noch Türke ist. Weiter geht es mit der Kanaksprak um eine spezifische Form der Übersetzung, die ein unerwartetes Potential dieser Generation sichtbar macht. »Ich kann es nicht mehr hören, dass von sprachdefizitären Jugendlichen gesprochen wird. Diese sind einfach multimedial. Die Youngster können Denglish, sie können Kanak Sprak, sie können Video-Clip-Deutsch, und sie können wunderbares Deutsch. ${ }^{627}$ Mit der Wut der zweiten Generation klingt ihre Sprache wie folgt:

Der Kanake sagt, wörtlich übersetzt, „Haßhand teilt gerne aus, bricht sich aber viele Knochen« und meint "wer von Haß erfüllt ist, greift ohne Rücksicht auf Verluste zur Gewalt«. Der Kanake sagt »Gott fickt jede Lahmgöre« und meint »wenn man weiterkommen will, muß man sein Schicksal selbst in die Hand nehmen «. ${ }^{628}$

Vor dem Hintergrund dieser dekonstruktiven Arbeit mit Vorurteilen und Differenzen wäre es weder plausibel noch leserwartungskonform tatsächlich die Sprache der türkischstämmigen Jugendlichen wieder zu geben oder von einer gestohlenen Jacke auszugehen, um die multikulturelle Wirklichkeit in Deutschland für den deutschen Zuschauer zu übersetzen. Das Gleiche gilt für Şenocaks Ausgangspunkt, dass der Islam eine ideale Religion für Männer sei, die Bärte, Sperma und Fußgeruch produzieren.

In solchen alternativen Zugängen verbirgt sich eine existenziell körperliche Form von Transnationalität und Transkulturalität, die nicht in das multikulturelle Narrativ der 1990er Jahre passt, weil ihnen das Kulturspezifische bzw. der Akt der kulturellen Grenzüberschreitung fehlt. Um die eigene Versace-Jacke als Statussymbol würde wahrscheinlich jeder streiten und unter Umständen sogar kämpfen. Wie macht man diesen allgemeinen Konflikt um Besitz anschlussfähig und erzählbar in einer Gesellschaft, die sich immer mehr als einen Teil der Welt und Multikultur als Problem oder als Bereicherung begreift? Ohne einen spezifischen kulturellen Einsatz ist dies nicht möglich. In Akıns Film hat dieser Einsatz nicht einfach mit einer marktstrategischen Kalkulation oder der Kompatibilität

626 ZAIMoĞLU (1995): S. 14. Heute bezeichnen sich männliche und weibliche Salafisten auf Arabisch als Brüder und Schwestern. Siehe hierzu: MANsour, Ahmad (2015): Generation Allah. Warum wir im Kampf gegen religiösen Extremismus umdenken müssen, Frankfurt a. M.: Fischer, S. 22.

627 »Existentielle Geschichten aus einer dunklen Welt«, Feridun Zaimoğlu interviewt von Erker-Mitherausgeber Frank Lingnau. in: https://amerker.de/int46.php (zuletzt 15.05.2021).

628 Ebd. 
mit dem Zeitgeist zu tun. Schon die Filme der 1970er und 1980er Jahre haben nicht einfach nur die Erwartungen der Mehrheitsgesellschaft bedient und erfüllt. Wie bereits erwähnt wollte Akın mit KURz UND SCHMERzLos und besonders mit GEGEN DIE WAND - wie Zaimoǧlu mit der Kanak Sprak und Zafer Şenocak mit seiner Literatur und seinen essayistischen Texten - einfach nicht mehr »der Türke vom Dienst « sein. Und um dies zu artikulieren, sind bei Akın, Zaimoǧlu aber auch bei Şenocak die Positionsbestimmungen der Akteure stets zentral. Sie bewegen sich immer zwischen Exklusion und Inklusion im Niemandsland der Integration der 1990er Jahre, zwischen ethnischem Kollektiv und Assimilation. Die einzig bleibenden stabilen Referenzen für die Integration sind Auftritt, Artikulation und Körper der Protagonisten. Im Zentrum steht nicht die Repräsentation von Verhältnissen, sondern eine Umformung des Ablaufs des artikulatorischen Prozesses ${ }^{629}$, weil die politische Sprache über den ausländischen Mitbürger oder über die multikulturelle Gesellschaft die Wirklichkeit nicht wiedergeben kann. Deshalb bestimmen trotz der Kritik am deutschen Multikulturalismus-Diskurs Assoziationen, die eine Jacke hervorruft (wie Körperlichkeit, Schutz und öffentlicher Raum), weitaus mehr die Struktur von Akıns Filmen, die Sprechweise der Kanak Sprak und vielen anderen als kulturspezifische oder transnationale Einheiten.

Interessanterweise taucht die Jacke als unterschwelliges Motiv auch an vielen anderen Stellen in Literatur, Film und Forschung der 1990er Jahre auf. Sie steht für eine Form des Schutzes, der Verteidigung des eigenen Körpers. Sie tritt an die Stelle der »zweiten Haut«, des Türkischseins in Deutschland der 1980er Jahre. In Zaimoğlus Abschaum löst beispielsweise die Jacke eine intensive Auseinandersetzung zwischen einer Clique und einem Türsteher (»Rausschmeißer«) aus, der von den >Kanaken verlangt, dass sie ihre Jacken ausziehen müssten, um eingelassen zu werden. ${ }^{630}$ In Kutlu Atamans vielbesprochenem Film LoLA UND BILIDIKID bestimmt die schwarze Lederjacke des Protagonisten Bili dessen Identität. Eine ähnliche schwarze Lederjacke tragen die Protagonisten Erol (Tamer Yiğit) in Arslans Film GeSCHWISTER, Ertan Ongun (Luk Piyes) in Lars Beckers Verfilmung KANAK ATTAK (2000) nach Zaimoğlus Roman Abschaum und nicht zuletzt der männliche Protagonist Cahit in Akıns GEGEN DIE WAND (2004). Es gibt draußen keine Szene, in der er sie sie nicht tragen, d.h. sie gehört zu ihrem Auftritt dazu. ${ }^{631}$ Als Zivilpolizisten in Geschwister in einem Billard-Café Erols Clique

629 Siehe hierzu: BHABHA (1994): S. 162.

630 ZAIMOĞLU (1997): S. 24.

631 Interessanterweise spielen auch im deutschen Kino der 1990er Jahre Kleidung und Jacken wichtige Rollen. Entweder schenkt ein in Deutschland stationierter amerikanischer Soldat, den wir im ganzen Film nur in Zivilkleidung sehen, seiner neuen deutschen Freundin Frenzy (Katja Riemann) in Katja von Garniers Film ABGESCHMINKT seine Jacke oder fast alle Akteurinnen und 
auf Drogen durchsuchen, mahnt ein Freund Erols einen von ihnen an, dass er gefälligst aufpassen solle, wie er mit seiner neuen Jacke umgehe. Der zeitgleich entstandene Roman Die Brücke vom Goldnenen Horn von Emine Sevgi Özdamar sieht einen Rückgang linker Solidarität in der Türkei und in Deutschland, weil Genossen andere Genossen nicht mehr darauf aufmerksam machten, wenn sie ihre Jacken irgendwo vergessen. ${ }^{632}$ Ferner zeigt die wissenschaftliche Studie Turkish Power Boys. Ethnographie einer Jugendbande von Hermann Tertilt, die die Entstehung einer türkischen Jugendgang im Frankfurter Stadtteil Seckbach Anfang der 1990er Jahre analysiert, dass der Jackenklau (»Jacken-Tokat«) und die schwarze Bomberjacke als Markenzeichen in höchstem Maße gruppenkonstitutiv seien. ${ }^{63}$ In unterschiedlichen Aneignungs- und Gebrauchsformen ist die Jacke hier ein weiteres Indiz für die Wirkmächtigkeit des Narrativs »Wie lebt es sich in Deiner Haut? «, das ich für die 1990er Jahre herausgearbeitet habe. Im Folgenden werde ich die deutsch-türkischen Filmen KuRZ UnD ScHMERzLos von Akın sowie GESCHWISTER und DEALER von Thomas Arslan analysieren. Filmkritik und Forschung haben insbesondere an diesen Filmen Ende der 1990er Jahre eine neue Bewegung im Film zu erkennen geglaubt. ${ }^{634}$ Antworten auf die Frage »Wie lebt es sich in Deiner Haut?« geben auch APRILKINDER von Yüksel Yavuz, AusLANDTOURneE von Ayşe Polat und Lola Und BILIDIKID von Kutlu Ataman sowie schließlich GEGEN DIE WAND von Fatih Akın, deren Betrachtung in die Analyse miteinfließen werden.

Zum Bundesstart von Kurz und Schmerzlos hält die Filmkritikerin Claudia Voigt fest, das darin und in den Filmen von Thomas Arslan und Yüksel Yavuz die deutschen Zuschauer »verblüffende Einblicke [...] in das Leben jener rund zwei Millionen Türken im Land [bekommen], die viele Deutsche nur als Besitzer von Gemüseläden und als Frauen mit Kopftüchern kennen«. Ihre Filme machten auf eine zweite Generation aufmerksam, »die zwar in Deutschland groß geworden ist, deren Eltern aber zu Hause in Hamburg, Berlin oder Essen die türkischen und kurdischen Traditionen aufrecht erhalten haben «. ${ }^{635}$ Hätte Frau Voigt schon das Bonusmaterial der später erschienenen DVD gekannt, wäre ihr Befund womög-

Akteure in Dorris Döries KeINER LIEBT MICH definieren sich über ihre Kleidung. Siehe hierzu: GARNIER (1992); DöRRIE (1994).

$632 »$ Manchmal vergaßen die Mitglieder ihre Jacken oder Taschen, wenn sie nach Hause gingen. Aber wenn eine Jacke auf dem ersten Fraktionsstuhl hing, rief keiner von der zweiten Fraktion hinter dem Besitzer der Jacke her." Siehe hierzu: ÖzDAmAR (1998): S. 293. Zur Bedeutung der Jacke bei Özdamar siehe auch ebd., S. 37 u. 253.

633 Siehe hierzu: TeRTILT, Hermann (1996): Turkish Power Boys. Ethnographie einer Jugendbande, Frankfurt a. M.: Suhrkamp, S. 30-43.

634 Siehe hierzu: LÖSER (2004); MENNEL (2003); GÖKTÜRK (2000b); HAMDORF (1999).

635 Voigt (1998): S. 260. 
lich anders ausgefallen. Denn ihrer Einschätzung, dass KURZ UND SCHMERzLos ethnische »Kolonien« in Deutschland widerspiegele, stehen die Interpretationen der Schauspieler und des Regisseurs des Films gegenüber. Beispielsweise meint Adam Bousdoukus, dass es in diesem Film allgemein um das große und universelle Thema der Freundschaft gehe. ${ }^{636}$ Aleksander Jovanovic, der den Serben Bobby spielt, sieht den Kern der Geschichte im Verhältnis zwischen Mann und Frau und darin, wie alles aus den Fugen geraten kann, wenn das intime Privatleben nicht mehr stimmt. ${ }^{637}$ Wie für Şenocak in Die Prärie und für Ören in Berlin Savignyplatz ist für Jovanovic das eigentliche Thema der Multikultur die »interkulturelle Geilheit«. Und schließlich hält Fatih Akın selbst fest, das mit dem Label des deutsch-türkischen Films durch Kritik und Presse die Geschichte eines großen Missverständnisses begonnen habe. ${ }^{638}$

Diese gegenläufigen Innen- und Außeninterpretationen des Films scheinen sich durch die Nennung seiner Vorbilder und Paten wie Martin Scorseses MEAN STREETS (1973), Viscontis Rocco UND SEINE BRÜDER (1960) oder nacheinander genannte reale und fiktive Figuren wie Rocky (fiktiv), Tony Montana (fiktiv), Al Pacino (real) und Muhammad Ali (real) noch mehr zu widersprechen. Wie zuvor bei Özdamar, Ören und Şenocak ist auch hier die globale Referenz auf solche Figuren und die Wirkmächtigkeit über den deutsch-türkischen Kontext hinaus sehr wichtig für die beteiligten Akteure und ihre Erfinder, die Autoren und Regisseure. In Atamans Film ist diese Referenz schon im Titel LoLA UND BILIDIKID evident; er verweist sowohl auf Tom Tykwers Film LoLA RENNT als auch auf die amerikanische Kulturgeschichte (Billy the Kid). Die beiden deutsch-türkischen Protagonisten nennen sich selbst und werden auch so gerufen, obwohl ihre amtlichen Namen andere sind, die wir im Film allerdings nicht erfahren.

Ein spezifisch ethnischer Zugang ist trotz der Anrufung allgemein-menschlicher Themen wie Liebe, Freundschaft und Sexualität dennoch keineswegs von der Hand zu weisen. Beispielsweise sehen wir am Anfang von LoLA UND BILIDIKID das von homosexuellen Türken dargebotene Varieté Die Gastarbeiterinnen. Der beleibte, ebenfalls homosexuelle Entertainer Zeki steht in Ayşe Polats Film AusLANDSTOURNEE eindeutig für einen »radikalen Bruch mit der mythischen

636 Diese allgemeinen und universellen Themen stehen für den Regisseur Kutlu Ataman und seine Schauspieler Gandi Mukli (Lola) und Erdal Yıldız (Bilidikid) ebenfalls im Vordergrund. Auch wenn es in diesem Film explizit um die homo- und transsexuelle türkische Szene in Berlin geht, ist das Anliegen nicht das einer Minderheitenpolitik, sondern ein existenzielles und zugleich globales.

637 Siehe hierzu: AKIN, Fatih (1998): »Interviews«. In: Kurz und Schmerzlos (DVD).

638 Dieses Missverständnis reicht für ihn so weit, dass er GEGEN DIE WAND bei der Pressekonferenz explizit als einen Nicht-Gastarbeiterfilm ausgewiesen hat. Siehe hierzu: http://www.mmeansmovie.de/wand.html (27.07.2018). 
Figur des sprachlosen Türken «. ${ }^{639}$ Selbst nach über 20 Jahren Leben in der Bundesrepublik orientiert er sich noch immer an der Türkei. Er tritt nur in türkischen Bars in Deutschland, Holland und Paris auf, und sein großes Vorbild ist weder ein amerikanischer noch ein deutscher Travestiekünstler, sondern die türkische Diva Bülent Ersoy und der homosexuelle Sänger Zeki Müren, deren Liedtexte ihm auch persönlich wichtig sind. Die Welt, die in Film und Literatur kommuniziert wird, hat wie bei Özdamar und Şenocak ihre inneren und äußeren Grenzen und ihre spezifischen Reichweiten. Diesem vielfältigen globalen Bezugsraum von Freundschaft, Geschlecht, Einflüssen anderer Regisseure und Filme steht der Einsatz spezifischer kultureller Marker entgegen. Zudem kann von einem gleichberechtigten Umgang und Gebrauch von türkischen und deutschen Kennzeichen nicht die Rede sein. In Polats Film reisen die Protagonistinnen zwar etwa von Hamburg über Paris, Wuppertal, München bis Istanbul durch Europa, doch sind fast alle Orte von Türken oder der Türkei bestimmt. ${ }^{640}$ In Hamburg sind es die Geschwister des verstorbenen Schattenspielers Mahmud, in Paris ein türkischer Nachtlokalbesitzer, der in seinem Etablissement ausschließlich türkische Gäste hat. Und in München besucht der homosexuelle Zeki eine vergangene türkische Liebschaft, die einen türkischen Krämerladen führt und auf seine Briefe nicht reagiert hat. ${ }^{641}$ Identisches gilt für den Film LoLA UND Bilidikid, der jedoch im Unterschied zu AUSLANDSTOURnEE in Berlin spielt. Ebenso spielen die Filme HAPPY BIRTHDAY, TÜRKE! (1991), BERLIN IN BERLIN (1993) und GEGEN DIE WAND (2004) zwar alle in deutschen Städten, vor allem in Hamburg, Frankfurt und Berlin; deutsche Figuren spielen dabei aber keine wesentlichen Rollen. Sie sind - wie in der deutsch-türkischen Literatur der Zeit - kein wesentlicher Bestandteil der multikulturellen Gesellschaft in Deutschland. Bobbys deutsche Freundin Alice (Regula Grauweiler) aus KuRz UND SCHMERzLos musste Akın im Unterschied zu den anderen Hauptrollen erst erfinden. ${ }^{642}$ Die einzige wichtige deutsche Rolle in diesem Film war für ihn auch am schwersten zu besetzen. Alle anderen tragenden Rollen hatten ihr Vorbild in der Realität: Costa, der Grieche, wird von seinem deutsch-griechischen Pendant Adam Bousdoukus selbst gespielt. Die Eltern und der Bruder von Gabriel im Film sind im wahren Leben Eltern und Bruder von Fatih Akın. Nach seinem Gefängnisaufenthalt will Gabriel weder an der Nordsee noch an der ame-

639 PRIESSNER, Martina (2017): " $)$ Im Schwebezustand reisen Polat«. In: Deutsch-Türkische Filmkultur im Migrationskontext, hg. v. Ömer Alkın, Wiesbaden: Springer, S. 317-334, hier S. 324.

640 Siehe hierzu: Polat (1999).

641 Ebd.

642 Siehe hierzu: AKIN, Fatih (1998): »Audiokommentar zu >Kurz und Schmerzlos««. In: Kurz und Schmerzlos (DVD). 
rikanischen West- oder Ostküste ein Strandcafé eröffnen, sondern unbedingt in der Türkei. Das erzählt er dreimal im Film. Auch der äußerst maskulin auftretende homosexuelle Bilidikid in Atamans Film träumt von einem Strandleben in der Türkei - allerdings müsste sich sein Freund Lola dafür einer Geschlechtsumwandlung unterziehen, weil sie als schwules Ehepaar in der Türkei nicht leben dürften. In Berlin Savignyplatz tritt an die Stelle der interkulturellen Intimität zwischen dem Ich-Erzähler, der Deutschen Elfie, dem Spanier Franco und der Deutschen Maria im Laufe der Erzählung immer mehr die Figur Ali Itir. Im zweiten und letzten Kapitel des Romans hat sie sogar vollkommen die Macht über das Geschehen übernommen. ${ }^{643}$ In KURZ UND SCHMERLOS erwidert Gabriel auf Alice' Frage, warum er in der Türkei ein Strandcafé eröffnen wolle, dass ihm das im Gefängnis eingefallen sei. Dort bestimme keiner, was man wann zu machen habe und man sei nie allein. In der deutschen oder westlichen Gesellschaft vereinsame man, in der türkischen lebe man in einer Gemeinschaft. Im Audiokommentar hält Akın an dieser Stelle des Films fest, dass alle ihm bekannten Türken so reden und denken würden. ${ }^{644}$

Interessant im Zusammenhang der vorliegenden Kulturgeschichte der Migration in Deutschland ist zum einen Gabriels Berufswunsch, sich selbstständig zu machen, den in den 1990er Jahren viele Türkeistämmige in Deutschland hegen. ${ }^{645}$ Zum anderen ist Gabriels touristische Wahrnehmung der Türkei sowie die Kontaktpflege mit Touristen bemerkenswert: nahe am Meer, nicht im Zentrum des Landes, nicht repräsentativ sein, ungebunden arbeiten, aber dafür sein eigener Chef sein. Hier bündeln sich viele Motive, die wir bereits aus Şenocaks Gefährliche Verwandtschaft und Der Erottomane oder aus Kemal Kurt Was ist die Mehrzahl von Heimat? kennen und finden. ${ }^{646}$ Die deutsch-türkischen Protagonisten begreifen sich im Herkunftsland ihrer Eltern stets als Touristen. ${ }^{647}$

Eine weiteres türkisch-orientalisches Kennzeichen unter vielen anderen, ist, dass Akın den Namen des Ladens, den Alice als Kunstschmiedin in Hamburg Ottensen betreibt, von seinem ursprünglichen spanischen Namen in das vielsagende türkische »Kismet« (dt. »Schicksal«) umbenennt. Und ebenso oft wie

643 Siehe hierzu: ÖREN, Aras (1995): »Nacht«. In: ders.: Berlin Savignyplatz, Berlin: Elefanten Press, S. 124-173.

644 Siehe hierzu: AKIN (1998): »Audiokommentar«.

645 Es gibt keinen Film und keine Literatur deutsch-türkischer Herkunft in den 1990er Jahren, in denen die fiktiven deutsch-türkischen Figuren Angestellte des Öffentlichen Dienstes sind.

646 Zur Selbstständigkeit der Türken in Deutschland siehe: Coнn-Bendit/Schmid (1992): S. 129 f. u. S. 170.

647 Diese Konstellation findet sich auch in den Romanen von Feridun Zaimoğlu und Selim Özdoğan Liebesmale, scharlachrot und Mehr von 2000 und 2001. 
Gabriel im Film seinen Wunsch äußert, in die Türkei zurückzukehren, fragt ihn sein Vater, ob er denn nicht mit ihm das muslimische Morgengebet verrichten möchte. Erst ganz am Ende des Films wird er gemeinsam mit ihm beten, jedoch nicht um ihm einen Gefallen zu tun, sondern weil Bobby von Muhamer getötet wurde und Costa noch um sein Leben ringt. Nach eigener Aussage hat Costa sehr viel Schuld an dieser Tragödie, weil sie »immer Scheiße bauen «. ${ }^{648}$ In KuRZ UND ScHMERzLOS bestehen zwar Bindungen in den deutschen und globalen westlichen Raum, die sich als in Kommunikation stehende Einheiten begreifen lassen, doch sind sie narrativ immer im türkischen Raum verankert. Dabei lösen diese Zusammenhänge weder ein `Wieder-Türke-Werden-Wollen` aus, noch generieren sie ein spezifisches Narrativ des >Amerikaner-Werden-Wollens`. Diesen Bewegungen und Bindungen wirkt ein gewisser Stillstand entgegen, der sich von den inneren Spannungen der Akteure über die türkische Community vor Ort, Aufnahmen von Gesprächen und Konflikten in parkenden und geschlossenen Autos vornehmlich in Gabriels Taxi - erstrecken.

Die Kritiken zum Film bezeichnen ihn meist entweder als Multikulti-Thriller oder Gangsterfilm. ${ }^{649}$ In der Forschung hält Barbara Mennel fest, dass es sich bei KuRz UND SchmERzLos um einen Ghetto-Film handle, der im Zusammenhang eines globalen Migrationskinos zu sehen sei. ${ }^{650}$ Dasselbe hält sie für Arslans GeSCHWISTER fest. ${ }^{651}$ Sicher treffen diese Genrebezeichnungen für beide Filme $\mathrm{zu}$, doch ist der Verweis, dass sie auf der einen Seite Einblicke in ethnisch anders geprägte Parallelgesellschaften ermöglichen und auf der anderen Seite in einem globalen Zusammenhang stehen, aufgrund des auffallend asymmetrischen Gebrauchs deutscher und türkischer Marker zu oberflächlich. Zafer Şenocaks Protagonist hat zwar in Amerika seine Herkunft, so gut es ging, nicht thematisiert, ist am Ende in München und in Berlin aber doch wieder zum Deutsch-Türken geworden - und hat wieder auf Anfragen von Zeitungsredaktionen reagiert; allerdings mit einer ironischen Wendung und einem parodistischen Ton. Ironie und Parodie greifen auch in Atamans und Polats Filmen LoLA UND BILDIKID und AUSLANDSTOURNEE, wenn beispielsweise homosexuelle Türken Gastarbeiterin-

648 Das tun nach eigener Aussage auch die Protagonistinnen in L'Honneur DE MA FAMILLE. Siehe: BOUCHAREB (1996).

649 Siehe hierzu: Schifferle, Hans (1998): „Kurz und schmerzlos«. In: epd Film, Nr. 10, Oktober 1998; BEYER, Tom (1998): »Kurz und schmerzlos«. In: Schnitt. Das Filmmagazin, Nr. 12, April 1998. Siehe auch: VoIgt (1998).

650 Siehe hierzu: MENNEL (2003): S. 156.

651 Siehe hierzu: MenNel, Barbara (2008): „Globales Migrationskino, der Ghetto-Flâneur und Thomas Arslans >Geschwister««. In: Mann wird Man. Geschlechtliche Identitäten im Spannungsfeld von Migration und Islam, hg. v. Lydia Potts, Jan Kühnemund, Bielefeld: transcript, S. 53-64. 
nen und Gastarbeiter spielen. Doch erschöpfen sich diese Produktionen keineswegs in der Darstellung von Gegensätzen (inversio) oder von Verstellungen (dissimilatio). Denn zum einen sind die Grenzen zwischen der Türkei und Deutschland nicht mehr nur geografische, die physisch überschritten werden könnten, sondern sie verlaufen durch die Figuren hindurch. Zum anderen, war Sascha, im Falle Şenocaks, auch in Amerika nicht vor den Debatten zu Türken in Deutschland gefeit. In Akıns Film arbeitet schließlich, wie in den anderen genannten, eine Gleichzeitigkeit von Inklusion (Welt) und Exklusion (Türke-Sein), eine »innere Spannung «, die auch hier durch Ästhetik, Ironie und einem displacement zwischen Innenräumen und öffentlichen Räumen, zwischen dem Eigenen und Anderen aufgelöst wird.

Wie Özdamars Erzählerin, Şenocaks Sascha, Örens Erzähler in Berlin Savignyplatz und den noch lebenden Ali Itir begegnen wir auch den Protagonisten von Polat, Ataman, Cetin, Yavuz und Akın häufig auf der Straße. ${ }^{652}$ Sie sind ein sichtbarer Teil des öffentlichen Raums, der ihre Privatheit, ihr Deutsch-Türkischsein mit einschließt. Ihre Präsenz im Raum zeigt, dass sie dazugehören, auch wenn sie keine deutschen Staatsbürger sind. Wie bei den Reflexionen zur Denizenship und zur postnationalen Membership bestimmt das Wohnen, die Dauer und Präsenz in einem Land die Identität, denn die Herkunft. Deshalb ist ihre Präsenz auch mit der Darstellung eines bestimmten Verhältnisses zur Herkunft bestimmt. Die drei Freunde treffen sich nach Gabriels Haftstrafe das erste Mal wieder auf der hinsichtlich Musik, Tanz und Getränken traditionell türkisch ausgerichteten Hochzeit von Gabriels Bruder Cenk (Cem Akın). Auf der Stelle kommt es zu Streit und Missverständnissen. Costa erscheint mit einer Bomberjacke, während Gabriel und Bobby dem Anlass entsprechend Anzüge tragen. Gabriel knöpft sich Costa vor, zieht ihn vor den Augen der anderen Hochzeitsgäste in eine Abstellkammer und fragt ihn, was er sich dabei denke, mit so einer Jacke auf Cenks Hochzeit aufzutauchen. ${ }^{63}$ Ceyda, Gabriels Schwester und zu Beginn des Films noch Costas

\footnotetext{
652 In Yavuz' und Cetins' Filmen kommt wie in Özdamars Karawanserei-Roman der Türschwelle eine besondere Bedeutung zu. In APRILKINDER gibt es sehr viele Szenen, in denen eines der Geschwister die Wohnung verlässt. Wie viele andere Filme der 1990er Jahre beginnt auch dieser mit einer Straßenaufnahme. Siehe hierzu: YAvUz (1998).

653 Yavuz' APRILKINDER beginnt auch mit einem Streit. »Hast Du’n Knall oder was?! Heb’ das wieder auf«, fährt Mehmet seine Schwester Dilan an. Dilan deckt gerade den Esstisch für die Familie und hört dabei mit ihrem Walkman laut den türkischen Popsong Şıkıdım des türkischen Sängers Tarkan. Weil Dilan Mehmet deshalb nicht hört, greift er fest nach ihrem Arm, tut ihr weh und wiederholt seinen Befehl. Sie zieht ihren Arm weg und beschwert sich bei ihm. Warum Mehmet sich so aufregt, erfährt der Zuschauer nicht. Man muss den Ton dieser ersten Sequenz des Films sehr laut stellen, um zu hören, dass eine Zeitschrift auf den Boden gefallen ist, als Dilan den Tisch deckt. Da aber der Regisseur dies selbst nicht deutlich macht, will er vor allem zeigen,
} 
Freundin, stößt wütend $\mathrm{zu}$ ihnen und schlägt Costa mit einer schweren Tüte, in der sich ein Anzug für Costa befindet, auf den Kopf. Dieser eine Schlag wird in short cuts zweimal gezeigt, was ihn noch intensiver wirken lässt. ${ }^{654}$ Zuvor hatte Gabriel Costa versichert, dass er heute Abend für ihn bürge. Der »Haufen «, den er da draußen sehe, "geiert nur rum «, und sie kämen dann zu ihm, beschwerten sich über seinen Auftritt, weil er mit so einer Jacke gekommen sei. Gabriels Verwendung des Begriffs »Bürgen« verdeutlicht, dass Costa und er zusammengehören und nicht der »türkische Haufen « und er. Gleich nach dieser Auseinandersetzung umarmen sie sich und küssen sich auf die Wangen.

Überhaupt küsst und umarmt man sich häufig in dieser Eröffnungssequenz des Films, der türkischen Hochzeit in Deutschland. Später wird Gabriel wieder auf diesen türkischen »Haufen « Bezug nehmen, um sich zu positionieren. Ceyda hat sich von Costa getrennt, und seine beiden Freunde versuchen ihn zu trösten. Noch am gleichen Tag sehen sie alle drei, wie Ceyda ihren neuen deutschen Freund Sven in Altona öffentlich küsst. Bobby und Costa fangen eine Schlägerei an, haben gegen Sven aber keine Chance, so dass Gabriel einschreitet, »der Muhammad Ali von Altona«. Gabriel schlägt Sven mit vielen harten Schlägen K.O. und tritt noch auf ihn ein, als er am Boden liegt. ${ }^{655}$ Als Ceyda und Gabriel

dass seine Akteurinnen und Akteure von Beginn an gereizt sind. Siehe hierzu: YAvUZ (1998). Auch Auslandstournee beginnt mit einem Streit. In der ersten Sequenz des Films von Ayşe Polat schließt ein Mann um die Vierzig eine Haustür und verlässt das Haus. In derselben Einstellung sehen wir links neben ihm ein junges Mädchen, das mit einem Koffer und einer Tasche auf ihn wartet. Er läuft an einem gelben Briefkasten und an dem Mädchen vorbei, ohne ein Wort zu sagen. Er wirkt angespannt und genervt. Dann geht er in eine gelbe Telefonzelle. Das Mädchen, das eine ebenfalls gelbe Jacke trägt, folgt ihm und wartet draußen auf ihn. Er telefoniert auf Türkisch mit einer Frau namens Çiçek (»Blume«), fragt sehr herzlich, wie es ihr geht und sagt, dass er ihre Telefonnumer von ihren Nachmietern erhalten habe. Danach sagt er, dass alles in Ordnung sei und Çiçek legt auf die Antwort schlagartig auf. Der Mann ruft ihr in den Hörer erregt noch hinterher, doch vergebens. Er flucht heftig. Er geht aus der Zelle und sagt dem Mädchen, dass sie Çiçek nun endlich gefunden hätten. Siehe hierzu: PoLAT (1999).

654 Ebenfalls in Form von short cuts wird später gezeigt, wie Gabriel seinen Freund Bobby in einer Videothek ins Gesicht schlägt, weil der sich eine Waffe gekauft hat.

655 Beim Dreh dieser Sequenz wollten viele der Crewmitglieder des Films, dass Gabriel nicht so häufig auf den am Boden liegenden Sven eintritt, weil das die Hauptfigur zu unsympathisch machen würde. Akın hingegen war es wichtig, dass die Gewalt auf diese Weise herausbricht. Beim Versuch, seine Freunde aus den Fängen der albanischen Mafia zu befreien, wird Gabriel später selbst äußerst brutal zusammengeschlagen. Danach sehen wir ihn mit blutüberströmtem Gesicht auf dem Boden liegen. In GEgEN DIE WAND wird auf den Protagonisten Cahit ebenfalls eingetreten und eingeschlagen, als er schon auf dem Boden einer türkischen Disco in Hamburg liegt. Zu Anfang des Films ist es hingegen Cahit selbst, der in einer Hamburger Kneipe einen Gast auf den Boden wirft und ihn mit Füßen tritt. Eine ähnliche Sequenz finden wir in Polats AuslandstourneE. Dort wird der homosexuelle Varieté-Sänger Zeki von deutsch-türkischen 
sich später in Gabriels Zimmer über diesen Vorfall streiten, hält er ihr vor, dass sie gefälligst nicht in Altona mit ihrem neuen Freund »rummachen« solle, sondern in Eppendorf oder Wansberg, aber eben nicht hier. Das gehe ihn gar nichts an, wo sie mit wem rumknutsche, erwidert Ceyda. Er habe sie immer vor ihren Eltern beschützt, hält Gabriel dagegen. »Du kannst nachts so lange wegbleiben, wie Du willst. Welche Türkin kann das, zeig mir die? « ${ }^{656}$ Er habe sie bisher immer respektiert und vor den anderen verteidigt. ${ }^{657}$ Mit den »anderen « meint er die Türken von Altona. Wie Sascha und Michaela in Şenocaks erstem Band seiner Tetralogie grenzen sich Gabriel und Ceyda in Akıns Film von einem türkischen Kollektiv ab, zu dem auch ihre Eltern gehören, leben aber, anders als bei Şenocak, noch zuhause. ${ }^{658}$ Wie die Skizze dieser Sequenzen zeigt, liegt Akıns Fokus ebenfalls auf den Figuren und ihrem Verhältnis zu Freunden und Kollektiven. Dies spiegelt sich auch in dem sehr aufwendigen Casting wider. ${ }^{659}$

Wie Gabriel wird auch Bobby im Film als nicht mehr zur vermeintlich eigenen Community dazugehörender eingeführt. Auch hier ist die erste Interaktion ein Konflikt. Denn sein serbischer Onkel hat erfahren, dass er bei der albanischen Mafia einsteigen möchte, bei den Erzfeinden - nicht nur auf dem Hamburger Kiez. Der Onkel wirft ihn brutal aus dem serbischen Restaurant auf die Straße. »Bei deiner toten Mutter. Ich breche dir alle Knochen«, ruft er seinem Neffen noch hinterher, bevor er sich in sein Billard-Café zurückzieht. Im Vordergrund liegt Bobby, sein Kopf erhebt sich in Nahaufnahme vom Boden, und er schaut aus dem Bild heraus. Dieses Bild wird für zwei, drei Sekunden eingefroren und ein schreibmaschineller Schriftzug mit den Worten »Bobby, Serbe« wird eingeblendet, dass Bobby auf der Straße sein Glück suchen muss. ${ }^{660}$ Auf dieselbe Weise werden die beiden anderen Protagonisten Costa und Gabriel eingeführt,

Machos in Wuppertal nach einem Konzert in einem türkischen Nachtclub auf dem Boden liegend mit Füßen und Fäusten blutig geschlagen. Siehe hierzu: AKIN (1998); AKIN (2004); PolAT (1999). Überhaupt gibt es einige Filme in den 1990er Jahren, die an prominenten Stellen vom Boden aus ganze Sequenzen filmen. Siehe hierzu für viele die Einstiegssequenzen der Filme HAPPY BIRTHDAY TÜRKE und NACHTGESTALTEN: DöRRIE (1991); DRESEN (1998).

656 AKIN (1998).

657 Auch der deutsch-türkische Protagonist Serdar in Feridun Zaimoğlus Roman Liebesmale, scharlachrot von 2000, der seinem Freund Hakan in Kiel aus der Türkei Briefe nach Deutschland schreibt, konstatiert als eine für ihn wichtige Erkenntnis während seines Türkeiaufenthalts, dass »Respekt vor dem Passanten zivilisiertes Verhalten« sei. Siehe hierzu: ZAIMOĞLU (2000): S. 32.

658 In Yüksel Yavuz' APRILKINDER versuchen die verliebten Figuren Dilan und Arif, sich an belebten Orten zu treffen. Da aber die anderen Türken reden und Dilans Familie davon erfahren würde, treffen sie sich auf dem Friedhof. Siehe hierzu: YAvUZ (1998).

659 Siehe hierzu: AkIN (2011): S. 55-60.

660 Vgl. TERKESSIDIS (1999): S. 249. 
als sie sich in ähnlich brisanten Situationen befinden: „Costa, der Grieche«, zerschlägt ein Autofenster, um einen Laptop zu klauen. „Gabriel, der Türke«, wird gezeigt, als er aus dem Gefängnis entlassen und von seinem Vater zur Begrüßung erst geschlagen und dann umarmt wird. Konflikt, national-kulturelle Zuschreibung, Gewalt und öffentlicher Raum sind als zusammengehörige Einheit die Ausgangsposition in KuRz UND SCHMERzLos. Sie macht aus dem Innen als Raum (Wohnung) oder als Psyche eine unbehagliche, von Unruhe geprägte Behausung. Daher kommen in deutsch-türkischen Filmen der 1990er Jahre wohl auch kaum establishing shots vor. Wie können stattdessen einzelne Akteurinnen und Akteure einen overall space bestimmen?

Filmtechnisch könnte man diese Aufnahmen zu Beginn des Films durchaus als eine besondere Form des establishing shot beschreiben, besteht dessen Funktion doch darin, den Raum zu definieren, in dem das darauffolgende filmische Geschehen stattfindet. Sie beschreiben den oben genannten »overall space« und dienen dem Zuschauer als Orientierung. Für eine Klassenzimmersequenz wäre ein klassischer establishing shot etwa die Aufnahme einer Schule von außen. ${ }^{661}$ In Yavuz' AUSLANDSTOURNEE wird die erste Sequenz, der oben beschriebene Konflikt zwischen den Geschwistern Mehmet und Dilan, ebenfalls nicht mit einem establishing shot durch den Vorspann des Films eingeführt. Im Vorspann, in dem der Titel des Films eingeblendet wird, sehen wir eine Straße in einem Wohngebiet. Es ist Abendstimmung, wir sehen Fahrräder vorbeifahren, man denkt an eine ruhige Straße in einer deutschen Stadt. Ein Straßenname ist, wie in den anderen besprochenen Filmen, nicht zu erkennen. Wie in vielen deutsch-türkischen Produktionen wird auch in APRILKINDER nur natürliches Licht eingesetzt. Ein Gebäude in dieser Straße sieht von außen wie ein Wirtshaus aus, doch können wir nicht lesen, was auf der Leuchtreklame am Eingang steht. Dafür hören wir sehr genau aus dem Off, irgendwo von der Straße, das klassische türkische Klagelied Ölürsem Kabrime gelme istemem (»Falls ich sterbe, komme nicht an mein Grab«) in einer arabesken Version. In der anschließenden Einstellung sehen wir wie Dilan, vielleicht in einem der zuvor gesehenen Häuser, den Tisch deckt. Doch auch hier sind weniger Straße und Küche miteinander verbunden, sondern es ist vielmehr die Musik, die eine Verbindung schafft, indem die arabesken Klänge aus dem Vorspann in die türkische Popmusik von Tarkan übergeht, die wir aus Dilans Kopfhörern mithören. ${ }^{662}$

661 In der äußerst erfolgreichen Serie TÜRKISCH FÜR ANFÄNGER, die zwischen den Jahren 2006 und 2009 produziert und im deutschen öffentlichen Fernsehen ausgestrahlt wird, gibt es kaum eine Sequenz, der ein establishing shot nicht vorausgeht. Siehe hierzu: DAğTEKIN, Bora (2009): Türkisch für Anfänger, Fernsehserie, Hofmann \& Voges Entertainment, Deutschland.

662 Tarkan ist der international bekannteste türkische Popsänger. Er wurde 1972 im rheinhessischen Alzey geboren. Sein bürgerlicher Name ist Tarkan Tevetoğlu. Die Familie Tetvetoğlu kehrte 
Dieser orientalisierende Anstrich zu Beginn des Films wird durch Mehmets unhöflichen und aggressiven deutschen Straßen-Slang gebrochen.

Die Orientierungsfunktion, die in Yavuz' Film der Übergang von der elegischen türkischen Musik zum energischen Popsong einnimmt, ein Übergang, der zugleich die deutschen Straßen mit der türkischen Wohnung verbindet, erfüllen in Akıns KuRz UND ScHMERzLos meiner Ansicht nach die oben beschriebenen Einführungen der Protagonisten zu Beginn des Films. Sie sind schon allein deshalb die »delineations of overall space ${ }^{663}$, weil Akın kaum eine Innen- oder Außenaufnahme im Film mit establishing shots einführt. Dabei gibt es in KuRz UND SCHMERzLos unterschiedliche Innen- und Außenaufnahmen, die allerdings kaum definiert oder markiert werden - im Gegensatz zu den Akteuren. Von der türkischen Hochzeitsfeier über Wohnungen, über Restaurants, Bars bis hin zu unbestimmten Strandplätzen, Straßen und Sackgassen weiß man als Zuschauer dieses Filmes nicht, wo man sich genau befindet. Dasselbe gilt für die Filme von Polat und Yavuz. Die Akteurinnen und Akteure sind darin zwar viel unterwegs, doch wir können immer nur schwer bestimmen, in welcher Stadt wir uns befinden oder in welcher Straße. In Akıns Film sind zudem die Innenräume nicht eindeutig bestimmt. Man weiß z. B. nicht, in wessen Wohnung die Freunde sich gerade treffen oder wo genau sie bei Außenaufnahmen in Hamburg-Altona sind. Der Zuschauer ist immer gleich mittendrin. Man kann immer nur unterscheiden, ob man gerade draußen oder drinnen ist. Durch diese Unbestimmtheit wird nicht der Ort, sondern die Unterscheidung zwischen drinnen und draußen zur Leitunterscheidung. ${ }^{664}$ Die Filme der 1990er Jahre leben sehr stark davon, Raum zu schaffen, sich aber in diesem Prozess nicht klar zu positionieren. Der Verweis auf Globalisierungszusammenhänge, ein Verbundenheitsgefühl nimmt dabei eine besondere Funktion ein. Beispielsweise hängen in Mehmets Zimmer in APRILKINDER Poster von Bruce Lee. In Dilans Zimmer hängen Poster von Tarkan, der in den 1990er Jahren wegen seines Tanzstils in der Türkei auch als der türkische Michael Jackson gefeiert wurde. ${ }^{65}$ Wie bei Bhabha ist der Ort, hier Dilans Zimmer, natio-

1986 in die Türkei zurück. Mit seinen äußerst erfolgreichen Musikalben Aacayapsin von 1994 und Ölürüm sana von 1997 wurde er in der Türkei und unter den Deutschländern überaus bekannt. Der Song Şımark aus der LP Ölürüm sana machte ihn weltweit berühmt, für den er auch 1999 den World Music Award in Monaco erhielt.

663 Siehe hierzu: BoRdwELL/THOMPSON (2010): S. 235.

664 Diese topografische und filmtechnische Konstellation finden wir auch in den Filmen OsTKREUZ (1990), LEBEWOHL, FREMDE (1991), HAPPY BiRTHDAY TÜRKE (1991), GESCHWISTER (1997), APRILKINDER (1998), AUSLANDSTOURNEE (1999) und LOLA UND BILIDIKID (1999).

665 TAKviм (2009): »Michael'e benzemek için 50 bin € harcadi«. In: Takvim, 25.07.2009, https:// www.takvim.com.tr/saklambac/2009/07/25/michaele_benzemek_icin_50_bin_harcadi (zuletzt 06.02.2019). 
nal codiert. ${ }^{666}$ Wir wissen, sie lebt mit ihrer Familie in Deutschland. Und die Akteurinnen und Akteure schaffen durch ihre Bewegungen zwar Räume, generieren jedoch keinen spezifischen Ort. Es gibt also keine Instanz, die die soziale Frage irgendwie koordinieren würde.

Diese Interpretation stützen besonders zwei weitere Aufnahmetechniken in KuRz UND SCHMERzLos. Aufnahmen in die Tiefe des Raums kommen meist nur draußen, im öffentlichen Raum vor, nicht in Innenräumen wie Wohnungen. Dort wird oft vor Wänden fotografiert, und die Aufnahmen sind im Unterschied zu den Außenaufnahmen flach. Der einzige Ort, der neben den kurzen Figurenskizzen des Films mit establishing shots eingeführt wird, ist Gabriels Taxi. Es ist ein halb-öffentlicher Raum, der innen und außen bündelt und die Akteure wie eine Jacke schützt. ${ }^{667}$ Meist wird erst das parkende Taxi von außen gezeigt, danach folgen Gespräche im Innenraum, die im Schuss- Gegenschuss-Verfahren aufgenommen sind. Bobby erzählt Gabriel im Taxi, wie er sich in Alice verliebt hat. Alle drei Freunde unterhalten sich im Taxi über Costas Beziehung zu Ceyda. Auch Gabriel und Alice führen ihren romantischsten Dialog im Taxi. In diesem Taxi, in diesem halb-öffentlichen mobilen Raum, äußern die Akteurinnen und Akteure ihre wahren Gefühle. ${ }^{668}$ Dass Fatih Akıns erster abendfüllender Kinofilm bei solch einer Konstellation aus Öffentlichkeit und Privatheit am Ende des Films sprichwörtlich in einer Sackgasse irgendwo in Altona enden muss, ist nicht nur dem Genre des Gangsterfilms geschuldet, sondern liegt auch an der Unbestimmtheit der Innen- und Außenräume, dem unbestimmten Dazwischen. ${ }^{669}$ Aus ihm resultiert die Ausweglosigkeit der Protagonisten, in die sie sich auch selbst hinein manövrieren. Dass dabei sie selbst schuld sind, nicht die Aufnahmegesellschaft, nicht die Herkunftskultur und auch nicht die Eltern, hat zum einen damit zu tun, dass sie sich von all diesen Kategorien emanzipieren wollen.

Die Einsamkeit der Akteure hat zum anderen damit zu tun, dass sie sich, anders als in den 1980er Jahren draußen aufhalten. Draußen existiert kein Ort, der »als eine momentane Konstellation von festen Punkten [...] einen Hinweis

666 ВНАВНА (2000): S. 251.

667 In einer ähnlichen Verschränkung beschreibt auch Jeff Weintraub Mitte der 1990er Jahre die Aspekte des Öffentllichen und Privaten in der Verwendung dieser großen Unterscheidung von öffentlich/privat. Auch bei ihm ist das Private im Öffentlichen wie auch andersherum. Siehe hierzu: WEINTRAUB (1997).

668 In Kutlu Atamans Film LoLA UND BILDIKID hat das Taxi des Bruders des Protagonisten eine ähnliche Funktion.

669 In Örens Berlin Savignyplatz verschwimmen ebenfalls die Grenzen. Oft können wir nicht sagen, ob wir uns in den Beschreibungen noch in der Kneipe, auf dem Savignyplatz, in der Wohnung des Erzählers oder in der Vergangenheit oder Gegenwart von Ali Itir befinden. Siehe hierzu: ÖREN (1995). 
auf eine mögliche Stabilität« erlauben würde. ${ }^{670}$ Daraus ergibt sich eine Unbestimmtheit des öffentlichen Raums, die seine Regeln invisibilisiert. Wenn Regeln im Spiel sind, dann sind es kulturell-spezifische und nicht allgemeine: Sprache, der Wechsel vom Deutschen ins Türkische und Normen wie die, dass man mit einer Bomberjacke nicht zu einer türkischen Hochzeit kommt und als türkische Frau nicht einen deutschen Mann in der Öffentlichkeit küsst. Diese Codes beherrschen die Akteure, während sie mit ihren starken Emotionen, Wünschen und ihrer Körperlichkeit nicht umgehen können. In Yavuz' APRILKINDER wird dies eindrücklich, als Cem und Kim kurz vor dessen Hochzeit mit seiner Cousine aus der Türkei im Treppenhaus der Eltern von Cem halböffentlich Sex haben; ein Akt, der ihre endgültige Trennung zur Folge hat. Es geht immer wieder um Energien und Potentiale, die beispielsweise Bobby davon träumen lassen, ein Mann wie Al Pacino oder Tony Montana zu sein oder Gabriel beim ersten Kontakt in Alice verlieben lassen, obwohl sie die »wahre Liebe « seines besten Freundes ist. Wie Şenocaks Protagonist Sascha und Örens Erzähler verliebt sich auch Gabriel im Modus »Liebe auf den ersten Blick« sehr schnell. ${ }^{671}$ Ein derartiger Impuls bringt auch Gabriel dazu, auf den am Boden liegenden Sven einzutreten. Dazu ertönt die Musik, die wir bereits aus der Kampfszene im Vorspann kennen. ${ }^{672}$

Woher dieses hohe Maß an Gewalt, Energie und Körperlichkeit kommt, diese große innere Unausgeglichenheit, bleibt ungeklärt. Es bricht einfach aus - wie die »interkulturelle Geilheit« zwischen Alice und Gabriel. In der Hochzeitssequenz lassen sich drei Spannungsfelder erkennen: die Verwandtschaft zwischen ethnischem Kollektiv und Assimilation, die Bürgschaft der Freunde füreinander und die sich anbahnende Liebesgeschichte zwischen Alice und Gabriel. Auf diesen Grundlagen basiert der Plot von KuRZ UND ScHMERzLOS. Er verschränkt sie derart, dass die Tragödie am Ende als eine selbstverschuldete erkennbar wird. Hinzu kommt, dass weder die Eltern noch der Staat in repräsentativen Formen, beispielsweise durch Behörden oder Beamte, auftreten, somit auch nicht die

670 De CerteAu, Michel (2006): »Praktiken im Raum«. In: Raumtheorie. Grundlagentexte aus Philosophie und Kulturwissenschaften, hg. v. Jörg Dünne, Stephan Günzel, Frankfurt a. M.: Suhrkamp, S. 343-353, hier S. 345.

671 Cem hatte sich auch bereits beim ersten Kontakt in die deutsche Prostituierte Kim verliebt, und in Polats AuslandstourneE verliebt sich die elfjährige Protagonistin Şenay ebenfalls bei der ersten Begegnung in den deutschen Pagen eines Hotels in Wuppertal. Siehe hierzu: PoLAT (1999).

672 In Çetins Film BERLIN IN BERLIN (1993) kämpfen Mürtüz und Thomas auch oft miteinander. Mehrmals unternimmt Mürtüz den Versuch, Thomas mit Gewalt aus der Wohnung zu drängen. Da er in den Augen seiner Eltern ein »Gast Gottes« (Tann Misafiri) ist, kann er ihn nur außerhalb der Wohnung töten. Siehe hierzu: ÇETIN (1993). 
Regeln der Ankunftsgesellschaft. Die spezifische Verbindung von Erzählung und Schuld verdeckt das »displacement « zwischen privaten und öffentlichen Räumen, das den Film in struktureller Hinsicht prägt.

Genau dasselbe displacement, das ebenfalls mit einer bemerkenswert hohen körperlichen Energie einhergeht, bringt Feridun Zaimoğlu mit viel Kampf und Ironie in seinem Protagonisten Ertan Ongun in Abschaum auf den Punkt. Denn die >Kanaken « kämpfen nur für ein »Pseudoterritorium «, das kein Teil von ihnen ist. ${ }^{673}$ Die politische Aussage, dass sich der Multikulturalismus im privaten, aber nicht im öffentlichen Raum ausbreiten könne, weist in dieselbe Richtung. ${ }^{674}$ Aus dieser widersprüchlichen Konstellation heraus wird verständlich, warum Bobby und Gabriel sich wünschen, wie Tony Montana zu sein oder ein Strandcafé in der Türkei zu eröffnen.

Wo kämen sie identitätspolitisch denn auch sonst unter, wenn nicht in einem türkischen Exportgeschäft, einem türkischen Café, einem türkischen Imbiss oder in einer türkischen Moschee in Deutschland? Als in Arslans Film GEschwISTER Erol (Tamer Yiğit) seinen Bruder Ahmed (Savaş Yurderi) wieder einmal um Geld bittet, erwidert dieser, er solle doch mal arbeiten gehen. Erol fragt, ob er wirklich wolle, dass er etwa in einer Dönerbude Fleischstreifen vom Spieß schneide. Zu diesem »Fleisch schneidenden « Kollektiv gehört Erol nicht, und will das offensichtlich auch nicht. Obwohl er durch und durch Berliner ist, sieht er einen Ausweg allein beim türkischen Militär. Diese Abgrenzung und Ortlosigkeit, die kulturell und zugleich sozialstrukturell codiert sind, sind in KURZ UND SCHMERZLos und Geschwister noch deutlicher. Die Akteure treten in Hamburg-Altona oder Berlin-Kreuzberg so selbstsicher auf, als würden die entsprechenden Orte zu ihnen gehören und sie zu diesen - obwohl die staatsbürgerliche Neuregelung von 1990 sie nur als »halbe Inländer « zu adressieren vermag und die Orte selbst unbestimmt bleiben. Wenn Identifikation nach Stuart Hall ein Prozess der Artikulation und nicht der Territorialisierung ist, so ist in den 1990er Jahren eine spezifische Verbindung von Politik, Ästhetik und Performanz nötig, von Erzählung und Integration als gleichzeitige Exklusion und Inklusion, um sprechen zu können. Dieser Zusammenhang spiegelt sich auch in der Kernaussage des Manifests der Bewegung der »Kanak Attack« von 1998:

Wir treten an, eine neue Haltung von Migranten aller Generationen auf die Bühne zu bringen, eigenständig, ohne Anbiederung und Konformismus. Wer glaubt, daß wir ein Potpourri aus Ghetto-Hiphop und anderen Klischees zelebrieren, wird sich wundern. Wir

673 ZAIMOĞLU (1998): S. 65.

674 Sie stammt von Eckart Schiffer, dem »Chefdenker« des damaligen Bundesinnenministers Wolfgang Schäuble. Siehe: »Der Koran ist nicht Gesetz«. In: DER SPIEGEL Nr. 40 (1991). 
sampeln ganz selbstverständlich verschiedene politische und kulturelle Drifts, die allesamt aus einer oppositionellen Haltung heraus operieren. Wir greifen auf einen Mix aus Theorie, Politik und künstlerischer Praxis zurück. Kanak Attack sinniert nicht über Kulturkonflikte, lamentiert nicht über fehlende Toleranz. Wir äußern uns: mit Brain, fetten Beats, Kanak-Lit, audio-visuellen Arbeiten und vielem mehr. Dieser Song gehört uns. ${ }^{675}$

Die Lage hat sich geändert: In Şerif Görens Film ACI VATAN ALMANYA von 1979 verbindet noch ein vom Gastarbeiter Mahmud gesungenes türkisches Volkslied die heterogene Gruppe der türkischen Arbeiterinnen und Arbeiter miteinander. Anstelle von Markern einer klar bestimmbaren Herkunft, die in den 1980er Jahren wichtiger Bezugspunkt ist, sind es nun Auftritt, Körper, Stil und Artikulation als eine Verbindung von Körper und Ästhetik, die ohne eine spezifische historische Referenz auskommt. Diese Einheiten verschaffen der ortlosen Zugehörigkeit eine Art Besitzverhältnis, das jedoch wesentlich fragil bleibt. Inwieweit Sprechen und Auftreten der `Kanaken` tatsächlich »Handlungsfähigkeit« belegt, ist nach KURz UND SCHMERzLOS zumindest eine offene Frage. So selbstbewusst cool und individuell die Protagonisten in Akıns erstem Film auch auftreten und dargestellt werden, fügen sie sich doch in hohem Maße dem, was sie als ihren Pakt, als ihr Schicksal bezeichnen ${ }^{676}$ Das gilt auch für Cem in APRILKINDER, der sich am Ende dem Wunsch seiner Eltern beugt und seine Cousine heiratet. Selbst in GEgEN DIE WAND flieht die Tochter nicht einfach aus ihrem verhassten Leben in der türkischen Familie. Sie hat Geld angespart, um damit irgendwann eine türkische Hochzeit zu finanzieren. ${ }^{677}$

Diese Spannung und dieser Widerstreit zwischen Individuum, Kollektiv und körperlicher und fiskalischer Ökonomie, zwischen Selbstbestimmung und Schicksal, spiegeln sich auch in den unterschiedlichen Lesarten von KURZ UND SCHMERZLos. Nicht nur die kulturellen Zuschreibungen und die dazu konträr stehenden Selbstbeschreibungen von der multikulturellen Realität über die »interkulturelle Geilheit« bis hin zum universellen Thema Freundschaft, ${ }^{678}$ sondern auch der Schluss von KURZ UND SCHMERZLOS sind unterschiedlich wahrgenommen worden. Am Ende singt Costa in KURZ UND SchmerzLos ein griechisches Lied und stirbt nicht. Dass Costa überlebt, obwohl viele Zuschauer vom Gegenteil ausgehen, ist

675 Siehe hierzu: http://www.kanak-attak.de/ka/about/manif_deu.html (06.08.2018).

676 Auch in Fatih Akıns Film IM JuLI spielt das Motiv des Schicksals eine herausragende Rolle. Siehe hierzu: AkıN, Fatih (1999/2000): Im Juli, Spielfilm, Wüste Film Produktion, Deutschland.

677 Siehe hierzu: AKIN (2004).

678 Auch wenn beispielsweise der Film LolA Und BILIDIKID von 1998 die Szene der homosexuellen Türken zweiter Generation in Berlin ausleuchtet, stehen nach Aussagen und Intentionen von Regisseur und Schauspielern die allgemeinen und universellen Themen der Liebe und Freundschaft im Vordergrund. Siehe hierzu: Ataman (1998). 
Akın sehr wichtig, wie er im Audiokommentar betont. Fünf Jahre nach der ersten Drehbuchfassung beantwortet der Regisseur die Frage des Albaners am Ende des Films, wie es denn nun weitergehe, aus dem Off damit, dass es weitergehe und das weder im Diesseits noch im Jenseits eine Ankunft zu erwarten sei. Vor diesem Hintergrund sind die Protagonisten keine Opfer. Ein Ende ist nur in Sicht, wenn die Erzählung oder das Bewegt-Sein aufhören. Şenocaks Frage der Integration ist hier eher eine Frage der Erzählung und des eigenen Körpers als der eigentlichen Heimat. ${ }^{679}$

Was in den Positionsbestimmungen der Akteure im Manifest der Kanak Attak und in Akıns Film besonders auffällt, ist die Rolle der Eltern. Im Unterschied zu den 1980ern treten sie weder als fördernde noch als unterdrückende Figuren auf. Außerdem halten sie sich in fast allen Filmen der 1990er Jahre nur zuhause auf. ${ }^{680}$ Ihre Anwesenheit im privaten und Abwesenheit im öffentlichen Raum akzentuieren auf besondere Weise das insgesamt unausgeglichene Verhältnis zwischen innen und außen, das Film und Literatur jener Zeit auszeichnet. Die Kinder müssen sich draußen allein behaupten, und wenn Post von Anwälten, Gerichten, Stadtverwaltungen und Banken auf Deutsch bei den Eltern eingehen, sind sie es, die sie für ihre Eltern übersetzen. In der Anthologie Kanaksta beschreibt Zaimoğlu, wie er seinen Vater oft auf der Couch im Wohnzimmer müde liegend gesehen habe und wie dieser dabei immer sagte, dass die deutschen Behörden »seine Ehre mit Füßen treten « würden. ${ }^{681}$ Die Außenwelt ist derart Teil der Innenwelt. Im Briefroman Liebesmale, scharlachrot definiert der Erzähler den Respekt als eine angenehme Begegnung im öffentlichen Raum.

Obwohl so schöne und große Themen wie Freundschaft, Familie und Liebe vermeintlich im Vordergrund der Erzählungen und Filme stehen, wie wir auch in den folgenden Filmanalysen sehen werden, sind ihre Akteure für deren Gelingen viel zu gereizt und unausgeglichen. Denn die Umsetzungen dieser großen Themen sind als Übersetzungen im Sinne Şenocaks, Özdamars und Örens zu verstehen. Sie finden an Nahtstellen statt, die wehtun, wenn man ihnen zu nahe kommt und selbst der Übersetzer ist. Schmerz und Naht werden in Fatih Akıns

679 Siehe hierzu: ŞENOCAK (2009): S. 57.

680 Auch in Michael Kliers Film OstKREUZ von 1991 ist die 15-jährige Tochter und Hauptdarstellerin des Films mehr auf der Straße als anderswo. Die Mutter ist dagegen vor allem in den Wohnzimmern aufgenommen. Und wie in Özdamars Roman, in der Kanak Sprak und in den genannten deutsch-türkischen Filmen ist die Tochter auch hier stärker als die Mutter. Sie ist es auch, die illegal, aber selbstständig versucht, Geld zu verdienen, damit Mutter und Tochter aus der Containersiedlung ausziehen können. Siehe hierzu: KLIER (1991).

681 ZAIMoĞLU, Feridun (1999): »Eure Coolness ist gigaout«. In: Kanaksta. Geschichten von deutschen und anderen Ausländern, hg. v. Joachim Lottmann, Berlin: Quadriga, S. 23-32, hier S. 25. 
großem Erfolg GEGEN DIE WAND sogar visualisiert. Nach dem zweiten Selbstmordversuch der Protagonistin Sibel sehen wir, wie ihre aufgeschnittenen Pulsadern genäht werden und sie überlebt. Auf ganz ähnliche Weise beschreibt Stuart Hall kulturelle Identitäten als umkämpfte, als »instabile Identifikationspunkte und Nahtstellen«, »die innerhalb der Diskurse über Geschichte und Kultur gebildet werden «. ${ }^{682}$ Und es ist spätestens in GEGEN DIE WAND dieser zweite Selbstmordversuch der Protagonistin, die die Schuld für ihre schwierige Situation nicht mehr bei Ihren Eltern sieht. Kurz nach dem Schnitt beginnt sie nämlich, sich selbst ins Gesicht zu schlagen, vor Wut über die maßlose Dummheit, die sie wieder begangen hat. Interessanterweise beschreibt Stuart Hall die Arbeit an der Naht auch als eine Beziehung, »wie die Beziehung des Kindes zur Mutter [...] >nach der Trennung، [...]. Sie wird immer durch Erinnerung, Phantasie, Erzählungen und Mythen konstruiert «. ${ }^{683}$ Aras Ören spricht in Berlin Savignyplatz passenderweise von der »Legende« um Ali Itir. ${ }^{684}$

In meinen Analysen geht es allerdings nicht um die Verarbeitung von Mythen, sondern darum, wie in Literatur und Film ein hohes Maß an körperlicher und sozialpsychologischer Energie soziale Bindungen wie die Beziehung zwischen Mann und Frau, Freundschaft, Familie und Liebe in ihrem Kern zerrüttet werden und möglichen Kohäsionen im Wege stehen. Mich interessiert vor allem der Zusammenhang zwischen realen, materiellen und symbolischen Effekten. Denn genauso wichtig wie der Raum, den das deutsch-türkische Kino und die Literatur der 1990er für die deutsch-türkische Beziehung schafft, ist auch der Ort, an dem sich Emotionen und Bedürfnisse versammeln und verdichten können. Dieser Ort ist z. B. das Strandcafé an der türkischen Westküste. In der Logik der 1990er Jahre bleibt er aber nur Vorstellung und wird nicht Realität.

Thomas Arslans erster Kinofilm GeSCHWISTER ist von einem Rückkehrmotiv getragen, das nie in eine reale Rückkehr mündet. Eines der deutsch-türkischen Geschwister in Arslans Film hat sich zu Beginn des Films dazu entschlossen, seinen Militärdienst in der Türkei zu leisten. Der Junge spricht im Film fast durchgehend perfektes Kiezdeutsch, wenig Türkisch und erscheint als jemand, der einfach nach Berlin gehört. Warum er dennoch zum Militär in die Türkei will, darauf gibt der Film viele mögliche Antworten, von denen aber keine für sich allein bestehen kann. Erneut ist der Ausgangspunkt die spürbare und evidente Unruhe in der Wohnung und in den Akteuren selbst. Auch wenn die Filmkritik Akın und Arslan als sehr unterschiedliche Regisseure behandelt, deren formale

682 HALL, Stuart (1994): »Kulturelle Identität und Diaspora«. In: ders.: Rassismus und kulturelle Identität. Ausgewählte Schriften 2, Hamburg: Argument, S. 26-43, hier S. 30.

683 Ebd., S. 30.

684 ÖREN (1995): S. 7. 
Sprachen gegensätzlich seien, sind KURZ UND SCHMERZLOS und GESCHWISTER von denselben inhaltlichen Komponenten und körperlich-psychischen Stimmungslagen ihrer Akteurinnen und Akteure bestimmt.

\subsection{Koordinationen, Befindlichkeiten und Zugehörigkeiten im Film}

»Man darf hier überhaupt nichts mehr sagen«, ärgert sich der türkische Vater in Thomas Arslans Geschwister. ${ }^{685}$ Bei einem abendlichen Familienessen will er von seinem Dienst beim türkischen Militär erzählen, weil sein ältester Sohn Erol am Vormittag den Einberufungsbescheid vom türkischen Militär erhalten hat: In vier Wochen soll Erol seinen Dienst in der Nähe von Istanbul antreten. Vor allem die »Mutti«, wie der Vater seine deutsche Frau hier nennt - Arslan hat den Eltern keine Namen gegeben -, möchte nicht schon wieder davon hören. Sie will nämlich nicht, dass ihr ältester Sohn die türkische Wehrpflicht erfüllt. Die Mutter hat Angst, dass er im Krieg zwischen dem türkischen Militär und der vebotenen kurdischen Arbeiterpartei PKK im Osten der Türkei eingesetzt werden könnte. Der jüngere Sohn Ahmed kommentiert Erols Entschluss mit einem lakonischen »selber Schuld«. Erol besteht darauf, dass dies seine eigene Entscheidung sei, die niemanden etwas angehe. Mit dem jüngsten ihrer Kinder, der Tochter Leyla, geraten die Eltern in dieser Szene ebenfalls aneinander. Auf ihre Frage, ob sie wieder bei ihrer Freundin Sevim übernachten dürfe, entgegnet der Vater: »Du bist ja mittlerweile mehr bei Sevim als bei Deiner eignen Familie, als wenn Du kein eigenen Zuhause hättest«. Das habe damit nichts zu tun, erwidert sie, und es heiße »eigenes Zuhause und nicht eigenen Zuhause«. Er lebe und arbeite nicht seit über zwanzig Jahren in Deutschland, um sich nun von seiner Tochter belehren zu lassen, antwortet der Vater verärgert. Ahmed steht auf der Seite seines Vaters, wenn er meint, dass sie doch gleich zu Sevim ziehen solle, wenn es ihr hier nicht passe. ${ }^{686}$

Der Vater versucht die Lage zu entspannen, indem er mit allen am Tisch auf den zukünftigen Soldaten anstoßen will. Was in den deutschen Medien über die Türkei stehe, sei alles »Propaganda«. Das Land habe sich entwickelt und sie sollten wieder einmal dort hingehen. Statt von der Türkei zu schwärmen, hätte er sich lieber mehr darum gekümmert, dass sein ältester Sohn die Schule abschließt und eine Lehre beginnt, kontert die Mutter, bevor sie noch aggressiver hinzufügt,

685 ARSLAN, Thomas (1997): Geschwister, Spielfilm, Mainz: Zweites Deutsches Fernsehen. 686 Ebd. 
dass sie nicht wieder die Geschichte von seiner Militärzeit hören will. Der Vater verlässt mit der oben zitierten Aussage, dass man hier nichts mehr sagen dürfe, den Esstisch, zieht sich in das Wohnzimmer zurück und schaltet den Fernseher ein, in dem eine türkische Talkshow läuft. ${ }^{687}$ Diese letzte Einstellung und die Bewegung des Vaters durch die Wohnung bis vor den Fernseher kommt ohne Schnitt aus. Die Stimme des türkischen Moderators dringt in den derart geschaffenen Raum ein. Im Vordergrund sehen wir die anderen Familienmitglieder weiter am Tisch sitzen und schweigen. ${ }^{688}$ In diese spannungsgeladene Ruhe wiederholt die 17-jährige Leyla ihre Frage, ob sie denn nun bei Sevim übernachten dürfe. »Von mir aus. Hier macht ja sowieso jeder, was er will«, meint die Mutter. Es ist zugleich das Ende dieser Sequenz, in der alle Familienmitglieder im Bild zu sehen sind. Niemand hat etwas gegessen. ${ }^{689}$

In der nächsten Sequenz ist Erol beim Kickboxtraining. Sein Freund Tayfun boxt auf einen Boxsack ein. Dass auf die Familienszene ohne Übergang oder establishing shot das Kickboxtraining von Erols Clique Erols folgt, mag auf den ersten Blick wie eine beliebige Abfolge wirken. Genauer betrachtet verschiebt und übersetzt sie aber die ungelöste gereizte Atmosphäre und Spannung beim Abendessen, als niemand so richtig zu Hause sein will, in eine körperliche Aktivität. ${ }^{690}$ Diese komplexe Vermischung von individuellen und kollektiven Rahmungen wie »Nation« und »Familie« ist nicht nur an den Aussagen der Akteure und Arslans Aufnahmetechnik zu erkennen. Auch der narrative Verlauf des Films gibt diese Spannung bis zum Schluss wieder. Denn der beschriebenen Sequenz am Esstisch geht kein Konflikt voraus.

Bevor Erol und sein Vater mit Pizzen für das Abendessen nach Hause kommen, decken Leyla, Ahmed und die Mutter gemeinsam den Tisch. Leyla fragt die Mutter, wie sich die Eltern kennengelernt hätten; in der Straßenbahn,

687 In den Filmen der 1990er Jahre sitzt man oft am Esstisch, isst aber kaum. Vielmehr bieten diese Sequenzen in der Regel das Setting für einen Konflikt. Siehe hierzu: BAŞER (1991); GARNIER (1992); DÖRRIE (1992/1994); BECKER (1995-1997); AKIN (1998, 1999,2004); POLAT (1999); YAVUZ (1998).

688 Die Verstärkung der Verbindung von türkisch und deutsch durch türkisches Fernsehen in Wohnungen in der Bundesrepublik finden wir in vielen Filmen der 1990er Jahre; auch in Kutlu

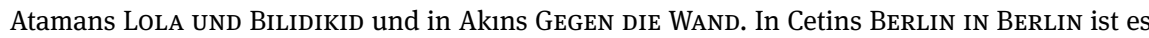
noch umgekehrt. Dort wird in der Wohnung vor allem Türkisch gesprochen, nur das Fernsehprogramm ist deutsch. Auch in den 1980ern wird zuhause nur Türkisch gesprochen.

689 Siehe hierzu: YAvUz (1998).

690 Auch Yüksel Yavuz' Film APRILKINDER beginnt mit einem Streit am Essenstisch, ohne dass einer der Beteiligten was isst. Auf diesen Streit folgt direkt eine Sequenz ohne establishing shot am Arbeitsplatz des deutsch-türkischen Protagonisten, einem deutschen Schlachthof. Siehe hierzu: YAVUZ (1998). 
antwortet die Mutter. ${ }^{691}$ Ein Jahr lang haben sie sich dort immer wieder gegrüßt, bis sie sich dann einmal verabredet haben. «Dein Vater sah sehr gut aus, ist als Student nach Deutschland gekommen, konnte sehr schlecht Deutsch und war schüchtern «, erinnert die Mutter ihren jetzigen Ehemann. Auf Ahmeds Frage, ob sie damals gut Türkisch sprechen konnte, erzählt die Mutter von ihrer gemeinsamen Zeit in Istanbul, als Erol und Ahmed noch sehr klein waren, und sie sich mit ihren Türkischkenntnissen immerhin habe verständigen können. In dieser Zeit sei sie oft mit den Kindern alleine zu Hause gewesen, während der Vater mit Verwandten unterwegs gewesen sei. Mehr erfahren wir in Arslans Film nicht über die Vergangenheit der Eltern oder die der Kinder.

Auch Ahmeds scheinbar empathielose Aussage, dass sein älterer Bruder selber schuld sei, wenn er den Militärdienst in der Türkei antreten wolle, rückt in ein anderes Licht, wenn man frühere Szenen hinzuzieht: Beide Brüder sitzen draußen irgendwo in Kreuzberg auf einer Bank, hinter ihnen eine Wand mit Graffitis. Sie reden über Erols Entscheidung, von der Ahmed ihn abzubringen versucht. Er fragt ihn, ob er das wirklich machen wolle. Er habe es doch nicht nötig, nur Idioten gingen dorthin: "Sie werden Deine Haare abrasieren, Dich in eine Uniform stecken und wie einen Trottel aussehen lassen.« Und Türkisch spreche er ja auch nicht. Natürlich spreche er Türkisch, und was er hier machen solle, fragt Erol energisch zurück. Seine Freunde seien doch auch hier und er könne doch hier viel machen, meint Ahmed. Welche Freunde, reagiert Erol wütend, »es gibt doch keiner einen Fick auf mich«. »Ey, wenn Du keinen Fick auf die anderen gibst, dann geben die auch keinen Fick auf Dich. Denkst Du, die rennen Dir alle hinterher? «, kontert Ahmed. Was er denn jetzt hier machen solle, »kannst Du mir diese scheiß Frage beantworten«, fragt Erol erneut. Vielleicht bringe ihm das Militär ja etwas. »Willst Du hart werden oder was? «, fragt Ahmed. »Ey, verarsch' mich nicht, okay. Ich kann im Moment nicht gebrauchen, dass Du mich verarschst«, antwortet Erol. »Ich verarsch’ Dich nicht. Denkst Du bist mir egal oder was? Wenn ich mir keine Sorgen machen würde, würde ich nicht versuchen, Dich vom Gegenteil zu überzeugen«, entgegnet Ahmed. »Du verstehst das nicht. Meine Entscheidung steht fest. Vergiss’ es Alter«, beendet Erol das Gespräch. ${ }^{692}$

691 ARSLAN (1997). Siehe hierzu auch: ŞENOCAK (1995): S. 19.

692 Siehe hierzu: Arslan (1997). Bemerkenswert ist, dass Arslan nicht die Option ins Spiel bringt, die jeder Deutsch-Türke der zweiten Generation hatte: sich nämlich vom türkischen Militär freizukaufen. Gegen eine Gebühr von damals 5000 DM war es möglich, eine verkürzte Militärzeit von 3 Monaten zu absolvieren statt der vorgesehenen zwölf Monate. In der Regel verbrachten Deutsch-Türken der zweiten Generation, die von diesem Recht Gebrauch machten, ihre drei Monate Militärzeit in der türkischen Stadt Burdur. Aufgrund ihrer mangelnden Erfahrung wurden sie nicht in Krisen- oder Kriegsgebiete entsandt. 
Ähnlich wie beim Abendessen löst Arslan dieses Gespräch mit wenigen Schnitten und nicht mit klassischen Schuss- Gegenschussaufnahmen auf. In jedem Redeabschnitt sehen wir beide Brüder aus der jeweils anderen, der zuhörenden Perspektive. Vor diesem Gespräch am Nachmittag hat Erol mit seiner Mutter über den anstehenden Wehrdienst gesprochen, nachdem die anderen Kinder in die Schule (Ahmed) bzw. zur Lehre (Leyla) gegangen sind. Anders als am Abend und am Nachmittag begründet Erol im Gespräch mit seiner Mutter seine Entscheidung damit, dass er Türke und der Militärdienst daher dann nun einmal seine Pflicht sei. Die Unterhaltung wird genauso gefilmt wie die am Nachmittag mit dem Bruder.

Erol wechselt also zwischen unterschiedlichen Begründungen für seine Entscheidung, die sozialkulturell von äußerst differenten Kategorien wie subjektiver, kollektiver Identifikation bis zur existenziellen Perspektivlosigkeit reichen. Diesen Motiven fügt Arslan lose zwei weitere hinzu, die nichtdiskursiv sind und auch nicht den jeweiligen Dialogpartnern angepasst werden können. Kurz nach dem ebenfalls erhitzten Gespräch mit der Mutter sehen wir Erol auf den Straßen Kreuzbergs. Wie die Kamera Ahmed zur Schule begleitet hat, ist sie nun an Erols Seite. Während Ahmed sich gelassen mit herunterhängenden Armen und den Händen in den Hosentaschen durch die unbenannten Straßen bewegt, tritt Erol anders auf. Mit seiner schwarzen Lederjacke wirft er »die Schultern beim Gehen wie ein Rapper hin und her « ${ }^{693}$ und macht seinen Körper breiter. Dennoch wirkt sein Auftreten nur bis zu einem gewissen Grad künstlich oder kopiert. Denn in seinen Bewegungen liegen zudem eine Nervosität und Gereiztheit, die im Laufe des Films oft ausbrechen. ${ }^{694}$ Dies hat mehrere Gründe.

693 Nicodemus, Katja (1997): »Cruising Kreuzberg«. In: TIP Magazin Nr. 25 (1997).

694 In seiner programmatischen Einleitung zu Kanak Sprak macht Feridun Zaimoğlu darauf aufmerksam, dass die Körpersprache ein zentrales Artikulationsorgan der Befindlichkeit der zweiten Generation sei. Heute wirken die Beschreibungen in dieser Einleitung, was ein Kanake meint, wenn er sich so und so bewegt, unfreiwillig komisch. Das liegt mitunter daran, dass der Kanake der 1990er Jahre in den 2000er Jahren in vielen Kabarett- und Comedy-Formaten karikiert wird. Den Anfang machte Kaya Yanar mit seiner sehr erfolgreichen Sendung WAS GUCKST Du?!, die in 120 Folgen zwischen 2001 und 2005 auf Sat 1 ausgestrahlt wurde. Nur drei Jahre zuvor gab es diese Form der Karikierung noch nicht. Eindrücklich zeigt sich dies in der Talkshow III NACH NEUN vom 8. Mai 1998, in der die Moderatorin Gaby Hauptmann, die Politiker Heide Simonis, Norbert Blüm, der Journalist Giovanni di Lorenzo und viele andere auf die Literatur der Kanak Sprak im Beisein von Feridun Zaimoğlu reagieren. Die Kategorien »deutsch« und »türkisch « ließen sich damals in der Semantik der Öffentlichkeit offenbar nicht zusammendenken. Die Sendung ist in zwei Teilen auf YouTube einsehbar: https://www.youtube.com/watch?v=wrV7adgbcMc (06.12.2017). In Tom Cheesemans vielzitiertem Buch Novels of Turkish Settlement von 2006 bildet die Analyse dieser Sendung sogar den Ausgangspunkt seiner wissenschaftlichen Arbeit. Ähnlich wie Leslie Adelson vertritt Cheesman die These, dass die Türken mit der Literatur 
Zum einen fühlt Erol sich wie die >Kanaken` in Zaimoğlus Texten auf der Straße »immer angesprochen«. Er überreagiert in vielen Situationen und versucht, »seine körperliche Überlegenheit zu beweisen «. ${ }^{695}$ Er lädt Blicke, »Handlungen und Äußerungen anderer projektiv« auf. ${ }^{696}$ Zum anderen ist er hoch verschuldet. Kurz nachdem wir ihn am Kottbusser Tor gesehen haben (der einzige Hinweis im ganzen Film, dass wir uns in Berlin-Kreuzberg befinden), wird Erol gleich zu Anfang des Films von deutschen Geldeintreibern verfolgt, denen er Geld schuldet. Da sie im Auto sitzen, kann er durch Einkaufspassagen entkommen. In der nächsten Sequenz findet das oben geschilderte Gespräch mit Ahmed statt. Dieselben Geldeintreiber tauchen gegen Ende des Films wieder auf. Dann werden sie ihn erwischen und ihm ein letztes Mal drohen: Wenn er in einer Woche seine Schulden nicht begleiche, werde es für ihn sehr unschön werden. Am nächsten Morgen fliegt Erol zum Militärdienst in die Türkei. Erol hat nicht nur bei Kriminellen Schulden, sondern auch bei Freunden. So versteckt er sich plötzlich in einem Hauseingang vor jemandem, dem er Geld schuldet. Sein Bruder kommentiert dies genervt mit den Sätzen, bei wem er denn in der Stadt keine Schulden hätte. ${ }^{697}$

in Deutschland angekommen seien. Siehe hierzu: CheEseman, Tom (2007): »Prelude in the Television Studio«. In: ders.: Novels of Turkish Settlement, New York: Camden House, S. 1-11. Gegen das Ernstnehmen dieses übertrieben körperlichen Auftritts spricht sich auf der anderen Seite etwa Vera in Wolfgang Beckers Film DAS LEBEN IST EINE BAUSTELLE aus, die sich darüber lustig macht, wie "machomäßig« Jan sich bewegt. Auch die Protagonisten dieses Films sind häufig in der Stadt unterwegs. Die Figur von Jan Nebel bezeichnet Katja Nicodemus in ihren zeitnahen Reflexionen zum Film der 1990er Jahre als den melancholischen Leinwandhelden dieser Dekade, der einen »Paradigmenwechsel« eingeleitet habe: »Die Leinwand öffnete sich wieder für Figuren und Milieus, die jahrelang weder im Kino noch im gesellschaftlichen Diskurs eine Rolle gespielt haben«. Siehe hierzu: Nicodemus (2005): S. 335.

695 Neubauer (2011): S. 295.

696 Ebd., S. 299.

697 Finanzielle Schulden spielen in sehr vielen Filmen der 1990er Jahre eine wichtige Rolle. In DAS LEBEN IST EINE BAUSTELLE schlägt Jan bei einer 1. Mai-Demo unbeabsichtigt einen Polizisten nieder. Er wird mit einer Kaution von 5000 DM auf Bewährung freigelassen, muss dieses Geld aber in kurzer Zeit aufbringen. In Tom Tykwers bekanntem Film LoLA RENNT unternimmt Lola mehrere Anläufe, um ihrem Freund Manni so schnell wie möglich 100000 DM zu besorgen, der sonst wahrscheinlich umgebracht wird. In Michael Kliers Film OstKREUZ ist es die Kaution von 3000 DM für eine Wohnung, die die junge Elfie (Laura Tonke) für sich und ihre Mutter (Susanne von Borsody) aufbringen will, damit beide endlich aus der Containersiedlung ausziehen können. In Andreas Dresens NACHTGESTALTEN sind 100 DM als eine Gabe von oben den gesamten Film über im Umlauf, die die vielen Akteurinnen und Akteure zusammenbringt. Zu Anfang des Films bekommt eine Obdachlose hundert Mark von jemandem, den weder wir noch sie gesehen haben. Am gleichen Tag ist in Berlin der Papst zu Besuch. Bei aller Ähnlichkeit hinsichtlich der Geldfrage gibt es einen zentralen Unterschied zwischen den deutschen und den deutsch-türki- 
Erol wird seine Schulden nicht zurückzahlen können. Denn kaum hat er etwas Geld, kauft er sich neue teure Markenturnschuhe, ${ }^{698}$ worüber sich sein Freund Tayfun, dem er ebenfalls Geld schuldet, sehr aufregt. Die Verbindung von Schulden, Geldeintreibern, Statussymbolen und dem daran anschließenden Flug in die Türkei zum türkischen Militär erinnern an das eigentliche Sujet von Fatih Akıns KuRz Und Schmerzlos: Tommi flieht vor Geldeintreibern nach Serbien zum Militär. Dass dies auch Erols Entscheidung motiviert haben könnte, deutet Arslan zwar an - lässt dieses Motiv aber keineswegs alleinstehen. Die eigene Entscheidung, nationale Pflicht, Perspektivlosigkeit vor Ort, nicht zu begleichende Schulden (auch die Familie hat finanzielle Probleme), sind im gesamten Verlauf des Films assemblageartig miteinander verknüpft. Letztlich bleibt es offen, warum genau sich Erol nun für das türkische Militär entscheidet. In jedem Fall sind beide Themen im Film gleichwertig präsent. ${ }^{699}$

Während die Erklärung dafür, warum Erol zum Militär geht, heterogen und unbestimmt ist und bleibt, ist Arslans Film in der Darstellung des Alltags, der Bewegungen und der Physis deutsch-türkischer Akteure der zweiten Generation äußerst präzise. ${ }^{700}$ Erol und Ahmed gehören dem öffentlichen Raum an, so wie der Erzähler in Örens Roman zum Berliner Savignyplatz gehört, auch wenn seine Freunde ihn den "großen Türken« nennen. ${ }^{701}$ Diese Spannung zeigt sich auch

schen Filmen. In den deutschen Produktionen wird Geld entweder wie in OSTKREUZ oder in LoLA RENNT aufgebracht, es zirkuliert und stiftet soziale Verbindungen wie in NACHTGESTALTEN, oder aber Vera schenkt Jan ihr Herz, weil eigentlich sie für die Verstrickung von Jan in die 1. Mai-Demonstration verantwortlich ist. Diese Formen des ökonomischen und emotionalen Ausgleichs finden in den deutsch-türkischen Produktionen nicht statt. Interessanterweise ist das Geld in Filmen von Rainer Werner Fassbinder, besonders in KATZELMACHER und ANGST ESSEN SeELE, das Gegenteil der guten Gefühle. Im Unterschied zu den Filmen der 1990er Jahre macht es laut Emmi aus ANGST ESSEN SEele Auf »alles kaputt«. Siehe hierzu: EzLI, Özkan (2012): »Peripherien zwischen Repräsentation und Individuation. Die Körper der Minderheiten in Fassbinders KatZelmacher und ANgST ESSEN SeELE AUF«. In: Prekäre Obsessionen. Minoritäten im Werk von Rainer Werner Fassbinder, Bielefeld: transcript, S. 93-124.

698 NEUBAuER (2011): S. 294.

699 Auch Şenocak hält in Gefährliche Verwandschaft fest, dass die Türken genau wüssten, worum es in Deutschland gehe: um das Geld. Deshalb kümmerten sie sich auch nicht um so "wertlose Dinge« wie den deutschen Pass. Siehe hierzu: ŞENocaK (1998): S. 12.

700 In Besprechungen zu Yavuz' Film APRILKINDER heißt es beispielsweise auch, dass es diesem Film überzeugend gelinge, präzise eine rauhe Stimmung auf deutschen Straßen zu schaffen. Siehe hierzu: REINECKE, Stefan (1999): »Aprilkinder«. In: epd Film, Nr. 2, Februar. http://www. filmportal.de/node/3995/material/687652 (15.12.2017).

701 Der Erzähler gehört beispielsweise in der Berliner Kneipe »Florian« zu den Stammgästen, die von der Inhaberin Gerti persönlich begrüßt werden. Doch als wir Zeuge dieser Vertrautheit des Türken in Berlin werden, hat sich Ali Itir als seine fiktive Gastarbeiterfigur ebenfalls Zugang zu dieser Kneipe verschafft. Der Erzähler bezeichnet ihn am Ende seines Romans als seinen »Ver- 
darin, dass Erol, das Kind einer Deutschen und eines Türken ist, obwohl er sich selbst ausschließlich als Türken ansieht. Er redet fast nur Deutsch. Als er seiner Mutter auf Berliner Kiezdeutsch genervt antwortet, es sei seine Entscheidung und er mache dies, weil er ein Türke sei, ${ }^{702}$ setzt diese Szene durch diesen Widerstreit und Widerspruch so viel in Bewegung, dass Erols anschließender öffentlicher Auftritt und seine Schulden als eigentliche Beweggründe erscheinen. ${ }^{703}$ Erol beharrt immer wieder darauf, dass es seine eigene Entscheidung sei, die auch nichts mit seinem Vater zu tun habe, was tatsächlich nur ihn selbst als Träger dieser Schuld übrig bleiben lässt, wie ja auch Ahmed feststellt: »selber schuld«. Würde Erol beide Elternteile einbeziehen, dann müsste er zwischen die Kulturen treten. Einen solchen Ort gibt es für die zweite Generation in den 1990er Jahren aber nicht. Ihr eigenes Ich, ihr Selbst und ihr Körper müssen unterschiedlichste Facetten zusammenfügen. Sie können nicht einfach einem Beruf nachgehen und sich als integriert ausweisen oder mit klarer kultureller Positionierung und Identifikation in eine Moschee gehen. Sie müssen die Uneinheitlichkeiten, die real wirkenden Widersprüche irgendwie kommunizieren, weil der öffentliche Diskurs und die Politik dies nicht tun. Geht es hier wirklich um eine multikulturelle Artikulation und Kommunikation, wie Charles Taylor und Jürgen Habermas sie sich vorstellen und mitunter wünschen? Handelt es sich dabei wirklich um Artikulationen, die aus dem tiefsten Inneren dieser Akteure kommen? Weitaus dringlicher als diese individuelle Artikulation scheint die Frage nach den Schulden und der Schuld in Literatur und Film zu sein.

folger«. ÖREN (1995): S. 155f. Ein Freund des Erzählers, Manfred Kohlhaas, versucht Ali davon zu überzeugen, dass er »ein Recht darauf hat, sich schuldig zu machen«. Doch dieser will nur beweisen, »daß er nicht `Er` ist«; dass er nicht die Person und zugleich der Tote ist, die/den Brigitte am Ende von Bitte nix Polizei, als ihren Vergewaltiger identifizierte. Siehe: ÖREN (1995): S. 157; ÖREN (1981): S. 116.

702 ARSLAN (1997).

703 In Kutlu Atmans Film LoLA UND BILDIKID sind Schuld und Schulden ebenfalls ineinander verwoben. Lola ist von seiner türkischen Familie, genauer von seinem eigenen älteren Bruder verstoßen worden, weil er sich geschminkt in Frauenkleidern der Familie zeigte. Als Lola nach Jahren wiederauftaucht, um ihren jüngeren Bruder zu sich zu holen, weist der ältere Bruder, der große Angst davor hat, dass der jüngere Bruder die Familie verlassen könnte, harsch Lola erneut im Treppenhaus aus dem Haus. Dabei schimpft er auf Lola, dass sie nicht seine Familie seien und er auch kein Geld kriegen werde, das ihm eigentlich zusteht. Am Ende des Films erfahren wir, dass der ältere Bruder Lola sexuell mißbrauchte und nach dem Coming-out von ihr/ihm vor der Familie große Angst hatte, es könnte herauskommen, dass er homosexuell ist. Er spielt in Atamans Film einen äußerst maskulin auftretenden und harschen türkischen Bruder, der seinen jüngeren Bruder immer wieder dazu bringen, ja zwingen will, dass er mit Frauen schläft. Wie in den 1990er Jahren üblich, geht er hierfür mit seinem Bruder zu den Prostituierten. Siehe hierzu: ATAMAN (1999). 
Die Frage der Schuld als Teil der Selbstbeschreibung war uns bereits in den Werken von Özdamar und Şenocak begegnet. Wie Sibel in GEGEN DIE WAND versucht Özdamars Protagonistin im Karawanserei-Roman zweimal, sich das Leben zu nehmen und zumindest bei einem Versuch trägt ihr Vater eine Mitschuld. Doch stellt der Roman dies anders dar. Die Kultur ist, anders als in den Beobachtungen der 1980er, ebenfalls nicht schuld. Übrig bleiben nur die Akteurinnen und Akteure, die Übersetzerinnen und Übersetzer selbst. Auch für Fatih Akın ist der Aspekt der Schuld für seinen Protagonisten Gabriel und für die Entstehung von KuRz UND ScHMERzLOS zentral: »Der Held fühlt sich immer schuldig, damit konnte ich mich wunderbar identifizieren ${ }^{704}$ Trotz dieses sehr komplexen Zusammenhangs zwischen Nation und Schuld, Multikultur, Verwandtschaft und Schuld sind die Akteure keine Opfer. Das hat damit zu tun, dass sie sich artikulieren, wenn es zu Diskriminierungen kommt, dass sie selbst diskriminieren und so den Verlauf der Erzählungen bestimmen: ${ }^{705}$ Sie erfinden, sind laut oder bewegen sich ganz körperlich von innen nach draußen. Letzteres zeigt sich in Arslans GESCHWISTER am deutlichsten. Die besondere Verstrickung von Innen und Außen erklärt das Unbehagen $\mathrm{zu}$ Hause und zeigt, welche wesentliche Bedeutung der allgemeine öffentliche Raum für die zweite Generation hat. Denn auch wenn ich den Film GESCHWISTER bislang anhand von Dialogen beschrieben habe, ist er durch und durch ein Film der Bewegung, der Mobilität seiner Akteure im öffentlichen Raum.

Die Filmkritikerin Katja Nicodemus hat Arslans Film als ein »Roadmovie ohne Autos« beschrieben. ${ }^{706}$ Wie schon öfter festgestellt, sind in den 1990er Jahren sehr viele filmische Akteurinnen und Akteure unterwegs: zu Fuß, mit dem Auto oder in der Bahn. ${ }^{707}$ In GESCHWISTER sind die Akteure ausschließlich zu Fuß unterwegs; vor allem Erol. Alle Schauspieler werden stets in Augenhöhe gefilmt, so dass wir meist ihren ganzen Körper sehen. Jahre später hält Arslan fest, dass die Geschwister »organisch« zur Stadt Berlin gehörten, auch wenn einer von ihnen seine türkische Herkunft stark thematisieren mag. ${ }^{708}$ Diese geradezu physische Zusammengehörigkeit zu verdeutlichen, gelingt Arslan, indem

704 AKIN (2011): S. 65.

705 Aus diesem Grund empfindet man auch keine Empathie oder Mitleid mit den Akteuren, selbst wenn Lola von ihrem älteren Bruder getötet wird, oder wenn Cem die nicht gewollte Ehe mit seiner Cousine für seine Familie eingeht.

706 Nicodemus (1997).

707 Selbst im Spielfilm LEBEwOHL FREMDE von Tevfik Başer, der auf einer norddeutschen Hallig spielt, sind die Akteure oft mit einem Auto, mit Fahrrädern oder der Fähre unterwegs. Die vier Flüchtlinge sind in einem Wohnwagen untergebracht. Die Hallig selbst ist für so viel Bewegung eigentlich zu klein. Siehe hierzu: BAŞER (1991).

708 Siehe hierzu: ARsLAn, Thomas (2008): Kommentar zu seiner Berlin-Trilogie. In: ARSLAN (2008): Geschwister, Berlin: Filmgalerie 451. 
er das Gehen der Akteure »in ganz wenigen Straßen, die auch ganz bewußt immer wiederkehren«, gedreht hat. Wie für die deutschen Filme der 1990er Jahre war die »Totale keine Einstellung für Berlin ${ }^{709}$ Arslan will statt einer umfassenden Perspektive zeigen, dass das »doch recht kleine Umfeld, in dem sich die Geschwister und ihre Freunde bewegen, Tag für Tag, möglichst präzise abgesteckt wird. Es ist wichtig, daß sie gerade über dieses Gehen dann auch den Raum miterzählen können. « ${ }^{710}$ Verstärkt wird diese "Präzision « durch die besondere Tonspur in diesem Film, die den sehr lauten Verkehrslärm oder beispielsweise das Rattern der Nähmaschinen in der Ausbildungsstätte von Leyla und Sevim wiedergibt. Die vor Ort aufgenommenen Geräusche wollte er nachträglich »nicht mehr modifizieren oder glätten«. Es war Arslan wichtig, »daß man Kamera und den Ton dem ausliefert, was man vorfindet, und das dann auch als Einheit behandelt «. ${ }^{711}$ Nach Barbara Mennel ist in Arslans GEschwISTER deshalb auch die Location wichtiger als die Narration. ${ }^{712}$ Doch ist dieser Befund nur bedingt richtig. Denn die vermeintliche Einheit wird immer wieder durch die besondere Verschränkung von Innen- und Außenräumen auf unterschiedlichsten Ebenen unterminiert. Darauf deuten im Besonderen die fehlenden establishing shots hin, deren Funktion gerade darin besteht, zu präzisieren worin oder wo genau etwas stattfindet. Hier sind es vielmehr die Akteure selbst, in denen mit ihren Gereiztheiten und durch ihre Verhaltensweisen etwas stattfindet. Sie verweisen damit auf die verschränkte Konstellation des Öffentlichen und Privaten, des privat-intimen wie auch kollektiv-zugänglichen. Es handelt sich dabei um eine Verschränkung, die auch in all den anderen bislang genannten und analysierten Filmen der 1990er Jahre vorkommt, because they »carry their wound inside them «. ${ }^{713}$

Dies zeigt nicht nur die Sequenz beim Abendessen eindrücklich, sondern auch eine bereits erwähnte Sequenz in der Mitte des Films, die alle von mir gezeigten Themen und aufgegriffenen Kategorien miteinander verbindet. Erol steht mit seinen Freunden vor einer türkischen Imbissbude und regt sich über zwei gleichaltrige Dunkelhäutige wie er selbst auf, denen sie zuvor begegnet waren. »Habt ihr gesehen, wie die uns angeschaut haben? Zigeuner und Asylanten. Die sind das Letzte«, meint Erol. »Glaubst Du, Du bist was Besseres? Es gibt auch türkische

709 Nicodemus (2004): S. 338.

710 Zitiert nach ebd.

711 Zitiert nach: Nicodemus (1997). In Cetins BerLin IN BERLIN wird in vielen Sequenzen die Lautstärke von Geräuschquellen wie Fernsehern oder Autos signifikant heruntergedreht. Siehe: CETIN (1993).

712 MenNel (2002): S. 144.

713 Ebd., S. 154. 
Asylanten«, kontert ein Freund. »Das ist was anderes«, erwidert Erol. Tayfun, ein anderer Freund, gibt zu bedenken, dass Erol doch gar kein richtiger Türke sei. Darauf reagiert Erol sehr gereizt, doch Tayfun weist sachlich darauf hin, dass er der Sohn eines Türken und einer Deutschen sei. Mit einem »hab keinen Bock auf das hier« lässt Erol seine Freunde genervt stehen. ${ }^{714}$ Anschließend sehen wir, mit einer Handkamera aufgenommen, wie er wütend nachts durch Berlin läuft. Lichtquellen sind nur Straßenlaternen und das Scheinwerferlicht der vorbeifahrenden Autos, ${ }^{715}$ bestimmend ist auch der Straßenlärm. Bei diesen Aufnahmen laufen wir Erol gewissermaßen hinterher, sehen auf seinen Rücken, der wieder in der schwarzen Lederjacke steckt. Irgendwann bleibt er stehen, lehnt sich an eine Straßenwand und blickt auf die vielbefahrene Straße. Eine solche Sequenz gibt es auch in Akıns Kurz und SchMERzLos. Der Deutsch-Grieche, der kurz zuvor erfahren hat, dass Bobby gestorben ist, wird ebenfalls von hinten gefilmt, hat eine Bomberjacke an und ist ebenso wütend wie Erol nachts in der Stadt unterwegs.

Dass Erol in der beschriebenen Sequenz einfach irgendwo in der Stadt stehenbleibt, ist kennzeichnend für die Grundstruktur der Gehsequenzen in diesem Film. Denn von keinem Akteur wissen wir, wohin er geht; mitunter auch, weil niemand davon spricht, wohin er will. Nur ein einziges Mal sehen wir in diesem Film, wie jemand einen Ort verlässt und an einem anderen ankommt: als Ahmed in die Schule geht (die wir wiederum kein einziges Mal von innen zu Gesicht bekommen). Die einzige abgeschlossene Bewegungsabfolge in GESCHWISTER führt zugleich neben dem Militärdienst das zweite wichtige Thema des Films ein: die Schule, zu der die beiden Brüder Ahmed und Erol in einem gegensätzlichen Verhältnis stehen.

Ahmed geht aufs Gymnasium und wird Abitur machen. Erol hat die Schule abgebrochen. Trotz dieser Differenz stehen sich die Brüder sehr nahe: räumlich, körperlich und geistig. Sie teilen sich wie Cem und Mehmet in APRILKINDER ein Zimmer und wir sehen sie oft nebeneinander durch die Kreuzberger Straßen gehen und miteinander reden, ohne sich dabei anzusehen. Auch beim Abendessen sitzen sie nebeneinander. Im Gegensatz zu dieser körperlichen Nähe stehen ihre unterschiedlichen Ansichten. Auch wenn sie Brüder sind, bezeichnet sich Ahmed im Unterschied zu Erol an keiner Stelle im Film als Türken (aber auch nicht als Deutschen). In einer der wenigen Sequenzen innerhalb der Wohnung schaut sich Erol, gelangweilt auf dem Bett liegend, einen Bruce Lee-Film an. Über

714 ARSLAN (1997).

715 Auch Yavuz, Polat und Akın nutzen kaum zusätzliche Lichtquellen. Dort, wo sie zum Einsatz kommen, stehen sie für eine besondere Form der Verstellung oder der Ironie. 
seinem Bett hängt ein Bruce Lee-Plakat. ${ }^{716}$ Ahmed hingegen liest ein Buch. Er verlangt von Erol, dass er diesen »Scheiß« ausschalten solle, weil er lesen müsse; er verstehe nicht, wie man hundertmal denselben Film anschauen könne. Erol fragt genervt zurück, was mit ihm los sei. Bevor der Film zu Ende ist, schläft Erol ein und Ahmed deckt ihn zu. Zwar setzt Arslan die Distinktion Bildung und Nicht-Bildung als Differenz zwischen den Brüdern bewusst ein, doch sehen wir Ahmed nur dieses einzige Mal ein Buch lesen. Viel markanter als sein Bildungsweg - er weiß ja noch nicht, was er später einmal werden möchte -, ist sein Versuch, das Thema »Herkunft « zu vermeiden. ${ }^{717}$ Als ein Onkel von ihnen erkrankt und Erol dies Ahmed gegenüber erwähnt, erwidert dieser nur, dass es ihm recht geschehe, weil er sie früher immer genervt habe. Erol ist empört, da der türkische Onkel doch zur Familie gehöre. Hatte Ahmed etwa vergessen, dass er einen türkischen Namen trage ${ }^{718}$

Für Barbara Mennel verkörpern die Brüder Erol und Ahmed zwei unterschiedliche Migrationstypen: "the foregrounding of body culture versus a humanist, universalist emphasis on education « ${ }^{719}$ Im Unterschied zu Erol habe Ahmed die Assimilation gewählt. ${ }^{720}$ Die derart konstruierte Opposition zwischen einem Schulabbrecher, der sich einer anderen Kultur zugehörig fühlt und einem, der das Abitur machen will und sich im Hier und Jetzt verortet, verleiten Mennel wohl zu der Feststellung, dass Ahmed assimiliert und in Deutschland angekommen sei. Einer gelungenen Form von Assimilation widerspricht allerdings zum einen, dass Ahmed nicht über seine Herkunft als etwas bewusst Aufgegebenem sprechen will. Zum anderen bezeichnet er sich, wie gesagt, an keiner Stelle als einen Deutschen und sieht sich erst recht nicht als jemanden an, der für einen »universalist emphasis on education « steht. Außer auf seinem einmaligen Schulweg zu Beginn des Films sehen wir ihn auch meist ähnlich wie Erol einfach abhängen. Kurz gesagt, ist Ahmed nicht der Geist, der dem Körper Erols fehlen würde. Denn Ahmed ist mit Ausnahme einer Sequenz ebenfalls vorwiegend performativ und körperlich angelegt. Auch in sozialer Hinsicht kann Ahmed nicht als ein Paradebeispiel der Assimilation gelten. Sicher hat Erol in Arslans Film mehr Identitätsstress als Ahmed, doch ist Letzterer umgekehrt kein Garant sozialer Kohäsionen, wie es sich Ezra Park oder Milton Gordon vorgestellt haben. Auch eine Inklusionstheorie, die von dem Faktum der gleichzeitigen Exklusion ausgeht, von der Tren-

716 Auch in Yüksel Yavuz’ APRILKINDER hängen in einem ebenfalls von zwei ungleichen Brüdern geteilten Zimmer Bruce Lee-Plakate an den Wänden.

717 Siehe hierzu: Neubauer (2011): S. 315.

718 Siehe hierzu: ARSLAN (1997).

719 Mennel (2002): S. 145.

720 Siehe hierzu: Ebd., S. 148. 
nung von Person und Körper, greift hier nicht. ${ }^{721}$ Ahmed und Erol sind einander nicht eindeutig entgegengesetzt.

Im Gegenteil teilen sie den nach Milton Gordon sehr wichtigen Integrationsmarker, das »feel comfortable« oder sich »als Individuen heimisch fühlen können« (Luhmann). ${ }^{722}$ Denn beide zeichnen sich durch ihr Gereizt-Sein aus, dessen Quellen Arslan zwischen Identifikation, Desidentifikation und Sozialstruktur ansiedelt, aber vage lässt. So ist auch der Unterschied, den Erol selbst zwischen sich und seinem Bruder festmacht, integrationstheoretisch kaum $\mathrm{zu}$ messen. Gegen Ende des Films fragt Erol sich und seinen Bruder, warum bei ihm selbst alles schieflaufe und bei Ahmed alles klappen würde. Ahmed habe einfach Glück gehabt und er nicht, beendet Erol das Gespräch. Ahmed und Erol stehen nicht für zwei unterschiedliche Integrationstypen, sondern antworten vielmehr unterschiedlich auf die Frage: „Wie lebt es sich in Deiner Haut?« Der eine hält es insgesamt in seiner Haut gut aus, weil er sich selbst keine Fragen stellt und einfach etwas macht. Dieses Aktiv-Sein eröffnet ihm Möglichkeiten, auch wenn diese nicht beschrieben werden. Allein die Aussicht auf das Abitur und seine deutschen Partnerinnen deuten Möglichkeiten in der Mehrheitsgesellschaft an. Katja Nicodemus schildert Ahmed in dieser assimilatorischen Unbestimmtheit als jemanden, »der seinen Weg schon gehen wird«. Der andere hingegen hofft, dass ihm dieser Weg woanders, in der Türkei, gelingen wird. Das unterschiedliche Gefühl in der eigenen Haut zeigt eindrücklich, wie verschieden sie sich durch die nicht benannten Straßen Kreuzbergs bewegen. Wie für Şenocaks Protagonist sind für Erol und Ahmed weder die Türkei noch die Bundesrepublik noch Kreuzberg ihre eigentliche Heimat, sondern ihre Körper. Die Stadt, in der GESCHWISTER spielt, könnte also auch eine ganz andere sein.

In Hark Bohms Film YASEMIN ist die weibliche Protagonistin auch auf dem Weg, Abitur zu machen. Im Unterschied zu Ahmed hat sie aber bereits konkrete Berufspläne, sie will Kinderärztin werden. Ein weiterer zentraler Unterschied ist, dass eine deutsche Lehrerin ihr dabei helfen und auch ihren Vater davon überzeugen möchte. Der inhaftierten Figur Elif, in Başers zweitem Spielfilm ABSCHIED VOM FALSCHEN PARADIES aus den 1980er Jahren, hilft ebenfalls jemand bei ihrem Integrationsprozess: eine Sozialarbeiterin. Elif möchte nach der Haftstrafe Busfahrerin werden. Waren in den 1980ern Folgen der Migration als Kulturkonflikte und Integration in filmischen und literarischen Erzählungen eng miteinander verknüpft, gehören sie in GESCHWISTER nicht mehr zusammen. Denn Arslan weist Ahmed und Erol mit ihrer Sprachkompetenz und ihrem Aufritt im öffentlichen

721 Siehe hierzu: LuHManN (1998): S. 621 u. S. 633.

722 Ebd., S. 621. 
Raum als ihrer städtischen Umgebung zugehörige aus. Dabei geben sie sich autonom, benutzen kaum öffentliche Verkehrsmittel, sondern erlaufen die Stadt. Sie laufen einfach, die Räume, zu denen sie gehören. Diesem »cruising « durch die Stadt und der Zugehörigkeit, die dadurch entsteht, sind das Forcieren identifikatorischer Konflikte oder deren Vermeidung als Immobilitäten entgegengesetzt. Auch Ahmed wirkt, selbst wenn es ihm in seiner Haut etwas besser geht als Erol, auf seine Art rastlos.

Die einzige Figur in GeSCHWISTER, die genauer zu wissen scheint, was sie will, ist Leyla, also wiederum eine Frau. Aus einem Gespräch zwischen ihr und ihrer besten Freundin erfahren wir, dass beide nach ihrer Ausbildung zur Schneiderin ihre Elternhäuser verlassen und zusammenziehen wollen. Leyla setzt sich außerdem vom türkischen Vater am stärksten ab. Als er ihr im letzten Drittel des Films nicht erlaubt wird, dass sie mit einem türkischen Jungen allein von Berlin nach Hamburg fährt, beschimpft sie ihren Vater als einen »Vollidioten «, den sie auch einfach damit hätte belügen können, dass sie mit einer Freundin zusammen nach Hamburg fährt. Leyla möchte ähnlich wie Michaela (Melek) in Şenocaks Erzählung Das Haus nicht mehr mit ihren Eltern und Brüdern zusammenleben. So endet der Film Geschwister nicht etwa damit, dass Erol die Grenze am Flughafen passiert oder damit, dass Ahmed nun allein in seinem Zimmer sitzt. Die letzte Einstellung des Films gehört Leyla und ihrer Freundin Sevim. Wir sehen sie bei Sonnenschein auf einer belebten Straße in Berlin-Kreuzberg gehen.

Arslans Geschwister dokumentiert für Deniz Göktürk den Übergang von einem pflichtbewussten Migrationskino der 1980er Jahre $\mathrm{zu}$ einem Kino »der Freuden der Hybridität« in den 1990 Jahren. Sie bemüht für diese Interpretation besonders die Schlusssequenz mit Leyla und Sevim. ${ }^{723}$ Knapp sechs Jahre später hält Jessica Gallagher dagegen fest, dass es zwar richtig sei, dass die Akteure in den Filmen der 1990er Jahre aus den verschlossenen Wohnungen und Gefängnissen heraustreten, doch sei der eroberte öffentliche Raum eingeschränkt. In Arslans ersten beiden Filmen seiner Berlin-Trilogie zeige sich für sie eindrücklich, dass an die Stelle der Gefängnisse der Innenräume der 1980er nun der öffentliche Raum als Gefängnis getreten sei. ${ }^{724}$ Diese Verschiebung vom Gefängnis in den eigenen vier Wänden zum öffentlichen Raum als Gefängnis konnte ich anhand der Analysen von Aysel Özakıns Literatur und den Dokumentarfilmen von Hans-Dieter Grabe und Jeanine Meerapfel bereits für die 1980er Jahre nachweisen. Im Gegen-

723 Siehe hierzu: GöKTÜRK, Deniz (2000b): »Migration und Kino. Subnationale Mitleidskultur oder transnationale Rollenspiele?«. In: Interkulturelle Literatur in Deutschland. Ein Handbuch, hg. v. Carmine Chiellino, Stuttgart, Weimar: Metzler, S. 329-347, hier S. 333.

724 Siehe hierzu: Gallagher, Jessica (2006): "The Limitation of Urban Space in Thomas Arslan's Berlin Trilogy. In: Seminar Nr. 42 (3), S. 337-352, hier S. $343 f$. 
teil leidet der öffentliche Raum in den 1990er Jahren nicht an hochgezogenen Mauern und unsichtbaren Grenzziehungen, sondern an seiner Unbestimmtheit, daran, dass ihm Orte fehlen. Vielmehr sind es die Akteure selbst, in denen das Öffentliche und das Private ineinander verschränkt sind und durch ihre Artikulationen diese Vernahtung sichtbar wird. Zwei Jahre nach Gallaghers Interpretation konstatiert Barbara Mennel in ihrer zweiten Analyse von Arslans Film, dass er ein Ghetto-Film in einem globalen Migrationsrahmen sei. Sie bezeichnet die Akteure im Film auch als »Ghetto-Flaneure«. Ihre These beruht auf zwei Grundlagen: Zum einen werde der Bezirk Berlin-Kreuzberg »dokumentarisch anhand von Straßennamen und U-Bahnstationen markiert«. Zum Ghettocharakter trage außerdem bei, dass »weder die Figuren noch die Kamera Kreuzberg« verlassen, schließlich sei »die Bewegung der Figuren durch den Bezirk charakterisiert «. ${ }^{725}$ Den komplexen Zusammenhang von Mobilität und Immobilität, zwischen Körper in Bewegung, Lokalität und Identitätspolitik, wie ihn Arslan in seinem Film auf unterschiedlichsten Ebenen ausführt, kann weder mit den »Freuden der Hybridität« noch umgekehrt mit dem Befund, dass nun der öffentliche Raum das Gefängnis sei, noch mit der filmischen Gattung des Ghetto-Films oder mit der Benjamin'schen Figur des Flaneurs analytisch sinnvoll gerahmt und begriffen werden. ${ }^{726}$

Erstens sieht man kaum Freude in diesem und anderen Filmen der 1990er Jahre. Stattdessen dominieren Konflikte. Zweitens ist der Übergang vom eingeschränkten öffentlichen Raum zum Gefängnis für Arslans Film nicht tragbar, allein weil der Regisseur mit seiner Kamera keine sichtbaren Grenzen zeigt oder sichtbare Mauern aufzieht. Vielmehr kann am Ende einer der Protagonisten ohne Probleme die Grenze am Flughafen überqueren. Aus diesen Gründen und schon allein aus der Tatsache heraus, dass im Gegenteil zur Beschreibung des Berliner Ghettos im ganzen Film kein einziger Straßenname abgefilmt wird oder auf eine andere Art ein konkreter topografischer Anhaltspunkt auftaucht, gibt auch die Bezeichnung »Ghetto-Film« die eigentliche Grundlage der Spannung und der Widersprüche in diesem Film nicht wieder. In Fatih Akıns KuRz UND SCHMERzLos sehen wir nur ein einziges Mal am Ende des Films ein Schild, auf dem »Altona» steht. Dass sowohl Arslan als auch Akın keine topografischen establishing shots einsetzen, widerspricht den Zugängen, die sich auf Gefängnis und Bezirk konzentrieren. Es entstehen keine Orte, die Grenzen und fixe Koordinaten haben.

725 MENNEL (2008): S. 55f.

726 Benjamins Flaneur ist ein einsames und verschlossenes Subjekt. Die Deutsch-Türken der zweiten Einwanderer-Generation, die die deutschen Straßen bewohnen, stehen hingegen immer in Kontakt, wovon auch ihre Körper Zeugnis ablegen. Benjamins Flaneur ist von Distanz geprägt, die Figuren Arslans, Akıns, Yavuz' und Polats von körperlicher Nähe. 
Arslan schafft Räume im Sinne Michel de Certeaus, indem er die Menschen mit den Orten etwas machen lässt. »So wird zum Beispiel die Straße, die der Urbanismus geometrisch festlegt, durch die Gehenden in einen Raum verwandelt. ${ }^{727}$ Es sind nach de Certeau Erzählungen, die Orte in Räume verwandeln. Doch müssen sie auch umgekehrt die Räume wieder in Orte verwandeln können. ${ }^{728}$

Eine vergleichbare Doppelbewegung zeichnet auch Vilém Flusser nach, wenn er fordert, dass auf die Ironie, die die Migration für ihn eigentlich erst einführt, das Engagement als zweite Bewegung folgen müsse. Da die Orte als Raum unbestimmt bleiben, geht es in Arslans und Akıns Filmen nicht um diese Rück- oder zweite Übersetzung. Beide rücken die Akteure in den Vordergrund, ihre Bewegungen, Sprechweisen, das, was sie nachahmen und nicht nachahmen. ${ }^{729}$ Sie zeigen ihren Gang, wie sie sich bewegen. In den behandelten filmischen und literarischen Werken ist eine spezifische Verbindung von Innen und Außen zu erkennen, die auch Tragisches und Komisches untrennbar miteinander verschränkt. Besonders eindrücklich ist, als Erols Freunde ihn als Bastard beschimpfen, er überhaupt nicht besser sei als ein Asylant. Bevor die Auseinandersetzung zwischen den Freunden gewalttätig wird, ist das Gespräch, das sie kurz davor führen, von einer Komik geprägt, die ab den 2000er Jahren die Kabarettbühnen erobern wird. Die Freunde streiten darüber, ob gewisse Passanten »Zigeuner « gewesen seien oder Albaner oder Griechen. Der eine ist sich sicher, dass es Zigeuner sind. Der andere erwidert, es könnten auch Albaner, Griechen oder Jugoslawen sein. Darauf der andere: »Jugoslawien gibt es nicht, guckst Du kein Fernsehen, oder was? « Vielleicht seien es auch »Alabaner « gewesen, korrigiert sich nun der, der sich sicher war, dass es sich um »Zigeuner « handelte. Der andere verbessert ihn erneut: Es heiße »Albaner« und nicht »Alabaner«. Dass diese Sequenz trotzdem ernst bleibt und nicht zu einem Auslachen der anderen Ausländer führt, liegt am Setting. Es ist dunkel, nur Straßenlaternen und die Leuchtreklame aus dem türkischen Imbiss geben Licht. Außerdem folgt darauf die bereits erwähnte Auseinandersetzung, dass Erol sich gar nicht über Asylanten beschweren dürfe, weil er selbst ja nicht einmal ein »richtiger« Türke sei, sondern ein »Bastard «. ${ }^{730}$

727 De Certeau (2006): S. 345.

728 Ebd., S. 346.

729 Diesen Fokus auf Kleidung, Sprechweisen und Bewegungen im öffentlichen Raum und weniger auf Orte, wo Menschen oder Figuren stehen und von wo aus sie sprechen, finden wir auch in den Studien von Sigrid Nökel, Grit Klinkhammer, Günter Seufert und Hans-Ludwig Frese. Siehe hierzu: FrESE, Hans-Ludwig (2002): »Den Islam ausleben«. Konzepte authentischer Lebensführung junger türkischer Muslime in der Diaspora, Bielefeld: transcript.

730 ARSLAN (1997). 
$\mathrm{Zu}$ Arslans (aber auch Akıns) Fokus auf die Akteure passt die aufwendige Recherche und das langwierige Casting für GeSCHWISTER. Arslan und sein Team haben »fast alle Jugendzentren in Berlin und viele Schulen abgeklappert«. Es gab auch einen Aufruf über das Radio, dass in Deutschland geborene deutschtürkische Jugendliche zwischen 16 und 20 Jahren für einen Spielfilm gesucht würden, in dem es um den Alltag der Jugendlichen gehe. ${ }^{731}$ Das Casting selbst bestand aus drei Runden. Danach habe sich das Drehbuch komplett geändert, konstatiert Arslan rückblickend.$^{732}$ Ausgangspunkt waren für Arslan wie für Akın zunächst die eigenen Erfahrungen. Zum einen spiegelt sich in dieser deutschtürkischen Elternkonstellation von GESCHWISTER Arslans eigene Biografie. Er selbst ist Sohn eines türkischen Vaters und einer deutschen Mutter. Er wurde 1962 in Braunschweig geboren, wuchs in Essen auf, verbrachte aber seine Grundschulzeit mit seinen Eltern in Ankara. Seine persönlichen Erfahrungen in Essen und in Berlin liegen der gesamten Trilogie zugrunde. Arslan wollte genauer wissen, was sich eigentlich vor seiner Haustür im Alltag abspielt. In der Aufnahme und Darstellung dieses Lebens wollte Arslan auch einer diskursiv-medialen Realität etwas entgegenstellen, weil sie nicht dem entsprach, was er sah.

Das Verhältnis von Deutschen und Türken wird auf einen alles durchdringenden Gegensatz von Moderne und Traditionalismus verengt. Hier das moderne, aufgeklärte Deutschland, dort eine archaischen Traditionen verhaftete Türkei. Hierbei werden die Heterogenitäten der als fremd eingestuften Kultur unterschlagen und gleichzeitig die Vermischungen und das Gewordene der eigenen (deutschen) Kultur verschwiegen oder verschleiert. ${ }^{73}$

Während die Unterscheidung von Moderne und Tradition, von Deutschland und Türkei Aysel Özakın in den 1980er Jahren noch dazu gebracht hatte, als eine selbstbestimmte, zivilisierte Türkin aufzutreten, weisen die Akteurinnen und Akteure in Literatur und Film der 1990er Jahre auf eine Vermischung und Verschränkung dieser Kategorien hin: Durch Sprache und Auftritt ist eine Körperlichkeit entstanden, die beide Pole vereint. In der Regel sind die deutsch-türkischen Figuren dieser Zeit selbstbewusst und anti-modern zugleich.

In diesem diskursiven Zusammenhang stehen Akıns Filme und Arslans Geschwister; aus ihm lösen sich zunehmend die beiden anderen Filme von Arslans Trilogie: DeAler und Der Schöne Tag. Für die kulturelle Positionierung seiner weiblichen Protagonistin im letzten Teil der Trilogie konstatiert Arslan, dass die »vielbeschworene Zerrissenheit zwischen zwei Kulturen« ihren

731 ARSLAN, Thomas (2011): »Thomas Arslan über Geschwister«. In: ders.: Geschwister, DVD, Berlin: Filmgalerie 451.

732 Ebd.

733 ARSLAN, Thomas (2001): Presseheft zu »Geschwister». 
Lebenserfahrungen nicht entspreche. Im Unterschied zu Erol und Ahmed läuft sie weder lässig noch breitschultrig durch die Stadt. Sie wirkt ausgeglichen und nicht gereizt. „Sie bewegt sich mit Selbstverständlichkeit durch die Umgebung, in der sie lebt. ${ }^{734}$ Zwischen beiden Filmen, dem ersten und dritten Teil der Trilogie, steht Arslans Erkenntnis, dass, gleich wie unterschiedlich sich die deutsch-türkischen Jugendlichen und Heranwachsenden untereinander zum Deutschen und Türkischen positionieren, eine Gemeinsamkeit sie alle verbindet: der äußerst enge und zugleich widersprüchlich wirkende Zusammenhang aus Vitalität und Fatalismus. Er ist auch in Akıns Film vorhanden. In GESCHWISTER zeigt er sich darin, dass Erol trotz mangelnder identifikatorischer Plausbilität in die Türkei zum Militär fliegt. Vor diesem Horizont ist auch Erols Einschätzung zu sehen, dass sein Bruder einfach Glück gehabt habe und er nicht. ${ }^{735}$

Auch in Emine Sevgi Özdamars Karawanserei-Roman gibt es einen gewissen fatalistischen Grundton, der sich schon im Titel widerspiegelt. Dieser Fatalismus leitet sich allerdings nicht aus der höheren Ordnung eines Schicksals ab - mag es sich dabei um Gott, Gesellschaft oder um ein anderes Abstraktum handeln. Stattdessen regieren Zufall und Glück. Was vielmehr unabtrennbar zu sein scheint und sich in die Körper der Akteurinnen und Akteure eingeschrieben hat, ist die Verknotung von Deutsch und Türkisch. Sie zeigt sich vor allem darin, wie sich die Akteure bewegen und wohin. Selbst wenn man sozialökonomisch abgesichert ist, entkommt man dieser Bestimmung in Literatur und Film der 1990er Jahre nicht. Şenocaks Erzähler Sascha Muhtesem kann weder in der amerikanischen Prärie noch in der amerikanischen Metropole bleiben, weil die Grenze zwischen dem Deutschen und Türkischen von außen nach innen vorgedrungen ist. Sie ist einfach keine Tür, durch die man hindurchgehen kann, sondern eine Zone, die es physisch wie im Gebrauch kultureller Marker zwischen zwei Türen abzulaufen gilt. Daher sind alle Akteure so körperlich aktiv. Der Zusammenhang von Vitalität und Fatalismus ist vielleicht die eindrücklichste Antwort auf das Narrativ der 1990er Jahre »Wie lebt es sich in Deiner Haut?«. Außerhalb der eigenen Person existieren weder Koordination noch Orientierung, die anleiten und führen könnten, obwohl die Akteure selbst viel in Bewegung sind.

734 Filmportal (2009): »Sowohl als auch: Das `deutsch-türkische« Kino heute«. In: Filmportal, 01.01.2009, http://www.filmportal.de/thema/sowohl-als-auch-das-deutsch-tuerkische-kino-heute (19.04.2017).

735 Nicht Glück, aber Zufall erwähnt der Migrationsforscher Andreas Pott häufig in seiner Studie, in deren Zentrum die Frage sozialstruktureller Mobilität und des beruflichen Aufstiegs der Deutsch-Türken der zweiten Generation steht. Siehe hierzu: Ротт, Andreas (2002): Ethnizität und Raum im Aufstiegsprozess. Eine Untersuchung zum Bildungsaufstieg in der zweiten türkischen Migrantengeneration, Heidelberg: Springer. 
Sehr klar zeigt sich diese dilemmatische Konstellation in Thomas Arslans zweitem Film seiner Berlin-Trilogie. DEALER erzählt die Geschichte des kleinkriminellen Dealers Can, der eine Freundin und eine kleine Tochter hat. Seine Freundin drängt ihn, mit dem Dealen aufzuhören und einer legalen Arbeit nachzugehen. Can dealt zwar gekonnt, aber insgesamt unmotiviert. Als sein Drogenzulieferer und Chef (Hussi Kutlucan) erfährt, dass er aufhören möchte, verspricht er Can die Geschäftsführung eines gastronomischen Lokals. Bis es soweit sei, müsse er noch weiter für ihn dealen. Diese Berufsperspektive ist nur vorgeschoben, um Can nicht zu verlieren. Dieser glaubt jedoch an das Versprechen oder möchte es glauben - solange, bis sein Chef auf offener Straße vor seinen Augen erschossen wird. Während seiner Zeit als Dealer hatte ihm ein deutsch-türkischer Freund angeboten, in einem türkischen Imbiss zu arbeiten. Doch nach dem Mord an seinem Zulieferer nimmt er eine Stelle in der Küche eines deutschen Restaurants an. Er gibt sie aber bald wieder auf, weil er diese Arbeit erniedrigend und furchtbar findet. Can beginnt wieder zu dealen und wird am Ende des Films mit Drogen erwischt. Dabei meint es ein deutsch-türkischer Polizist gut mit ihm und versucht durch gutes Zureden ihn davon abzubringen - vergeblich: Am Ende des Films landet Can im Gefängnis. Seine Freundin besucht ihn dort einmal, ohne Kind. Der Film endet jedoch nicht mit diesem Besuch, sondern mit stillebenhaften Aufnahmen der locations des Films, ohne Akteure. Aus dem Off kommentiert Can diese Bilder in einem distanzierten Ton mit dem Satz, »wie schnell sich doch alles ändert«. Für diese Passivitiät hat Arslan mitten im Film eindrückliche Aufnahmen gefunden. Denn insgesamt wird der einfache Plot von DEALER von inneren Zuständen und Affekten überlagert. ${ }^{736}$ Wir sehen den Protagonisten in mehreren Nahaufnahmen abends in der Stadt bewegungslos irgendwo hinschauen, im Hintergrund unscharfe Autoscheinwerfer. Im Unterschied zu GESCHWISTER setzt Arslan bei derartigen Einstellungen keine Straßengeräusche ein, sondern bringt sparsame elektronische Musik. Solche Einstellungen kennzeichnen Can als einen handlungs- und entscheidungsschwachen Akteur. ${ }^{737}$ Der Regisseur ist insgesamt weniger an der sozialen Handlung als daran interessiert, die Frage zu beantworten, wie es sich in der Haut eines Deutsch-Türken lebt. Im Unterscheid zu den 1980er Jahren bricht Kultur hier nicht von außen ein, sondern ist Teil der inneren Kommunikation. Zugleich folgt Arslan weiterhin seiner konzeptionellen Überlegung, dass, wenn es schon nicht möglich ist, den Klischees auszuweichen, man durch sie hindurchgehen müsse. Er muss sie »benutzen, um sie dann nach

736 Siehe hierzu auch: DeHn, Moritz (1999): „Die Türken vom Dienst. `Dealer« von Thomas Arslan oder ein weiterer Schritt heraus aus der Schublade >deutsch-türkisches« Kino«, https:// www.freitag.de/autoren/der-freitag/die-turken-vom-dienst (17.05.2017).

737 Siehe hierzu auch: Neubauer (2011): S. 210. 
und nach aufzulösen, so daß etwas anderes sichtbar werden kann «. ${ }^{738}$ Doch wird dieses Andere nicht wirklich sichtbar. Denn die innere Disposition überlagert die Stadt, ohne einen Ort außerhalb des Selbst zu generieren. Es gibt ein Bewusstsein der Heterogenität, aber keine Umwelt.

Sowohl Erzählung als auch die individuelle Disposition der Akteure changieren zwischen Aktivität und Passivität. Diese Konstellation findet sich auch in Texten und Filmen wie KuRz UND SCHMERzLOS, GESCHWISTER, APRILKINDER von Yüksel Yavuz, AuslandstourneE von Ayşe Polat, Lola Und BILIDIKID von Kutlu Ataman, Ich Chef, Du TurnschuH von Hussi Kutlucan und ANAM von Buket Alakuş. Ein Großteil der Forschungen befindet, dass diese Filme im Kern auf eine neue Wirklichkeit in der Bundesrepublik aufmerksam machen, dabei nationale Grenzen überschreiten und auf die Möglichkeit transnationaler und transkultureller Gemeinschaften verweisen würden. Dass es bei Andeutungen bleibt, wollte ich anhand der vorliegenden Filmanalysen zeigen. Denn das Ziel der Bewegung bleibt auch in den zuletzt genannten Filmen unbestimmt; eine Unbestimmtheit, die sich sogar in den Theorien des Transnationalismus oder des Multikulturalismus widerspiegelt. ${ }^{739}$ Ein hybrides Subjekt allein reicht also nicht aus, um das Dazwischen präzise beschreiben zu können. Die plurilokalen Verortungen müssen koordiniert sein. Im Zentrum der Koordination stehen die sozialen Strukturen des Dazwischen. Der Soziologe Ludger Pries macht einen Vorschlag, wie eine derartige Präzisierung des transnationalen Raums aussehen könnte. Orientieren sich nach ihm

\footnotetext{
Migranten vor allem an der Herkunftskultur, handelt es sich nicht um stransnationale soziale Räume`, sondern um `Diaspora`. Wenn sich die Migranten hingegen ganz der Kultur des Ankunftslandes zuwenden, so handelt es sich nicht um `Transmigranten`, sondern um Einwanderer. Erst wenn die räumlichen Positionierungen verschiedenen Lokalisierungen übergreifen, ist es sinnvoll, von transnationaler Migration zu sprechen. ${ }^{740}$
}

Diese Konzeption bringt es mit sich, die Koordination als eine Form der Homogenisierung zu begreifen, da der transnationale Raum nicht nur grenzüberschreitend, sondern im Unterschied zu Diaspora und Einwanderung begrenzt ist. Die Räume, die die Akteurinnen und Akteure mit ihren Bewegungen hervorbringen, umschließen oder schaffen keinen spezifischen Ort, der bei der Orientierung helfen würde. Selbst in Taylors Multikulturalismus-Modell steht das Individuum im Vordergrund, von dessen Aussage und Artikulation er

738 Filmheft zu Dealer.

739 Siehe hierzu: LEGGEwIE, Claus (1991): Multikulti. Spielregeln für die Vielvölkerrepublik, Berlin: Rotbuch, S. 9-20.

740 Ebd., S. 71. 
annimmt, dass sie aus seinem Inneren kommen. Charles Taylors Selbstpositionierung ist ebenfalls von einer individuellen Fatalität geprägt: »Ich bin aufgerufen, mein Leben auf diese Weise zu leben. [...] Mir selbst treu zu sein, bedeutet, meiner Originalität treu zu sein. « ${ }^{741}$ Wen hier Taylor »aufruft«, bleibt unbestimmt.

Obwohl Jürgen Habermas die Frage des kulturellen Kollektivs anders angeht, argumentiert er hinsichtlich der Frage der Individualität wie Taylor. Seine Grundlage ist keine kulturelle und kann es Anfang der 1990er Jahre kurz nach der deutschen Einheit auch gar nicht sein. Vielmehr ist sie politischöffentlich und baut darauf, dass es eine »Gleichursprünglichkeit zwischen privater und öffentlicher Autonomie« gibt. Eine solche »Gleichursprünglichkeit« existiert in Literatur und Film dieser Zeit nicht; ganz im Gegenteil sind öffentlich und privat über den Code der Schwelle untrennbar miteinander verschränkt. Obwohl die Dreier-Personenkonstellationen sehr prominent sind, haben wir es außerdem nicht mit kollektiven Akteuren zu tun, die in das multikulturelle Gefüge Taylors passen würden. Sie sind aber auch nicht doppelt in Bhabhas Sinne. Sie sind körperlich aktiv, fühlen sich zu Hause nicht wohl und bringen mit ihrem Weiterreden und ihrem sich drinnen und draußen bewegen Intimität und Öffentlichkeit in eine besondere Relation. Ihr Ausgangspunkt sind nicht Akteurinnen und Akteure, die ähnliche Bedürfnisse haben oder unterschiedlichen Kulturen und Nationen entstammen. Ihre Grundlage ist eine Art globales Verbundenheitsgefühl; der Glaube, Teil einer Kultur zu sein, die jedoch keine besondere Versammlungsform zur Verfügung stellt, um sich auf einer sozialen Ebene in der Realität wiederzufinden. Ihre Performanz besteht vor allem darin, Disparates wie Jeans und Kopftuch, wie den Genozid an den Juden und an den Armeniern, Türkei, deutsche Stadt und deutsche Sprache zu verbinden. Die daraus resultierende Heterogenität und das Bewusstsein für sie führen nach Bhaba zu einer gespaltenen Nation. Und diese Spaltung ist nach postkolonialen Theorien positiv, weil sie Vorstellungen von homogenen Nationen und Gesellschaften, von Mehrheiten und Minderheiten in Frage stellt. Nur wohin und wohinein diese Spaltungen führen sollen, wohin sich die Akteurinnen und Akteure letztlich bewegen und wozu, skizzieren weder Film und Literatur noch die Theorien.

741 TAYLOR (1994): S. 17. 


\subsection{Fazit zu »Wie lebt es sich in Deiner Haut?»}

Wenn sich in den 1980er Jahren metaphorisch ein Berg zwischen Wohnung und Straße schob und das Geschehen und die Beschreibungen von eigen und fremd bestimmte, tritt in den 1990er Jahren an seine Stelle die Schwelle, die für postmoderne und postkoloniale Theoretiker der Ort ist, an dem neue kulturelle Beschreibungsformen entstehen. Es geht daher nicht mehr um die Darstellung von „Verpflanzungen«, die etwa Tevfik Başer im Sinn hatte, wenn er vom Eingewurzelt-Sein vor Ort sprach - sondern die Frage der gemeinsamen Gegenwart. Sie wird auch jenseits jeder explizit ästhetischen Sprache von vielen Betroffenen nach den Brandanschlägen in Mölln und Solingen (1992/1993) ins Spiel gebracht. Dass Deutsch-Türken nach den Anschlägen die Bundesrepublik nicht verlassen haben, sondern im Gegenteil auf den Straßen ihren Protest bekundeten, zeigt, wie sehr sie in Deutschland verwurzelt sind, auch wenn sie sich selbst nicht als Deutsche beschreiben konnten oder wollten. ${ }^{742}$ Denn spätestens in den 1990er Jahren hatten die Türken der ersten Generation schon mindestens die Hälfte ihres Lebens und die zweite Generation sogar ihr ganzes Leben in der Bundesrepublik verbracht. Diese disparaten Ordnungen, das Türkischsein auf deutschem Boden, bringen sie zum Ausdruck.

Auch aus diesem Grund erfolgen in den 1990er Jahren keine Verinnerlichungen der deutschen Gesellschaft und Kultur etwa in Form der Annahme der deutschen Staatsbürgerschaft oder einer Mitgliedschaft in deutschen Vereinen. Diese Übersetzungen sind kaum zu leisten. Körper und Verkörperungen verbinden Hier und Dort auf eine neue Weise. An die Stelle politischer Gruppen, religiöser Vereine und türkischer Kaffeehäuser mit expliziter Türkeiorientierung treten immer mehr Kulturvereine muslimischer oder türkischer Provenienz, die vom Leben in Deutschland bestimmt sind. Ein vermeintlich einfaches »Türkisch-Sein « wie in den 1980er Jahren ist nicht mehr möglich. In vielen Vereinen vollzieht sich ab Mitte der 1990er Jahre in diesem Zusammenhang eine Orientierung am Inland. ${ }^{743}$ Werner Schiffauer weist sie beispielsweise beim Verband der Milli Görüş bei der

742 GRUmbaCh, Detlef (1999): Nich wien aleman sein! Feridun Zaimoğlu zwischen »Abitur-Türken« und »Kanakstern«, Feature vom 01.06.1999, Köln: Deutschlandfunk.

743 Auch im Begleitbuch der ersten großen Ausstellung zur türkischen Migration nach Deutschland Fremde Heimat. Yaban Silan Olur von 1998 im Ruhrlandmuseum steht als eine zentrale Aussage der Ausstellung, dass die ehemaligen »Gastarbeiter « und ihre Kindeskinder nun zu »Inländern« geworden seien. Dies gelte es explizit festzuhalten, da besonders die bundesrepublikanische Politik seit der Deutschen Einheit weiterhin eine sei, die diese Wirklichkeit noch nicht wahrhaben wolle. Dabei ist es nach Ansicht der Ausstellungsmacher eben kein Widerspruch mehr zu sagen, dass man Türke ist und zugleich Duisburger und Berliner. Siehe hierzu: ERYILMAZ, Aytac/Jamin, Mathilde (Hg.) (1998): Fremde Heimat. Yaban Silan Olur, Essen: Klartext. 
zweiten Generation seiner Mitglieder nach. ${ }^{74}$ Diese komplexe Bindung führt er zwar nicht näher aus, doch hält der Politikwissenschaftler und Mitbegründer des Vereins der säkularen Türkischen Gemeinde Deutschland Hakkı Keskin fest, dass die nun eingeschlagene Richtung entscheidend sei und diese nur Deutschland sein könne. Von der Politik der 1980er sich absetzend hält Keskin fest, dass »das bisherige Jammern und Klagen der Betroffenen nichts verändert hat und auch nichts ändern [wird], solange diese selbst nicht bereit sind, engagiert für ihre Interessen einzutreten «. ${ }^{745}$ Für Keskin ist wie für viele andere, von denen in diesem Kapitel die Rede war, klar: Die heterogene Verbindung von Türkei, Kultur und deutscher Stadt wird gelingen, wenn Akteure selbstbewusst auftreten, sich so auch artikulieren und wissen, was sie wollen. Wirksam wird eine derartige Politik der Performanz als Intervention, die koppelt, aber nicht zusammenführt. So bindet das Bewusstsein für Heterogenität in einem realen, aber unbestimmten »Draußen« nicht einfach, sondern spaltet auch.

Daher ist die Kopplung von heterogenen nicht-gegenständlichen und gegenständlichen Einheiten wie Nation und Stadt keineswegs einfach, besonders wenn diese nicht als selbstverständlich und nicht als zugehörig, sondern als fremdartig im öffentlichen Raum wahrgenommen werden. In Debatten und Reden über »die Ausländer in Deutschland« wurde dieses Spannungsfeld nicht zu Ende gedacht; vor allem nicht, was seine psychischen, körperlichen und erzählerischen Aspekte betrifft. Hinzu kommt, dass in den 1990er Jahren trotz allem Sprechen über Multikulturalität nie eine multikulturelle Politik verfolgt wurde. Die politische Integration in den 1990ern ist in der Praxis keine kulturelle Frage. Zehn Jahre nach Dolf Sternberger, der wie die deutsch-türkischen Filme und Bücher von dem Gedanken als Bewegung von innen nach außen beseelt war, dass die »Gelegenheit« und der »Wille sich fänden, dass auch die Verfassungsfreunde einmal auf die Straße gingen ${ }^{746}$, bringt Jürgen Habermas dessen Verfassungspatriotismus in einen abstrakt-universalistischen Mobilisierungszusammenhang. Der Verfassungspatriotismus sei der einzig legitime Patriotismus, der die Bundesrepublik vom »Westen nicht entfremdet«. Dabei müsse jede »ethische Integration von Gruppen und Subkulturen mit je eigener kollektiver Identität [...] also von der Ebene der abstrakten, alle Staatsbürger gleichmäßig

744 SChiffauer (2004): S. $364 \mathrm{f}$.

745 KeSKIN, Hakkı (1998): »Die Richtung ist entscheidend. Belirleyici olan yöndür«. In: Fremde Heimat, S. 19-22.

746 STERNBERGER, Dolf (1982): „Verfassungspatriotismus«. In: Grundfragen der Demokratie. Schriftenreihe der Niedersächsischen Landeszentrale für Politische Bildung. Folge 3, hg. v. der Niedersächsischen Landeszentrale für Politische Bildung 1982, S. 7. 
erfassenden politischen Integration entkoppelt werden «. ${ }^{747}$ Die Türken könnten ja wie Muslime leben, doch sollten sie wie Universalisten denken und sprechen. Auch Habermas agiert wie die deutsch-türkischen Autorinnen und Autoren und Filmemacher von der Schwelle aus, imaginiert Verbundenheit und Universalität, nur dass er sich im Unterschied zu den Figuren der Texte und Filme auf der anderen Seite, der der Inklusion, befindet. Auf der Exklusionsseite und weil politische und kulturelle Integration voneinander getrennt sind, kann die Grenze und Differenz zwischen Deutsch und Türkisch weder territorial noch topografisch verlaufen. Sie verläuft in den Körpern und in den kulturellen Verkörperungen der 1990er Jahre. Daraus ergibt sich eine Konstellation aus Hier und Dort, in deren Zentrum nicht sozialstrukturelle Ähnlichkeit oder kulturelle Differenz, sondern eine existenzielle Körperlichkeit und ein globales Verbundenheitsgefühl stehen. Dabei werden soziale Handlungen in Film und Literatur als Einheiten kaum zu Ende ausgeführt. Es gibt beispielsweise keine einzige Essenssequenz in der gegessen wird und wir wissen auch nie, wohin die Akteure gehen, wenn sie unterwegs sind. Es ist zum Beispiel kaum möglich, Emine Sevgi Özdamars, Zafer Şenocaks Romane und Thomas Arslan, Yüksel Yavuz‘ und Ayşe Polats Filme der 1990er Jahre mit Beschreibungen alltäglicher sozialer Praktiken wiederzugeben oder darin das Hauptaugenmerk dieser ästhetischen Reflexionen zu sehen. Auch für einen Kenner der Türkei ist es unmöglich, aus Emine Sevgi Özdamars Beschreibungen darauf zu schließen, in welcher Stadt gerade die Familie ihrer Ich-Erzählerin wohnt. In ihnen dominiert vielmehr der Bruch von Mechanismen und erwartbaren sozialen Handlungen. Ziel ist es vielmehr, mit Plakaten an der Wand und einem bestimmten Auftritt im öffentlichen Raum an die Stelle des Ortes Räume zu setzen. Denn im Raum gibt es nach Certeau im Unterschied zum Ort »weder eine Eindeutigkeit noch die Stabilität von etwas 〉Eigenem««. Dadurch wird aber möglich, dass zwei unterschiedliche Dinge an ein und demselben Ort sein können. ${ }^{748}$ Deshalb wird präzise in Film, Literatur und in der Publizistik gezeigt, dass das Dort zugleich ein Hier geworden ist. Der Übergang von einer Entweder-oder-Logik - für Aysel Özakın beispielsweise ist man entweder Teil der Zivilisation, der Moderne oder nicht - zu einer Sowohlals-auch-Logik wird möglich, weil an die Stelle der Unterscheidung von Innen und Außen, durch den Körper, der als letztes Territorium verblieben ist, etwas »Zwischenhaftes« gerückt ist.

747 Zitiert nach: LÖFFLER, Berthold (2011): Integration in Deutschland, München: Oldenbourg, S. 200.

748 Siehe hierzu: CERTEAU (2006): S. 345. 
Vielen Wissenschaftlerinnen reicht es $\mathrm{zu}$ sehen, dass die Deutsch-Türken Plakate von Bruce Lee an ihren Wänden hängen haben oder seine Filme ansehen, um das Dargestellte als Transkulturalität und Hybridität zu interpretieren. Oder es reicht, wenn Zafer Şenocak über das Thema des Genozids die deutsche und türkische Seite in einer Figur verbindet, ohne dabei tatsächlich zu beschreiben, welche grausamen und barbarischen Verbrechen auf deutscher wie auf türkischer Seite begangen wurden. Diese Form der Bearbeitung gehört bei Şenocak zum Konzept seiner »negativen Hermeneutik«. In diesem Zusammenhang kann es sich bei Şenocaks Roman höchstens um ein »Hinzufügen« zur deutschen Geschichte handeln, um ein Supplement, statt um eine »Einschreibung« oder »Vervollständigung« dieser Geschichte. Şenocaks Gefährliche Verwandtschaft ist ein supplementärer Einsatz, der bricht und irritiert, aber nicht erklärt. Es geht um die Vorstellung einer zukünftigen, noch nicht vorhandenen, sondern erst herzustellenden Verbindung. Ob sie tatsächlich zu realisieren ist, ist nach Ansicht von Şenocaks Protagonistem fragwürdig. So ist die Reaktion deutsch-türkischer Kulturproduktionen auf die multikulturelle Realität der Bundesrepublik in den 1990er Jahren eine traumartige. Dieses Explizitmachen der Erzählung machen Literatur und Film zu angemessenen Ersatzhandlungen, die die reaktiven Kräfte, Gefühle des Diskriminiertseins nicht obsiegen lassen. Die Erzählung ist hier eine Aktivität, die die reaktiven Kräfte ausagieren lässt und somit eine Form der sozialen Interaktion zwischen Mehrheit und Minderheit. Dabei sind die kulturellen Marker zentrale Bestandteile der Erzählungen.

Es ist also nicht die deutsche Geschichte allein, die hier zur Disposition steht. Der Genozid an den Juden steht in den 1990er Jahren auf den Lehrplänen der deutschen Schulen. Was aber bis heute nicht gelehrt wird, ist die Geschichte der Migration in die Bundesrepublik und ihre Folgen. Eindrücklich zeigt sich dies in Arbeiten der bekannten Historiker und Politikwissenschaftler zur deutschen Geschichte als System oder als eine Kulturgeschichte, die ab Mitte der 2000er Jahre entstehen. ${ }^{749}$ Was darin überhaupt keine Berücksichtigung erfahren hat, ist das Material und der Verlauf der vorliegenden Kulturgeschichte, in deren Produktionen der 1990er Jahre direkt oder indirekt immer wieder Bezug auf die Folgen der deutschen Wiedervereinigung genommen wird. Denn der Grund dafür, dass Şenocak und andere sich so präzise auf ihre Akteure, auf ihren Auftritt im öffentlichen Raum, auf ihre Körper als ihre eigentliche Heimat konzentrieren und als

749 Siehe hierzu: Schmidt, Manfred (2008): Das politische System Deutschlands, München: Beck. WeHLER, Hans-Ulrich (2008): Deutsche Gesellschaftsgeschichte (1949-1990), München: Beck. SchILDT, Axel (2009): Deutsche Kulturgeschichte. Die Bundesrepublik von 1945 bis zur Gegenwart, München: Hanser. Wolfrum, Edgar (2006): Die geglückte Demokratie. Geschichte der Bundesrepublik von ihren Anfängen bis heute, Stuttgart: Klett-Cotta. 
Ort der Austragung begreifen, liegt daran, dass die körperlich gewordene Verbindung von Türkisch und Deutsch weder im öffentlichen noch im privaten Raum selbstverständlich ist. ${ }^{750}$ Sie muss mit viel Aufwand, nicht zuletzt mit einem erzählerischen, hergestellt werden, wobei neben dem Körper das Brechen von Kommunikationsregeln und die vorgestellte Verbundenheit die eigentlich zentralen Funktionen einnehmen. Mag es der Mutterbauch, die islamische Geschlechterordnung, mögen es die Jacken der Akteurinnen und Akteure sein, ihre Narben im Gesicht, das Aufschneiden der Pulsadern, das »Ficken« in der Sprache oder in der Praxis: der offene Körper ist die Metapher der Migration in den 1990er Jahren. Sie steht für eine Trennung der Kultur von der Existenz, die aber selbst ohne kulturelle Marker nicht vollzogen und nicht sichtbar werden kann.

Was diese paradoxe Operation erzählbar macht, ist der Einsatz kultureller Kategorien, die eine vermeintliche Weltverbundenheit markieren. Sie zeigen zugleich, dass wir es nun mit anderen Politiken der Performanz zu tun haben als noch in den 1970er Jahren. Wir sehen aber auch, welche äußerst wichtige Funktion hier die Fiktion einnimmt, die wir im Großteil der Rezeption der literarischen und filmischen Erzählungen der 1990er Jahre nachweisen konnten. Sie zeigt sich darin, dass Özdamars surreale Texte oder Zaimoğlus überzogene Kanak Sprak als Spiegelungen der bundesrepublikanischen Realität und als Sprachrohre der türkischen Minderheit in der Bundesrepublik gelesen und gesehen wurden, was sicher auch daran liegt, dass weder Debatte noch Theorie in den 1990er Jahren etwas Vergleichbares artikulierten. Daher ist vielleicht Zaimoğlus Sprecherrolle mit der Figur der Ich-Erzählerin in Özdamars Karawanserei-Roman vergleichbar. Sie erfindet und findet Geschichten auf der Straße, um gehört zu werden, um mit ihrer Mutter in einem Modus des Weitersprechens, letztlich in einem der Geselligkeit in Kontakt zu kommen. ${ }^{751}$ Die Ziele von Özdamars und Zaimoğlus Texten

750 Von den wenigen Türken, die in den 1990er Jahren in die Türkei zurückgekehrt sind, sind mittlerweile viele von ihnen innerhalb der Türkei in eingezäunte Wohnanlagen, in gated communities, gezogen. Einige dieser Rückkehrer hat die Dokumentarfilmerin Aysun Bademsoy Mitte der 2000er Jahre in Mersin, im Süden der Türkei interviewt. Die meisten von ihnen machen darauf aufmerksam, wie die Literaten auch, dass die deutsche Einheit und seine Folgen, sie nochmals aus dem Land ausgeschlossen hätten. Davor ging es ihnen eigentlich gut, doch nach dem Fall der Mauer häuften sich wieder die Aussagen, wann sie denn endlich in die Türkei wieder zurückkehren würden. Siehe hierzu: BADEmsoy, Aysun (2006): Am Rand der Städte, Berlin: Harun Farocki Filmproduktion.

751 Ein programmatischer Aufsatz zu deutsch-türkischen Produktionen der 1980er Jahre von 1995 hat den vielsprechenden Titel Zwischen Abwehr und Umarmung. Die Konstruktion des anderen in Filmen. Siehe hierzu: HickethieR, Knut (1995): »Zwischen Abwehr und Umarmung. Die Konstruktion des anderen in Filmen«. In: »Getürkte Bilder«. Zur Inszenierung von Fremden im Film, hg. v. Ernst Kapf, Doron Kiesel und Karsten Visarius, Marburg: Schüren, S. 21-40. 
in den 1990er Jahren waren mit ihren Ästhetiken schließlich, eine Soziabilität zwischen eigen und fremd, zwischen Mehr- und Minderheiten in der Bundesrepublik zu generieren. Von einer vergleichbaren Rolle und Funktion der Fiktion, der ästhetischen Produktion ist auch die Rezeption von Fatih Akıns Film GEgEN DIE WAND bestimmt.

Dass sich eine Türkin nie so verhalten würde, urteilte die türkische Presse über den Film SHIRINS HochzEIT aus dem Jahre 1976. Die türkische Regierung wie auch die türkischen Medien protestierten gegen diesen Film. ${ }^{752}$ GEGEN DIE WAND wurde hingegen gefeiert. Obwohl Shirin von den Umständen und Bedingungen in der Bundesrepublik zur Prostitution getrieben wird, ist sie keine repräsentative Türkin. Die Schauspielerin Ayten Erten wurde sogar als Vaterlandsverräterin beschimpft. ${ }^{753}$ Auch Alda und Hoppa in Paul Geiersbachs Dokumentation Bruder, muß zusammen Zwiebel und Wasser essen von 1982 fanden den Schluss des Films »überhaupt nicht gut «. ${ }^{754}$ Während in SHIRINS HochzEIT die äußeren Zwänge, die Mechanismen gesellschaftlicher Unterdrückung eindrücklich zeigen, dass Shirin nur mittels Prostitution ihre arme türkische Familie finanziell zu unterstützen vermag und diese Mechanismen nichts an ihrem guten und reinen Charakter ändern, will die Protagonistin am Anfang von GEGEN DIE WAND ausdrücklich leben und mit so vielen Männern wie möglich »ficken «. ${ }^{755}$ Dabei haben wir bis zu dieser Aussage über das unterdrückte Leben von ihr kaum etwas erfahren. Man sieht hier sehr schön, dass in der Rezeption die informelle Geschichte der Migration in der Bundesrepublik wirkt: Denn die Zuschauer nehmen Sibel die Unterdrückung ohne Weiteres ab. Aras Ören, Helma Sanders-Brahms, Rainer

752 Im türkischen Parlament wurde am 01.05.1976 über eine Stunde über Sanders-Brahms Film debattiert. Ein Jahr zuvor hatte sie auch auf Vorlage des Drehbuchs keine Drehgenehmigung für die Türkei erhalten. Die Dorfsequenzen in SHIRINS HochzeIT hat Sanders-Brahms dann in der Eifel gedreht. Siehe hierzu: SANDERS, Helma (1980): Shirins Hochzeit, Panta Rhei Filmverlag. 753 In Ratgebern wie Işçi olarak Almanyaya nasıl gidilir? (»Wie geht man als Arbeiter nach Deutschland?«) oder Türk, öğün, çallş ve güven (»Türke, sei von nun an fleißig und zuversichtlich«) der Türkischen Anstalt für Arbeit und Arbeitsvermittlung, der IIBK, von 1963 wird von türkischen Gastarbeitern verlangt, dass sie der Falle des Kommunismus durch Geld und Frauen nicht erliegen sollen. Der türkische Arbeiter und die Arbeiterin sollen fleißig und ehrenvoll wie die Deutschen werden. Siehe hierzu: TÜRKISche ANSTALt FÜR ARBEIT Und ARbeITSVERmitTLUNG (2011): »Wie der türkische Arbeiter sich in einem fremden Land verhalten und seine Identität wahren soll«. In: Geteilte Heimat. 50 Jahre Migration aus der Türkei. Paylaşllan Yurt, hg. v. Aytaç Eryilmaz, Cordula Lissner im Auftrag von DOMID, Essen: Klartext, S. 81-82, hier S. 81.

754 Siehe hierzu: GeIERSBACH, Paul (1982): Bruder, muss zusammen Zwiebel und Wasser essen, Berlin: Dietz, S. 172.

755 In GEGEN DIE WAND weist nur eine Aussage auf den Zwang hin, dem sie in der türkischen Familie ausgesetzt war: als nämlich Sibel Cahit erzählt, dass ihr Bruder ihr die Nase gebrochen habe, als er sie das erste Mal mit einem anderen »Typen« Hand in Hand gesehen habe. 
Werner Fassbinder und selbst Günter Wallraff haben im Unterschied dazu die Mechanismen der Unterdrückung und Diskriminierung erst aufdecken, explizit, sicht- und nachvollziehbar machen müssen.

So gegensätzlich in unserem Beispiel Shirin und Sibel als Figuren zueinander stehen, so anders nimmt sich, wie gesagt, auch die Reaktion auf GEGEN DIE WAND in der türkischen Presse aus. Nach der Verleihung des Goldenen Bären feierte selbst die konservativ-religiöse Zeitung ZAMAN Akıns Film und ignorierte dabei etwa die Tatsache, dass die Hauptdarstellerin Sibel Kekilli im wirklichen Leben als Pornodarstellerin gearbeitet hatte. Der damalige türkische Kultur- und Tourismusminister Uğur Mumcu meinte in der türkischen Tageszeitung Hürriyet dazu, dass ein »Politiker [...] zur Verantwortung gezogen werden kann, aber den Erfolg eines Künstlers berühren solche Fehler seiner Vergangenheit nicht«. Die nationalistische Zeitung Türkiye feierte, dass endlich - 40 Jahre nach SusUz YAZ (»Trockener Sommer«, 1964) - wieder ein türkischer Film den Goldenen Bären der Berlinale bekommen habe: »Was zählt, ist der Preis «. ${ }^{756}$

In seiner Multikulturalismustheorie stellte Charles Taylor die Aspekte der Anerkennung und der Individualität kultureller Aussagen ins Zentrum. Genau dieser Aspekt macht Akıns Film für die türkische Seite so kompatibel. Das Mädchen hat zwar Probleme mit ihren Eltern, aber weder die Eltern noch die Kultur sind direkt daran schuld, sondern die Akteure selbst - ohne dabei sich selbst zum Opfer zu machen. Mitunter deshalb löste die pornodarstellerische Vergangenheit weder in einer nationalistischen, liberal-konservativen noch einer konservativ-religiösen türkischen Zeitung einen Skandal aus. Es war die deutsche Bildzeitung, die einen Tag nach der Preisverleihung titelte: »Film-Diva in Wahrheit ein Porno-Star«. Tatsächlich erfuhren die Eltern von Sibel Kekilli erst dadurch von der heiklen Vergangenheit ihrer Tochter und brachen daraufhin den Kontakt zu ihr ab. In GEGEN DIE WAND erfährt die Familie von Sibel ebenfalls aus einer Zeitung, dass sie mit einem Deutschen fremdgegangen ist und ihr Mann, Cahit, den Deutschen getötet hat. ${ }^{757}$

Was sich wie ein türkischer Ehrenmord lesen lässt, ist in der filmischen Erzählung ein Totschlag aus Liebe. Zwei kulturell vermeintlich gegensätzliche Motive, Liebe und Ehre, werden hier zusammengeführt. Genau diese Kopplung von vermeintlich nicht Zusammengehörigem, von - überspitzt formuliert - Moderne und Tradition macht die Erzählungen in den 1990er Jahren aus. Nico beleidigt Cahit aufs Schlimmste, als er in seiner Kneipe schreiend von ihm verlangt, dass

756 AKIN, Fatih (2004): Gegen die Wand. Das Buch zum Film mit Dokumenten, Materialien, Interviews, Köln: Kiepenheuer \& Witsch, S. 219.

757 Siehe hierzu: AKIN (2004). 
er seine türkische Hure »griechisch, von hinten, ficken « möchte. ${ }^{758}$ Auf diese Provokation hin greift Cahit spontan nach einem Aschenbecher und schlägt so stark auf Nico ein, dass er stirbt. Stunden zuvor hatte Sibel Nico auf der Straße abblitzen lassen. Nico sagt ihr nach der ersten gemeinsamen Nacht, dass er sich »voll« in sie »verknallt « habe. Sibel meint aber, dass diese Nacht ein Fehler gewesen sei. Sie habe einfach wissen wollen, wie er im Bett sei. »Jetzt weiß ich's, und das Ding ist durch. Geh du mir aus dem Weg, und ich geh dir aus'm Weg, okay? «, reagiert Sibel selbstbewusst und kühl auf Nicos Drängen. »Wie redest du mit mir?«, entgegnet Nico und hält sie am Arm fest. Sibel wird wütend und schreit Nico an: »Ich bin 'ne verheiratete Frau. Ich bin 'ne verheiratete türkische Frau, und wenn du mir zu nahekommst, bringt mein Mann dich um, verstehst du!? «"759

Interessant an dieser Szene ist nicht nur die Verbindung zwischen der selbstbewussten und der "verheirateten türkischen« Frau, sondern auch die wandelnde Mimik und Gestik der Protagonistin. Zunächst gibt sie Nico cool einen Korb. Als sie sich dann belästigt fühlt, reagiert sie emotional und aggressiv. Beide Dimensionen gehören zu einer Person. Das `Andere` wird nicht auf Distanz gehalten, in einer anderen Person verkörpert oder es bricht als andere Kultur von oben herein, sondern wird miteinbezogen. Dieser Schlagabtausch steht exemplarisch für weitere Szenen im Film, an denen deutlich wird, dass durch die Protagonisten disparate Ordnungen kommunizieren, die sich nicht repräsentieren lassen, sondern nur intensiv dargestellt werden können. Cahit diskriminiert etwa die Türken als Kollektiv, tanzt aber auf seiner türkischen Hochzeit, geht in eine türkische Disco und fährt am Ende des Films sogar in seine türkische Geburtsstadt Mersin. Ob er dort noch Familie hat, wissen wir nicht. Wir wissen nur, dass seine Eltern in Deutschland gestorben sind und er zu seiner einzigen Schwester, die in Frankfurt lebt, keinen Kontakt mehr hat. Sein Geburtsort und seine Familie sind wie in Özdamars erstem Roman kein Teil der Diegese, sondern müssen mitgedacht werden. Fest steht nur, dass er ein Mensch ist. Dies antwortet er seinem Kollegen Şeref, als dieser ihn dazu überreden will, statt dauernd Bier doch Wasser zu trinken. Er sei doch kein Tier, sondern ein Mensch, erwidert Cahit. Es ist sein erster Satz in Akıns Film; ${ }^{760}$ ein Mensch, der in der folgenden Sequenz versucht, sich das Leben zu nehmen. ${ }^{761}$

758 Ebd.

759 Ebd.

760 Siehe hierzu: AKIN (2003/2004).

761 Mit einer ähnlichen Rahmung setzt auch Emine Sevgi Özdamars Roman ein, wenn zu Beginn die »Baumwolltante« der schwangeren Frau im Zug hinterherruft, dass sie sich keine Sorgen machen solle, denn schließlich würden alle Menschen »rauskommen«. Ihr Leben ist ebenfalls 
Diese inhaltlich einfache, aber ästhetisch äußerst intensive und aufwendige Kommunikationsform, die die pure Existenz in den Vordergrund rückt, hat wie Salman Rushdies erzählerische Diktion für die imaginary homelands zum Ziel, möglichst viele Menschen anzusprechen. Die Differenz zwischen Inhalt und Form als Grundlagen der Reichweite dokumentieren die Reaktionen der türkischen und der deutschen Presse zu GEGEN DIE WAND eindrücklich. In der deutschen Presse ist er ein deutscher Film, in der türkischen ein türkischer. ${ }^{762}$ Zudem beweist der anschließende Siegeszug von GEGEN DIE WAND - neben dem Goldenen Bären erhält der Film im gleichen Jahr den Europäischen Filmpreis als Bester Europäischer Film und ein Jahr darauf den Preis des Verbands der amerikanischen Filmkritiker -, dass er auch international sehr gut funktioniert. ${ }^{763}$ Auch haben nach der Preisverleihung konservative wie auch nicht konservative Deutsch-Türken auf den Straßen Berlins die Prämierung des Films gefeiert. ${ }^{764}$ Allein dieses Beispiel veranschaulicht, wie Formsprachen in den 1990er Jahren Realitätseffekte auslösen und die Fakten den Fiktionen folgen. ${ }^{765}$

Dieser Form der Erzählung, wie ich sie nun für die 1990er Jahre bis GEGEN DIE WAND aufgezeigt habe, war keine lange Dauer beschieden. ${ }^{766}$ Das lag an zwei Problemen. Zum einen wollte man hinsichtlich der Frage der Anerkennung endlich jede Art homogener Vorstellung von Identität durch eine explizit erzählerische Politik der Differenz brechen. Cahit, Sibel, Zeki, Lola, Sascha, Melek und wie sie alle heißen, bewegen sich über ihre Körperlichkeit und Sexualität als existenzi-

von Beginn an gefährdet; einen Selbstmordversuch wird auch sie begehen. Siehe hierzu: ÖzDAMAR, Emine Sevgi (1992): Das Leben ist eine Karawanserei, Köln: Kiepenheuer \& Witsch, S. 11.

762 Auch auf den großen Welterfolg Sexbomb (gesungen von Tom Jones) des deutsch-türkischen Musikproduzenten Mousse T. reagierten deutsche wie türkische Medien, dass es sich bei diesem Erfolg um einen deutschen und um einen türkischen handelt. Siehe hierzu: CELIK, Neco (2007): Ganz oben. Deutsch - Türkisch - Erfolgreich, Mainz: ZDF.

763 Siehe hierzu: https://www.filmportal.de/film/gegen-die-wand_060306a55a8c405488a066 bb947509ba (27.03.2018). Dasselbe gilt für Özdamars Roman Das Leben ist eine Karawanserei. Siehe hierzu: Goytisolo, Juan (1994): »On Emine Sevgi Özdamar«. In: Times Literary Supplement 12 (International Book of the Year), 02.12.1994.

764 Siehe hierzu: LöSER, Claus (2004): »Berlin am Bosporus. Zum Erfolg Fatih Akıns und anderer türkischstämmiger Regisseure in der deutschen Filmlandschaft«. In: Apropos: Film. Das Jahrbuch der DEFA-Stiftung, Berlin, S. 129-147, S. 130.

765 Siehe hierzu: KoschoRKE, Albrecht (2012): Wahrheit und Erfindung. Grundzüge einer Allgemeinen Erzähltheorie, Frankfurt a. M.: Fischer, S. 25.

766 Auf der Pressekonferenz zu GEgEn DIE WAND bemerkte Akın, dass er zum ersten Mal in seinem Filmschaffen nun nicht mehr wisse, was er anschließend erzählen solle. Zuvor sei ihm beim Abschluss eines Projektes immer klar gewesen, was als nächstes folgte. Siehe hierzu: https://www.berlinale.de/de/archiv/jahresarchive/2004/06_streaming_2004/06_streaming_listing_2004.php?item=26446\&navi=2 (20.04.2018). 
elle Figuren jenseits kultureller Stereotype, begehen aber dennoch Ehrenmorde, haben türkische Sängerinnen und Sänger als Vorbilder oder wollen in der Türkei am Strand leben. Auf Ironie, Komik und Tragödie folgt kein Engagement, auf die Vorstellung eines neuen globalen Raums nicht seine reale Verortung. Wir haben es hier mit Grenzüberschreitungen ohne Landnahmen zu tun. In den analysierten Texten und Filmen der 1990er Jahre kommt niemand irgendwo an - weder tatsächlich noch im übertragenen Sinn. Diese spannungsgeladene und widersprüchliche Assemblage von Unbestimmtheit, existenzieller Notwendigkeit und selbstverständlichem Auftritt hat ihre Grundlage in der Nichtselbstverständlichkeit des öffentlichen Raums als Ort für die Akteure. So ist die Unsichtbarkeit von Straßennamen, obwohl die Akteure dauernd draußen sind, kein Zufall, sondern konstitutiver Bestandteil dieser Erzählungen. Wie in den behandelten Theorien bewegen wir uns auch in den filmischen und literarischen Erzählungen dieser Dekade zwischen gespaltenen Subjekten und gespaltenen Nationen als Orte der Ambivalenz; Orten, an denen keine sozialen Auseinandersetzungen mehr stattfinden. Diese Eigenheiten sind nur dann die Grundlage für eine stabile hybride Identität, wenn sie letztlich „draußen“ auch so anerkannt werden; wenn sie letztlich als »Baustellen «, als Transitbereiche verstanden werden, die eine neue Globalität, neue transkulturelle und transnationale Gemeinschaften ankündigen. So ließ sich Akıns Film zugleich als deutscher und als türkischer Film wahrnehmen. Doch sind diese Erzählungen eines globalen Verbundenheitsgefühls in höchstem Maße kontingent und fragil. Die Kette raumschaffender Handlungen durch Bewegung, Auftritt und A-soziation markiert keine Bezugspunkte, »die auf das hinweisen, was sie produziert (eine Vorstellung von Orten) oder was sie beinhaltet (eine lokale Ordnung) «. ${ }^{767}$ Und äußerst ausschlaggebend kommt hinzu, dass keiner der Protagonisten in den 1990er Jahren einem Beruf nachgeht, der ihn oder sie auf Dauer über Wasser halten könnte.

Knapp 15 Jahre später ist Fatih Akıns GEgen DIE WAND der Lieblingsfilm der Ich-Erzählerin Hazal aus dem Berliner Wedding in Fatma Aydemirs Roman Ellbogen von 2017. Sie lässt den Film von ihren Nachbarn auf CD brennen und schaut ihn sich mit ihrer Mutter an. Danach ist sie »wie aufgeputscht" und hat "zum ersten Mal das Gefühl«, nicht mehr »unsichtbar» zu sein. Ihre Mutter findet ihn dagegen absolut »unrealistisch «, denn »keine Türkin würde so Sachen machen wie die ${ }^{768}$ Sie meint, der Film sei nur gemacht worden, »damit wir Türken schlecht dastehen ${ }^{769}$ Dass den Film ein Türke wie sie gedreht hat, bleibt

767 CERTEAU (2006): S. 349.

768 Aydemir, Fatma (2017): Ellbogen, München: Roman Hanser, S. 78.

769 Ebd., S. 79. 
unerwähnt. Auch die Ich-Erzählerin ist weder mit Sibel noch mit Cahit zu vergleichen. ${ }^{770}$ Zwischen ihr und ihren Eltern besteht noch ein größerer Graben als zwischen Sibel und ihren Eltern. Weder ist Fatma Aydemirs Protagonistin wie Sibel vom Wunsch nach Freiheit und Sexualität bestimmt, noch verletzt sie sich selbst. Sie muss vielmehr auf einer emotionalen Ebene vom Film und seinen Protagonisten berührt sein. Denn im Gegensatz zu den äußerst individuellen Figuren steht in diesem Roman eine deutsch-türkische Mädchengang im Vordergrund. Und im Unterschied zu Sibel und Cahit ist ihre Wut weitaus unkontrollierter. Die Ich-Erzählerin Hazal und ihre beiden Freundinnen sind wütend auf die deutsche Mehrheitsgesellschaft und besonders auf die »Privilegierten « in ihr. ${ }^{771}$ Ihre Wut entlädt sich in der Mitte des Romans im spontanen Totschlag eines ihnen gänzlich unbekannten deutschen Studenten nachts an der Berliner U-Bahnhaltestelle Friedrichstraße. Zuvor wurde den Mädchen der Einlass in eine beliebte Berliner Diskothek verweigert, weil an diesem Abend nur Stammgäste Zutritt bekämen. »Wären wir aus Polen oder Spanien oder so, und hätten wir so dreckige Turnschuhe an, wären wir bestimmt reingekommen. Diese Bastarde!«, regt sich eine der Freundinnen auf. ${ }^{772}$ Doch löst diese wahrgenommene und empfundene Diskriminierung nicht die Tat aus. Es ist vielmehr eine Wut, deren Ursache im Roman unerklärt bleibt. Hazal hält nur fest, ihre Wut sei so groß, »dass sie nicht mehr in mich hineinpasst «. ${ }^{773}$ Im Unterschied zu den Akteuren aus GEGEN DIE WAND kann keine Akteurin hier in einem vergleichbar körperlichen Maße genießen wie in Akıns Film. Aus anderen Gründen als in den 1980er Jahren spielen nationale Kategorien nun wieder eine Rolle. Nicht einmal als Deutsch-Türken bezeichnen sich Hazal, ihre Freundinnen und ihre Verwandten, obwohl sie nun bereits seit drei Generationen in der Bundesrepublik leben. Der Roman beginnt damit, dass die Protagonistin wegen eines Ladendiebstahls ihr einziges Geld für ihren achtzehnten Geburtstag dem Ladendetektiv, der sie beim Klau erwischte, übergeben muss, um einer polizeilichen Anzeige zu entgehen. Sie arbeitet für ein Taschengeld in der Bäckerei ihres Onkels und später im Roman erfahren wir, dass sie eigentlich Ärztin werden wollte. ${ }^{774}$

Auch die im Veröffentlichungsjahr von Aydemirs Roman stattfindende Demonstration von Deutsch-Türken auf Berliner Straßen ist mit der zum Gewinn des Goldenen Bären für GEGEN DIE WAND nicht mehr zu vergleichen. Im April 2017 geht es nicht mehr darum, einen prämierten Film zu feiern, der die deut-

770 Ebd.

771 Ebd., S. 244.

772 Ebd., S. 110.

773 Ebd., S. 114.

774 Siehe hierzu: Ebd., S. 231. 
sche und türkische Seite als untrennbare und zusammengehörende paradoxe Einheit zeigt. Im Gegenteil wird im Frühjahr 2017 das Abstimmungsergebnis des türkischen Verfassungsreferendums gefeiert, dessen Ergebnis die Türkei mit dem Westen als Ort der repräsentativen Demokratie nicht mehr zusammenführt, sondern im Gegenteil von ihm trennt. ${ }^{775}$ Dabei ist im Unterschied zu den 1980er und 1990er Jahren von vornherein klar, dass selbst die Erdoğan-Wähler für immer in Deutschland bleiben werden. ${ }^{776}$ Dieser Auftritt ist ebenso wenig mit dem »Eingewurzelt-sein « der 1990er Jahre in Einklang zu bringen. Nach Ludger Pries haben wir es hier mit einer Konstellation zu tun, in der räumliche Positionen sich mit unterschiedlichen Verortungen überlagern. ${ }^{777}$ Sie greifen über die Struktur eines globalen Verbundenheitsgefühls hinaus. An die Stelle raumbildender Handlungen treten verstärkt Orte, die nun den Eindruck einer Ordnung wecken.

Inwiefern das Abstimmungsverhalten der Deutsch-Türken beim Referendum mit dem neu entstehenden Narrativ »Was lebst Du?« der 2000er Jahre zusammenhängt und inwiefern die Wut der Ich-Erzählerin in Aydemirs Roman wird ein Thema des letzten Kapitels sein. Es geht nun nicht mehr um Fragen des angemessenen repräsentativen Verhaltens oder der Angleichung von "patterns of action« in einem Prozess endogenen sozialen Wandels, wie noch in den 1960er und beginnenden 1970er Jahren. Um Anerkennung oder um das Anhören des Anderen geht es ebenfalls nicht mehr. Vielmehr wird es darum gehen, welche Zugehörigkeit sich über die Performanz artikuliert und zu welcher Ordnung diese gehört. In der Integrationsdebatte der 2000er Jahre wird dabei in der Regel auf das deutsche Grundgesetz, die Verfassung, auf die mit ihr verbundenen Werte unterschiedlichster politischer Positionierungen referiert. ${ }^{778}$

775 Die Welt (2017): »Presse zu Erdogans Sieg: >Die Türkei ist nicht länger Europa««. In: Die Welt, 17.04.2017, https://www.welt.de/politik/ausland/article163753003/Die-Tuerkei-ist-nicht-laengerEuropa.html (27.03.2018).

776 Siehe hierzu: Uslucan, Hacı-Halil (2017): »Türkeistämmige in Deutschland. Heimatlos oder überall zuhause?«. In: Aus Politik und Zeitgeschichte, Jahrgang 2017, Fremd in der Heimat?, http://www.bpb.de/apuz/243864/tuerkeistaemmige-in-deutschland-heimatlos-oder-ueberall-zuhause (zuletzt 03.01.2019).

777 Aus: LANGENoHL, Andreas/RAUER, Valentin (2011): »Reden an die Transnation. Eine Analyse der öffentlichen Reaktionen auf die Reden von Erdoğan und Wulff in Deutschland «. In: Sociologia internationalis 2011, Bd. 49, 1, S. 69-102, hier S. 72.

778 Siehe hierzu: KeLEK, Necla (2005): Die fremde Braut. Ein Bericht aus dem Inneren des türkischen Lebens in Deutschland, Köln: Kiepenheuer \& Witsch, S. 12f. Siehe hierzu auch die Website des größten muslimischen Dachverbands in der Bundesrepublik. Die Diтıв (Türkisch Islamische Union der Anstalt für Religion e. V.), wirbt auf ihrer Homepage damit, dass ihre Ziele »ausschließlich mit dem Grundgesetz der Bundesrepublik Deutschland im Einklang stehen«. http:// www.ditib.de/default1.php?id=5\&sid=9\&lang=de (14.01.2018). 
Während in den 1990er Jahren die Performanz der zweiten Generation auf deutschen Straßen eine irritierende Intervention darstellt und eine Infragestellung kultureller Zuschreibungen und Selbstbeschreibungen, verschiebt sich in den 2000er Jahren die Struktur der Performanz in Richtung einer Veränderung der gesellschaftlichen Ordnung. In einer Arbeitsgrundlage für die Zuwanderungskommission der CDU, der ersten überhaupt in der bundesrepublikanischen Geschichte, heißt es im Herbst 2000, dass mit Integration nicht die »Aufgabe der eigenen kulturellen und religiösen Prägungen [gemeint sei], aber die Bejahung und Einordnung in den bei uns für das Zusammenleben geltenden Werte- und Ordnungsrahmen «. ${ }^{779}$ Damit wird betont, dass Integration nicht Assimilation meint. Doch korrespondiert diese Aussage auch nicht mit einer Trennung der Kultur vom öffentlichen Raum wie noch in den 1990er Jahren. Vielmehr stehen beide Ebenen, Kultur und Öffentlichkeit, in einem neuen Verhältnis zueinander, und es scheint klar zu sein, dass kein Bereich autonom für sich existieren kann. Dieser Wandel verändert zugleich das Verhältnis von privat und öffentlich.

Außerdem basiert dieser Wandel wiederum auf einer erzählerischen und widersprüchlichen Operation. Denn nach über vierzig Jahren Migrationsgeschichte in der Bundesrepublik werden die Türken in der Integrationspolitik der 2000er Jahre nun als Angekommene angesehen und auch symbolisch so empfangen. Nicht zuletzt aufgrund dieser neuen integrationspolitischen Konstellation, wie sie mit der Änderung des Staatsbürgerschaftsrechts von 2000, der Einführung des ius soli, den Zuwanderungskommissionen 2000, ${ }^{780}$ der Verabschiedung des Zuwanderungsgesetzes 2005, des Allgemeinen Gleichbehandlungsgesetzes (Antidiskriminierungsgesetz) und mit den Integrationsgipfeln, Islamkonferenzen 2006 und der Verabschiedung eines Nationalen Integrationplans 2007 in den 2000ern einsetzt und fortsetzt, war die Politik weder auf einen endogenen sozialen Wandel noch auf eine emische Form der Selbstfindung aus. Im Zentrum dieser Maßnahmen steht die Kompatibilität der Lebensformen im öffentlichen Raum. Dieses Anliegen erklärt sich auch daraus, dass der Terroranschlag vom 11. September 2001 in den Vereinigten Staaten, die Morde am Rechtspopulisten Pim Fortuyn 2002 und am Filmemacher Theo von Gogh 2004 in den Niederlanden, die terroristischen Anschläge in London und Madrid 2005 und der Karikaturenstreit Anfang 2006 in dieser Dekade der neuen Migrationspolitik eine besondere Dringlichkeit und dramatische Schärfe geben. Neben »Integration« avanciert in den 2000er Jahren das »Zusammenleben « zum zentralen Begriff. Die

779 Aus: GöKTÜRK et al. (2010): S. 249.

780 Neben der sehr bekannt gewordenen Süssmuth-Kommission Zuwanderung gestalten - Integration fördern (2000-2001) gab es im gleichen Zeitraum auch eine Zuwanderungskommission unter der Leitung von Peter Müller. 
Frage, die Film, Literatur, Theorien und Debatten in dieser Zeit umtreibt, lautet nicht mehr, »Wie lebt es sich in Deiner Haut?«, sondern »Was lebst Du?«, also: wofür steht, was Du lebst, was du im öffentlichen Raum machst? Diese Frage beschwört das Vorhandensein einer identitätspolitischen Ordnung, die Zugehörigkeit, Integration und Desintegration durch und an den Praktiken der Akteure misst, als an ihrer Artikulation und weltverbundener Hybridität. Eine Antwort auf diese neue Frage finden wir beispielsweise im Titel So wie ich will. Mein Leben zwischen Moschee und Minirock von Melda Akbaşs Autobiografie. ${ }^{781}$ Die Verbindung von Ort und entgegengesetztem Kleidungsstück (und damit auch: Lebensstil) verlangt nun eine spezifische Ordnung. Dass es diese jedoch genauso wenig wie in den 1990er Jahren gibt, macht die Arbeit an ihr umso dringlicher - auch, weil der Wert der Fiktion als wichtiges Element der Darstellung von Wirklichkeit rapide abnimmt.

Daher ist auch jenseits des Zusammenhangs von Politik, Religion und Integration die Verknotung von Kultur und Person im öffentlichen Raum in den filmischen und literarischen Erzählungen konstitutiv. Diese Verbindung wird jedoch um eine besondere ökonomische Ebene ergänzt. Denn Kultur wird in den 2000er Jahren zu einer bedeutenden Ressource. Explizit ökonomisch dokumentiert dies nicht zuletzt die Charta der Vielfalt. Für Diversity in der Arbeitswelt, die 2006 von vier deutschen Unternehmen ins Leben gerufen wird. ${ }^{782}$ Kultur, oder genauer der Migrationshintergrund, wird identitätspolitisch aber auch karrieretechnisch ebenfalls zu einer Ressource. In der bereits erwähnten großangelegten Studie Viele Welten leben. Lebenslagen von Mädchen und jungen Frauen mit griechischem, italienischem, jugoslawischem, türkischem und Aussiedlerhintergrund (2004) von Ursula Boos-Nünning und Yasemin Karakaşoǧlu wird die Religion

781 AkBAŞ, Melda (2010): So wie ich will. Mein Leben zwischen Moschee und Minirock, München: C. Bertelsmann.

782 Siehe hierzu: https://www.charta-der-vielfalt.de/ueber-uns/ueber-die-initiative/ (zuletzt 15. 04.2019). Ab den 2000er Jahren ist auch bei der Interkulturellen Woche das zentrale Ziel, eine „Kultur der Zugehörigkeit“ vor Ort zu schaffen. Die Begriffe Multikulturalität, Anerkennung, Fremdheit und Welt werden nun abgelöst durch Vielfalt, Integration, Zusammenleben und Stadt. Dabei zeigen sich unter der Koordination und Moderation der Integrationsbeauftragten in den Städten in unterschiedlichen Graden eine bewußte Distanzierung von kulturalisierender Folklore und eine Verortung von Integrations- und Zugehörigkeitsfragen. Bei diesen Verortungsprozessen avanciert die Stadt zum zentralen Identifikationsmarker, der mit Perspektivierungen, Individualisierungen und Historisierungen der Migration gestärkt und bespielt wird. Siehe hierzu: Ezli (2020). Siehe auch: SACHVERSTÄNDIGENRAT FÜR INTEGRATION UND MigRATION (2021): Normalfall Diversität? Wie das Einwanderungsland Deutschland mit Vielfalt umgeht?, Jahresgutachten 2021, S. 95. https://www.svr-migration.de/wp-content/uploads/2021/05/SVR_Jahresgutachten_2021.pdf (zuletzt 15.05.2021). 
ebenfalls als eine »identitätskonstitutive Ressource « begriffen. ${ }^{783}$ Jedoch in erster Linie nicht mehr als ein Nachweis von Modernität in Abgrenzung zu einem traditionellen Islam. Vielmehr als eine Ressource, als ein Potential für den Alltag und die Integration in der Bundesrepublik. ${ }^{784}$ Und die bekannte Theaterindentantin des Ballhaus Naunynstraße in Berlin, Shermin Langhoff, die den Begriff »Postmigration« mit dem postmigrantischen Theater Ende der 2000er Jahre populär macht, konstatiert, dass für sie jeder biographische Bruch ein Potential berge. Von Brüchen sind die Erzählungen der 1990er Jahre - wie gezeigt - durchweg geprägt, doch verweisen sie in keinem Fall auf ein brachliegendes Potential. Im Gegenteil verschwenden sich die Akteurinnen und Akteure der 1990er Jahre aus einer ökonomischen Perspektive, und ihr Leben ist andauernd in Gefahr. ${ }^{785}$ Und genau in dieser Verschränkung liegt auch ihr Potential gesellschaftlicher Kritik. In Langhoffs Aussage und Verbindung von Bruch und Potential hingegen lässt sich die Grundlage eines Narrativs erkennen, das Performanz und Politik der 2000er bestimmen wird. Schon Anfang der 2000er hält Zaimoğlu fest, dass der kulturelle Diskurs für ihn wie für andere nun einen »Markt der Möglichkeiten« darstelle. Doch bevor die Bindung von Ressource, Potential, Markt und Migra-

783 Siehe hierzu: Boss-NüNning, Ursula/KaRAKaşoğLu, Yasemin (2004): Viele Welten leben. Lebenslagen von Mädchen und jungen Frauen mit griechischem, italienischem, jugoslawischem, türkischem und Aussiedlerhintergrund, https://www.bmfsfj.de/blob/84598/2094d4132e37142394 5367 fdf3d967f3/viele-welten-lang-data.pdf (zuletzt 16.03.2018), S. 483-486.

784 Interessanterweise vertritt diesen Befund Necla Kelek in ihrer Dissertation von 2003 Islam und Alltag ebenfalls, der in Gegensatz zu ihrem Befund in Die fremde Braut steht. In Islam und Alltag. Islamische Religiosität und ihre Bedeutung in der Lebenswelt von Schülerinnen und Schülern türkischer Herkunft zeigt sie auf, dass die muslimische Religiosität kein Integrationshindernis darstellt. Im Gegenteil passen sie dort nach Kelek ihre religiösen Bedürfnisse differenziert, individuell und pragmatisch an die deutschen Lebensumstände an. Sie beschreibt sie als »Experten ihrer Lebenswelt«. Siehe hierzu: KELEK, Necla (2002): Islam und Alltag. Islamische Religiosität und ihre Bedeutung in der Lebenswelt von Schülerinnen und Schülern türkischer Herkunft, Münster: Waxmann, S. 94. Zwei Jahre später beschreibt sie in Die fremde Braut die zuvor als selbstbewusst im öffentlichen Raum charakterisierten Muslime nun als an die muslimische Umma überangepasste und nicht mehr als Akteure, die Innen und Außen in einen schonenden und praktikablen Ausgleich bringen. Das Kopftuch ist nun kein Integrationsmedium mehr, das deutschen Alltag und Religion in einen Zusammenhang bringt, sondern stellt nun in der Schule klar ein Integrationshindernis dar. Die Ressource der Integration ist nun nicht mehr die individuelle Übersetzung der Religion in den Alltag, sondern die Kompatibilität der Praktiken mit dem deutschen Grundgesetz. Siehe hierz: KeleK (2005): S. 258f.

785 Hierfür sind allein die Akteure wie Erol in Arslans Film Geschwister, wie Cem in Yavuz Film APRILKINDER, wie Ertan in Zaimoğlus Roman Abschaum und nicht zuletzt Gabriel, Costa, Bobby in KuRz und Schmerzlos und Sibel und Cahit in GeGEN DIE WAND stellvertretend. Sie akkumulieren nicht, sondern verausgaben sich körperlich und ökonomisch. 
tion stabil wird, müssen die Migranten erst einmal ankommen. Da in den 2000er Jahren die Bundesregierung erstmals aktiv die Integration der eingewanderten Menschen, besonders der Nachfolgegenerationen gestaltet, beginnt das letzte Kapitel der vorliegenden Kulturgeschichte mit der Darstellung dieser politischen Konstellation. 